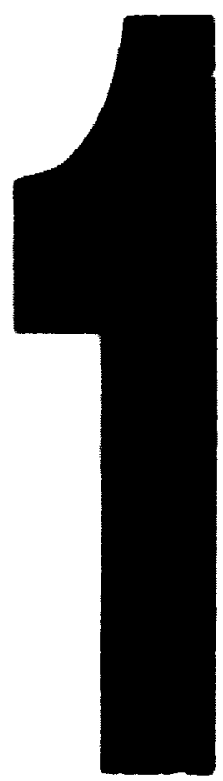

PM-1 3' 2" $x$ " PHOTOGRAPHIC MICAOCOPY TARGET NES 1010 a ANSI/ISO \#2 EQUIVALENT

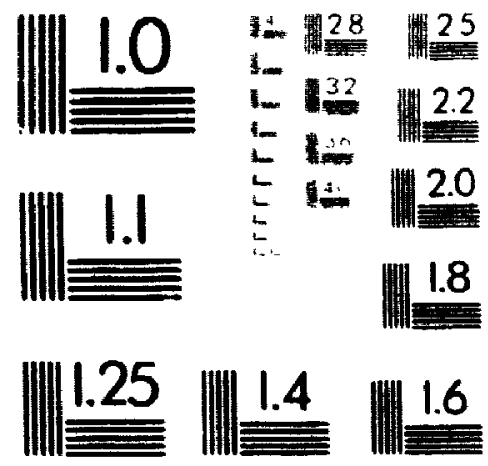

PRECISIONSM RESOLUTION TARGETS 


\title{
Behaviour of Slender Webs of WWF Shapes and Stiffened Bridge Girders Subjected to Concentrated In-Plane Loads : Experimental Investigation
}

$$
\text { by }
$$

\section{Dayle Prowse}

BSc. Civil Engineering. University of Alberta, Edmonton. Alberta, Canada

\author{
A thesis submitted to the \\ Faculty of Graduate Studies and Research \\ in partial fulfillment of the requirements \\ for the degree of \\ Master of Engineering* \\ Department of Civil and Environmental Engineering \\ Carleton University \\ Ottawa, Canada \\ November, 1996
}

*The Masters Degree in Civil Engineering

is a joint program with the University of Otawa, administered by the Ottawa-Carleton Institute for Civil Engineering

(C) 1996

D. Prowse 
The author has granted an irrevocable non-exclusive licence allowing the National Library of Canada to reproduce, loan, distribute or sell copies of his/her thesis by any means and in any form or format, making this thesis available to interested persons.
L'auteur a accordé urie licence irrévocable et non exclusive permettant à la Bibliothèque nationale du Canada de reproduire, prêter, distribuer ou vendre des copies de sa thèse de quelque manière et sous quelque forme que ce soit pour mettre des exemplaires de cette thèse à la disposition des personnes intéressées.

L'auteur conserve la propriété du droit d'auteur qui protège sa thèse. Ni la thèse ni des extraits substantiels de celle-ci ne doivent être imprimés ou autrement reproduits sans son autorisation. 
Maroule Prewe

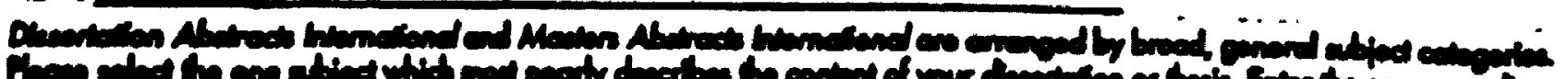

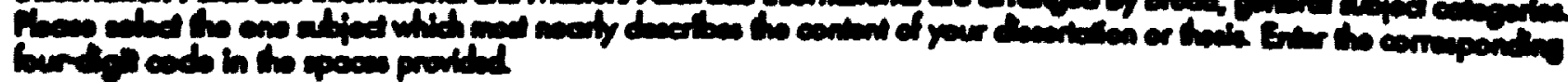

Crint Ensituming

Sulvet Conoming

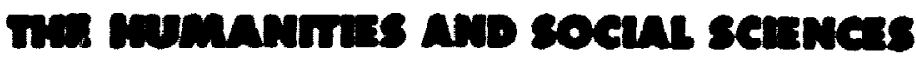

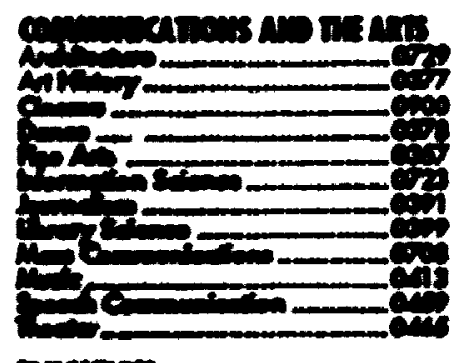

ringen

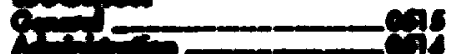

Ris 1 -

C

$-1-20$

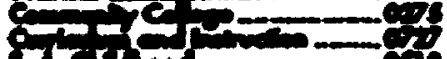

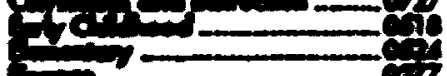

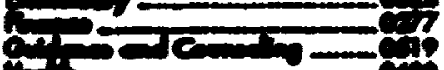

$+2$

$+-2=$

Din - is

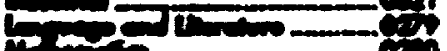

$x+2=$

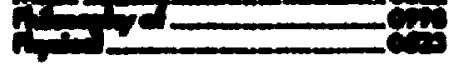

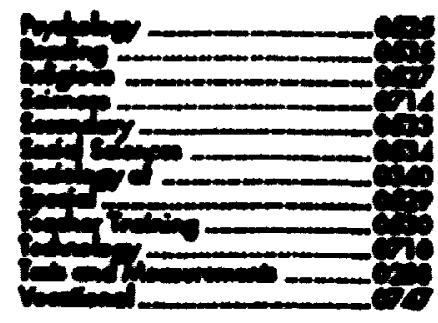

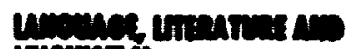

tompins

$\rightarrow$

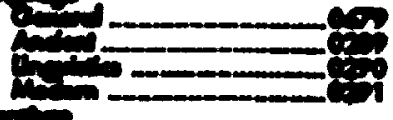

0

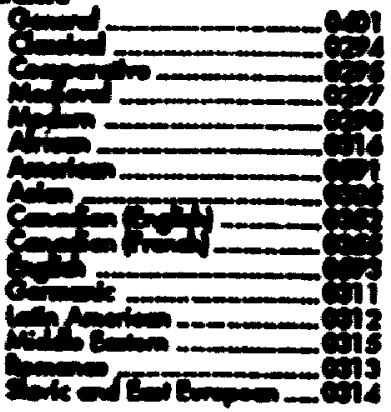

Amascin, cramin as

tring

trim

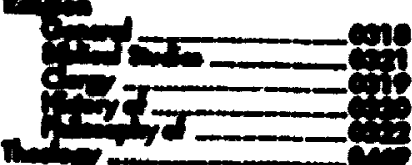

seanesests

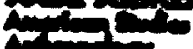

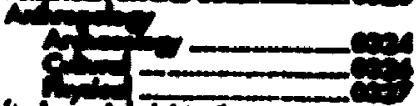

$\min$

900

en-

$\lim ^{2}$

$x^{2}=$

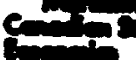

20

$x-1$

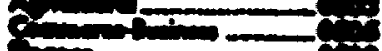

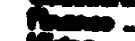

$+\infty$

min-

gand

2

en
대덩 UMI

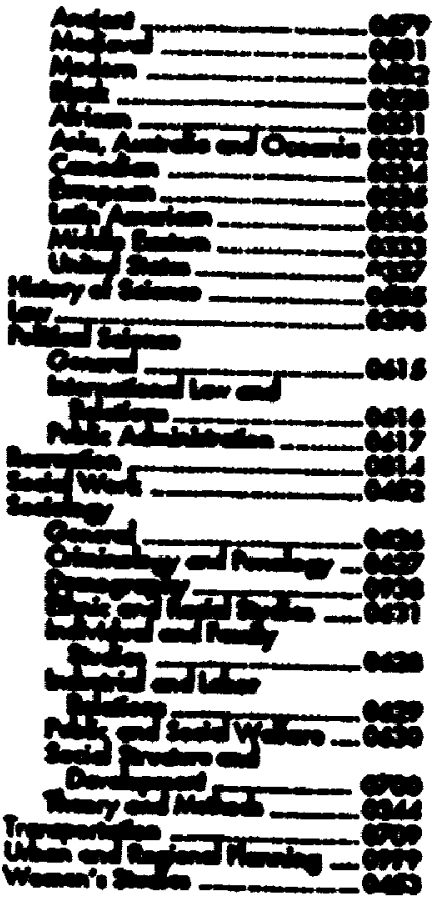

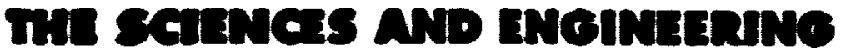

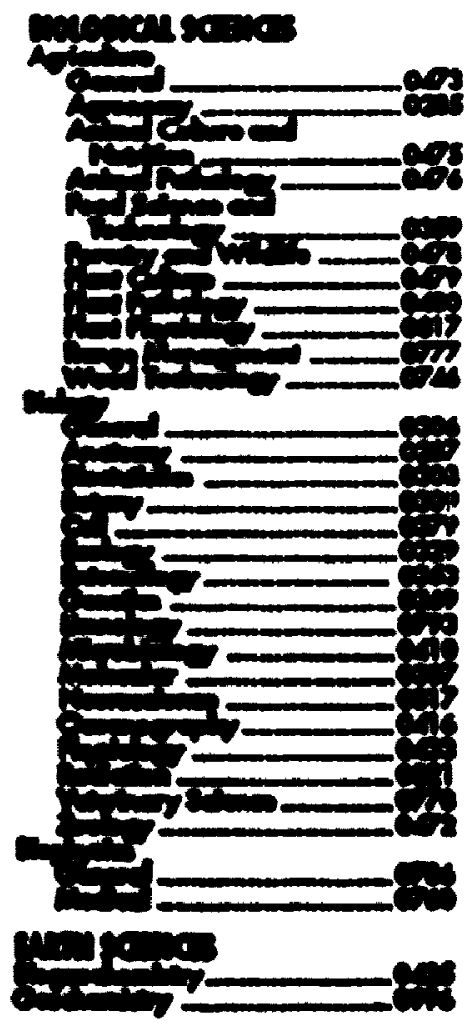

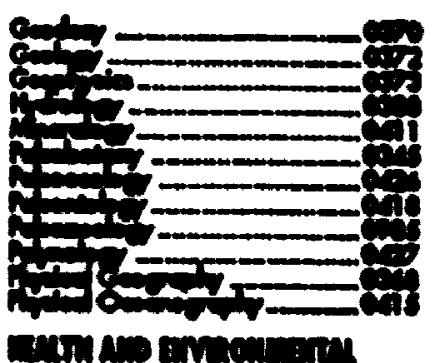

sing.

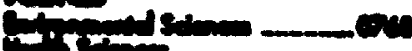

itren

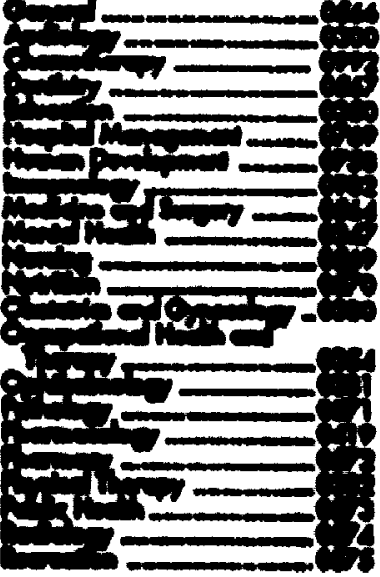

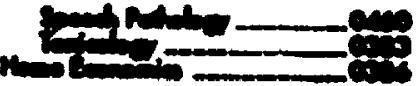

mines earos

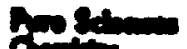

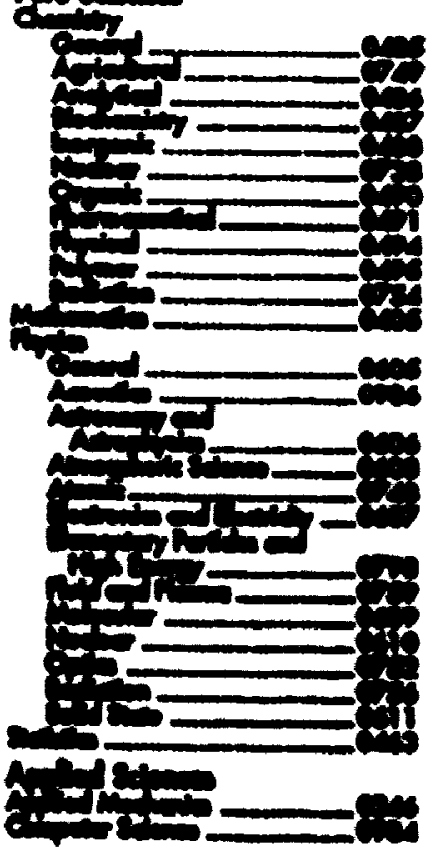

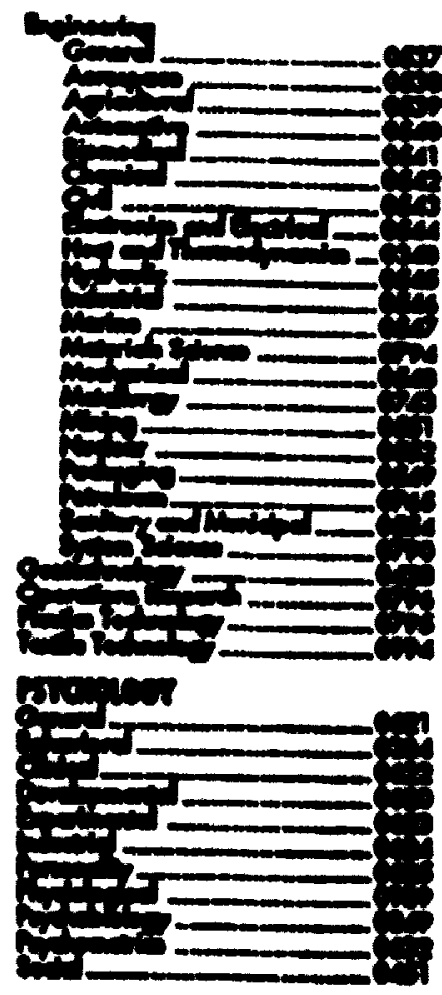




\section{Department of Civil and Environmental Engineering}

The undersigned recommend to the Faculty of Giaduate

Studies and Reserarch acceptance of the thesis

Behaviour of Slender Webs of WWF Shapes and Stiffened Bridge Girders Subjected to Concentrated In-plane Loads : Experimental Investigation submitted by

\section{Dayle Prowse}

in partial fulfilment of the requirements for the degree of Master of Engineering

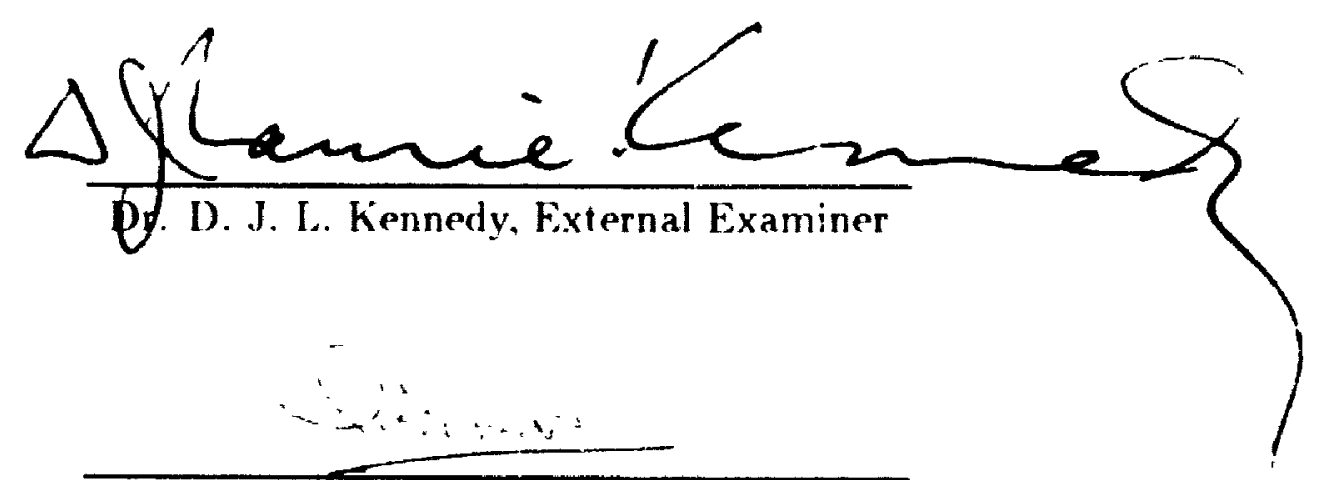

Dr. J. L. Humar. Chair, Department of Civil and

Environmental Engineering

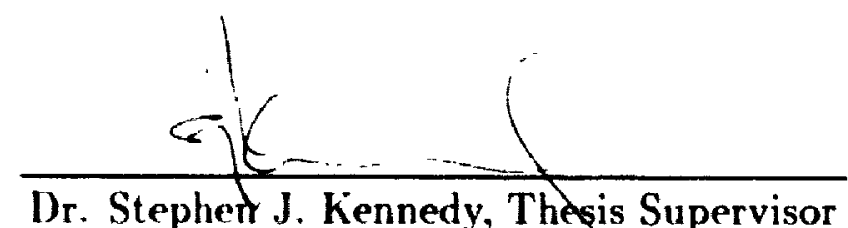

Dr. Stephen J. Kennedy, Thesis Supervisor

Carleton University

Ottaw: Ontario, Canada

November, 1996 


\section{Abstract}

This experimental study is an investigation of the behaviour of webs of slender WWF sections and bridge girders under concentrated in-plane loading. Previous tests donc by Benichou (1994) and Kirkhope (1995) tested the full range of W and WWF shapes manufactured in Canadian Mills. This research, combined with analyses recently completed by Prabha (1996), led to the development of the equivalent column concept and appropriate design equations applicable to $W$ and WWF sections. This research considers the behavious of built-up sections, the next topic of investigation.

A total of eight tests were conducted. Four tests consisting of two interior reaction tests and two end reaction tests were made on two WWF $985 \times 71$ sections. These two sections had different welds with the web to flange welds either on both sides of the web. as is the normal practice, or on one side only. Four tests with interior loads were made on bridge girders with longitudinal stiffeners and with $h / w$ ratios varying from 175 to 285 . The test data acquired from these tests, together with measurements of the initial imperfections, and geometric and material properties, provide the basis for further analytical and statistical investigations to be extended to modify the equivalent column models to include built-up sections, as may be required. 


\section{Acknowledgements}

I would like to thank Professor Stephen Kennedy for his guidance, and input and the long hours spent in expiditing this work I would also like to thank Ken McManin. Stan Conley, Pierre Trudel and Karl Richter for all their extra effort in the stnuctures laboratory Their sense of humour and encouragement throughout the duration of my laboratory work was greatly appreciated Also, many thanks are extended to $\mathbf{K} \mathbf{R}$ Prabha. Aldo Martino, Angelo Ferro, Michael Bennett and Jason Gilmore for their friendship

Funding for this project was provided by ALGOMA Steel, CANRON. The CANAMMANAC Group, STELCO, the Steel Structures Education Foundation. and the Natural Sciences and Engineering Research Council Their involvement and generosity is greatly. appreciated

Finally, I would like to dedicate this work to Tina for keeping life in Ottawa interesting. to Timo for waiting so patiently for me to finsh, and especially to my parents for insisting that I would someday need all those science courses Without all of you this work would never have been completed 


\section{Table of Contents}

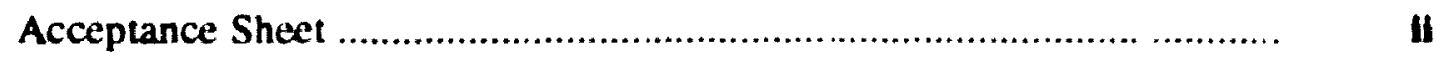

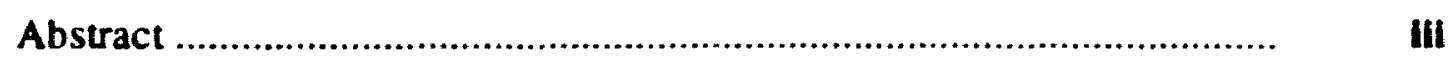

Acknowledgements ............................................................. Iv

Table of Contents ...................................................................... v

List of Figures ...................................................................... vil

List of Tables ..........................................................................

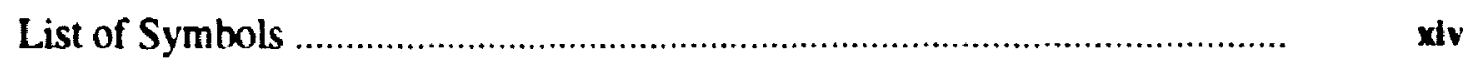

1.0 Introduction

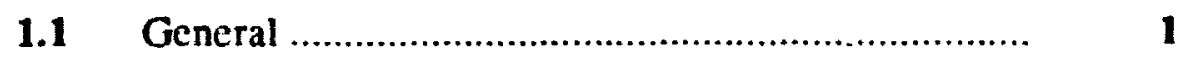

1.2 Web Behaviour and Bearing Resistance ................. 2

1.2.1 Elastic Web Buckling ........................... 2

1.2.2 Inelastic Web Buckling and Web Yielding ..... 3

1.3 Objectives and Scope .......................................

1.4 Outline ........................................................

$2.0 \quad$ Experimental Program ..................................................... $\quad 16$

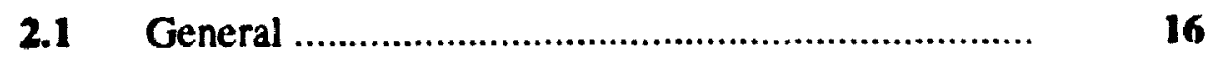

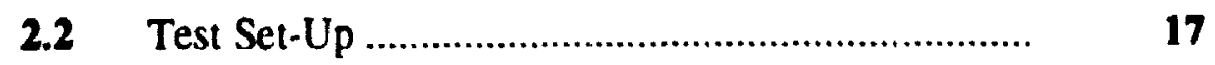


2.2.1 Loading System and Suppon Details

2.2.2 Laterai Support (Watt Mechanisms) ............ 18

2.2.3 Instrumentation and Measurement ................ 19

2.3 Alignment and Test Procedure ................................ 22

2.3.1 Alignment and Initial Loading ...................... 22

2.3.2 Test Procedure ………………………………... 22

2.4 Ancillary Tests (Tension Coupons) ........................... 23

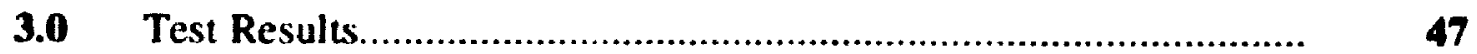

3.1 Geometric Properties................................................ 47

$3.2 \quad$ Material Properties.................................................. 48

3.3 Web Behaviour.....................................................

3.3.1 Load vs. Out-of-Plane Behaviour.................. 51

3.3.2 Web Strain Distribution................................. 54

4.0 Discussion and Application of Equivalent Column Concept............... 103

4.1 Equivalent Column Concept...................................... 103

4.2 Stress Distributicn ..................................................

4.3 Deflected Shapes....................................................... 107

5.0 Results, Conclusions and Recommendations..................................... 132

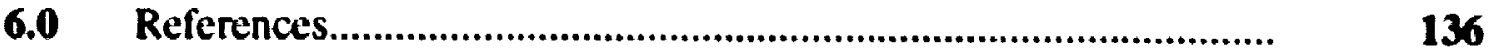




\section{List of Figures}

1.1 Research Development for Web Buckling.............................................

2.1 Geometric Property Definitions and Reference Orientation........................ 24

2.2 Schematic Diagram of Test Set-up...................................................

2.3 Cross-Section of Reaction Frame................................................... 31

$2.4 \quad$ View of Lateral Support System...................................................... 32

2.5 Plan View of Watt Mechanisms and Test Specimen...................................

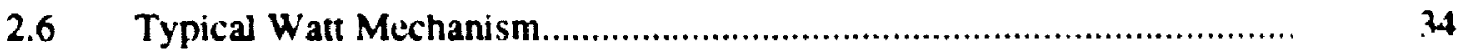

2.7 Schematic Diagram of a Typical Want Mechanism...............................

2.8 Strain Gauge Locations and Numbering for all Flanges............................

2.9 (a) Strain Gauge Locations for WWF $985 \times 71$ Webs ................................. 36

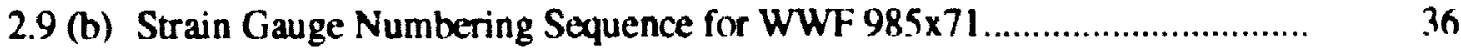

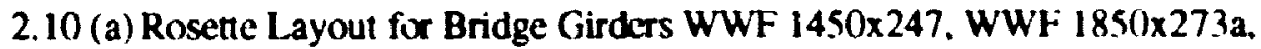
WWF 1850x 257.................................................................................. 37

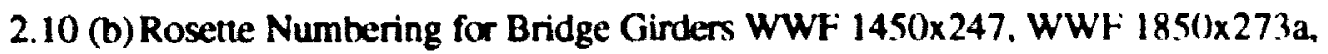

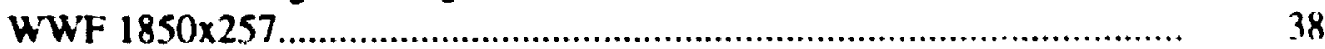

2.11 (a) Rosette Layout for Bridge Girders WWF 1850x 27.3b................................ 39

2.11 (b) Rosette Numbering for Bridge Girder WWF 1850x 273h........................... 41)

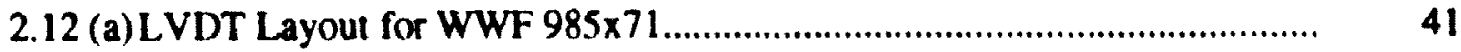

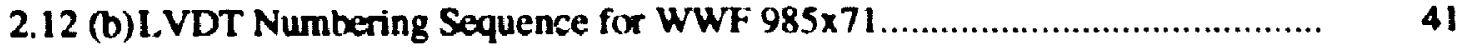

2.13 (a) LVDT Layout for Bridge Girders WWF 1450) 247, WWF 1850) $273 \mathrm{a}$. 


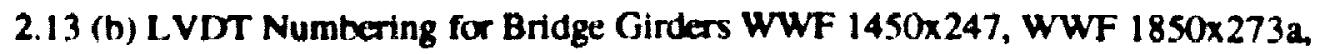
WWF $1850 \times 257$

2.14 LVDT Layout for Bridge Girders WWF 1850x 273b.............................. 43

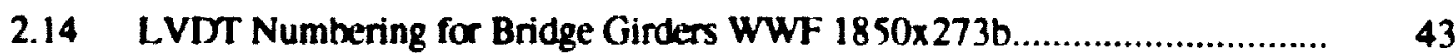

2.15 Numbering Sequence and LVDT Set-Up for All Shapes.............................

2.16 Tension Coupon Definition...................................................................... 45

2.17 Tension Coupon Identification for WWF Sections...................................... 46

3.1 (a) Definition of Measurements for Beam Geometry...................................... 72

3.1 (b) Schematic Diagram of Imperfection Measuring Device.................................. 72

3.2 Typical Uniaxial Stress Strain Curves from Tension Coupon Tests............... 73

3.3 Laad vs. Maximum Displacement Curve for WWF 985x71 (a), Interior Load 74

3.4 Load vs. Maximum Displacement Curve for WWF $985 \times 71$ (b), Interior Load 74

3.5 Load vs. Out-of-Plane Web Deformation for WWF $985 \times 71$ (a), Endtest... 75

3.6 Load vs Out-of-Plane Web Deformation for WWF $985 \times 71$ (b). Endtest..... 75

3.7 WWF $985 \times 71$ (b) Endtest, Rotation of Unloaded Flange.............................. 76

3.8 (a) Load vs. Displacement Curve for WWF 1450x247, Upper Panel (0.2h).... 77

3.8 (b) Load vs. Displacement Curve for WWF 1450x247, Lower Panel $(0.8 \mathrm{~h}) \ldots . . .77$

3.9 (a) Load vs. Displacement Curve for WWF 1850×273 (a), Upper Panel (0.2h) 78

3.9 (b) Load us. Displacement Curve for WWF $1850 \times 273$ (a), Lower Panel (0.8h) 78

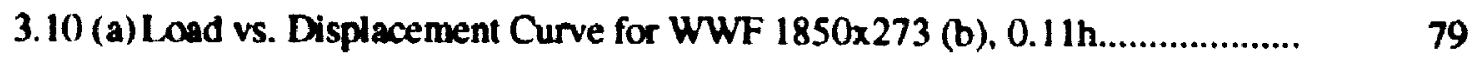

3.10 (h) Load vs. Displacement Curve for WWF 1850×273 (b), 0.5h....................... 79

3.10 (c) Load vs. Displacement Curve for WWF $1850 \times 273$ (b), $0.16 \mathrm{~h} \ldots \ldots \ldots \ldots \ldots \ldots . . . . . . . . \quad 80$

3.10 (d) Load vs. Displacement Curve for WWF 1850×273 (b), 0.3h..................... 80 
3.10 (e) Load vs. Displacement Curve for WWF $1850 \times 273$ (b), $0.2 \mathrm{~h} \ldots \ldots \ldots \ldots \ldots \ldots \ldots \ldots \ldots$

3.11 (a) Load vs. Displacement Curve for WWF 1850) 257. Upper Pancl (0.2h;.... 82

3.11 (b) Loed vs. Displacement Curve for WWF 185() 257, Lower Pancl (0.8h).... 82

3.12 (a) Out-of-Plane Web Deformation for WWF 985 77 (a). Centreline............... 83

3.12 (b) Out-of-Plane Web Deformation for WWF $985 \times 71$ (a), N/2 .....................

3.13 (a) Out-of-Plane Web Deformation for WWF $985 \times 71$ (b). Centreline .............. 84

3.13 (b) Out-of-Plane Web Deformation for WWF $985 \times 71$ (b). N/2..................... 84

3.14 (a) Out-of-Plane Web Deformation for WWF 1450x247, Centreline................ 8.

3.14 (b) Out-of-Plane Web Deformation for WWF 1450) 247, N/2......................

3.15 (a) Out-of-Plane Web Deformation for WWF $1850 \times 273$ (a). Centreline............. 86

3.15 (b) Out-of-Plane Web Deformation for WWF $1850 \times 273$ (a), N/2 ................... 86

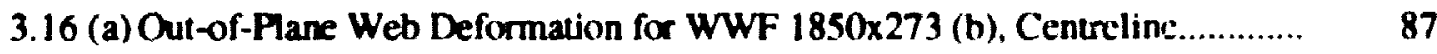

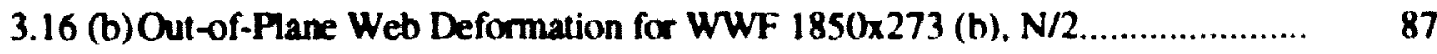

3.17 (a) Out-of-Plane Web Deformation for WWF 1850x 257. Centreline.................... 88

3.17 (b) Out-of-Plane Web Deformation for WWF $1850 \times 257$, N/2 ........................ 88

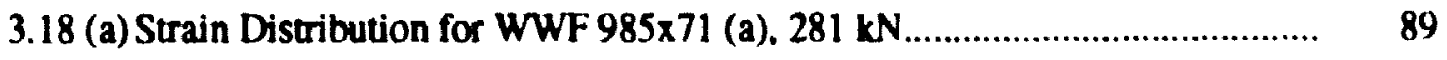

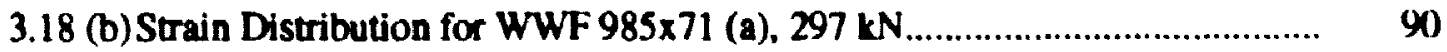

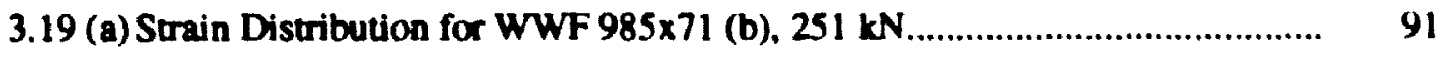

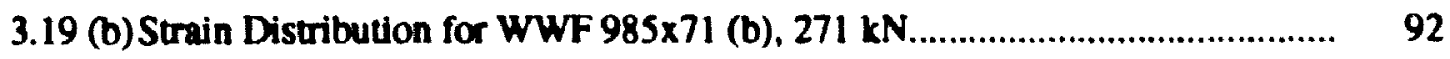

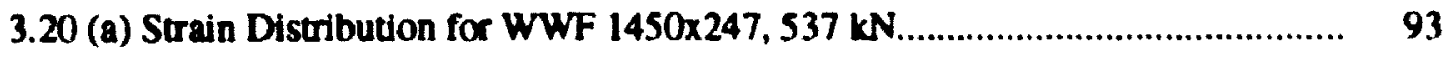

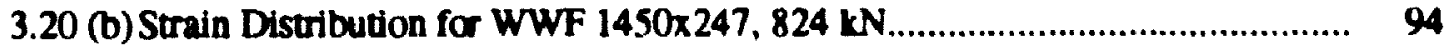

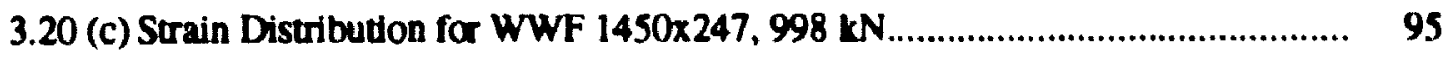

3.21 (a) Strain Distribution for WWF $1850 \times 273$ (a), 377 kN................................ 96 


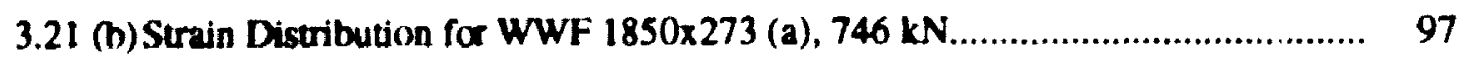

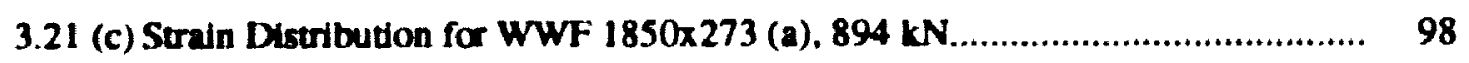

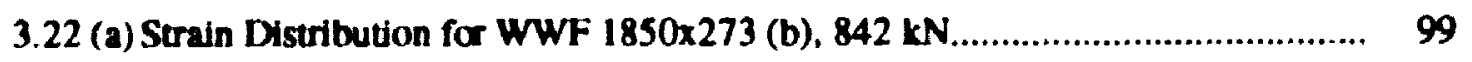

3.22 (b) Strain Distribution for WWF 1850×273 (b), $887 \mathrm{kN}$........................................ 100

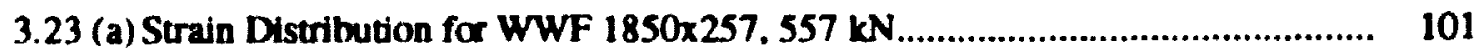

3.23 (b) Strain Distribution for WWF 1850×257. $633 \mathrm{kN}$........................................... 102

4.1 (a) Stress Distribution and Deflected Shape for WWF 1450x247. $537 \mathrm{kN}$.............. 113

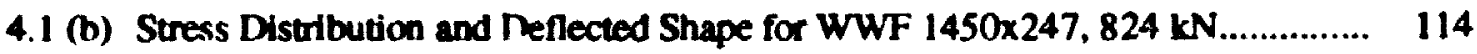

4.1 (c) Stress Distribution and Deflected Shape for WWF 1450×247, $998 \mathrm{kN} \ldots \ldots \ldots \ldots \ldots . .115$

4.1 (d) Yield Bands a Ulumate and Deflected Shape for WWF 1450x274.................... 116

4.2 (a) Stress Distribution and Deflected Shape for WWF 1850x273 (a), 377 kN......... 117

4.2 (b) Stress Distribution and Deflected Shape for WWF 1850x273 (a), $746 \mathrm{kN} \ldots \ldots \ldots . .118$

4.2 (c) Stress Distribution and Deflected Shape for WWF 1850×273 (a), 894 kN......... 119

4.2 (d) Yield Bands at Ultimate and Deflected Shape for WWF 1850×273 (a)................ 120

4.3 (a) Stress Distribution and Deflected Shape for WWF 1850x 273 (b), $842 \mathrm{kN} \ldots \ldots \ldots . .121$

4.3 (b) Stress Distribution and Deflected Shape for WWF 1850×273 (b), $887 \mathrm{kN} . \ldots \ldots \ldots .122$

4.3 (c) Yield Bands at Ulimate and Deflected Shape for WWF 1850×273 (b).............. 123

4.4 (a) Stress Distribution and Defected Shape for WWF 1850×273, $557 \mathrm{kN}$.............. 124

4.4 (b) Stress Distribution and Deflected \& hape for WWF 1850x273, $633 \mathrm{kN} \ldots \ldots \ldots \ldots . . . . .125$

4.4 (c) Yield Bands at Ultimate and Deflected Shape for WWF 1850x257..................... 126

4.5 Normal Stress Distribution and Fitted Curves for Bridge Girders....................... 127

4.6 Out-of-Plane Web Displacements at Various Levels for Girder 1450x247......... 128

4.7 Out-of-Plane Web Displacements a Various Levels for Girder 1850×273 (a).... 129 
4.8 Out-of-Plane Web Displacements a Various Levels for Circk 1850/27? (h) . I

4.9 Out-of-Plane Web Displacements at Various Levels for liirikt $1850 \times 297 \ldots . \quad 131$ 


\section{List of Tables}

1.1 Typical Dimensions of Bridge Girder in Current Use................................ 17

2.1 Nominal Geometric Properties for WWF 985x71 and Bridge Girders....... 28

3.1 Measured Geometric Properties for Test Specimens.................................. 57

3.2 Measured Web Plate Out-of-Straightness................................................. 58

3.3 Characteristic Material Properties Determined from Uniaxial Stress Strain Curves for the WWF 985x71........................................................ 59

3.4 Characteristic Material Properties Determined from Uniaxial Stress Strain Curves for the $6.4 \mathrm{~mm}$ plate parallel to rolling

3.5 Characteristic Material Properties Determined from Uniaxial Stress Strain Curves for the $6.4 \mathrm{~mm}$ plate transverse to rolling............................. 61

3.6 Characteristic Material Properties Determined from Uniaxial Stress Strain Curves for the $8 \mathrm{~mm}$ plate parallel to rolling

3.7 Characteristic Material Properties Determined from Uniaxial Stress Strain Curves for the $8 \mathrm{~mm}$ plate transverse to rolling.

3.8 Characteristic Material Properties Determined from Uniaxial Stress Strain Curves for the $25 \mathrm{~mm}$ plate parallel to rolling......................................

3.9 Characteristic Material Properties Determined from Uniaxial Stress Strain Curves for the $25 \mathrm{~mm}$ plate transverse to rolling...............................

3.10 Characteristic Material Properties Determined from Uniaxial Stress Strain Curves for the $10 \mathrm{~mm}$ plate parallel to rolling................................... 


\subsection{Characteristic Material Properties Determined from Uniaxial Stress}

Strain Curves for the $12.7 \mathrm{~mm}$ plate parallel to rolling.............................. 67

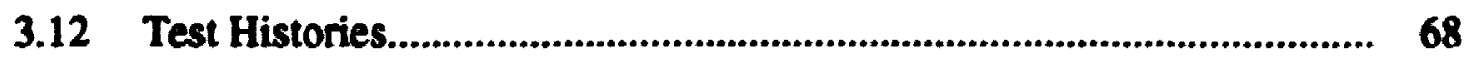

4.1 Material Properties Used in Strain Interpretation Program....................... 110

4.2 Formation of Yield Bands on Webs of Bridge Girders............................. 111

4.3 Test-to-Predicted Ratios Using Proposed Clause 15.9............................ 112 


\section{List of Symbols}

$\begin{array}{ll}\text { a } & \text { distance between vertical stiffeners } \\ \text { a } & \text { measured distance from flange tip to web face } \\ \text { b } & \text { width of flange tip to the face of the web } \\ \text { Br } & \text { bearing resistance of web } \\ \text { c } & \text { resistance factor } \\ \text { d,d }, d_{2} & \text { depths of beam } \\ \text { E } & \text { modulus of elasticity } \\ \text { E. } & \text { strain hardening modulus } \\ \text { Fy } & \text { yield stress of plate material } \\ \text { h } & \text { height of web plate } \\ \text { I } & \text { moment of inertia } \\ \text { K } & \text { effective length factor of equivalent column } \\ \text { K } & \text { distance from outer face of flange to the base of the web fillet } \\ \text { L } & \text { length of beam } \\ \text { N } & \text { length of patch load } \\ P_{\text {c }} & \text { elastic buckling load of equivalent column } \\ P_{w k} & \text { ultimate capacity of web } \\ \end{array}$




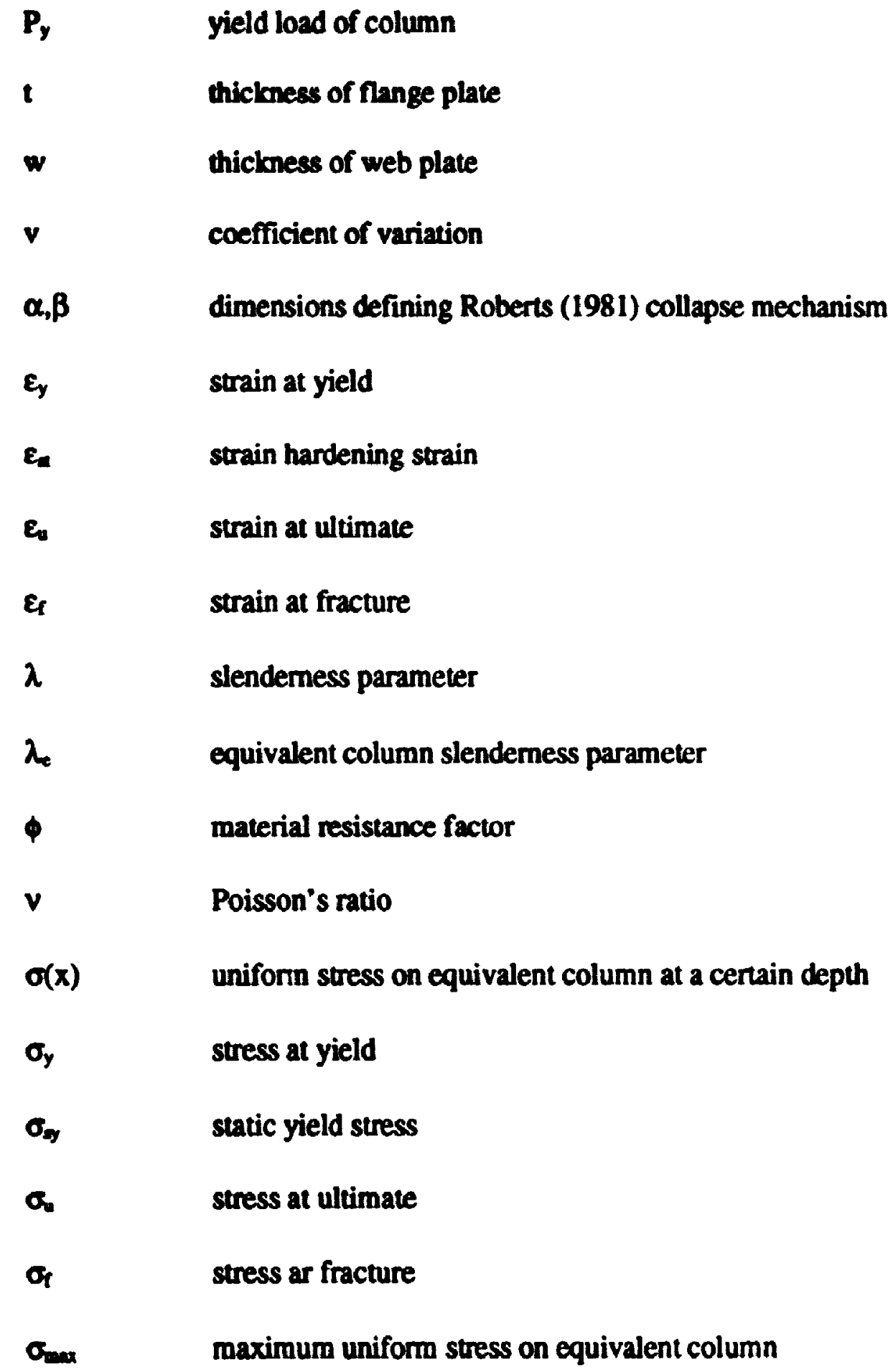




\section{Chapter 1}

\section{Introduction}

\subsection{General Introduction}

The bearing resistance of webs of rolled shapes, WWF sections and bridge girders must be sufficient to sustain all concentrated loads which may be applied by beams, purlins, or columns framing into the section or from wheel loads on gantry girders. In addition to these regular loading conditions, girders may be required to sustain various types of extreme loading conditions during construction, such as roller loads (i.e. Hillman rollers) which occur when a bridge is launched during construction. If the web capacity is not properly predicted either an excessive or inadequate number of bearing stiffeners may be provided. Obviously, a correct estimate of the resistance of the web is necessary for a reliable and economical design. Questions about the applicability of current design equations may lead to uncertainty, and in general, over-design and increased cost. The development of a consistent, unified, and easily understood approach for predicting the capacity of webs under concentrated loads therefore is of interest. 
The design equations for calculating the bearing resistance should cover the full range of behaviour from web yielding to elastic and inelastic web buckling for all shapes currently being mass produced by North American Mills, and for customized shapes either, with or without longitudinal stiffeners like those being used in long, multi-span. bridge girders.

\subsection{Web Behaviour and Bearing Resistance}

A chronological list of reseanchers with key words, reproduced and amended from Benichou (1994), is given in Figure 1.1. A detailed description of the work prior to 1994 can be found in Benichou (1994). A brief summary of recent research including work done by Benichou (1994), Kirkhope (1995) and Prabha (1996) is presented in the following sections.

\subsection{Elastic Web Buckling}

Elastic web buckling solutions and buckling coefficients based on classical plate buckling (energy methods) and numerical methods (finite difference and finite element analysis) were developed by Sommerfield (1906), and Timoshenko (1910), and White and Coutingham (1962), to determine the effects of plate geometry, boundary conditions, load 
effects, assumed deflected shapes, and intemal force distributions. These, however, are of limited value because they have not been applied to realistic geometries and load conditions, the slenderness parameter has not been identified, the corresponding rational. mathematical models have not been developed, and there is no evidence of any test ever failing by elastic web buckling.

\subsubsection{Inelastic Web Buckling and Web Yieiding}

While elastic buckling solutions were developed analytically, many tests were also done to establish empirical bearing capacities for inelastic web buckling and web yielding. Although many tests were done in the last 60 years, the empirical relationships are generally unsuitable for developing a rational model as the data are incomplete or the tests were conducted on shapes that either no longer exist, or were made of a low grade steel that is no longer used. It is however, of interest to discuss the historical background of these findings and their relevancy to this study.

Based on observations of Bergfelt et al. (1968, 1970, 1971), Bergfelt and Lindgren (1974), Bagchi and Rockey (1975), Skaloud and Novak (1972), Drdacky and Novotny (1977). Bergfelt (1979), and Roberts and Rockey (1979) developed a lower bound plastic mechanism model requiring the development of four plastic hinges in the flange and three yield lines in the web. Using the conservation of energy method and by minimizing the 
critical load with respect to the locations of the plastic hinges in the flange, the authors developed two semi-empirical formulae to predict the inelastic web buckling capacity (equation 1.1) and web yielding (equation 1.2) with the lesser of the two governing the capacity of the web. These are, respectively:

$$
\begin{gathered}
P_{0}=\frac{4 M_{1}}{\beta}+\frac{(4 \beta+2 N-2 \eta) M}{\alpha \cos \theta} \\
P_{0}=2(4 M, F, w)^{\omega}+F, w N
\end{gathered}
$$

where, $P_{u}=$ ultimate load, $\mathbf{N}$

$M_{w}=$ web plastic moment per unit width of web, $N \cdot \mathbf{m m}$

$\mathbf{M}_{\mathbf{f}}=$ plastic moment capacity of flange, $\mathrm{N} \cdot \mathrm{mm}$

$\beta=$ location of plastic hinges, $\mathrm{mm}$

$\theta=$ angle of yield lines, $\mathrm{mm}$

$\alpha=$ location of yield lines, $\mathrm{mm}$

$\eta=$ length of web which yielded in direct compression, $\mathrm{mm}$

Subsequently, Roberts, (1981), conducted more tests on slender short-spanned plate girders and modified the expression for inelastic web buckling to: 


$$
P_{.}=0.5 w^{\prime} \sqrt{E F, \frac{t}{w}}\left(10+3.0\left(\frac{N}{d}\right)\left(\frac{w}{t}\right)^{1 s}\right)
$$

where, $P_{\bullet}=$ web crippling luad, $\mathbf{N}$

$\mathrm{t}=$ flange thickness, $\mathrm{mm}$

$\mathrm{d}=$ web panel depth, $\mathrm{mm}$

This equation was adopted into the CSA Standard CAN/CSA-S16.1-M89, where the bearing resistance of webs failing by inelastic web buckling (crippling) for interior load cases is given in Clause 15.9 as follows:

$$
B_{t}=300 \phi w^{2}\left[1+3\left(\frac{N}{d}\right)\left(\frac{w}{t}\right)^{1, s}\right] \sqrt{F_{y} \frac{t}{w}}
$$

where, $B_{r}=$ factored bearing resistance, $N$

$$
\phi=\text { resistance factor, } 0.9
$$

When comparing these two equations there is a difference of 1.34 times the value of $\frac{300}{0.5 \sqrt{E}}$, based on a reassessment of Roberts' data. This equation was used for end reactions with the value of 300 reduced to 150 based on the assumption that in the limit for short reaction lengths, the load spreads out when transmitted through the flange to the web on one side rather than two as for interior loads. 
The upper limit to inelastic behaviour is defined as web yielding which in turn is defined by S16.1 Clause 15.9 (a) (i) as:

$$
B_{r}=1.10 \phi w(N+5 k) F y
$$

This expression is based on experimental research provided by Graham es al. (1959), on welded interior beam to column moment connections. The critical area is based on yielding of the web of the column opposite the compression flange of the beam with a load dispersion of 2.5 to 1.0 .

The applicability of these design equations is questioned bocause:

1. The web yielding equation (Eq. 1.5) is based on small load lengths equal to the beam flange thickness and stocky webs. A calibration coefficient of 1.1 was introduced when the standard was adapted to a limit states design format rather than redefining the critical area.

2. The inelastic web buckling (crippling) equations (Eq. 1.4) are based on the empirical expressions given by Rober's (1981), which in tum is based on experimental observations from tests on shapes which had gumetric prope ties and slendemess ratios that generally 
lay outside the range of values for $W$ and WWF shapes produced by Canadian Mills. The tests were also conducted on relatively stender plates, and generally on a small scale. This leads to problems wit: regard to providing realistic welding details, loaded lengths, boundary conditions, and imperfections. The limitations of flange thickness to web width ratio greater than or equal to 3.0 and the loaded length to web depth ratio less than or equal to 0.2 are not given as part of Clause 15.9 , although they are specifically stated by Roberts.

Based on the historical development of these design expressions in CAN/CSA S16.1-M89 including the obvious questions related to the applicability, the lack of a unified approach to define all forms of probable failure (i.e. web yielding, elastic web buckling), and the semi-empirical nature of the design equations (which have no physical interpretation for design engineers), Benichou (1994), Kirkhope (1995), and Prabha (1996) conducied further research. The objectives of these programs were:

1. to provide quality test data for the full range of $W$ and WWF shapes produced in Canadian Mills that exhibit all probable web failure modes;

2. to conduct finite element analyses to obtain a whole field description of the web behaviour. These are verified against test data; 
3. to develop a rational mathematical model and the corresponding design equations w resolve some of the issues cited previously.

Benichou's work encompassed experimental testing and finite element analyses of the full range of $\mathrm{W}$ shapes produced by Canadian mills for both interior loading conditions and end reaction tests. He developed an equivalent column concept which took into account the intemal stress distribution, the buckled shape of the web. the equivalent column dimensions for both $\mathrm{W}$ and WWF shapes. However, as a result of further experimental research conducted on WWF shapes, Kirkhope (1995) concluded these equations were in general not applicable to WWF shapes. His work served as a verification for finite element results recently completed by Prabha (1996).

From the finite element analysis, Prabha (1996), was able to revise Benichou's original equivalent column concept to make it applicable to WWF shapes. Prabha showed that the equivalent column width of $N+5 k$ originally determined by Benichou is not applicable to WWF shapes, the normal stress distributions were different, the assumed buckled shapes utilized inconsistent boundary conditions, ano the energy method solution that was used was based on columns not plates. Instead, a new equivalent column width of $N+10$, using the energy method of Timoshenko and Gere (1961) for the buckling of 
thin plates, was proposed as well as a new curve fit for the average normal stresses in the form below.

$$
\sigma(z)=\sigma_{\max }\left(\frac{z}{h}\right)^{p}
$$

where, $\sigma(z)=$ average normal stress distribution at any depth, $\mathbf{z}, \mathrm{MPa}$

$$
\begin{aligned}
& a_{\text {ax }}=\text { maximum average normal stress at root of fillet weld on the web, } \mathrm{MPa} \\
& \mathrm{p}=\text { any positive integer }
\end{aligned}
$$

From this, the elastic critical buckling load for a fixed end plate with the load distribution described above can be determined from:

$$
P_{\pi}=f(N+10 h) \frac{\pi^{2} D}{h^{2}}
$$

where, $f$ is a function of $h$ and $N+10$ as described by Prabha (1996) and $D$ is the plate. flexural rigidity. Prabha (1996) also gives an equivalent slendemess parameter so that column buckling curves can be used. This is found from: 


$$
\frac{P_{a}}{P_{y}}=\frac{1}{\lambda_{c}^{2}}
$$

where, $\lambda=c\left(\frac{b}{r}\right) \sqrt{\frac{F_{y}}{\pi^{2} E}}$

$r=$ radius of gyration of the equivalent column model cross section

$c=$ a plate buckling coefficient which is a function of the boundary conditions. the displaced shape, the average normal stress distribution, and aspect ratio of the plate.

Prabha (1996), working on webs subjected to concentrated loads, proposed a new Clause 15.9.1 for the factored bearing resistance of a web.

$$
B_{1}=\phi A F_{y}\left(1+\lambda^{2 n}\right)^{-\frac{1}{1}}
$$

where, $n=2.24$ and $\lambda_{k}$ is the equivalent slenderness parameter as defined previously.

In this summary, only beams with $\mathrm{W} / \mathrm{w}$ ratios of 87 or less were studied and therefore any piate girders or customized built-up WWF's are excluded. Currently. WW'F sections with thin webs up to an h/w of 285 are being fabricated but very litule experimental work has been done on beams with very thin webs and research is needed to establish the bearing resistance of such sections. 


\subsection{Objectives}

The focus of this study is to enable engineers to design stoel girders more accurately and economically Therefore some recently constnucted steel bridges were examined to determine the types of girders currently being used as shown in Table 1.1. The $\mathrm{h} / \mathrm{w}$ ratios range from 129 (the Annacis River Bridge in British Columbia) to 309 (Rideau Bridge in Ontario), with about $85 \%$ of the aspect ratios lying between 160 and 285, categorizing the girders as thin-webbed beams. Based on this, the girders selected for this research had $h / w$ ratios of 175 to 285 . The length of the beams tested, to ensure that true flexural action was achieved, ranged from $5.5 \mathrm{~m}$ to $7 \mathrm{~m}$, respectively.

Most of the bridge girders cited were designed and put into use without regard to experimental evidence to determine the actual capacity of their webs to concentrated loads. Engineers referred to altemate codes, specifications or material standards, such as the British Standards (BS 5400) that deal with web crippling in considerably more detail. Unfortunately, mixing of codes is not conducive to good design and should be done carefully. 
The objectives of this experimental study are:

1. to design a number of stiffened plate ginders that are representative of the full range of geometric parameters currently used in typical bridge construction that will fail by inelastic or elastic web buckling or web yielding:

2. to design a series of Watt Mechanisms to provide lateral support to the plate girders with minimal restraint in the plane of the web;

3. to design an LVDT support device to give a consistent reference point to improve the accuracy and reliability of transverse displacements of the web;

4. to test each girder to determine the complete range of web behaviour, generating thereby all the data required for the verification of the results of finite element analyses and the rational mathematical design models that will be used to describe the behaviour of thin-webbed plate girders subjected to concentrated loads;

5. to test two WWF $987 \times 71$ sections with an $\mathrm{h} / \mathrm{w}$ ratio of 180 , one with fillet welds on both sides of the web and one with welds on one side only, for interior loads and end reactions in order to provide the data to complete the series of tests on WWF sections. 


\subsection{Outline}

After a general introduction. Chapter 1 presents an analysis of Clause 15.9 in CANKSA S16.1-M94, a state of the art review including a general description of the behaviour of webs subjected to concentrated loads, and the justification for this research. Chapter 2 describes the experimental program and Chapter 3 presents the test results and a description of web behaviour under concentrated loads and the failure modes. The reduced data presented in Chapter 4 provide the information required for an accurate comparison and verification of the corresponding results of future finite element analysis and for the continued development of the equivalent column concept for bridge girders. A summary, conclusions and recommendations for future work are given in Chapter 5. 


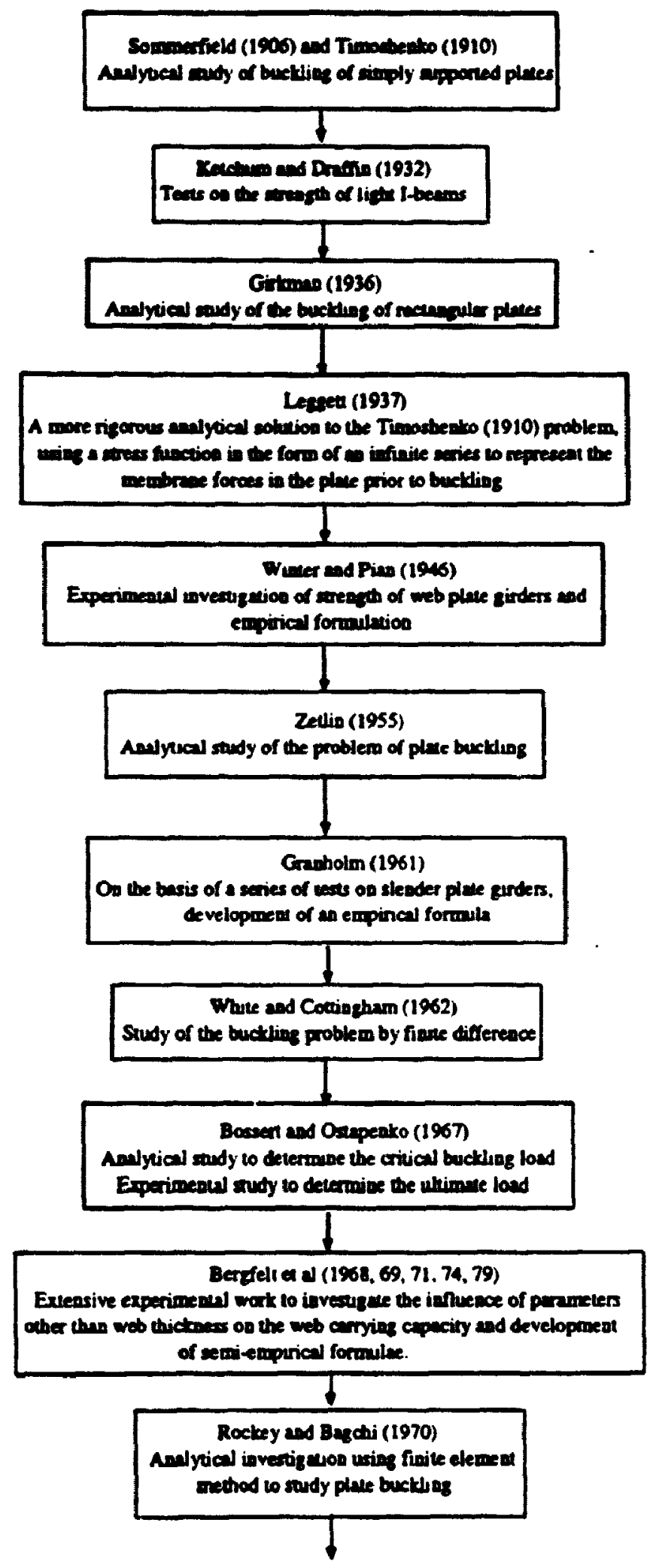

Figure 1.1 Research Development for Web Buckling 


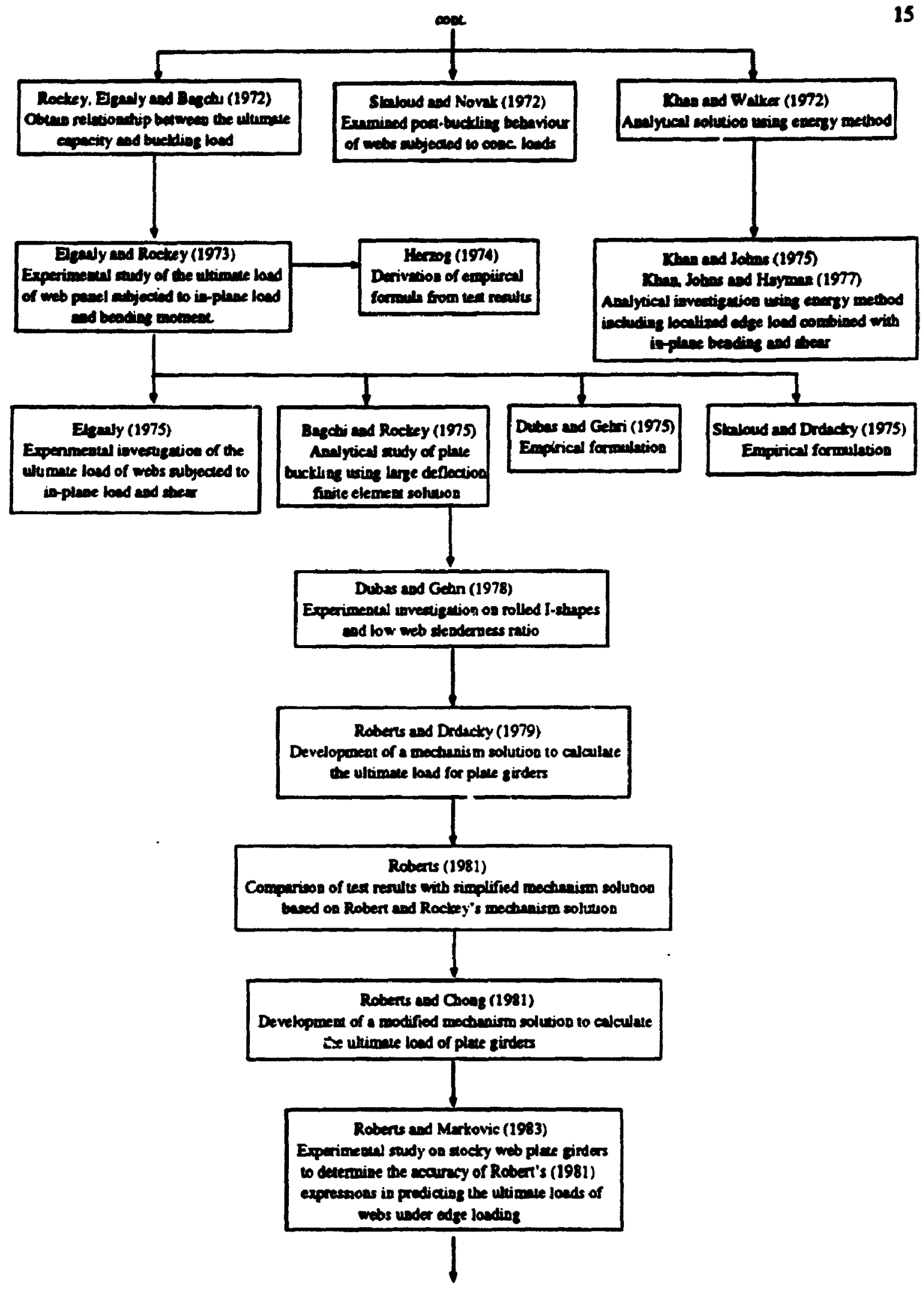

Figure 1.1 (cont) Research Development for Web Buckling 
Dopely and Nuane (1929)

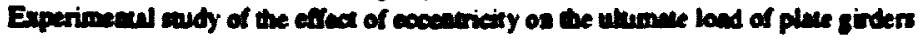

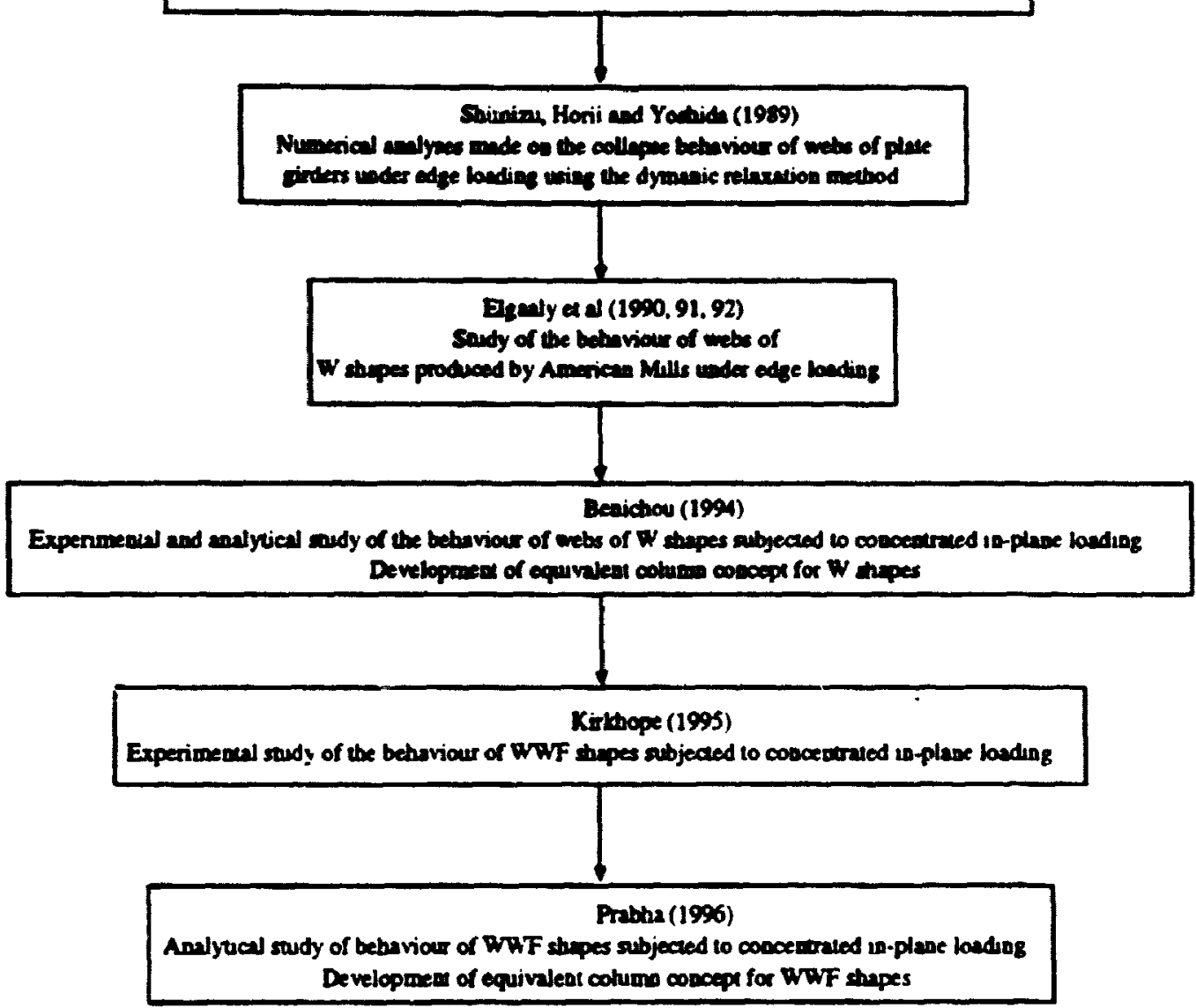

Figure 1.1 (cont) Research Development for Web Buckling 


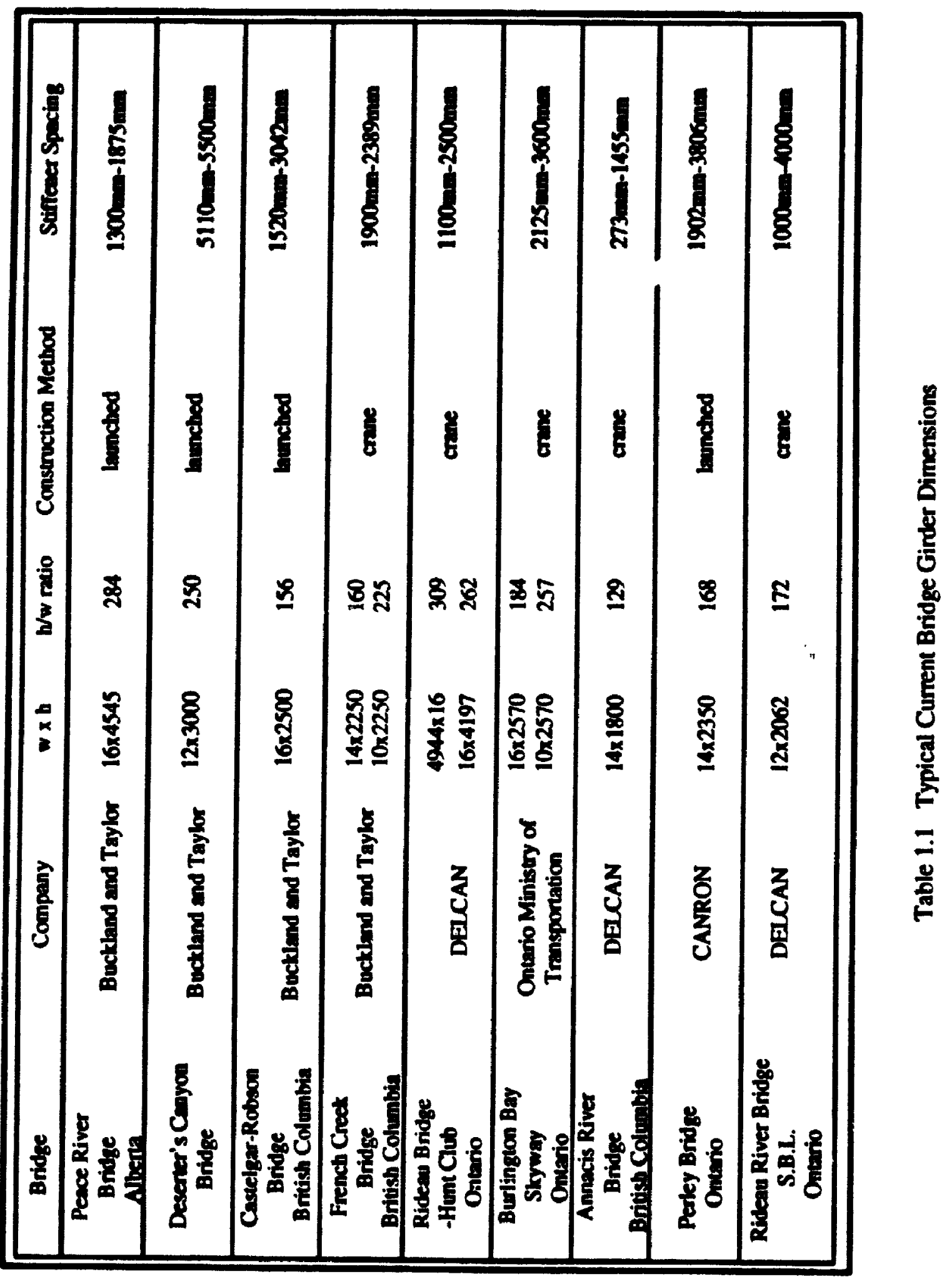




\section{Chapter 2}

\section{Experimental Program}

\subsection{General}

The experimental program was designed to ohtain test data that describes the behaviour and strength of thin-webbed girders subjected to in-plane concentrated loads. The dita is analyzed and presented in a format suitable for comparison with the results of finite element analyses.

The bridge girders and WWF $985 \times 71$ were selected to give a sample of slender plate girders with $\mathrm{h} / \mathrm{w}$ values varying from 175 to 285 . They were designed with shear span ratios of 1.67 to 1.96 , with spans of $2750 \mathrm{~mm} 103500 \mathrm{~mm}$ to avoid deep beam behaviour. The flanges were sized and enough lateral support was provided by the Watt mechanisms so that the moment capacity of the girders would not be exceeded in the tests. Verical stiffeners had to be added in order to increase the shear resistance beyond the probable load that would cause local failure of the web. For the WWF $985 \times 71$ sections, 
doubler places were clamped to the web over the reaction points to prevent local instability and failure at that location. For the end reaction tests the doubler plates were removed from one end and added to the central portion of the beam under the load for the same reason. The vertical and longitudinal stiffeners of the bridge girders were designed according to the Ontario Highway Bridge Design Code (1992).

The nominal geometric properties for the test girders are given in Table 2.1 and are shown in Figure 2.1. Also listed is the elastic critical buckling load as determined by Prabha (1996), from a bifurcation analysis using the commercial finite element program LUSAS, the nominal geometric properties and a value for the modulus of elasticity of $200,000 \mathrm{MPa}$. In total, eight web instability tests were conducted: two (one interior load and one end reaction) on each WWF $985 \times 71$ (one with a one-sided flange to web fillet weld, designated WWF $985 \times 71$ (a) and onc with a two-sided fillet weld, designated WWF 985x $7 \mathrm{i}$ (b)) and one interior load test on each of the four bridge girders. Two WWF $1850 \times 273$ girders were made so that a comparison of the behaviour and load carrying capacity of the web could be made depending on the location of the longitudinal stiffener with respect to the loaded flange. The WWF $1850 \times 273$ (a) and the WWF $1850 \times 273$ (b) girders have the longitudinal stiffener located at $0.2 \mathrm{~h}$ and $0.8 \mathrm{~h}$ from the loaded flange. respectively. Based on experience from similar type tests on W and WWF shapes, improvements were made to the lateral support devices and to the LVDT support frame to eliminate the possibility of rigid body rotation displacements. Minor modifications were 
made to the location of displacement and strain measurements program to include the testing of the bridge girders.

\subsection{Test Set-up}

The test set-up consisted of a frame supporting a $4450 \mathrm{kN}$ ( 500 Ton) hydraulic actuator, the test specimens supported on knife-edge roller assemblies, Watt mechanisms and lateral support columns, a hydraulic control system, and a data acquisition system for reading the electronic instrumentation. Details, cross-sections and elevations are shown in Figure 2.2, 2.3 and 2.4.

\subsubsection{Loading System and Support Detoils}

The vertical load was applied at midspan for the interior tests, through load plates of $100 \mathrm{~mm}$ and $200 \mathrm{~mm}$ lengths for the WWF $985 \times 71$, and the bridge girders, respectively. Additional load plates of $50 \mathrm{~mm}$ were used for the end reaction tests of the WWF 985x71. Otherwise, all reactions were taken directly through the knife-edge roller ascemblies. 


\subsubsection{Lateral Support (Wat Mechanisms)}

Six Watt mechanisms were built to restrain the test specimens from displacing Laterally without restricting movement of the restrained point in the vertical and horizontal directions for maximum distances of $75 \mathrm{~mm}$ and $280 \mathrm{~mm}$, respectively, as illustrated in Figure 2.6. These were attached at four locations along the top flange and two on the bottom as shown in Figure 2.5. The Wau mechanisms were designed specifically to be used with the support columns available in the laboratory. Because of this, the lengths of the arms had to be $770 \mathrm{~mm}$ each and the centre HHS section a length of $600 \mathrm{~mm}$. Each of the balls in the joints were attached to threaded rods which could be rotated for horizontal adjusoments to ensure a tight fit and to eliminate any lateral movement as can be seen in Figure 2.7.

\subsubsection{Instrumentation and Measurement}

Measurements of the applied loads, displacements, rotations, and strains which describe the behaviour of the test specimen, were reconded intermittently during the test using LABCON and a Hewlett Packard data acquisition system. These data were evaluated and are presented graphically in Chapter 3 in a form that is readily comparable to the load versus out-of-plane web displacements and principal stresses determined from non-linear finite element analyses of the test specimens. 
A total of 62 electrical resistant strain gauges were used to measure strains on the flanges and webs of the WWF $985 \times 71$ and 76 strain gauges on the bridge girders. Four gauges were placed at approximately $b / 3$ from the edge of the top flange of each beam and girder on either side of the load plate. with four more gauges mirroring them on the underside, providing sufficient data to determine the in-plane force due to bending and any localized bending of the top flange during testing. Two gauges were placed on both sides of the bottom flange at midspan to determine the in-plane tensile force due to bending. These locations and numbering sequences are illustrated in Figure 2.8. The locations of the strain gauge rosettes on the web and the corresponding numbering sequence are illustrated in Figures 2.9, 2.10 (a) and (b), and 2.11(a) and (b), for the WWF 985x71; the bridge girders with the longitudinal stiffener located closest to the loaded flange; and the WWF $1850 \times 273$ (b), respectively. The locations of the rosettes were based on experience from previous tests by Benichou (1994) and Kirkhope (1995) but modified to account for the longitudinal stiffener, Ten rosettes were placed on either side of the web for the WWF

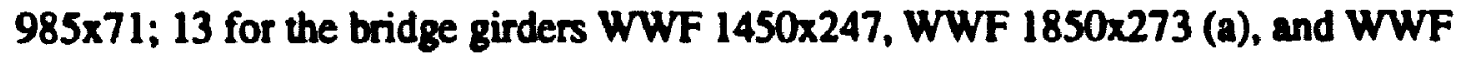
$1850 \times 257$ with nine within the short panel closest to the load plate; and 13 for the WWF $1850 \times 273$ (b) all within the panel closest to the load plate.

Micro-measurement high elongation strain gauges with a resistance of $120.0 \pm$ $0.15 \%$ ohms, a gauge factor of $2.055 \pm 0.5 \%$ at $24^{\circ} \mathrm{C}$ and a gauge length of $8 \mathrm{~mm}$. The 
Aanges were gauged with Showa surain gauges with a resistance of $119.9 \pm 0.5 \%$ ohms were used on both sides of the specimens, a gauge factor of $2.12 \pm 1.0 \%$ at $20^{\circ} \mathrm{C}$ and a gauge length of $5 \mathrm{~mm}$.

Displacements were measured by Linear Variable Differential Transformers (LVDTs). Again, es escentially two different specimens were being tested, the WWF 985x71 shapes and the bridge girders, two different LVDT layouts had to be chosen. These particular layouts allow monitoring of the effect of the longindinal stiffener on the buckled shape of the web, the deflected shapes of the webs, and any rotation and displacement of the flanges aiong the centre or at the ends.

Like the strain gauges, the positioning of the LVDTs was based on data collected in similar previous tests. For the testing of the WWF 985x71 shapes, 21 LVDTs were used to map displacements in ail directions and any rotations. Because of the sizes of the bridge girders, 21 LVDTs were needed to map the web alone, and 30 LVDTs were used in total. The layouts for each of the test types are in Figures 2.12, 2.13, and 2.14. On all tests, four LVDTs were used to measure rotation at both ends of the beams, three LVDTs to measure the vertical displacements of the bottom nange, and two measured the rotation and vertical displacement of the top flange around the load plate (centre of the beam) as seen in Figure 2.15. For the two end reaction tests of the WWF $985 \times 71$ shapes, the two 
LVDTs on the top flange were moved to the end of the beam to measure the rotation there.

The load was sontrolled and monitored using a calibrated pressure transducer on the pressure line attached to the hydraulic actuator and the LABCON program. The pressure transducer actuator combination was calibrated in the $1780 \mathrm{kN}$ Tinius Olsen testing machine with an MTS controller. The pressure between the electric pump and the solenoid valve was adjusted to minimize the pressure difference across the valve to provide adequate control of the load steps. For the WWF 985x71 shapes an Enerpac handpump was used to complete the test as the electric pump. solenoid valve, hydraulic control system retum loop was too slow and too coarse to give small load increments. At best, the load with the electric pump could be controlied to $\pm 10 \mathrm{kN}$.

At the end of each test, additional observations and measturements were taken to verify the data collecte $!$. 


\subsection{Allgnment and Test Procedure}

\subsection{Alignment and Initial Loading}

The flange-web junction at midspan of the test specimen was centered undemeath the actuator, and the longitudinal alignment adjusted to centre the specimen between the lateral support columns. The Watt mechanisms and the corresponding load plate was centered under the actuator. All load and reaction plates were leveled with dental plaster to ensure uniform bearing on the flanges. The LVDT support frames and LVDTs were attached and positioned as shown previously. The electronic instrumentation was connected to the data acquisition system and checked to ensure that it was functional. Subsequently, a small preload was applied to seat the test specimen. The load was removed just enough to maintain contact between the actuator and the load plate, and the keeper plates for the knife-edge roller assemblies were removed.

\subsubsection{Test Procedure}

The test specimens were loaded monotonically until failure using the following loading sequence: 
1. initial readings were taken at zero load with the actuator just in contact with the load plate;

2. the first load increment of approximately $15 \mathrm{kN}$ was applied;

3. all eloctronic measurements were taken and the readings scanned to ensure the complete operation of the system;

4. additional load was applied in appropriate increments as determined by the load deflection curve and the behaviour of the test specimen; observations were made and recorded with respect to deflection, yielding and yield patterns;

After failure, photographs were taken to document the failure and any additional observations or measurements were recorded in the experimental logbook. The specimen was unloaded and the residual out-of-plane deformations were recorded.

\subsection{Ancillary Tests}

Ten tension coupons were cut with a bandsaw from the flange and web plates of each of the specimens as shown in Figure 2.16, with the exception of the WWF 985x71 shapes which were taken from a $500 \mathrm{~mm}$ long section from the locations shown in Figure 2.17. These were milled and tested according to ASTM Standard E8M-91 (1991) using a gauge length of $200 \mathrm{~mm}$ and a width of $40 \mathrm{~mm}$. A typical tension coupon is also shown in 
Figure 2.16. The cross-ecctional dimensions of the reduced section were determined by uking ven measurements of the thicknesses and widths along this length with a digital micrometer. Each coupon had a pair of strain gauges, one mounted on either side, in the longitudinal direction. Two additional trunsverse stmin gauges were attached on coupons 'L2' and 'LA' (Or 'T2' and 'T4'), for the bridge girders (see Figure 2.16 for numbering) and coupons ' 5 ' and '7' for the WWF 985x71 shapes (coe Figure 2.17 for numbering). Larger strains were measured mechanically with dividers and a scale and manually entered into a computer file later. All tension coupons were tested in a $1780 \mathrm{kN}$ Tinius Olsen lesting machine. The stress/strain data derived from these measurements was then used subsequently to determine the material properties for each steel plate. 


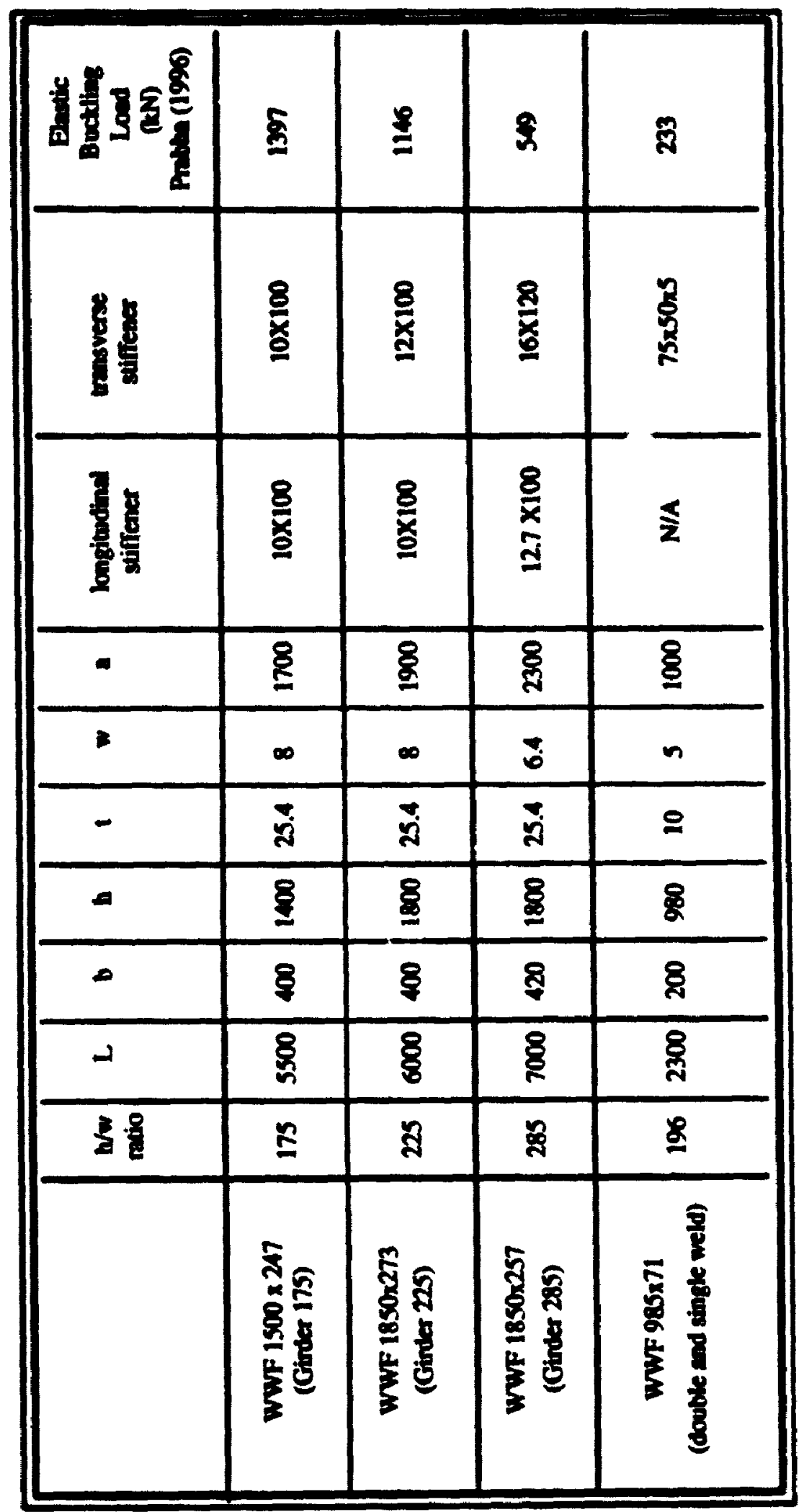

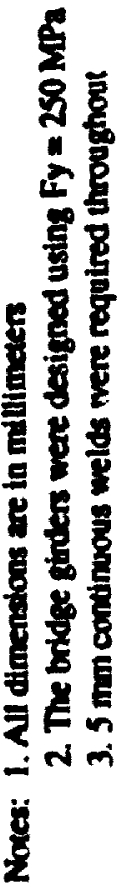

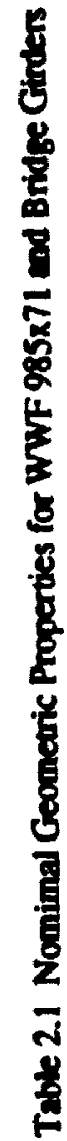




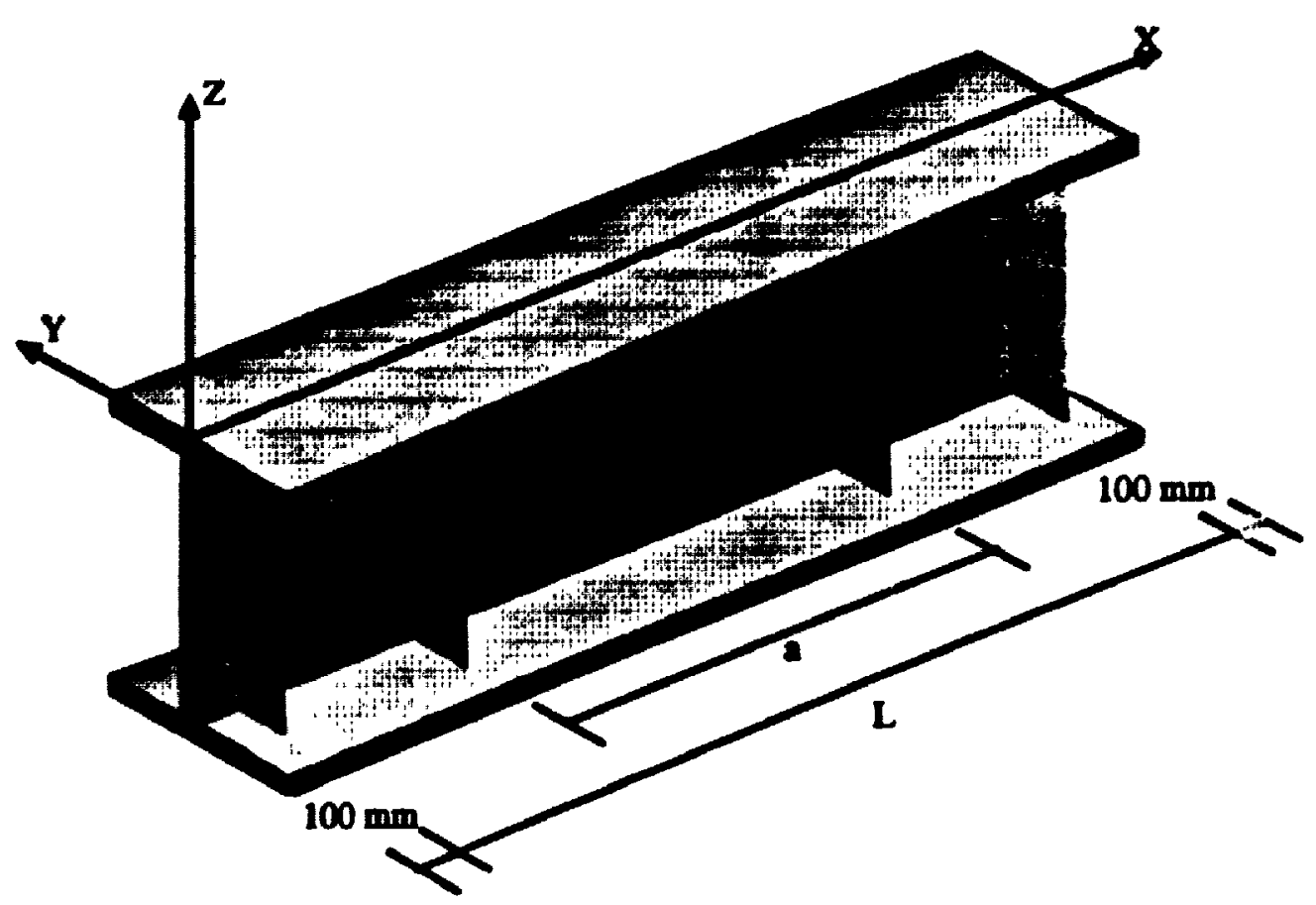

(a) Reference axis

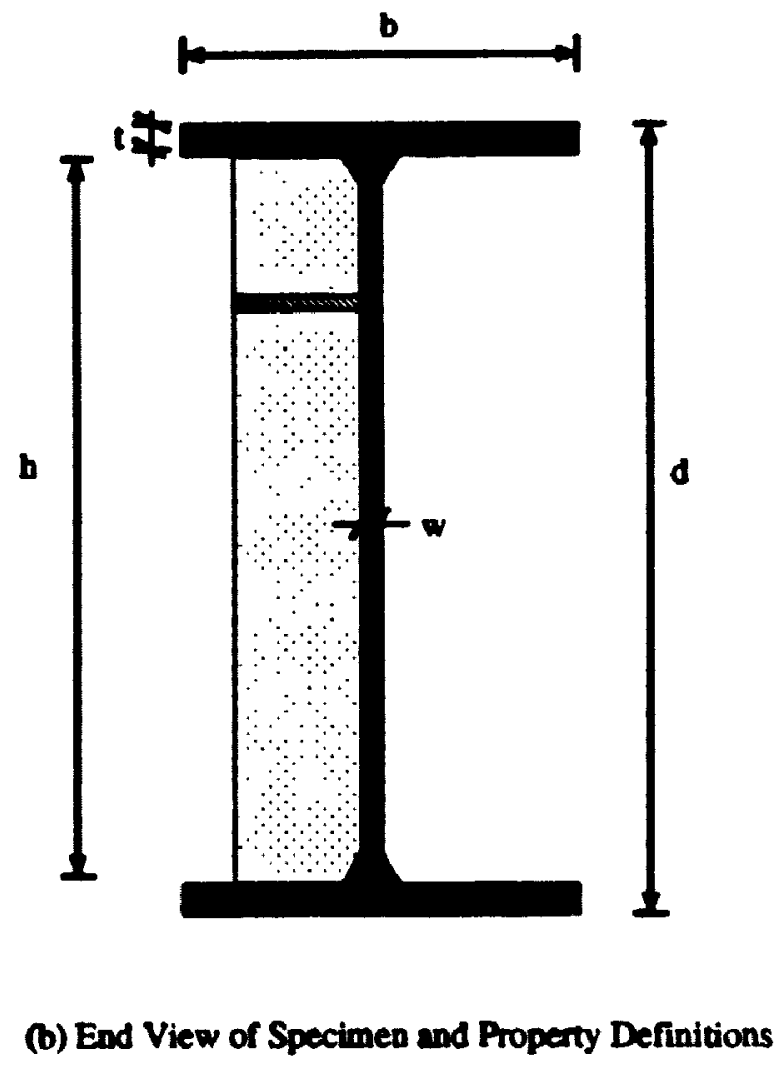

Figure 2.1 Geometric Property Definitions and Reference Orientation 


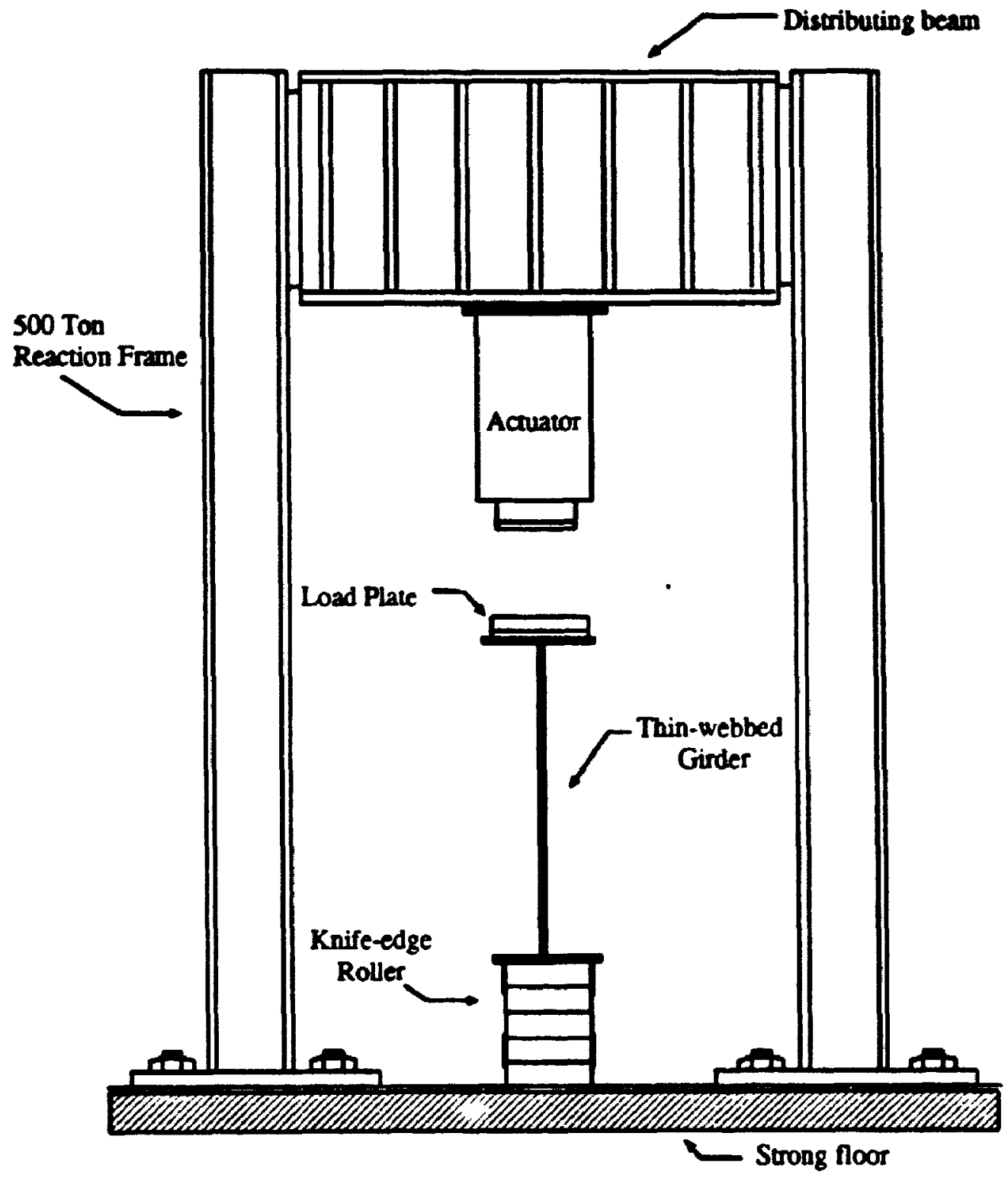

Figure 2.2 Scbematic Diagram of Test Set-up 


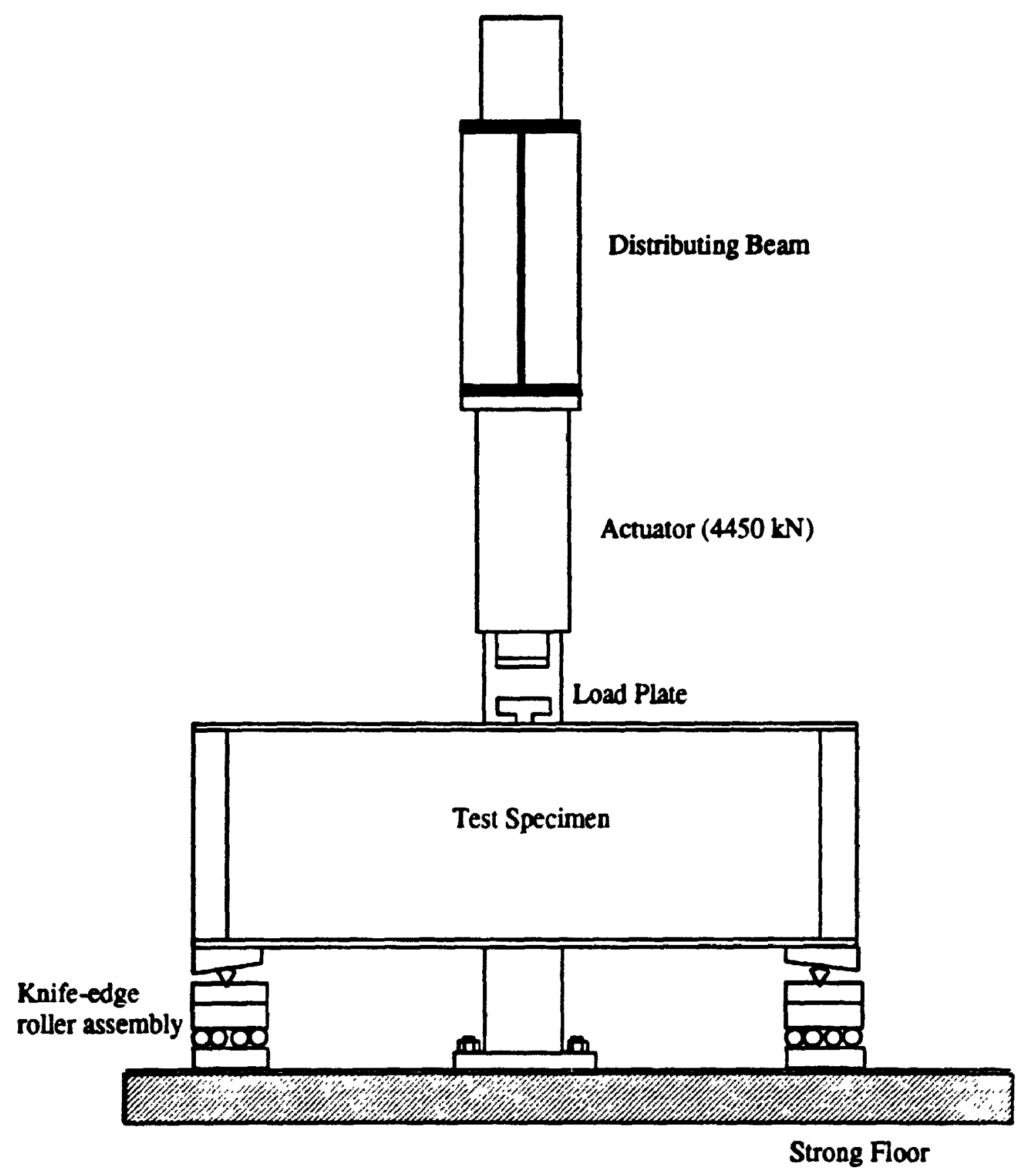

Figure 2.3 Cross-Section of Reaction Frame 


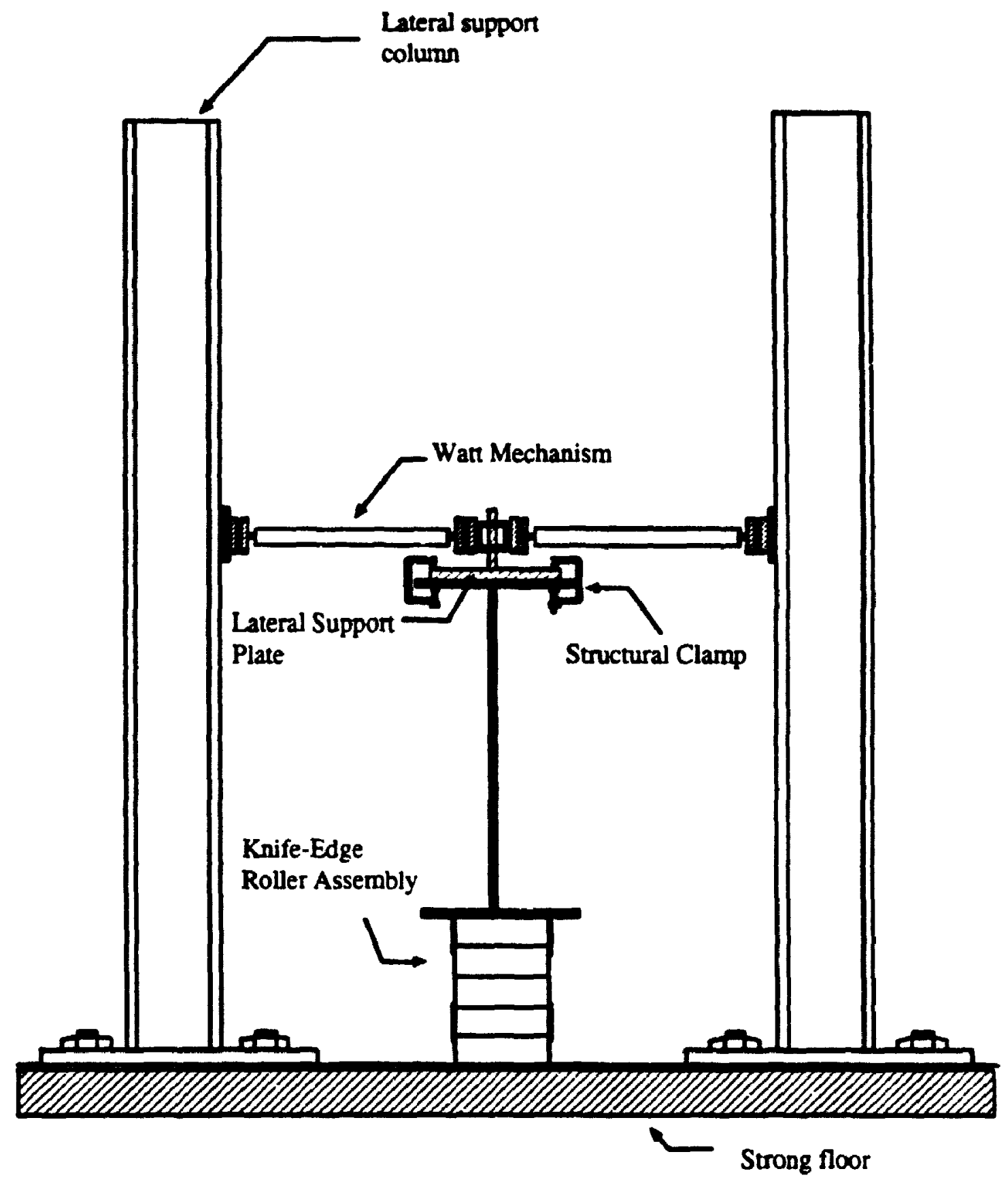

Figure 2.4 View of Lateral Suppont System 


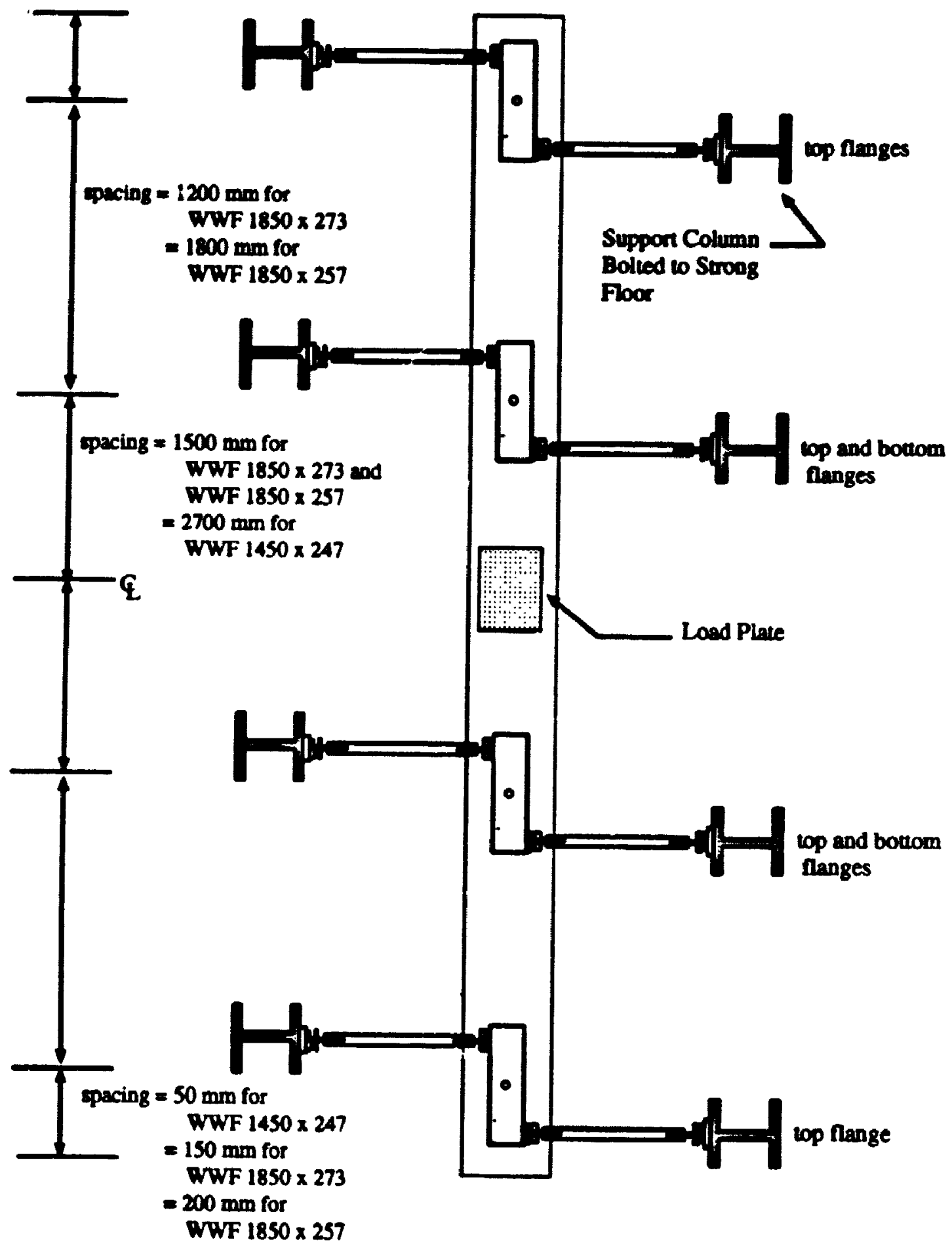

Figure 2.5 Plan View of Watt Mechanisms and Test Specimen 


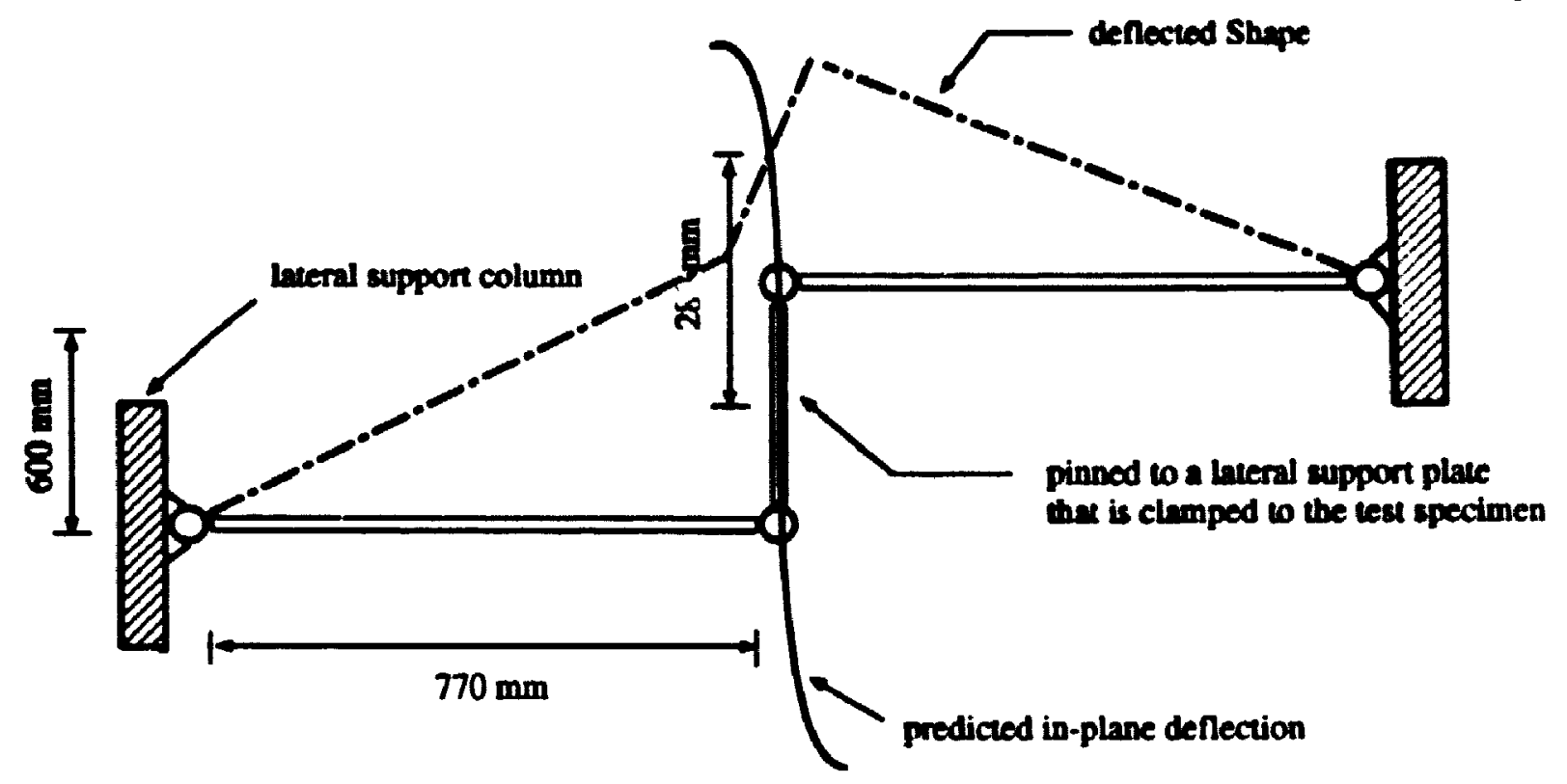

Figure 2.6 Typical Watt Mechanism

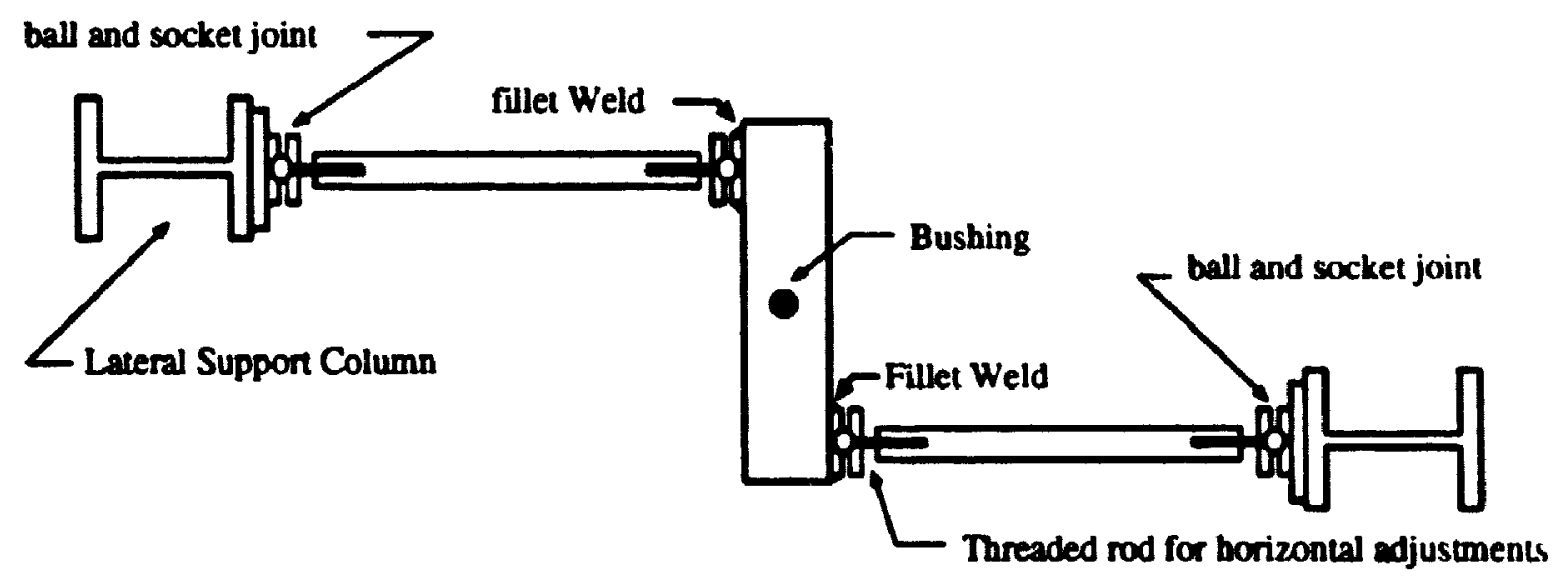

Figure 2.7 Schematic Diagram of a Typical Watt Mochanism 

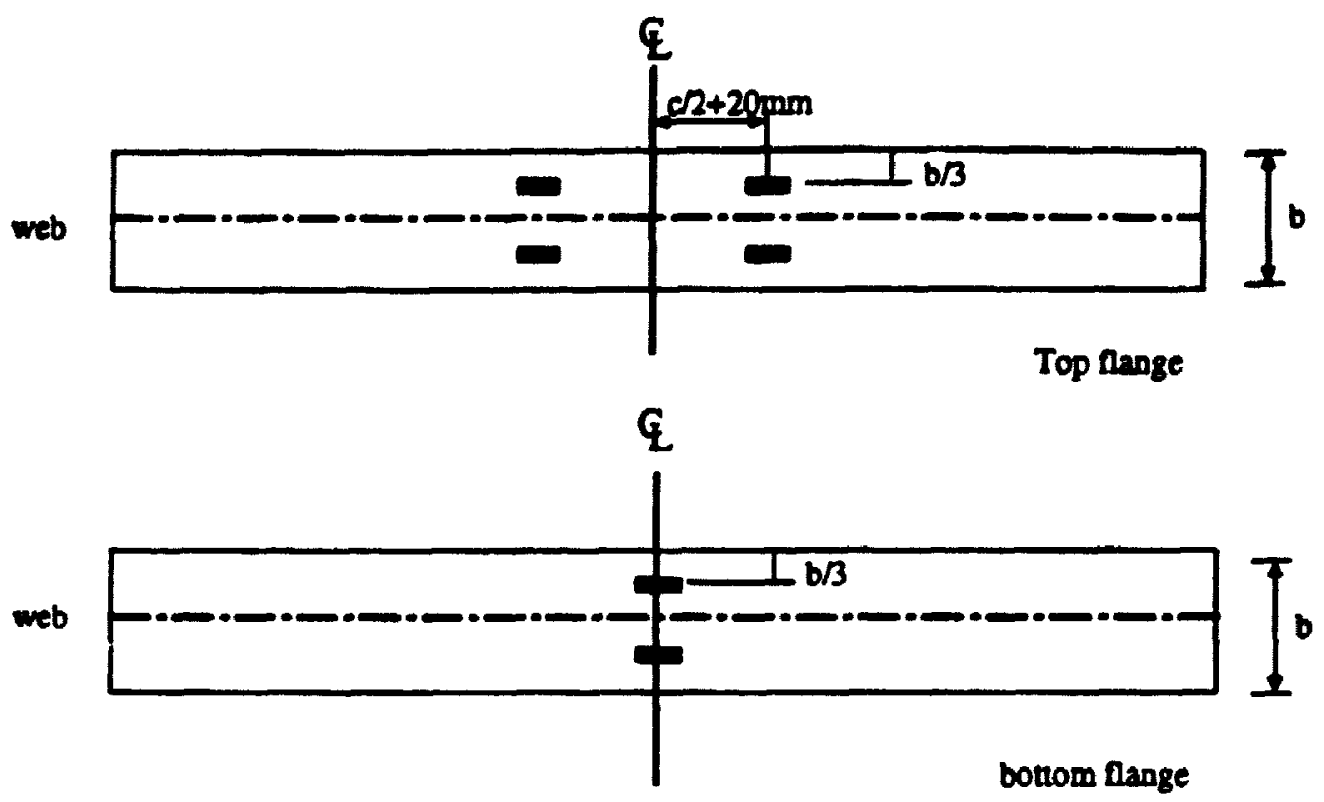

(a) Strain Gauge Layout for Flanges (all test set-ups)
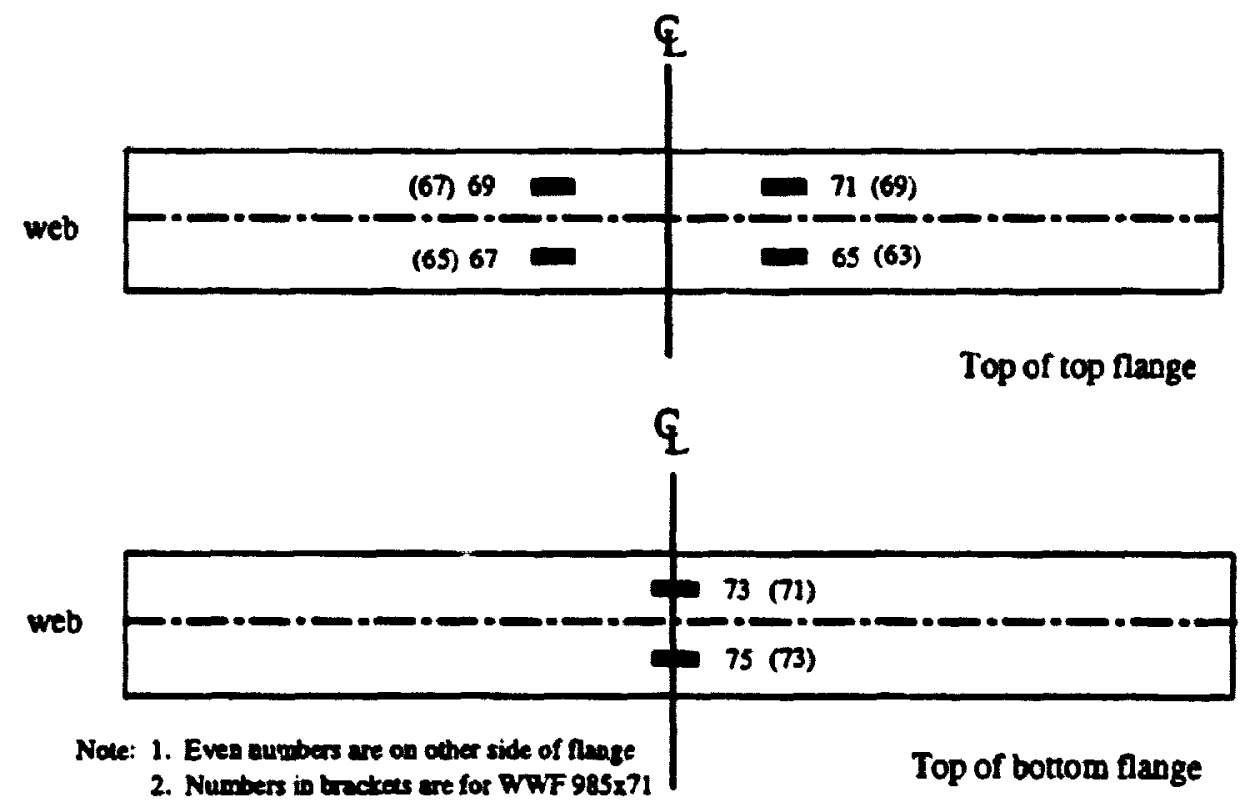

(b) Numbering sequence used for flanges on all tests

Figure 2.8 Strain Gauge Locations and Numbering for all Flanges 


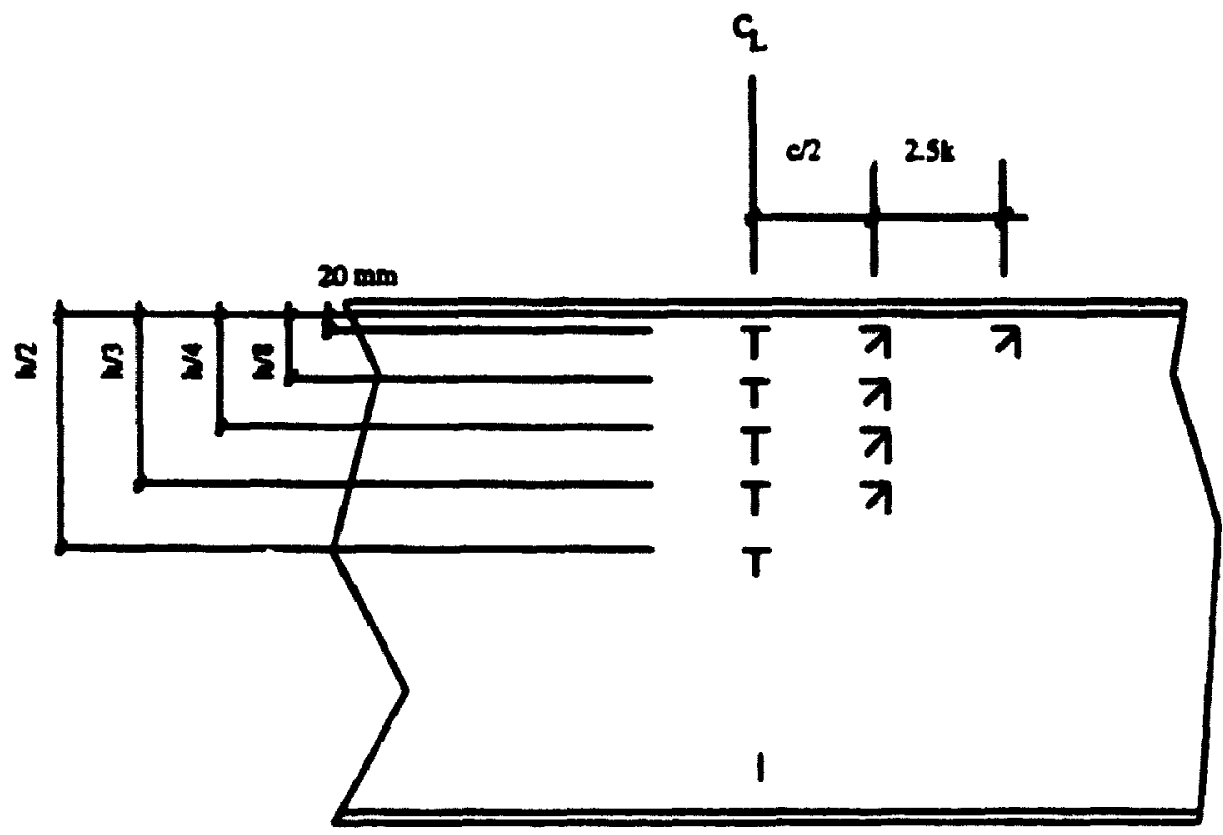

(a) Rosette Layout

$q$
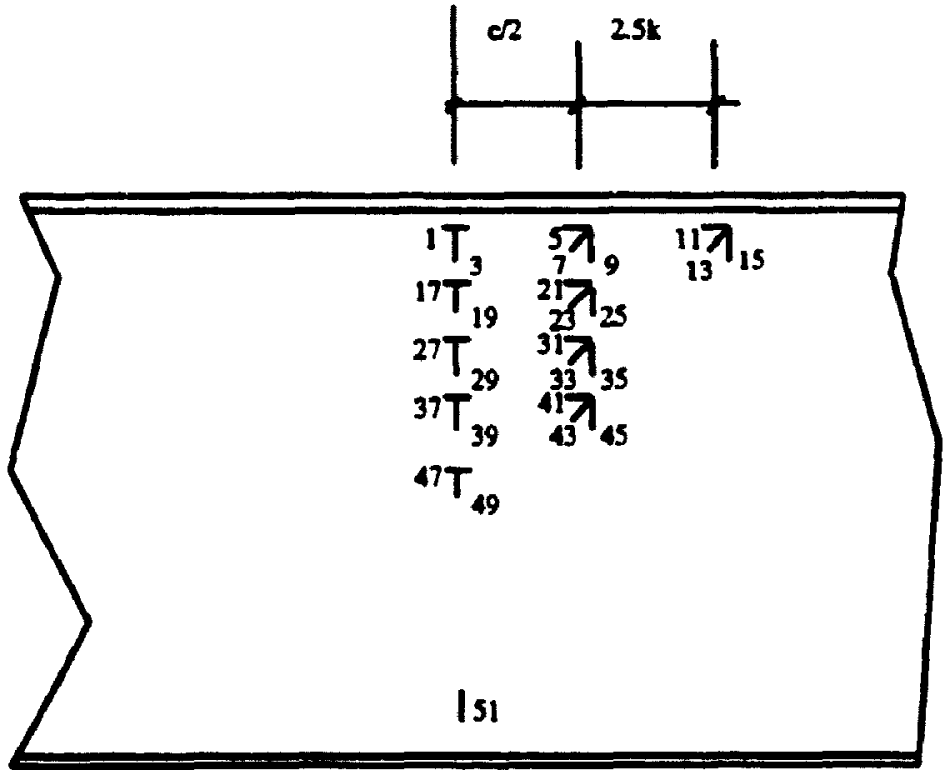

Note: Even numbers tre an other side of the web

(b) Strain Gauge Numbers

Figure 2.9 Strain Gauge Locations and Numbering Sequence for WWF 985x71 Webs 


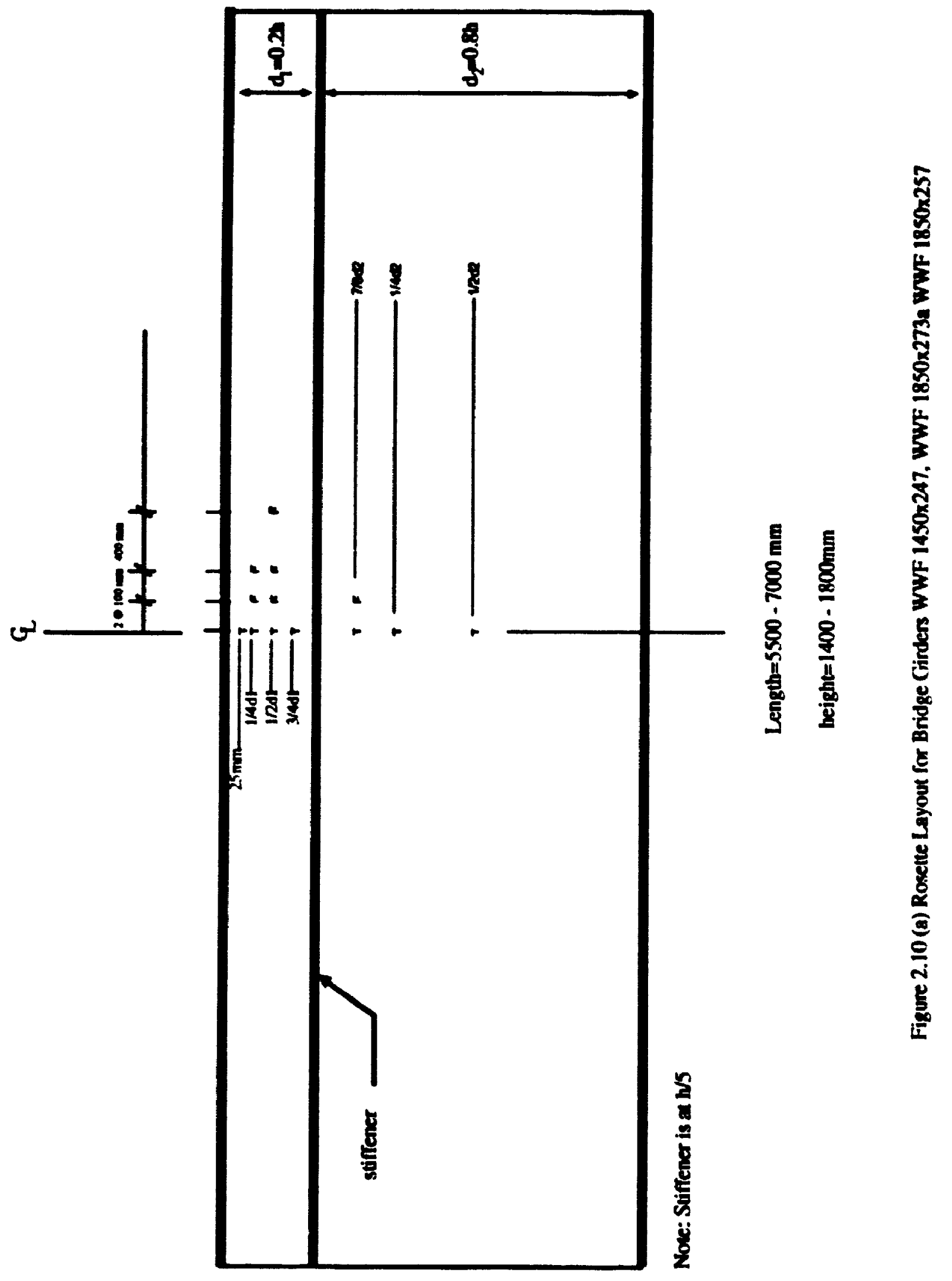




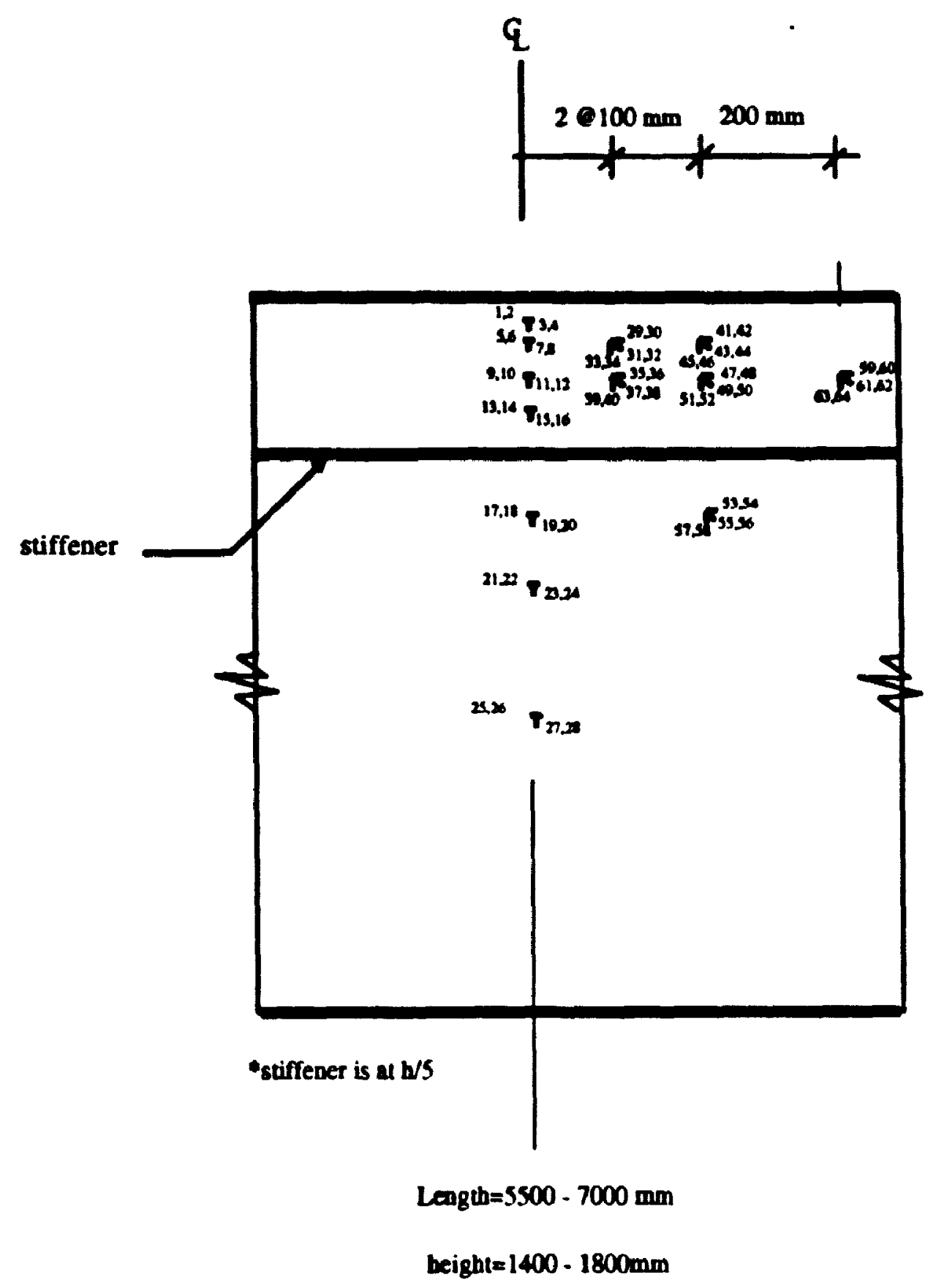

Figure 2.10 (b) Rosette Numbering for Bridge Girders WWF 1450x247, WWF 1850.273a. WWF $1850 \times 257$ 


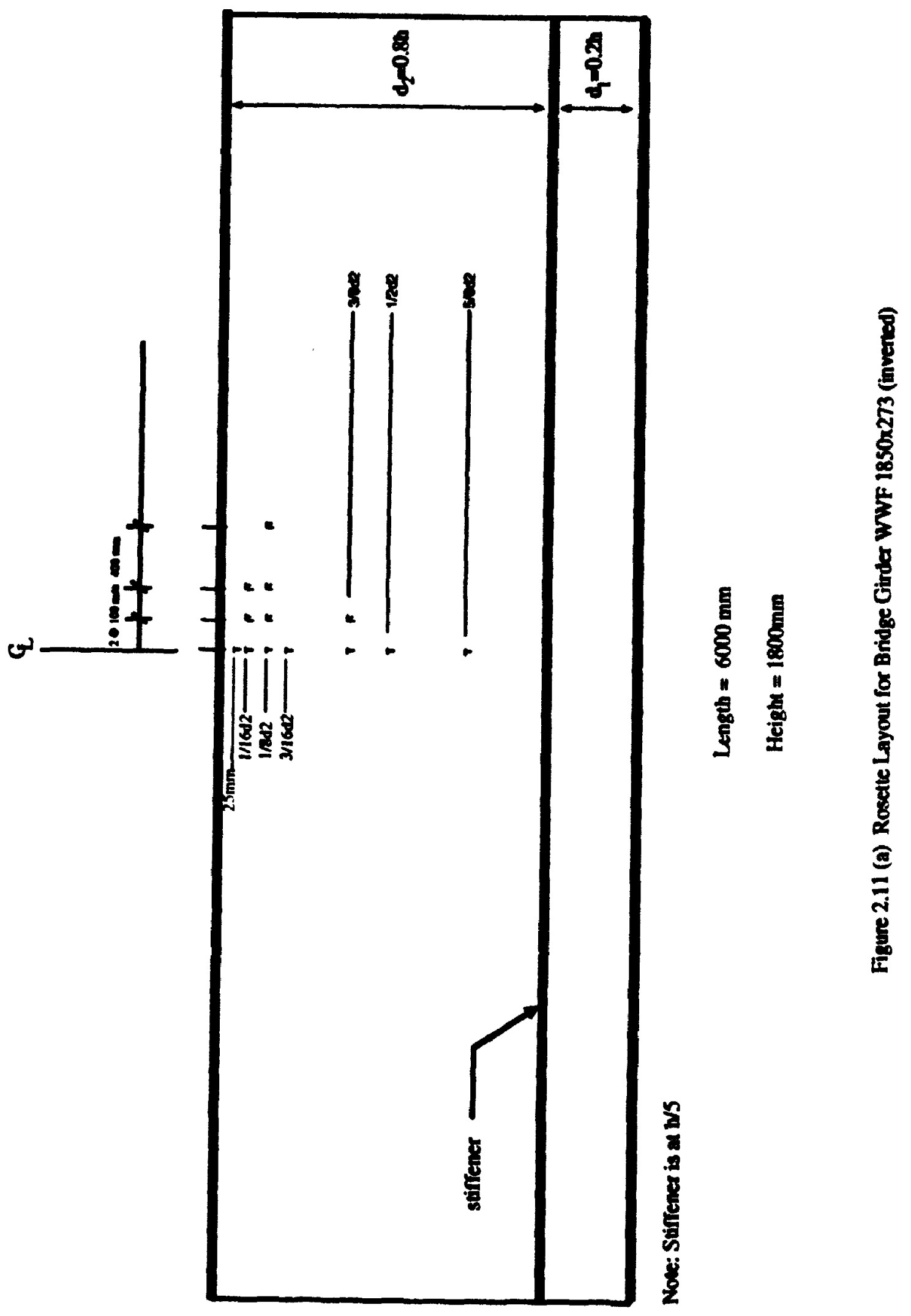




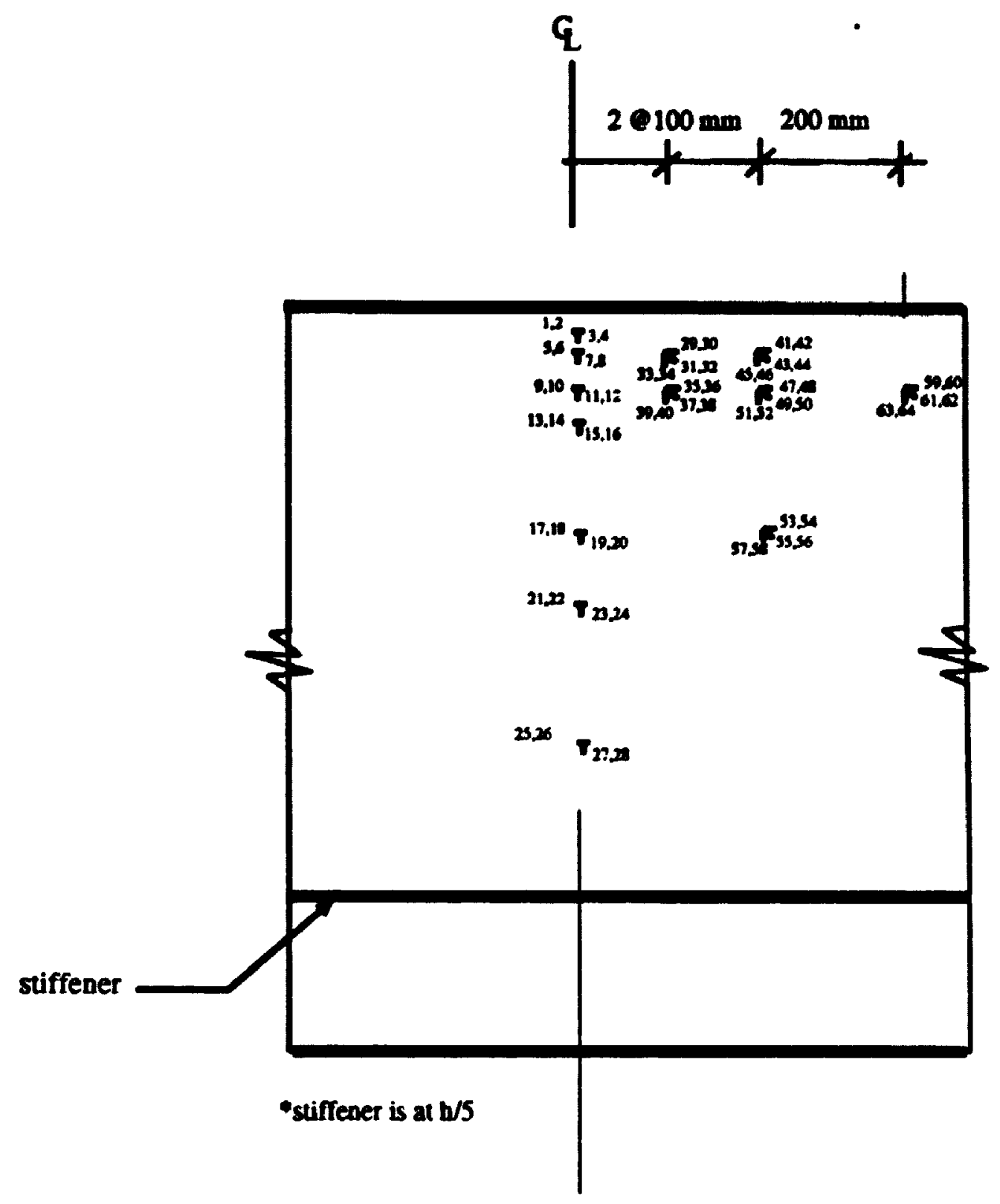

Length $=6000 \mathrm{~mm}$

teight $=1800 \mathrm{~mm}$

Figure 2.11 (b) Rosette Numbering for Bridge Girder WWF 1850×273 (inverned) 


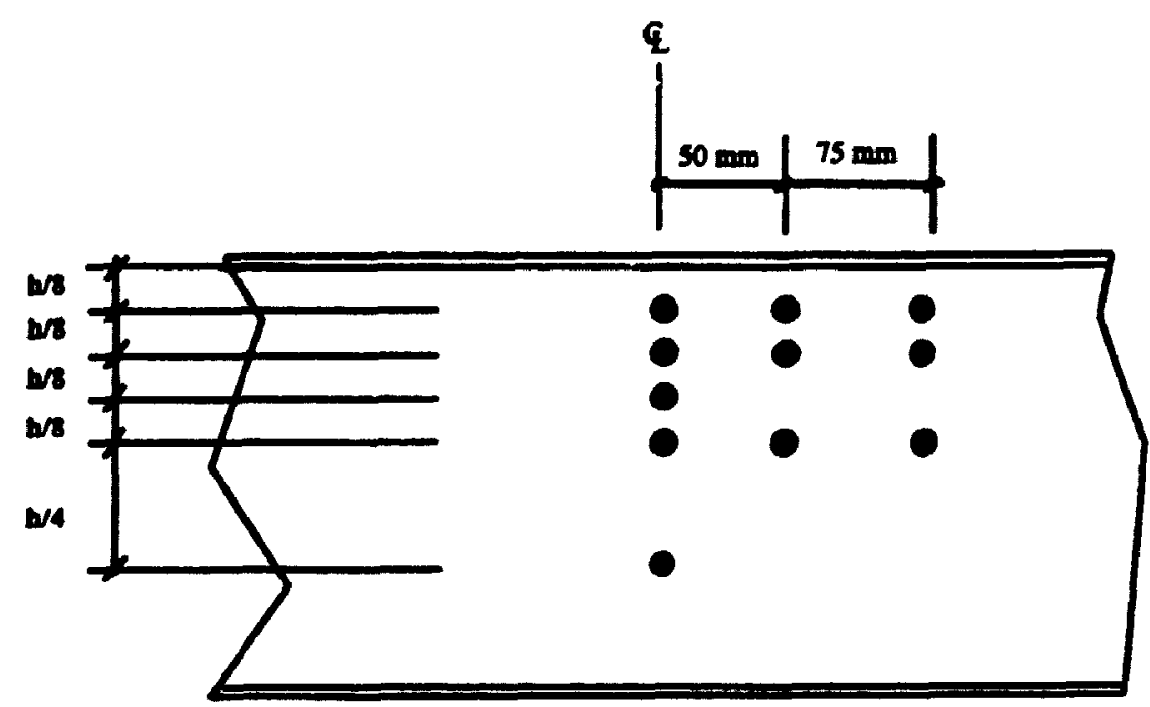

Noue : $c \Omega(50 \mathrm{~mm})$

(a) LVDT locations on Web

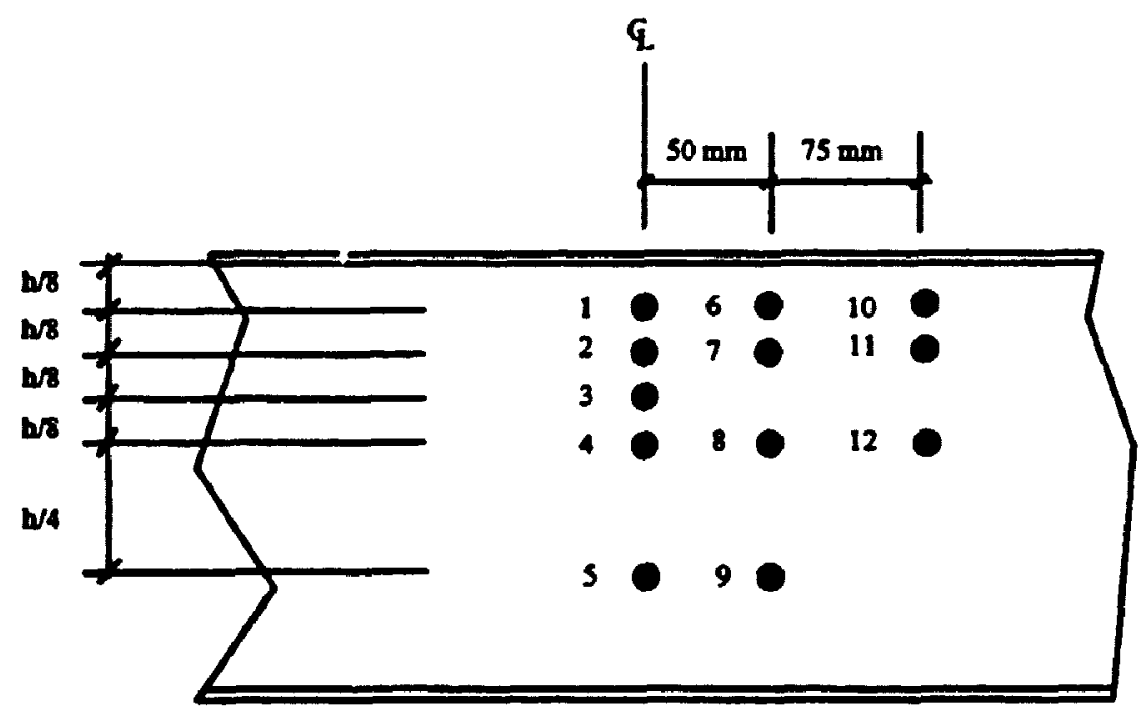

(b) LVDT Numbering

Figure 2.12 LVDT Layout and Numbering Sequence for WWF $985 \times 71$ 


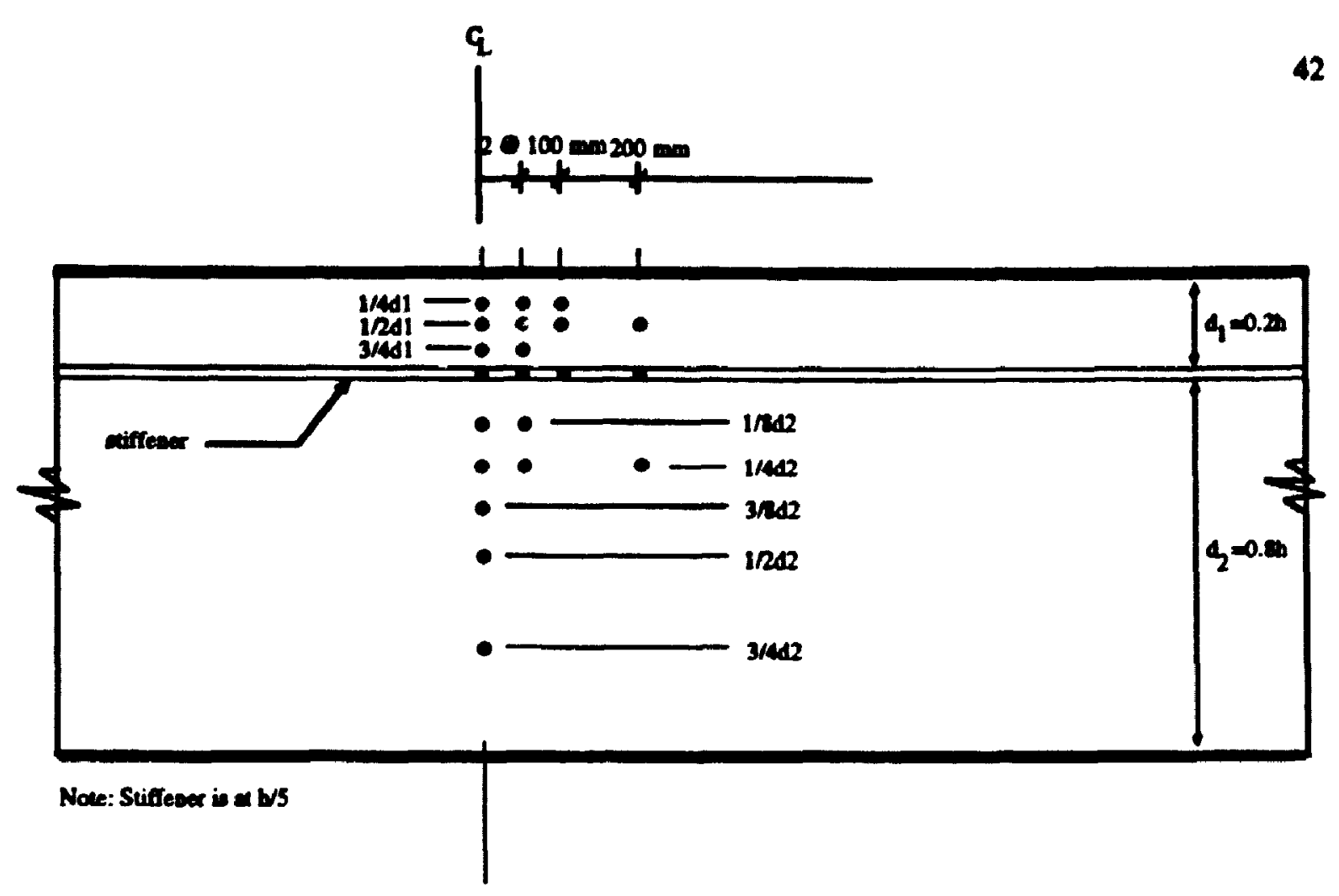

(a) LVDT Locations on Web

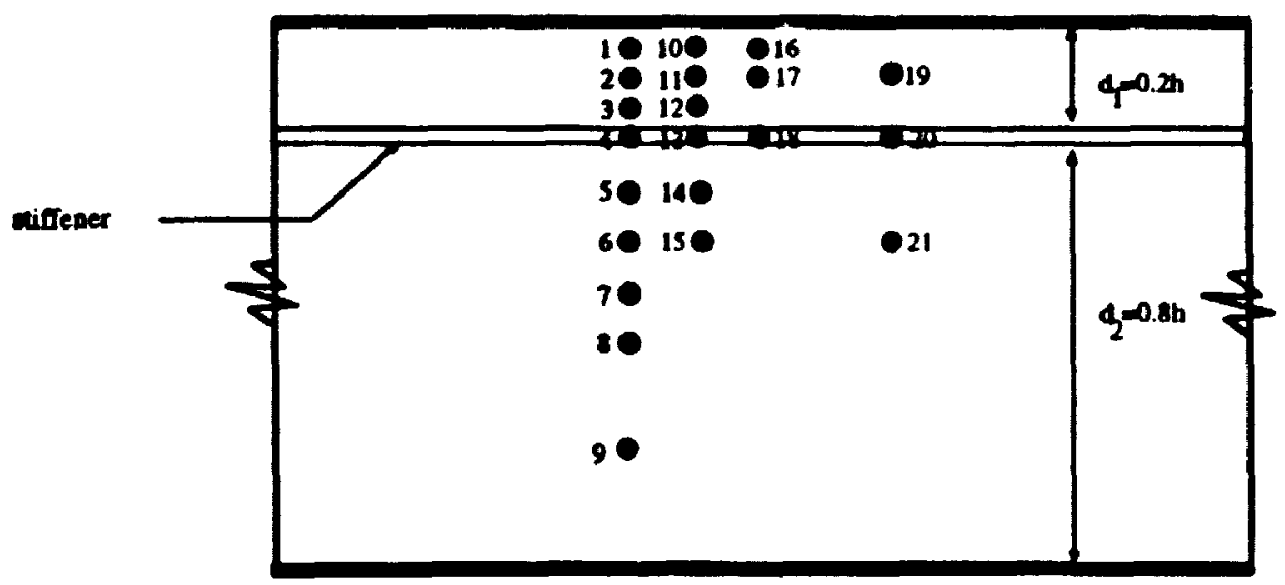

Note: Siffeer in a bs

(b) LVDT Numbering

Figure 2.13 LVDT Layout and Numbering for Bridge Girders WWF 1450×247. WWF $1850 \times 273 \mathrm{a}$, WWF $1850 \times 257$ 


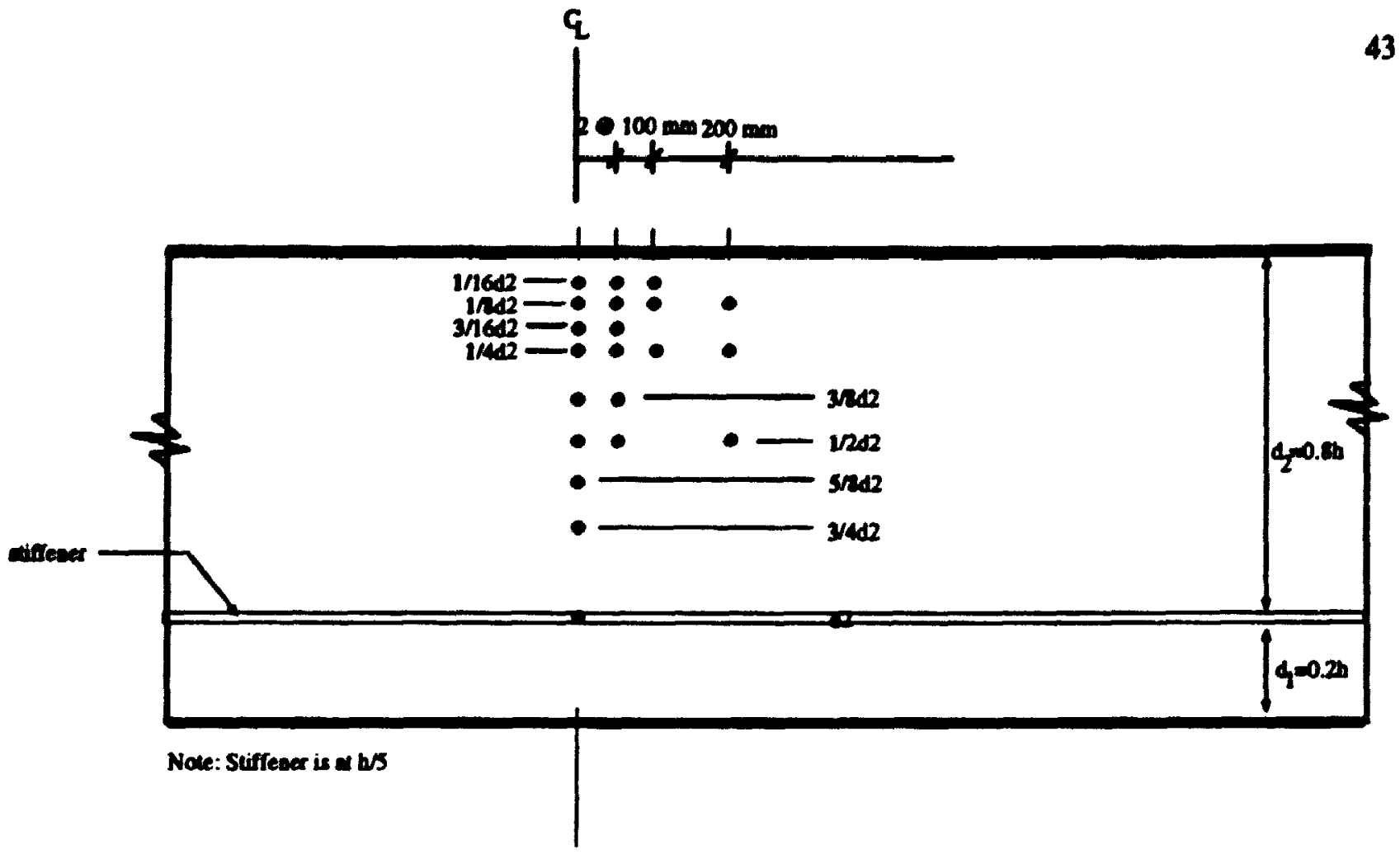

(a) LVDT Locations on Web

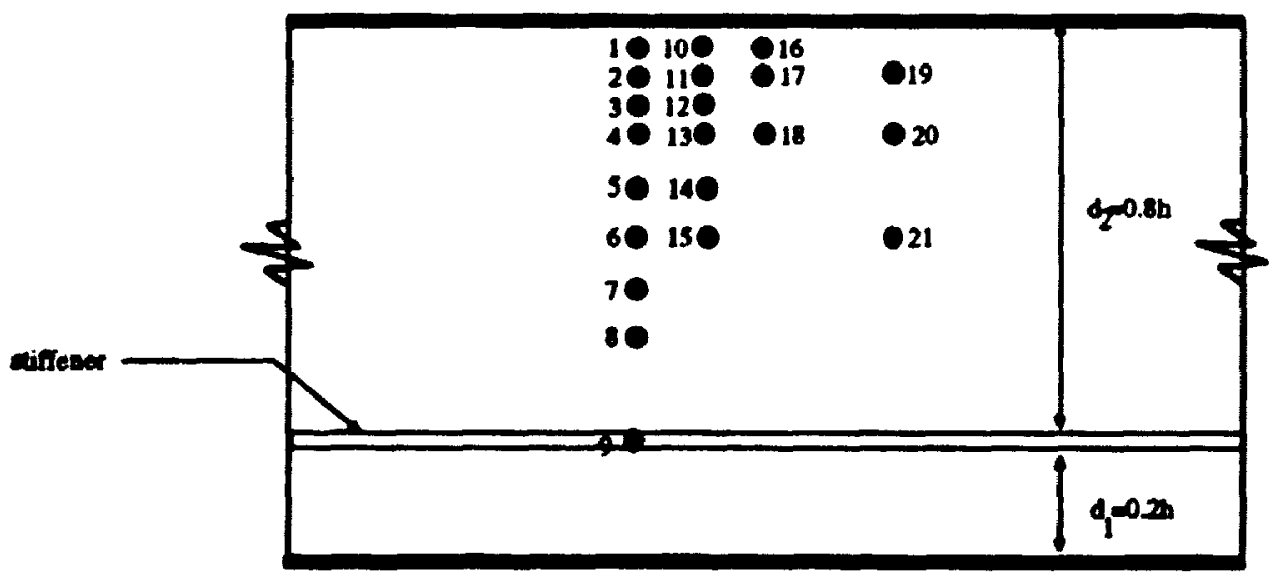

Nowe: Sufeer is a b/s

(b) LVDT Numbering

Figure 2.14 LVDT Layout and Numbering for Bridge Girder WWF 1850x273b 


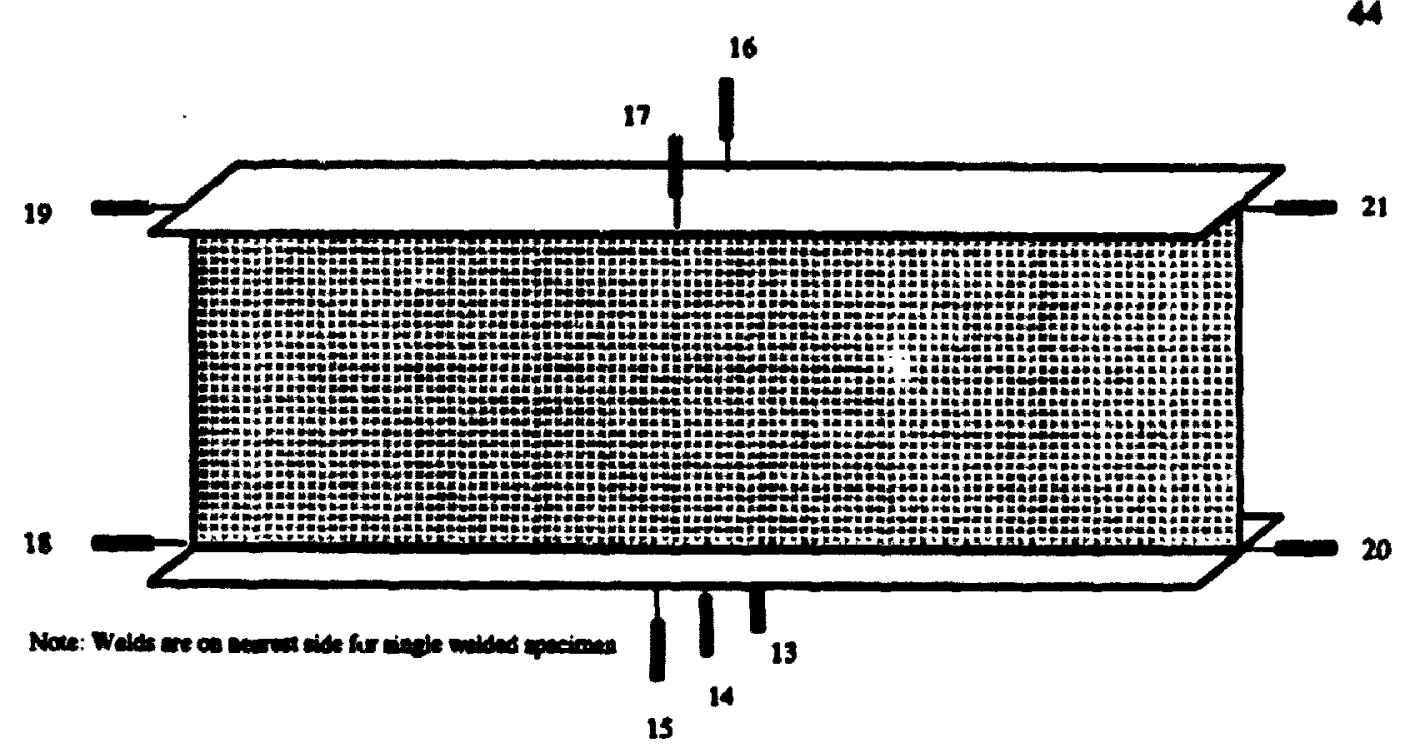

(a) Numbering Sequence and Set-Up for WWF $985 \times 71$

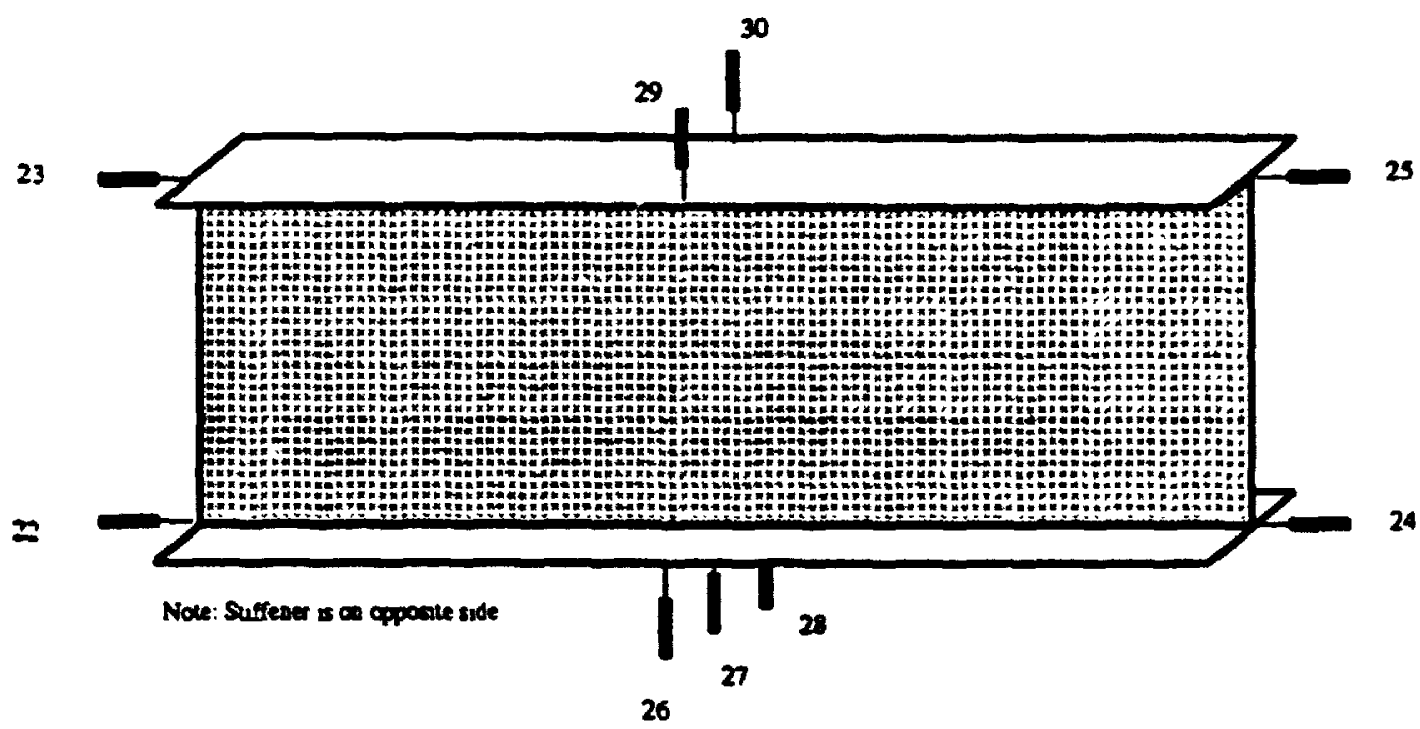

(b) Numbering Sequence and LVDT Sel-Up for Bridge Girders

Figure 2.15 Numbering Sequence and LVDT Set-Up for All Shapes 

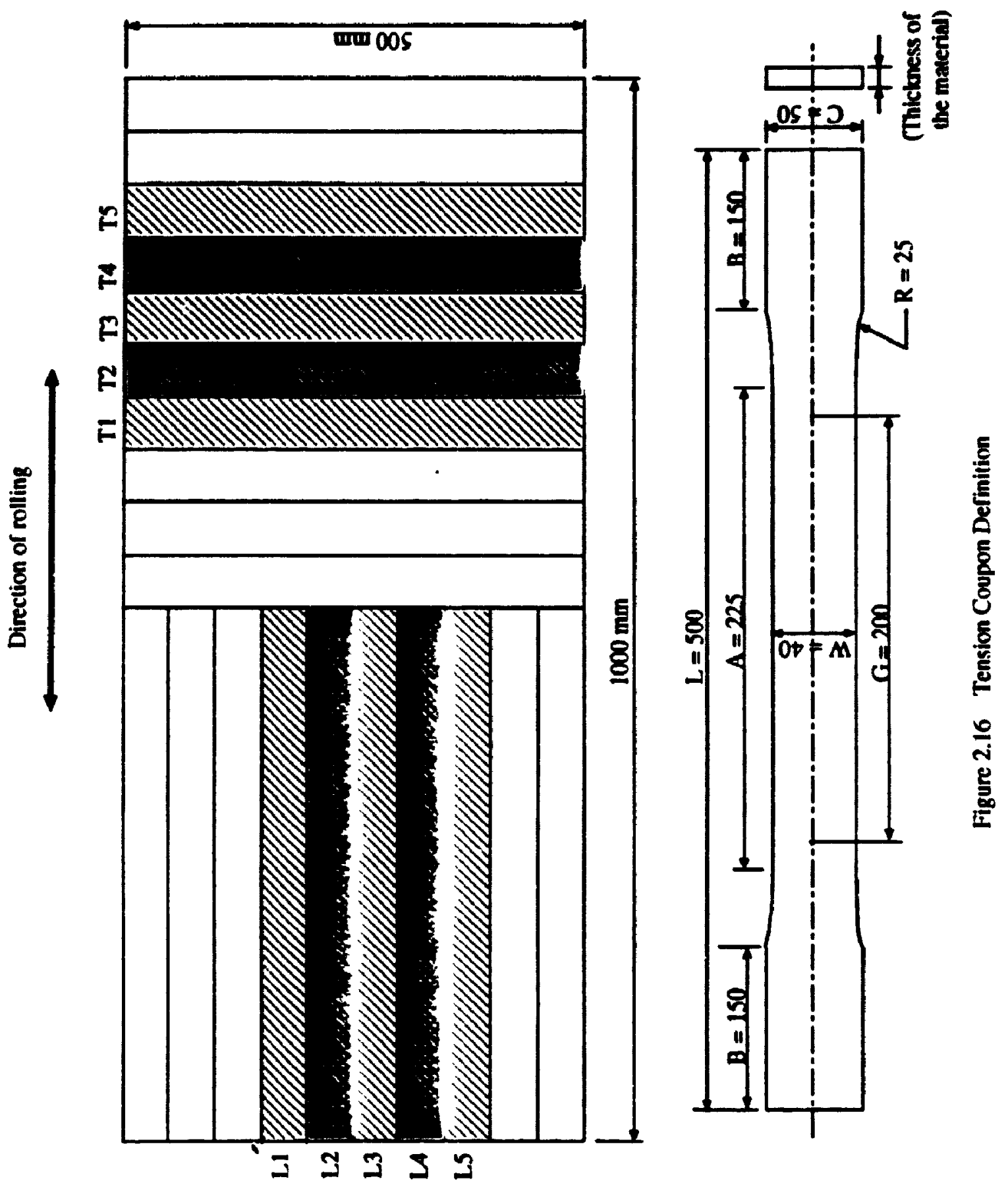


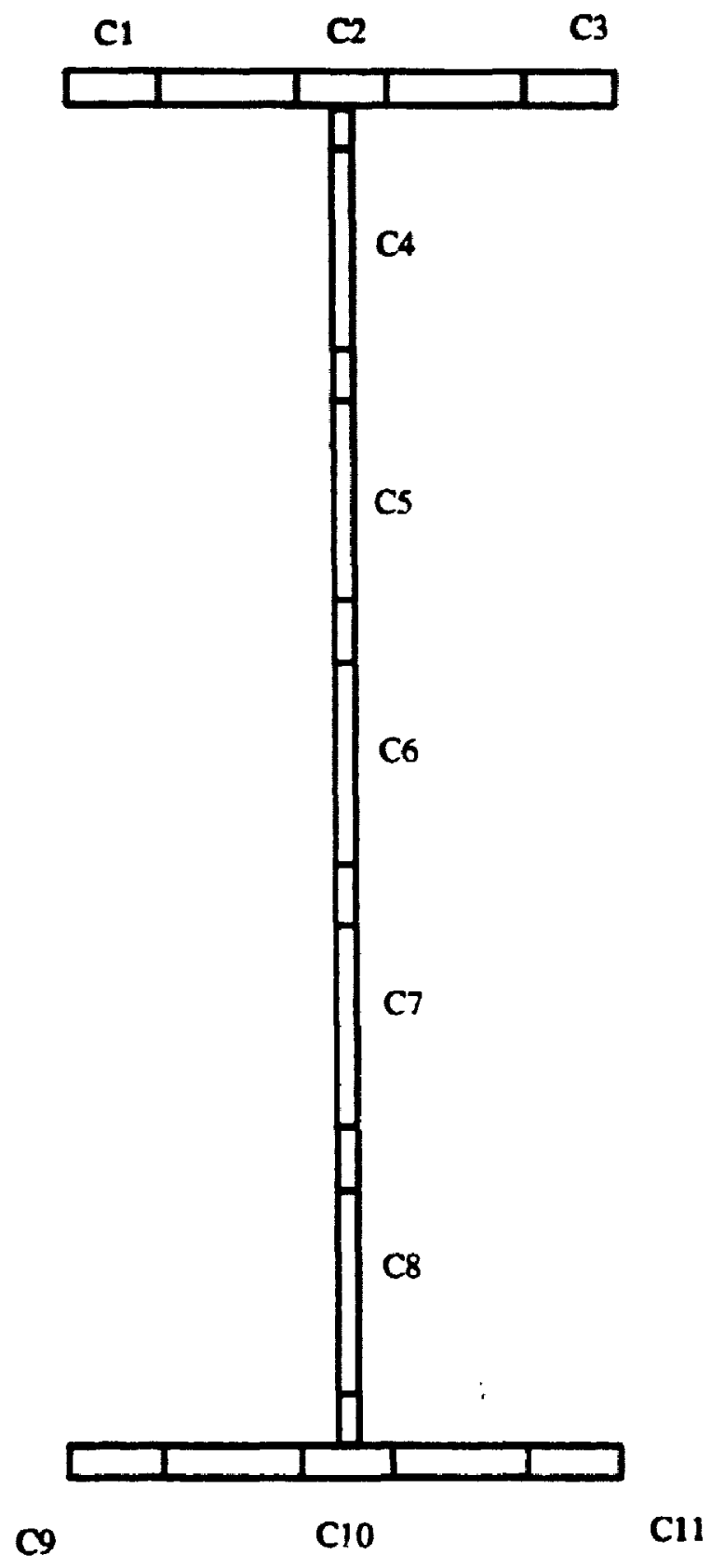

Figure 2.17 Tension Coupon Identification for WWF Sections 


\section{Chapter 3}

\section{Test Results}

\subsection{Geometric Properties}

The cross-sectional dimensions, defined in Figure 3.1 (a), were measured and are given in Table 3.1 in terms of the mean values and coefficients of variation. According to CAN/CSA G40.20-M87, which defines allowable fabrication tolerances, the tilt of the flanges must be less than $6 \mathrm{~mm}$ for a web depth over $300 \mathrm{~mm}$. The warping of the flanges was determined by measuring the depths $\left(d_{1}\right.$ and $\left.d_{2}\right)$ from flange tip to flange tip and comparing them with the depth at the web. The largest average difference was found to be approximately $9.5 \mathrm{~mm}$ for WWF $985 \times 71$ (b) with two fillet welds. The average measured tilt for each flange (top and botrom) is $4.75 \mathrm{~mm}$, which is less than the $6 \mathrm{~mm}$ wlerance.

The out-of-straightness for the web plates of each shape was determined at seven locations along the length of the WWF girder from measurements made using the imperfection measuring device illustrated in Figure 3.1 (b). The average out-of- 
straightness given in millimeters at depths of $0.1 \mathrm{~h}, 0.3 \mathrm{~h}, 0.5 \mathrm{~h}, 0.7 \mathrm{~h}$ and $0.9 \mathrm{~h}$, where the distance to the point on the web is measured from the top of the top flange, and the average maximum allowable out-of-straightness (web flatness) specified in CAN/CSA G40.20-M87 of $1 / 150$ of the shape depth are given in Table 3.2. With the exception of the WWF 985x71 sections which exceeded this value by two millimeters, all others meet this fabrication tolerance criteria. This excessive out-of-straightness for the WWF 985x71 section was the result of imperfections induced during fabrication that were not corrected. As for the bridge girders, the largest out-of-plane imperfection was $9.9 \mathrm{~mm}$ over 1800 $\mathrm{mm}$, which is 0.825 times the allowable tolerance.

The measured geometric properties and out-of-straightness web plate imperfections are to be used in supporting finite element analyses, the determination of test to predicted bearing resistance ratios from loads predicted using the proposed Clause 15.9 (based on the equivalent column concept), and the corresponding statistical analysis for determining the appropriate resistance factor.

\subsection{Material Properties}

A representative sample of tension coupons cut from the webs and flanges of each of the teat specimens were tested in accordance with ASTM standards E8M-91 (1991) to determine the material properties of the test specimens as specified in section 2.4. Eleven 
coupons, six from the flanges and five from the web, were taken from the WWF $985 \times 71$ section (as shown in Figure 2.17); ten coupons from each web and flange plate used to fabricate the bridge girders (five coupons aligned and five coupons perpendicular $w$ the rolling direction); and five coupons from each stiffener plate thickness (aligned in the rolling direction). The steel grade for all plates were specified as $350 \mathrm{~W}$ with the exception of the web plate for the WWF $1800 \times 257$ which was made with 300 W grade steel as a $350 W$ plate of that size was not available.

The stress-strain curves for coupons can be characterized by the two typical curves illustrated in Figure 3.2. The corresponding material properties evaluated from these curves are listed in Tables 3.3 to 3.11 for each plate. Curv' Type I was the most common but the $6.4 \mathrm{~mm}$ plate which consistently exhibited Curve Type II. The characteristic material properties include the modulus of elasticity, yield strength, static yield stress, yield strain, ultimate strength, ultimate strain, final stress and final strain. The final stress was evaluated using the natural log of the original area divided by the necked down area, and the final strain was calculated using the final length divided by the original length.

The measured material properties were used as input for the strain data interpretation program, Benichou (1994), to calculate the principal stresses and directions and are to be used subsequently in the determination of test-to-predicted bearing resistance and the corresponding resistance factor. 


\subsection{Web Behaviour}

Out-of-plane web displacements, flange rotations about the longitudinal axis of the beam and strains were measured at discrete locations (refer to section 2.2) to obtain a description of the behaviour of the slender webs of the WWF 985x71's and the bridge girders when subjected to concentrated in-plane loads. The data are presented in two sections entitled load versus out-of-plane web displacements and strain distributions. Graphs illustrated the load versus out-of-plane web displacements for the LVDT with the maximum displacement; the deflected shape through the depth at the centre of the load and at the edge of the load plate for the ultimate load and additional load levels where necessary. Figures give principal strains and orientations on both sides of each web for load levels coinciding with the progression of yielding. The strain distributions for the WWF 985x71 test are given in Prabha (1996).

A summary of the tests gives information about the location and number of lateral supports (Wat mechanisms), the failure load and mode, the maximum out-of-plane web displacement and location, and other relevant observations or comments are given in Table 3.12 . 


\subsubsection{Load vs. Out-of-Plane Web Behaviour}

The characteristic behaviour of the web is best described by load versus out-ofplane web displacement curves which are illustrated for the WWF 985x71 (a) and (b) sections for interior loads and end reactions in Figure 3.3 to 3.6, and for the bridge girders in Figures 3.8 to 3.11. The displacements shown are those of the LVDTs which give the maximum out-of-plane displacements. The location of that LVDT with respect to the loaded flange, and key load levels that coinc: ' $?$ with the progression of yielding, are also indicated. The intial slope gives an indication of the effects of the initial out-ofstraightness of the web and is large for small imperfections as can be seen. for example, in the upper panel of the WWF $1450 \times 247$ in Figure 3.8. The change in slope represents the reduction in stiffness which results from either the formation of yield bands in the web of the upper panel under consideration, or in the adjacent panel which provides support (as illustrated for the WWF $1800 \times 273$ (a) in Figure 3.9), or from second order effects of the load acting on the deformed web that has significant out-of-plane displacements of the order of magnitude of the web thickness, as illustrated for the end reaction tests for the WWF 985×71, in Figures 3.5 and 3.6, where the web was still elastic. There is also the possibility that a combination of both occurred.

The location of the maximum out-of-plane displacement of the web for the WWF $985 \times 71$ sections was found to be at about $0.25 \mathrm{~h}$ from the loaded flange for both interior 
and end reaction tests. For the bridge ginders, the maximum displacements occurred at approximately $0.1 d_{1}$ and $0.4 d_{2}$ of the top and botiom panels, respectively, with the exception of the inverted WWF $1800 \times 273$ (b), where it occurred at $0.6 d_{2}$, (see Figures 2.13 and 2.14 for layout).

All tests failed by inelastic web buckling. For the WWF $985 \times 71$ section tests, the flange and surrounding web offered liwle or no post-buckling restraint, and load decreased soon after the ultimate load was reached without further appreciable web displacements. The post buckling restraint provided to the upper panel for the WWF $1450 \times 247$. WWF 1850x273, and WWF $1850 \times 257$ is evident from the long plateau at the ultimate load level of the load deformation curve for this panel. The erratic displacement readings illustrated for LVDT 2 in Figure 3.10 (a) and 3.11 (a), are associated with very small out-of-plane web displacements that are masked due to the LVDT tip sliding over the web as the weh height decreases. Hand measurements show this vertical accrement to be as much as 5 mm. The verticd flange tip displacements for the WWF $985 \times 71$ (b), given in Figure 3.7. have been included for completeness of test data presentation and are to be used elsewhere for comparison with the results of the corresponding finite element analysis. Prabha (1996).

The displaced shapes of the web directly under the middle of the loaded length and at the edge of the loaded length, are drawn from the displacements measured by the 
LVDTs at ultimate load for WWF 985x71 (a) and (b) in Figures 3.12 and 3.13, and for the

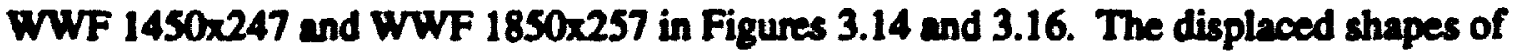
the web for WWF 1850×273 (a) and (b) are given at a series of load levels as yielding progresses, in Figure 3.15 and 3.16. For the bridge girders, the location of the longitudinal stiffener is indicated. The displaced shapes for the WWF $985 \times 71$ sections are compared with finite element results by Prabha (1996). The displaced shapes for the bridge girders clearly indicate that the longitudinal stiffener rest uns the web from the lateral displacement but not from rotation. The webs on either side behave similarly to two columns with pinned-fixed end conditions that buckle interactively. For the WWF $1850 \times 273$ (b), the longituuinal stiffener effectively reduces the web depth to $0.8 \mathrm{~h}$. The displaced shapes give an indication of restraint provided to the web plate within the equivalent column width from the flanges and surrounding web plate. These displaced shapes are to be used as a comparison for the finite element results and for further development and adaptation of the equivalent column concept and design equations for slender webs of bridge girders with longitudinal stiffeners. Based on hand measurements of displacements of the web, it was concluded that the LVDT support frame functions as designed and effectively eliminated any misleading displacements that occurred previously due to flange rotation (see Benichou (1994) and Kirkhope (1995)). 


\subsection{Web Straln Distribution}

All the measured strain data were converted into principal strains with their corresponding orientations, by using the strain interpretation program developed by Benichou (1994) and is illustrated at each discrete location for either side of the web, at different load levels as yielding progressed (as indicated by the load deflection curves), for the WWF 985x71 sections in Figure 3.18 (a) and (b) and 3.19 (a) and (b); and for the bridge girders in Figures 3.20 to 3.23. Three values appear beside each rosette location indicated by the symbol ' $T$ ' which graphically illustrates the orientation of the principal strains. The first value corresponds to the principal strain that is most closely aligned with the bar or flange of the 'T', the second to the stem of the ' $T$ ' and the third value in brackets gives the orientation of the stem in degrees measured positively counterclockwise from the vertical. For the WWF $985 \times 71$ sections, the diagrams are marked 'near side' and 'far side' where 'near side' indicates the side that bucisled out of the page. For the bridge girders, the buckled shape and location of the longitudinal stiffener are shown. The yield strain determined for the web from the corresponding tension coupon tests is also indicated on the figures. Note, the web is biaxially stressed and yielding at a given location is loosely interpreted as the exceedance of the uniaxial yield strain value shown. Strain gradients through the web indicate ont-of-plane bending and are easily identified by comparing values on either side of the web. Suspect strain data is indicated by '**' on the appropriate figure. These data are not used any further. 
Transformation of the inelastic strain data into stresses and the comparisons with the finite element analyses for the WWF 985x71's is discussed in Prabha (1996) and is not discussed further.

As generally illustrated in Figures 3.21 to 3.23, the orientation of the principal stresses are mirrored on opposite sides of the web as would be expected. A comparison of the principal strains with the yield strains at all loads gives an indication of the formation and location of the yield bands which form a mechanism in the web and define the ultimate load. A summary of this is presented in Table 4.2. A yield band is fully formed when one side is yielded in compression and the other yields in tension as a result of large out-of-plane bending of the web. Until this strain condition is achieved over the entire length of the horizontally oriented yield band on the web near the flange web junction and the circular arc yield band that forms in the web. the web is able to sustain more load with increasing out-of-plane web deformation. Other than stating the obvious, where the magnitude of the strains diminish with the distance from the load point ( approaching zero sverage vertical strain on the web near the unloaded flange along midspan, as would be expected), little else can be said until the finite element comparisons are made. 
The displaced buckled shape of the bridge girders indicates that the longitudinal stiffener acts as lateral support creating an inflection point along its length. The rotation of the longitudinal stiffeners is consistent with the buckled shape in which the panel can buckle in either direction. As previously described, the longitudinal stiffener creates two web panels with fixed-pinned end conditions that buckle interactively and are defined by the location of the stiffener. 


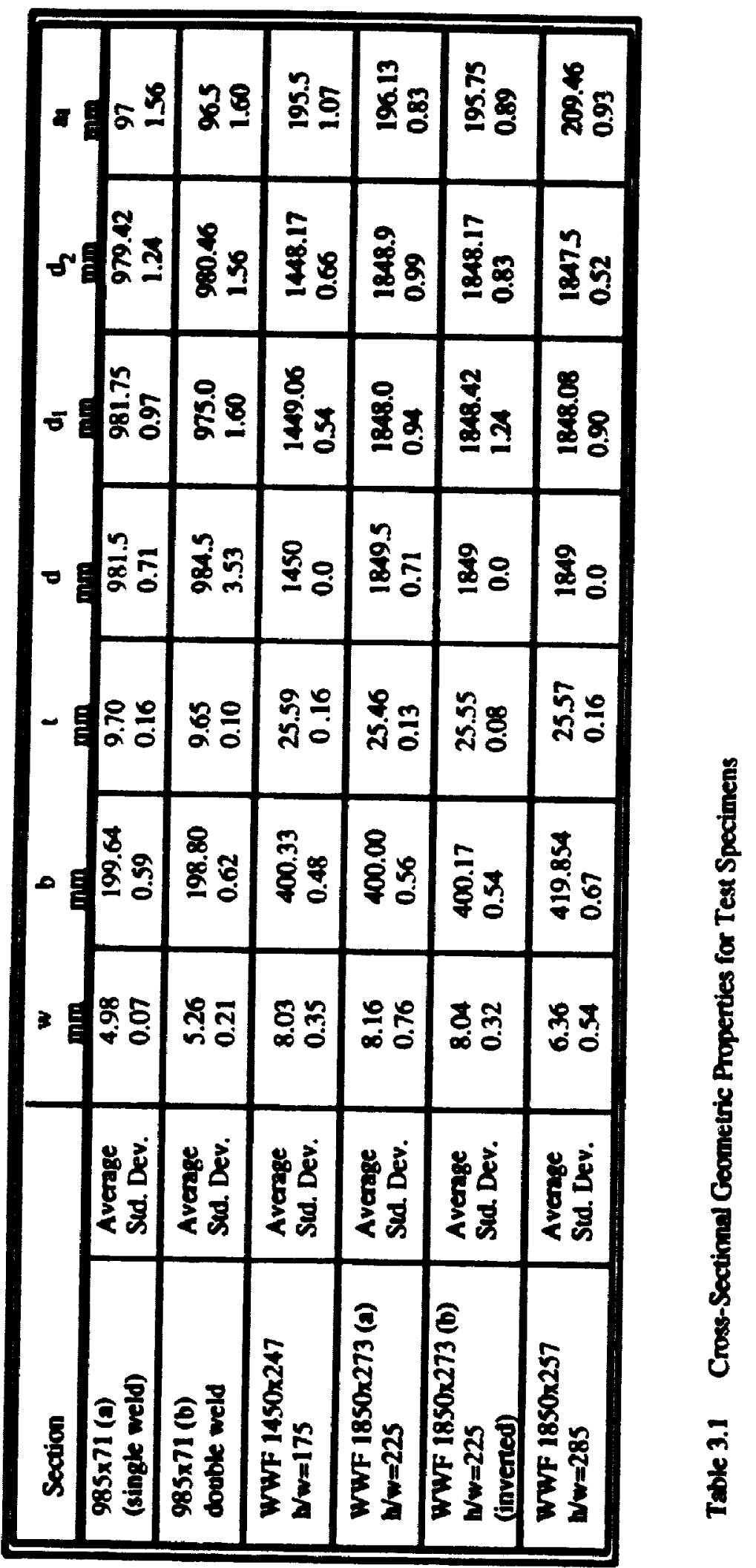




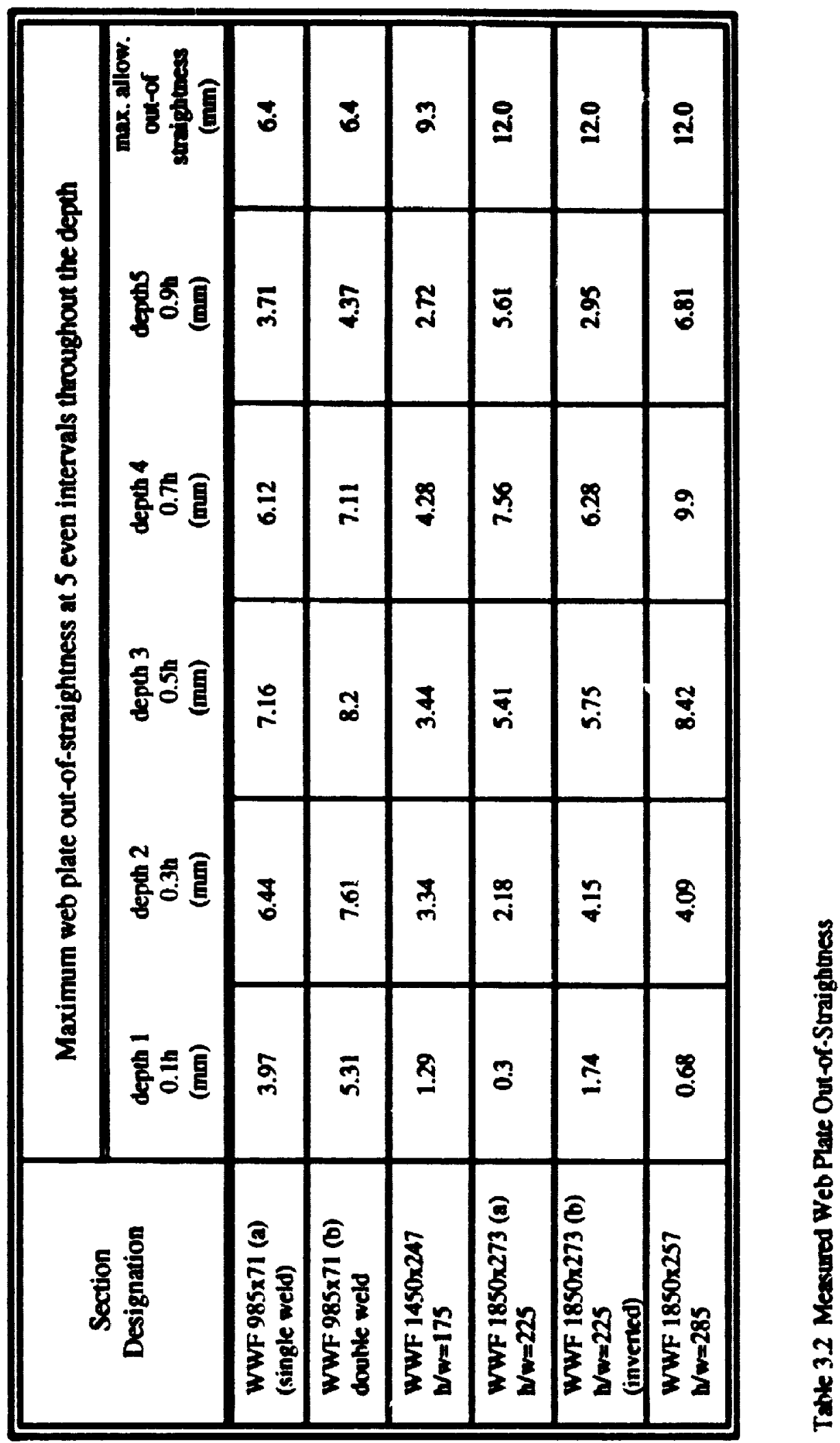




\begin{tabular}{|c|c|c|c|c|c|c|c|c|c|c|c|}
\hline 畐 & 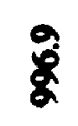 & $\Xi$ & 8 & 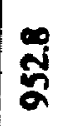 & - & s。 & yे & $\frac{n}{a}$ & $\$$ & 8 & 8 \\
\hline & 8 & 艿 & 8 & $\begin{array}{l}8 \\
8 \\
8 \\
8 \\
\end{array}$ & 8 & 8 & 응 & 8 & $\frac{8}{8}$ & 8 & ళ్రి \\
\hline & 8 & 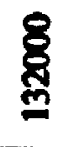 & 8 & ్ㅇㅇㅛ & 8 & 8 & 8 & 8 & 8 & $\underset{8}{\mathbb{2}}$ & 8 \\
\hline & $\underline{8}$ & 㫋 & है & 串 & - & 路 & 曺 & $\frac{8}{8}$ & హิ & 吾 & 量 \\
\hline & 8 & g & $\widehat{s}$ & $\frac{a}{8}$ & . & 点 & 点 & 是 & 향 & $\frac{5}{n}$ & $\overline{8}$ \\
\hline 5 & $\stackrel{m}{\mathscr{m}}$ & $\underset{0}{0}$ & 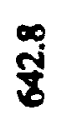 & ஜ̊̊̆ & $\frac{n}{n}$ & $\frac{\infty}{\tilde{n}}$ & 웅 & $\frac{4}{n}$ & ஜ̊ & ్ㅗㅇ & $\bar{m}$ \\
\hline $0=$ & $\underset{\infty}{\infty}$ & $\frac{n}{n}$ & 茴 & $\begin{array}{l}\stackrel{0}{\infty} \\
\text { స్ }\end{array}$ & $\frac{9}{3}$ & $\frac{3}{2}$ & $\frac{0}{n}$ & $\frac{9}{n}$ & 冓 & \&ँ & ถุ \\
\hline & $\stackrel{n}{\ddot{g}}$ & 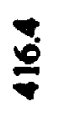 & 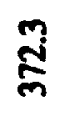 & 웅 & \% & $\frac{n}{2}$ & 움 & 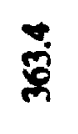 & $\underset{\infty}{\stackrel{N}{m}}$ & $\ddot{z}$ & 吕 \\
\hline 65 & $\underset{\dot{D}}{\mathbf{D}}$ & $\stackrel{\infty}{\stackrel{+}{\nabla}}$ & $\frac{m}{\infty}$ & ญ్ & ॅू & 8 & $\frac{\infty}{0}$ & $\stackrel{n}{n}$ & $\begin{array}{l}\infty \\
\dot{8} \\
\dot{m}\end{array}$ & $\frac{n}{7}$ & જૂ \\
\hline$\omega \frac{1}{2}$ & $\frac{8}{\frac{8}{7}}$ & $\frac{8}{8}$ & $\frac{8}{\frac{8}{\pi}}$ & $\begin{array}{l}8 \\
8 \\
8\end{array}$ & * & 8 & $\frac{8}{8}$ & $\frac{\mathbb{8}}{\mathbb{Z}}$ & 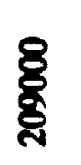 & $\frac{8}{\frac{8}{2}}$ & $\frac{\mathbb{8}}{\mathbb{2}}$ \\
\hline 8 & - & $N$ & $m$ & $\nabla$ & $n$ & 0 & $n$ & $\infty$ & $a$ & 으 & $=$ \\
\hline
\end{tabular}




\begin{tabular}{|c|c|c|c|c|c|c|c|c|}
\hline Ф5 & $\cong$ & $\bar{g}$ & $\frac{n}{\partial}$ & $\bar{\Sigma}$ & $\Xi$ & 8 & \pm & 5 \\
\hline & $\frac{n}{5}$ & $\frac{\infty}{\frac{\infty}{n}}$ & $\frac{8}{8}$ & $\frac{8}{\delta}$ & $\begin{array}{l}8 \\
8 \\
8\end{array}$ & $\frac{8}{8}$ & 咅 & $\frac{m}{0}$ \\
\hline 5 & $\stackrel{\circ}{\alpha}$ & $\frac{8}{8}$ & ชू & 5 & $\begin{array}{l}y \\
8 \\
8\end{array}$ & 品 & $\ddot{0}$ & ุํㅇ \\
\hline & 灾 & 8 & 8 & 8 & $\begin{array}{l}8 \\
8 \\
\frac{7}{2}\end{array}$ & $\frac{8}{9}$ & $\underset{7}{\mathbb{2}}$ & ஜㅇㅇㅇ \\
\hline $0^{5}$ & $\stackrel{\circ}{\circ}$ & $\stackrel{n}{8}$ & $\stackrel{0}{8}$ & $\begin{array}{l}a \\
\vec{j} \\
\vec{r}\end{array}$ & 옹 & $\begin{array}{l}\ddot{n} \\
\ddot{n}\end{array}$ & $\vec{i}$ & 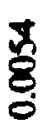 \\
\hline & * & $\bullet$ & • & $\bullet$ & 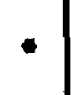 & $*$ & $\bullet$ & $\bullet$ \\
\hline $0^{t}$ & - & $*$ & $\bullet$ & $\bullet$ & * & $\bullet$ & $\bullet$ & $\bullet$ \\
\hline$\omega$ & 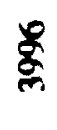 & $\begin{array}{l}\mathscr{\infty} \\
\dot{m}\end{array}$ & $\frac{ \pm}{\mathrm{N}}$ & $\underset{\infty}{\infty}$ & $\overline{5}$ & $\frac{8}{5}$ & $\bar{m}$ & : \\
\hline$\sigma \frac{5}{2}$ & $\frac{\bar{N}}{\mathrm{~N}}$ & 울 & $\bar{n}$ & 芦 & $\stackrel{n}{n}$ & $\stackrel{n}{0}$ & $\underset{H}{*}$ & $\frac{8}{8}$ \\
\hline$\omega \frac{\Sigma}{\Sigma}$ & 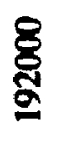 & 递 & $\frac{8}{8}$ & $\frac{8}{8}$ & 8 & 8 & $\underline{8}$ & 号 \\
\hline$\frac{8}{2}$ & $\bar{a}$ & 3 & 3 & $J$ & 3 & $\sum^{\infty}$ & $\begin{array}{l}\dot{b} \\
\dot{0}\end{array}$ & $\Rightarrow$ \\
\hline
\end{tabular}

을 


\begin{tabular}{|c|c|c|c|c|c|c|c|c|}
\hline $\boldsymbol{F}$ & $\frac{n}{\infty}$ & 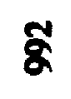 & 호 & $\Phi$ & $\stackrel{n}{\mathbf{x}}$ & 5 & $\overline{2}$ & $\frac{m}{b}$ \\
\hline$-\frac{8}{6}$ & 疍 & 是 & $\frac{8}{8}$ & $\frac{5}{5}$ & $\frac{5}{5}$ & $\stackrel{8}{\not 乛}$ & $\bar{z}$ & $\overline{8}$ \\
\hline 0 & 8 & $\overrightarrow{8}$ & $\begin{array}{l}9 \\
8 \\
2\end{array}$ & 옹 & 8 & $\stackrel{8}{8}$ & ชั & 옹 \\
\hline & 量 & 8 & 8 & 8 & $\frac{8}{8}$ & 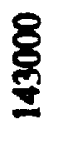 & 8 & $\frac{\$}{8}$ \\
\hline $0^{3} \frac{\mathbb{E}}{\Sigma}$ & $\stackrel{y}{\mathscr{2}}$ & $\overline{\mathbf{8}}$ & 웅 & $\stackrel{y}{\mathscr{8}}$ & 옹 & 영 & $\cong$ & శ్ \\
\hline & $*$ & 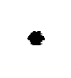 & $*$ & $\cdot$ & * & * & • & $*$ \\
\hline $0^{6} \frac{\pi}{\Sigma}$ & $\bullet$ & 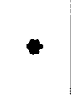 & $\bullet$ & - & $\bullet$ & $*$ & 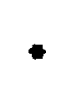 & $\bullet$ \\
\hline$w \stackrel{\circ}{x}$ & $\bar{q}$ & $\bar{\infty}$ & 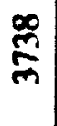 & 商 & $\stackrel{\partial}{\sigma}$ & 总 & 5 & $\stackrel{8}{8}$ \\
\hline$\sigma \frac{\Phi}{\Sigma}$ & $\ddot{n}$ & 횽 & $\bar{n}$ & $\begin{array}{r}\tilde{m} \\
\ddot{n}\end{array}$ & $\stackrel{n}{\infty}$ & $\frac{n}{n}$ & 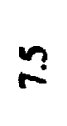 & $\bar{\delta}$ \\
\hline w & 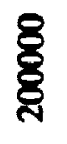 & $\frac{8}{8}$ & $\frac{8}{8}$ & 요용 & 艿 & క్రి & $\frac{\infty}{8}$ & $\frac{8}{8}$ \\
\hline$\frac{8}{8}$ & $E$ & $\mathcal{F}$ & $E$ & $\vec{F}$ & 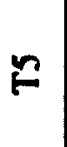 & $\sum^{\infty}$ & $\begin{array}{l}\dot{\partial} \\
\dot{D} \\
\dot{v}\end{array}$ & $>$ \\
\hline
\end{tabular}

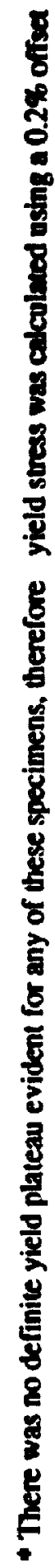




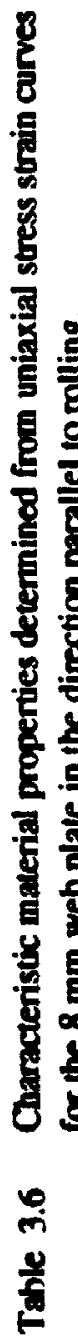

\begin{tabular}{|c|c|c|c|c|c|c|c|c|}
\hline$\omega \frac{5}{2}$ & $\$$ & 安 & 8 & 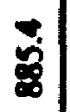 & $\frac{a}{2}$ & s & 충 & 8 \\
\hline & $\begin{array}{l}\text { 总 } \\
8 \\
8\end{array}$ & $\frac{8}{2}$ & 8 & $\begin{array}{l}\frac{N}{2} \\
\frac{2}{2}\end{array}$ & 8 & $\stackrel{8}{9}$ & $\begin{array}{l}\overline{8} \\
\stackrel{8}{8}\end{array}$ & ్ㅗㅇ \\
\hline$\sigma$ & $\frac{n}{n}$ & 8 & $\stackrel{n}{\$}$ & $\dddot{8}$ & 8 & $\frac{8}{8}$ & 8 & $\frac{8}{8}$ \\
\hline & 8 & 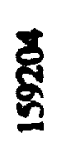 & $\frac{\mathbb{N}}{\mathbb{N}}$ & $\frac{R}{E}$ & $\frac{8}{8}$ & 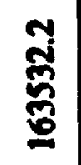 & $\underset{a}{a}$ & $\stackrel{8}{8}$ \\
\hline & g̊ & 舫 & $\frac{n}{n}$ & $\stackrel{0}{\stackrel{n}{*}}$ & $\begin{array}{l}m \\
\mathscr{n} \\
\tilde{n}\end{array}$ & $\begin{array}{l}n \\
n \\
n \\
n\end{array}$ & ్ㅠ & $\frac{n}{\circ}$ \\
\hline & \&్ & 疍 & 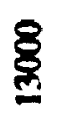 & ళ్ & 8 & 器 & 音 & 잉 \\
\hline 0 & $\frac{m}{\alpha}$ & $\stackrel{0}{\stackrel{g}{g}}$ & $\frac{y}{8}$ & $\stackrel{ }{8}$ & ్ㅗㄹ & $\frac{9}{5}$ & $\begin{array}{l}\mathscr{m} \\
\stackrel{N}{i}\end{array}$ & 8 \\
\hline & ర్తి & $\frac{n}{d}$ & $\stackrel{m}{a}$ & ষ্స్ & శ్ర్ & 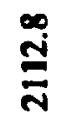 & $\frac{0}{\stackrel{0}{6}}$ & $\frac{8}{8}$ \\
\hline & 움 & 胥 & $\frac{0}{8}$ & $\frac{n}{9}$ & $\frac{9}{9}$ & $\begin{array}{l}\text { ్ָ } \\
\text { ర్రి }\end{array}$ & $\frac{\pi}{i}$ & हु \\
\hline w $\frac{E}{\Sigma}$ & 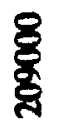 & 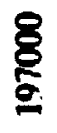 & $\frac{\mathbb{8}}{\pi}$ & 峉 & 总 & $\frac{8}{8}$ & $\tilde{\&}$ & 8 \\
\hline$\frac{8}{8}$ & 2 & $\mathfrak{I}$ & 3 & 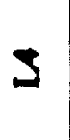 & 3 & $\sum^{\infty}$ & $\frac{3}{8}$ & $\Rightarrow$ \\
\hline
\end{tabular}




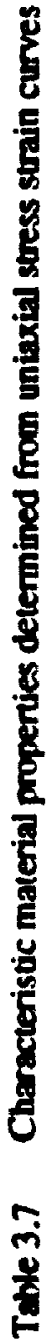

\begin{tabular}{|c|c|c|c|c|c|c|c|c|}
\hline a & $\bullet$ & $\stackrel{8}{8}$ & $\frac{0}{2}$ & $\frac{n}{\infty}$ & 8 & 8 & $\frac{1}{n}$ & 8 \\
\hline$\omega$ & & 8 & 8 & 8 & 8 & 8 & 8 & 8 \\
\hline 0 & $\bullet$ & 5 & 8 & $\ddot{R}$ & $\dddot{m}$ & $\mathscr{2}$ & $\Rightarrow$ & $\frac{n}{6}$ \\
\hline & $\bullet$ & 8 & $\frac{R}{8}$ & 8 & 8ิ & $\frac{6}{8}$ & $\frac{y}{8}$ & 8 \\
\hline $0^{3} \sum$ & $\bullet$ & $\frac{n}{8}$ & $\frac{8}{8}$ & $\frac{n}{n}$ & $\frac{a}{\infty}$ & $\frac{\infty}{n}$ & $\vec{r}$ & $\frac{9}{8}$ \\
\hline & 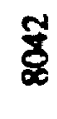 & 8 & $\frac{8}{5}$ & 8 & \& & $\frac{2}{8}$ & $\frac{9}{8}$ & 赵 \\
\hline $0^{5}$ & y & $\stackrel{n}{\sigma}$ & $\frac{n}{7}$ & $\ddot{\square}$ & $\stackrel{\infty}{8}$ & $\frac{9}{7}$ & $\infty$ & $\frac{a}{0}$ \\
\hline$\omega$ & $\frac{\pi}{N}$ & $\underset{\Sigma}{\alpha}$ & $\underset{z}{z}$ & \pm & $\frac{n}{8}$ & $\frac{0}{8}$ & $\frac{\infty}{8}$ & $\frac{y}{8}$ \\
\hline$\sigma \frac{d}{\Sigma}$ & $\stackrel{8}{8}$ & $\frac{n}{2}$ & $\frac{y}{8}$ & $\frac{\pi}{\sigma}$ & $\infty$ & 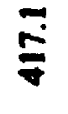 & 0 & $\stackrel{0}{0}$ \\
\hline$\omega \frac{d}{\Sigma}$ & 8 & $\frac{8}{8}$ & $\begin{array}{l}8 \\
8 \\
8\end{array}$ & ళ్ళ & $\frac{8}{8}$ & 8 & $\frac{8}{8}$ & 8 \\
\hline$\frac{8}{8}$ & $\vec{F}$ & $\mathbf{N}$ & $F$ & 5 & $\Leftrightarrow$ & $\underbrace{\infty}$ & $\ddot{\theta}$ & $>$ \\
\hline
\end{tabular}




\begin{tabular}{|c|c|c|c|c|c|c|c|c|}
\hline $5 \frac{5}{2}$ & $\begin{array}{l}0 \\
0 \\
0\end{array}$ & 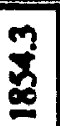 & - & $\stackrel{8}{8}$ & $\begin{array}{l}2 \\
8 \\
8\end{array}$ & $\underline{8}$ & $\stackrel{n}{8}$ & 8 \\
\hline 5 & $\frac{9}{8}$ & $\overline{8}$ & $\begin{array}{l}\Omega \\
\\
\mathbb{S}\end{array}$ & $\frac{5}{8}$ & 龺 & $\begin{array}{l}\mathcal{Y} \\
E \\
E\end{array}$ & कू & $\frac{8}{8}$ \\
\hline $0^{-}$ & $\frac{5}{8}$ & \& & $\underset{\mathbf{d}}{\mathbf{d}}$ & ్ㅗ․ & $\begin{array}{l}\infty \\
\ddot{d}\end{array}$ & $\stackrel{\circ}{8}$ & $\ddot{m}$ & 홍 \\
\hline & 尽 & 急 & 茖 & క్రి & $\begin{array}{l}\mathrm{g} \\
\mathbf{8} \\
\end{array}$ & 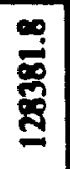 & $\frac{8}{8}$ & 훙 \\
\hline $0^{3}$ & $\underset{8}{3}$ & $\stackrel{\infty}{\frac{\infty}{0}}$ & $\underset{8}{x}$ & $\frac{9}{8}$ & ○ & $\ddot{8}$ & $\eta$ & 8 \\
\hline & $\underset{\mathbb{d}}{\mathbb{D}}$ & 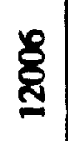 & $\bullet$ & $\frac{n}{2}$ & $\stackrel{9}{3}$ & $\stackrel{0}{\frac{5}{8}}$ & $\overrightarrow{0}$ & $\stackrel{90}{8}$ \\
\hline & gू & ष & $\bullet$ & $\begin{array}{l}0 \\
0 \\
0 \\
0 \\
0\end{array}$ & 窎 & $\stackrel{g}{g}$ & $\stackrel{\infty}{-\infty}$ & $\underset{0}{0}$ \\
\hline & 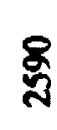 & $\frac{8}{3}$ & ఫ్స & జ్ & 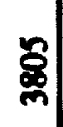 & $\underset{8}{\alpha}$ & $\stackrel{8}{\circ}$ & ह్ర \\
\hline$\sigma$ & $\underset{8}{8}$ & 8 & $\frac{n}{2}$ & $\frac{-}{\tilde{s}}$ & $\underset{\mathbf{s}}{\mathbf{s}}$ & $\begin{array}{l}\mathscr{0} \\
\stackrel{0}{0}\end{array}$ & $\frac{n}{m}$ & 8 \\
\hline 山上 & 密 & $\frac{8}{8}$ & 㿣 & $\begin{array}{l}\frac{8}{2} \\
\frac{0}{2}\end{array}$ & 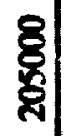 & $\begin{array}{l}\text { 思 } \\
\text { స }\end{array}$ & $\stackrel{8}{8}$ & 8 \\
\hline$\frac{5}{8}$ & $E$ & $\mathbf{N}$ & $F$ & $E$ & 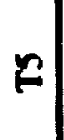 & 2 & $\begin{array}{l}\dot{8} \\
\text { 离 }\end{array}$ & $\rightarrow$ \\
\hline
\end{tabular}

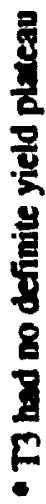




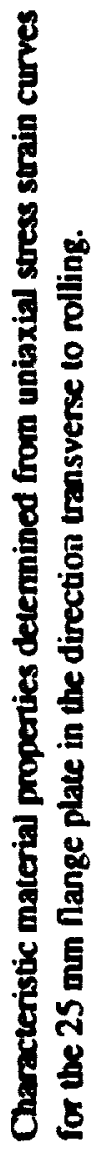

\begin{tabular}{|c|c|c|c|c|c|c|c|c|}
\hline 国至 & $\frac{a}{\tilde{z}}$ & $\frac{a}{\bar{n}}$ & • & $\frac{a}{5}$ & 궁 & $\begin{array}{l}3 \\
3 \\
8\end{array}$ & $\stackrel{\circ}{g}$ & 8 \\
\hline & E & 蒿 & $\bullet$ & $\frac{8}{8}$ & 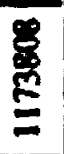 & 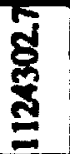 & 商 & $\frac{9}{6}$ \\
\hline & 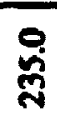 & స్ & • & $\stackrel{\infty}{8}$ & $\overrightarrow{8}$ & $\frac{8}{8}$ & $\frac{7}{N}$ & $\bar{g}$ \\
\hline & 8 & 8 & $\bullet$ & $\begin{array}{l}8 \\
8 \\
8\end{array}$ & $\frac{8}{8}$ & $\underset{8}{8}$ & 8 & $\underset{8}{8}$ \\
\hline & $\frac{a}{2}$ & 怘 & $\bullet$ & $\frac{y}{g}$ & $\underset{d}{\dot{d}}$ & $\begin{array}{l}n \\
\text { šn }\end{array}$ & i & 용 \\
\hline & 号 & ళ్ర్త్ర & \& & 8 & \&్ & $\frac{0}{\stackrel{0}{0}}$ & $\bar{E}$ & ర్ర \\
\hline & $\underset{\tilde{d}}{\tilde{d}}$ & Sू & $\stackrel{a}{g}$ & $\frac{r}{a}$ & $\underset{\infty}{\infty}$ & $\underset{j}{g}$ & $\overrightarrow{0}$ & है \\
\hline & 8ू & $\frac{\infty}{\sim}$ & $\overline{8}$ & $\Xi$ & $\underset{\sim}{\alpha}$ & 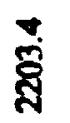 & $\frac{2}{2}$ & $\frac{0}{6}$ \\
\hline $0^{\circ} \frac{8}{\Sigma}$ & 总 & $\frac{n}{a}$ & $\overline{-}$ & $\underset{\mathcal{g}}{\stackrel{\alpha}{\alpha}}$ & ڤ̆ & 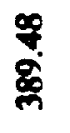 & $\stackrel{7}{i}$ & 용 \\
\hline$\omega \frac{d}{\Sigma}$ & 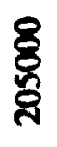 & & $\begin{array}{l}8 \\
8 \\
8\end{array}$ & $\begin{array}{l}8 \\
\frac{8}{8} \\
\text { 品 }\end{array}$ & ళ్ & $\begin{array}{l}8 \\
\text { \&్ } \\
\text { ह్ }\end{array}$ & 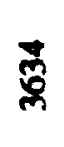 & $\stackrel{\infty}{0}$ \\
\hline $8^{8}$ & $\Xi$ & Y & 13 & $S$ & 3 & $\dot{0}$ & $\begin{array}{l}\vec{y} \\
\dot{y} \\
\dot{n}\end{array}$ & $\rightarrow$ \\
\hline
\end{tabular}




\begin{tabular}{|c|c|c|c|c|c|c|c|c|}
\hline w & $\stackrel{8}{8}$ & 8 & $\begin{array}{l}8 \\
8 \\
8\end{array}$ & $\frac{m}{\mathscr{n}}$ & 8 & $\vec{z}$ & $=$ & 8 \\
\hline & $\begin{array}{l}8 \\
\frac{8}{6} \\
8 \\
8\end{array}$ & $\frac{a}{5}$ & $\begin{array}{l}\frac{n}{8} \\
8 \\
8\end{array}$ & $\underset{\mathbf{n}}{\mathbf{g}}$ & 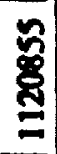 & $\frac{\infty}{\delta}$ & $\frac{8}{8}$ & 8 \\
\hline & $=$ & $=$ & 号 & $\stackrel{m}{8}$ & $\begin{array}{l}\stackrel{8}{0} \\
\text { bे }\end{array}$ & $\frac{\pi}{8}$ & n̆ & 8 \\
\hline & $\underline{z}$ & 胥 & $\overline{8}$ & $\begin{array}{l}8 \\
8 \\
8\end{array}$ & 8 & 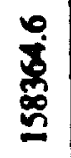 & $\stackrel{\mathscr{\theta}}{\bar{E}}$ & $\frac{9}{8}$ \\
\hline & $\ddot{m}$ & 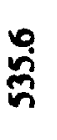 & $\frac{a}{n}$ & 㞭 & $\begin{array}{l}a \\
\\
\end{array}$ & 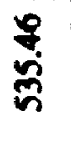 & $\stackrel{0}{0}$ & $\stackrel{8}{8}$ \\
\hline & $\underset{్}{8}$ & $\begin{array}{l}8 \\
\text { 号 }\end{array}$ & $\frac{\tilde{z}}{\sigma}$ & 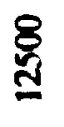 & 8 & 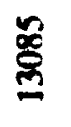 & $\vec{p}$ & t: \\
\hline & $\underset{\mathrm{g}}{\mathrm{g}}$ & $\begin{array}{l}\stackrel{\rho}{\leftrightarrow} \\
\stackrel{\infty}{\infty}\end{array}$ & \& & $\stackrel{0}{\stackrel{D}{\infty}}$ & $\underset{\mathbb{N}}{\mathbb{N}}$ & $\underset{n}{\frac{n}{\infty}}$ & ָे & $\stackrel{8}{8}$ \\
\hline & $\check{\Sigma}$ & $\underset{0}{0}$ & $E$ & $\frac{7}{8}$ & 8 & $\begin{array}{l}0 \\
\stackrel{\infty}{E}\end{array}$ & $\underset{\infty}{\mathscr{\infty}}$ & $\frac{0}{8}$ \\
\hline $6 \frac{5}{2}$ & $\frac{0}{\frac{0}{\infty}}$ & $\stackrel{a}{\mathscr{L}}$ & $\stackrel{\mathscr{D}}{\mathbb{m}}$ & $\frac{\square}{\infty}$ & $\overline{8}$ & $\begin{array}{l}\mathscr{0} \\
\stackrel{0}{0}\end{array}$ & $\bar{n}$ & 8 \\
\hline m & $\frac{8}{8}$ & 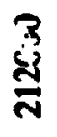 & $\frac{\delta}{8}$ & 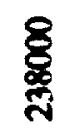 & $\frac{8}{\bar{n}}$ & $\frac{\mathbb{Z}}{\mathbb{Z}}$ & $\underset{\Xi}{\underline{\Xi}}$ & 8 \\
\hline$\frac{8}{8}$ & $\Xi$ & 3 & 3 & $J$ & 3 & $\sum^{\infty 0}$ & $\frac{3}{0}$ & $>$ \\
\hline
\end{tabular}




\begin{tabular}{|c|c|c|c|c|c|c|c|c|}
\hline DE & 8 & $\frac{\tilde{D}}{0}$ & ฉू & 용 & हू & 兽 & 7 & 웅 \\
\hline$\omega^{-}$ & $\begin{array}{l}8 \\
8 \\
8 \\
8\end{array}$ & $\overline{8}$ & 号 & $\frac{9}{8}$ & $\frac{8}{8}$ & 㤂 & $\frac{5}{8}$ & ஜ \\
\hline & 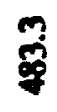 & $\frac{9}{\xi}$ & 8 & d & 8 & $\mathscr{8}$ & $\underset{m}{F}$ & ్ㅇㅇㅇㅇ \\
\hline & 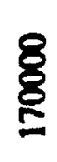 & $\frac{8}{ \pm}$ & 总 & 요 & ஜ్రి & 我 & 용 & 8 \\
\hline & $\frac{7}{3}$ & $\stackrel{0}{7}$ & $\frac{8}{8}$ & $\Xi$ & $\frac{\pi}{\infty}$ & $\frac{n}{5}$ & $\frac{\infty}{\vec{i}}$ & $\frac{8}{0}$ \\
\hline & $\frac{8}{2}$ & $\stackrel{\Xi}{\varrho}$ & 蛋 & 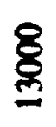 & $\frac{ \pm}{g}$ & $\begin{array}{l}8 \\
8 \\
8\end{array}$ & $\stackrel{\infty}{0}$ & $\bar{\delta}$ \\
\hline $0^{6}$ & $\stackrel{\infty}{8}$ & ڤ̊ㅜㄹ & & $\frac{\pi}{2}$ & 字 & శ్ల & $\vec{N}$ & 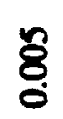 \\
\hline$\omega$ & 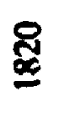 & $\stackrel{\mathscr{g}}{\Xi}$ & $\frac{5}{\infty}$ & $\underset{\mathbb{E}}{\mathbb{g}}$ & జ్ల & 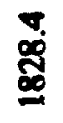 & $\stackrel{\infty}{8}$ & జ్ర \\
\hline$\sigma \frac{x}{\Sigma}$ & $\frac{n}{9}$ & \% & s. & $\tilde{d}$ & $\stackrel{0}{\mathscr{g}}$ & స్ & $\overline{\text { i }}$ & हु \\
\hline (1) $\frac{d}{2}$ & $\frac{8}{8}$ & $\frac{8}{\not ్ వ ి ~}$ & $\frac{8}{8}$ & $\frac{8}{8}$ & ళ్ర్ర & $\frac{8}{4}$ & 8 & $\tilde{\delta}$ \\
\hline 量定 & 5 & 9 & 3 & $\$$ & 3 & $\sum^{\infty}$ & $\begin{array}{l}\dot{z} \\
\dot{j}\end{array}$ & \\
\hline
\end{tabular}




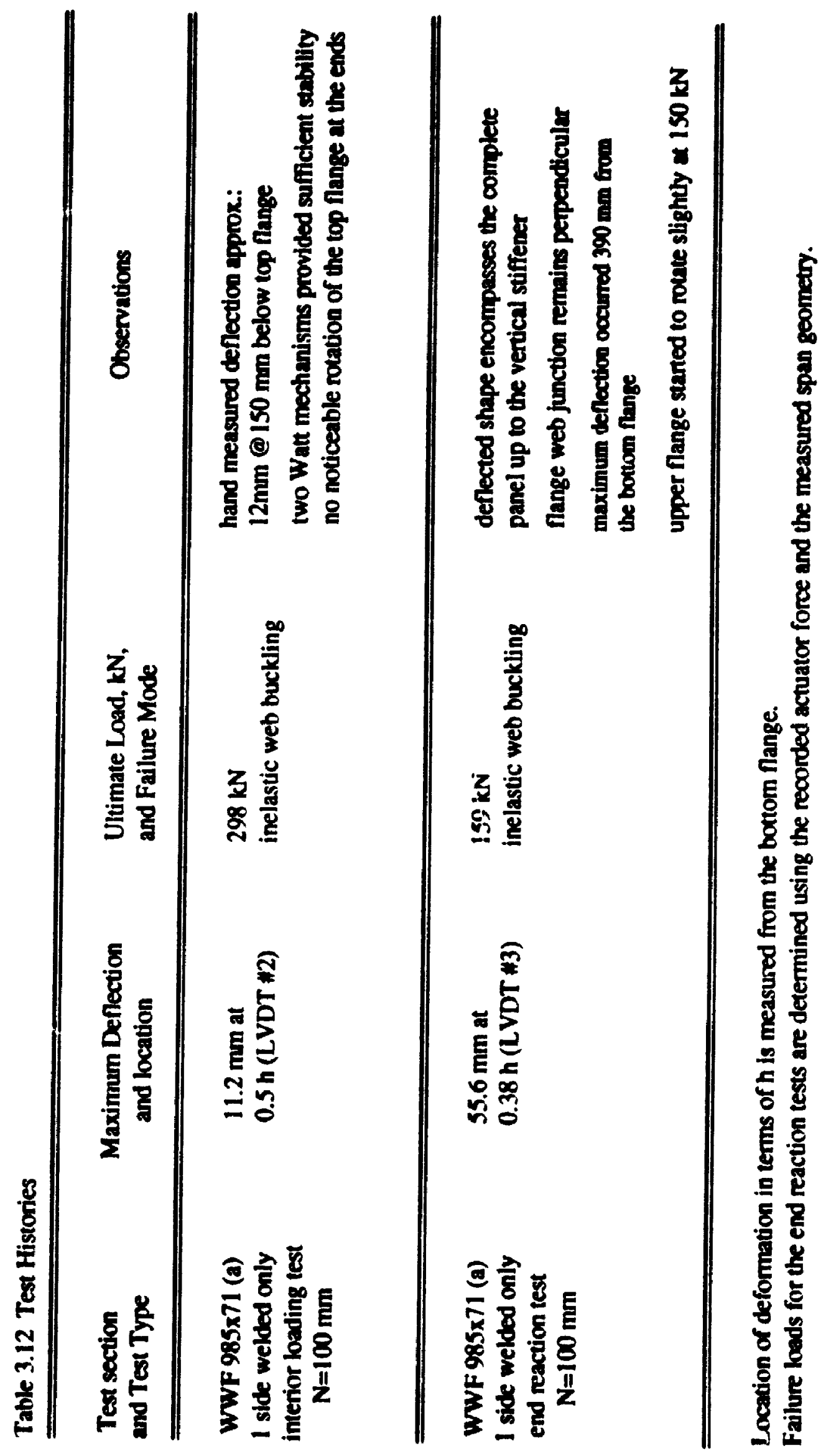




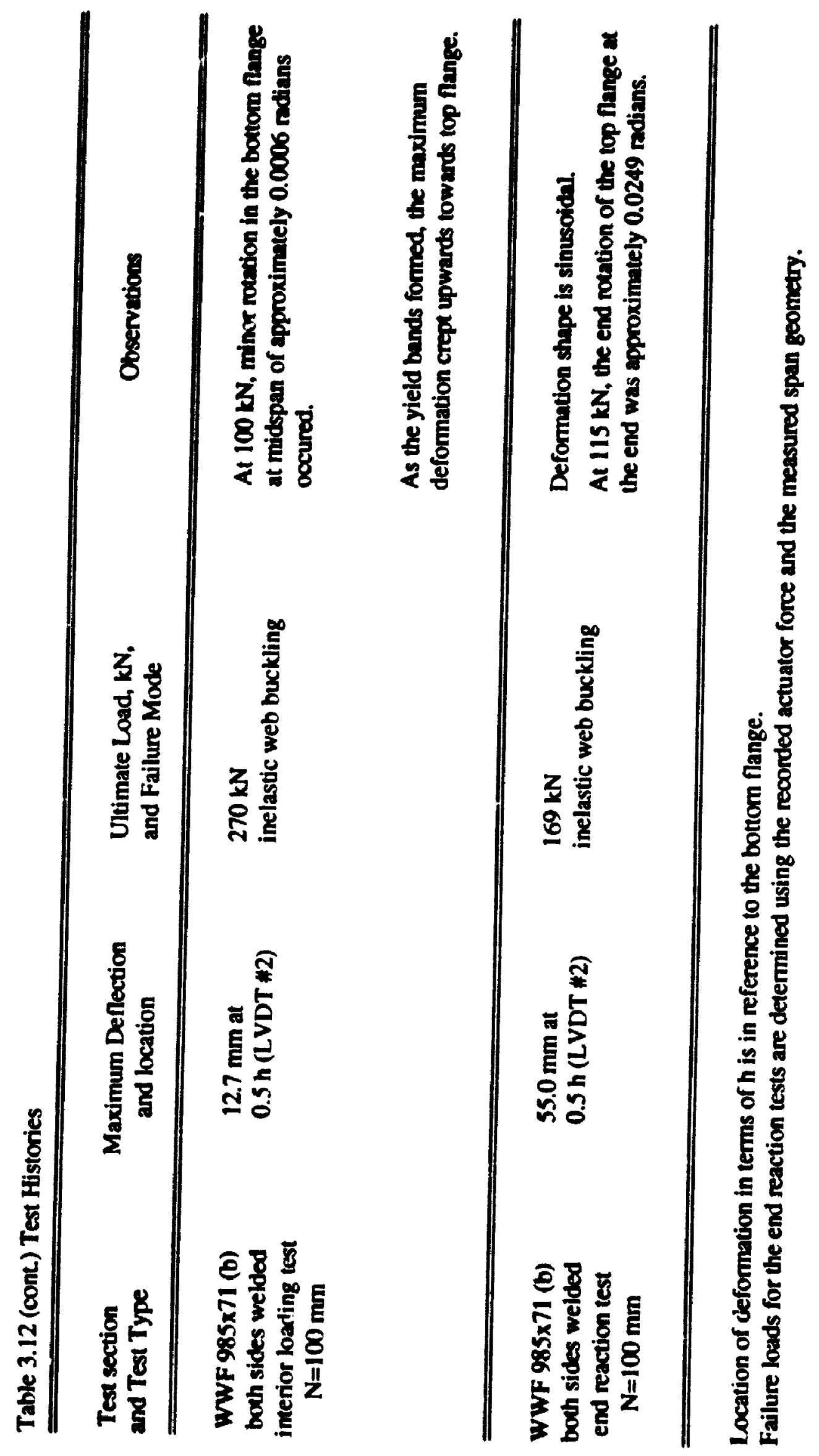




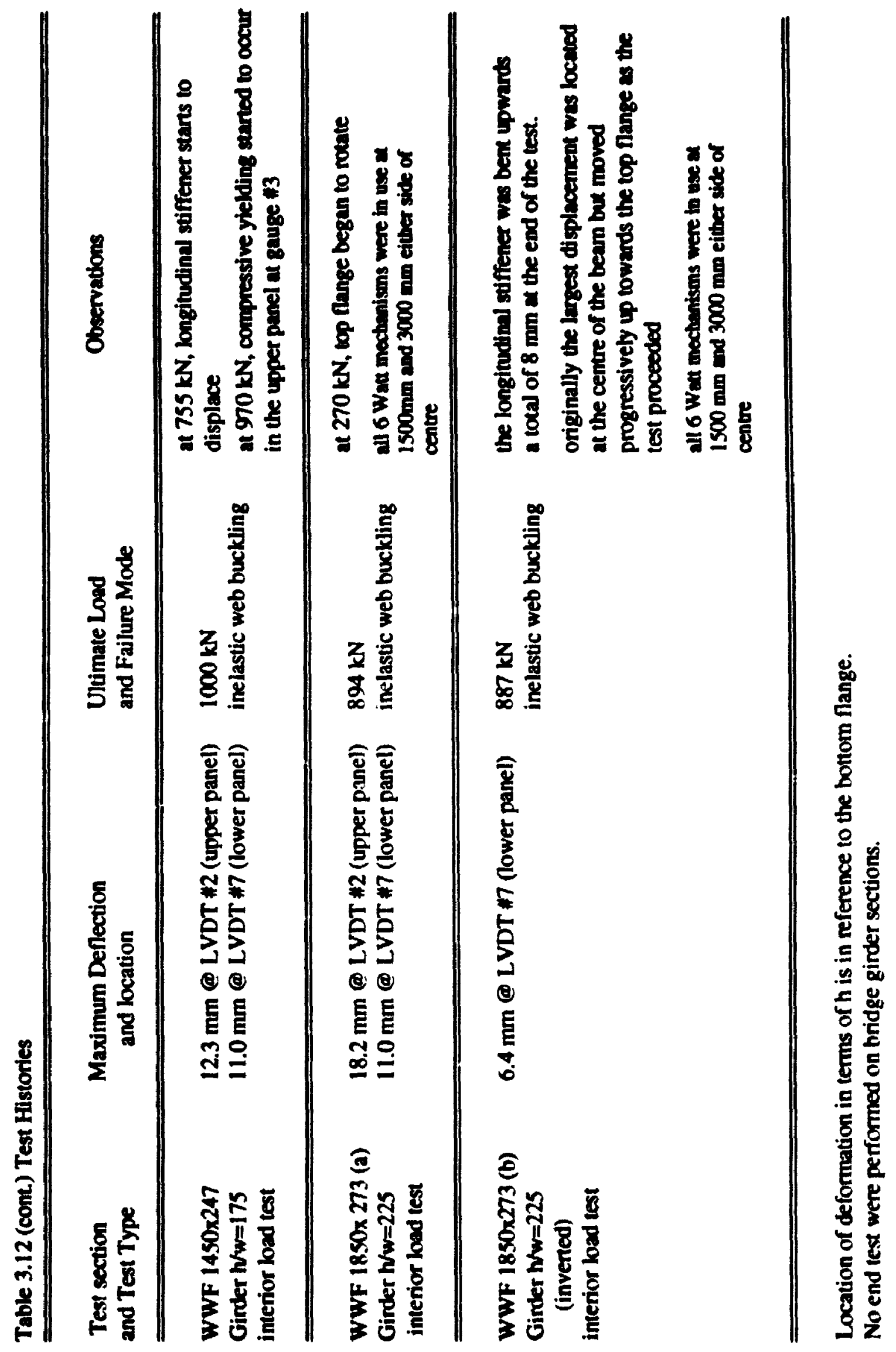




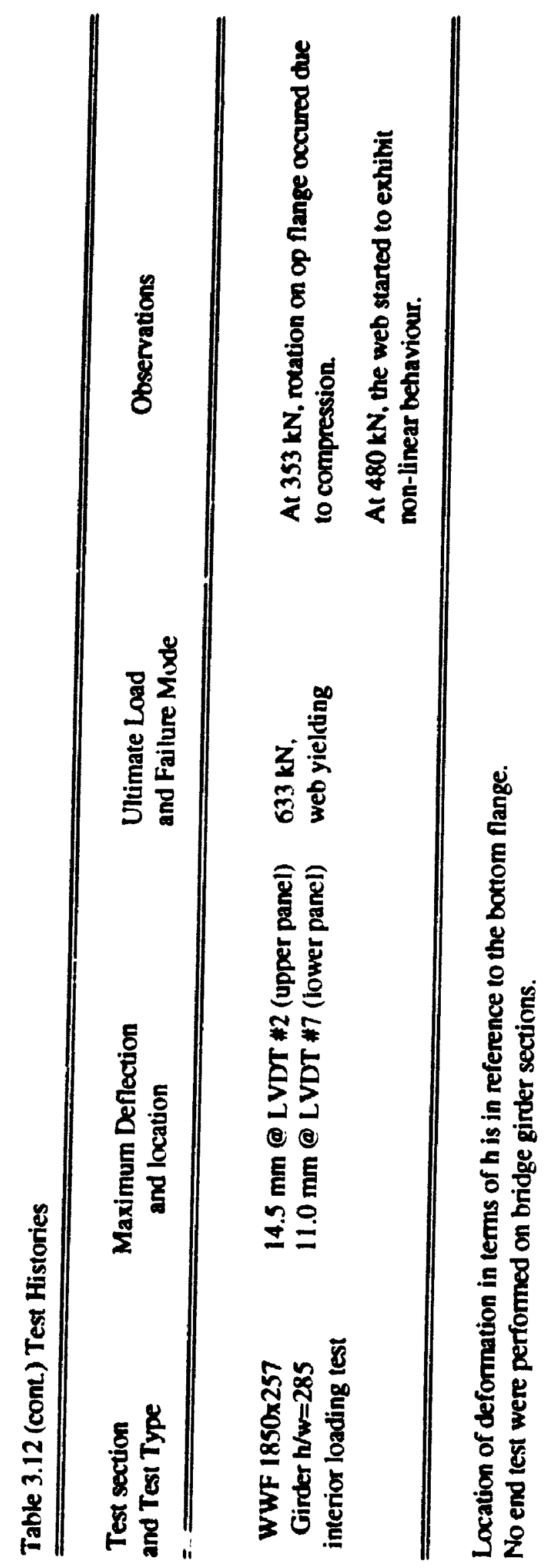




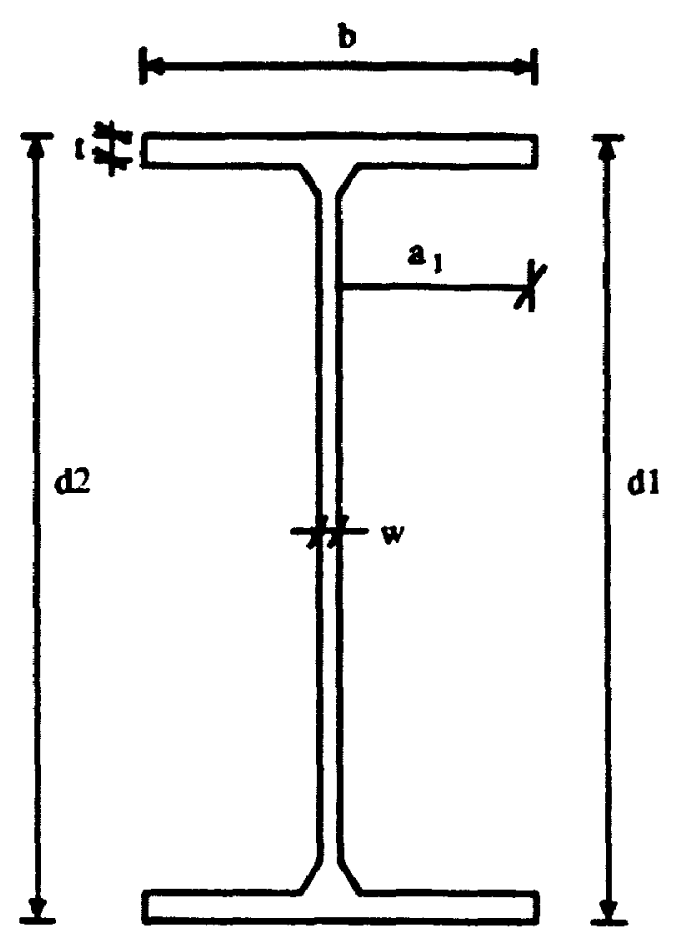

(a) Recorded Dimensions and Geometry

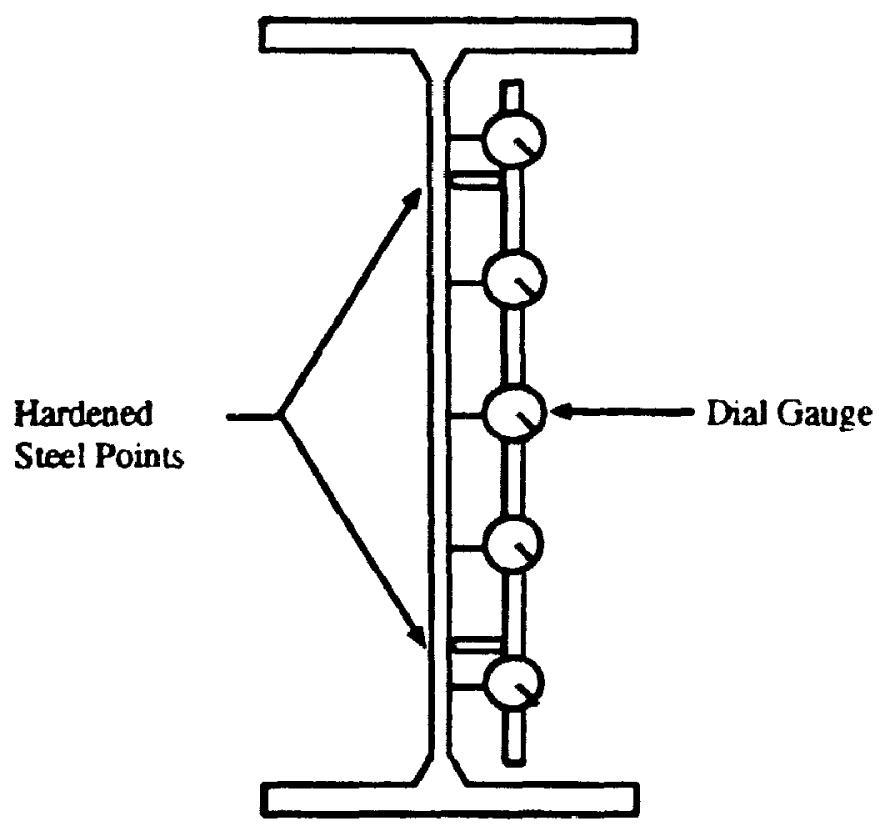

(b) Schematic Diagram of Imperfection Measuring Device

Figure 3.1 Definitions of Measurements For Beam Geometry 


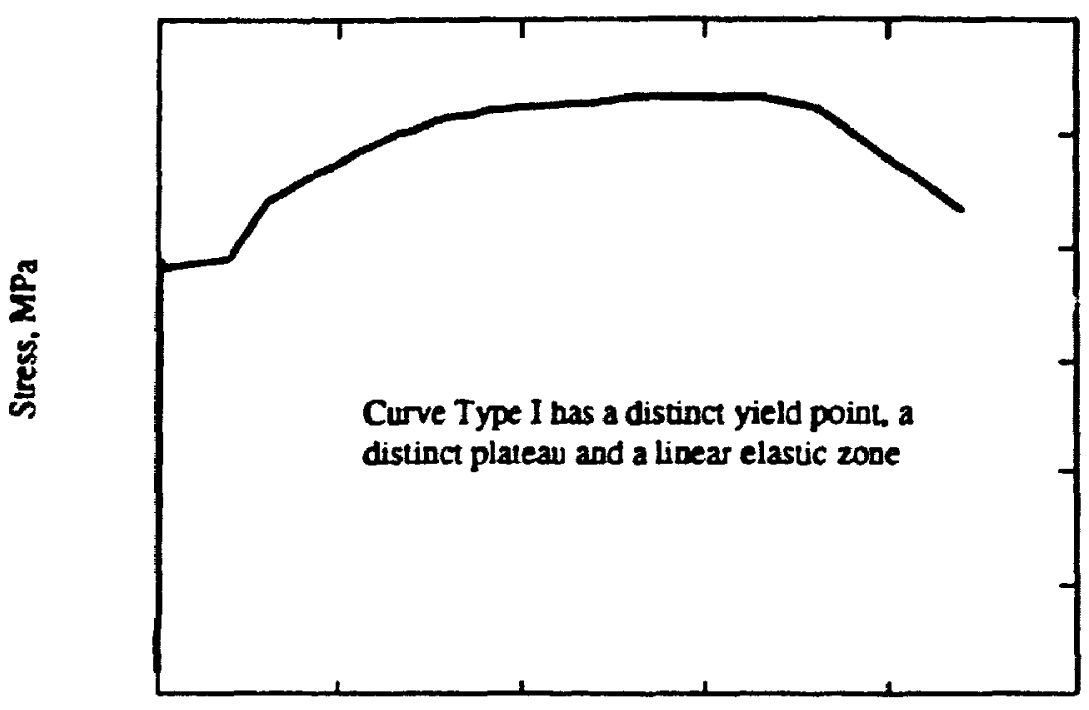

Strain, microstrain

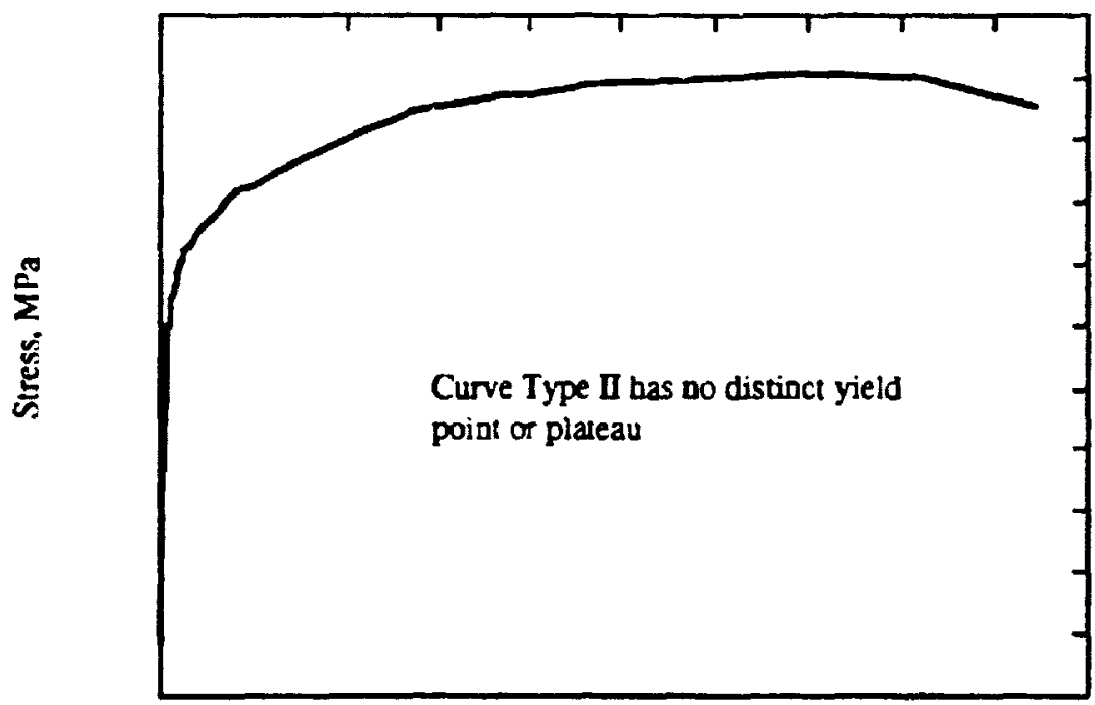

Strain, microstrain

Figure 3.2 Typical Uniaxial Stress Strain Curves from Tension Coupon Tests 


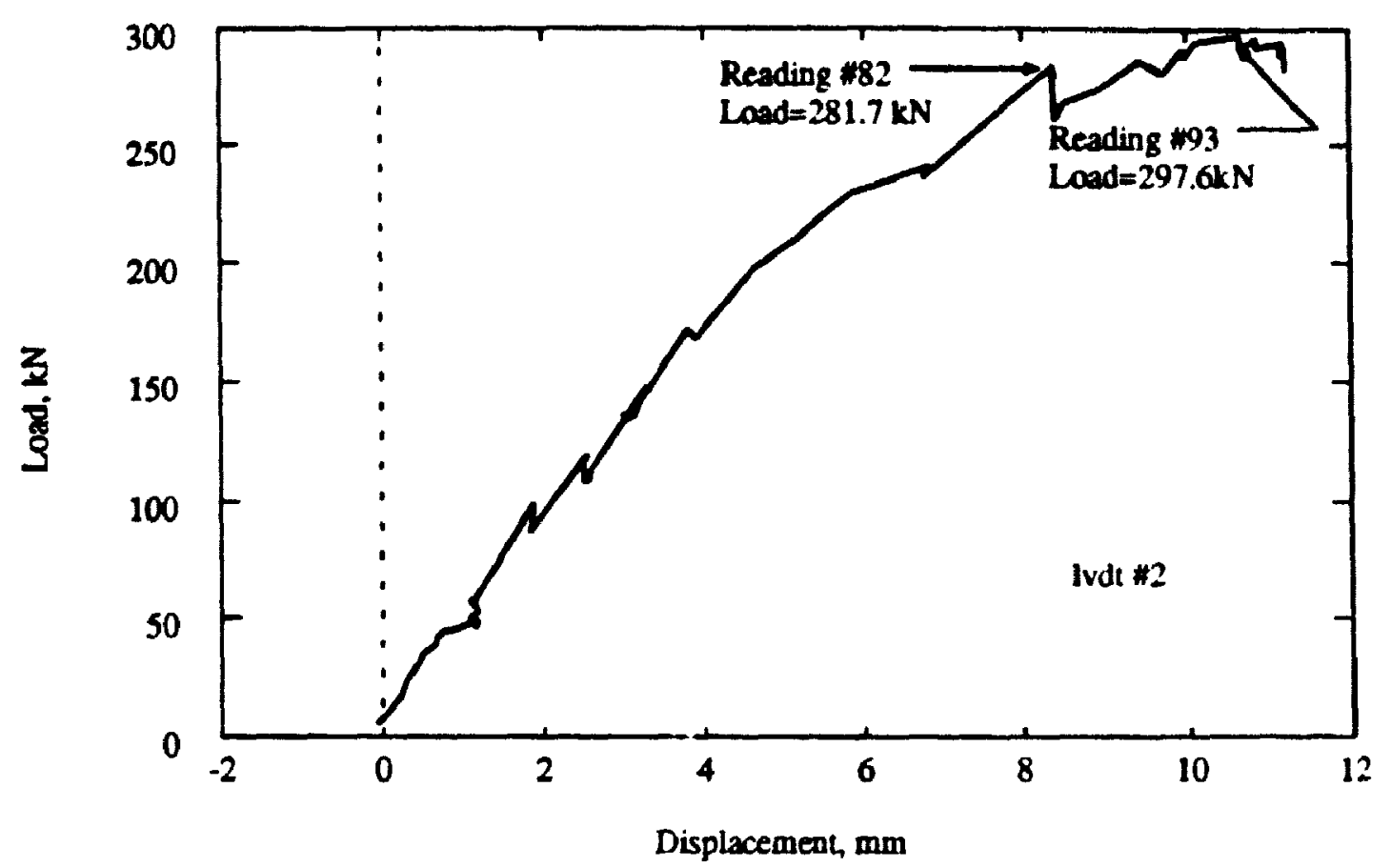

Figure 3.3 Load vs. Maximum Displacement Curve for WWF 985×71 (welded one-side), Interior Laad

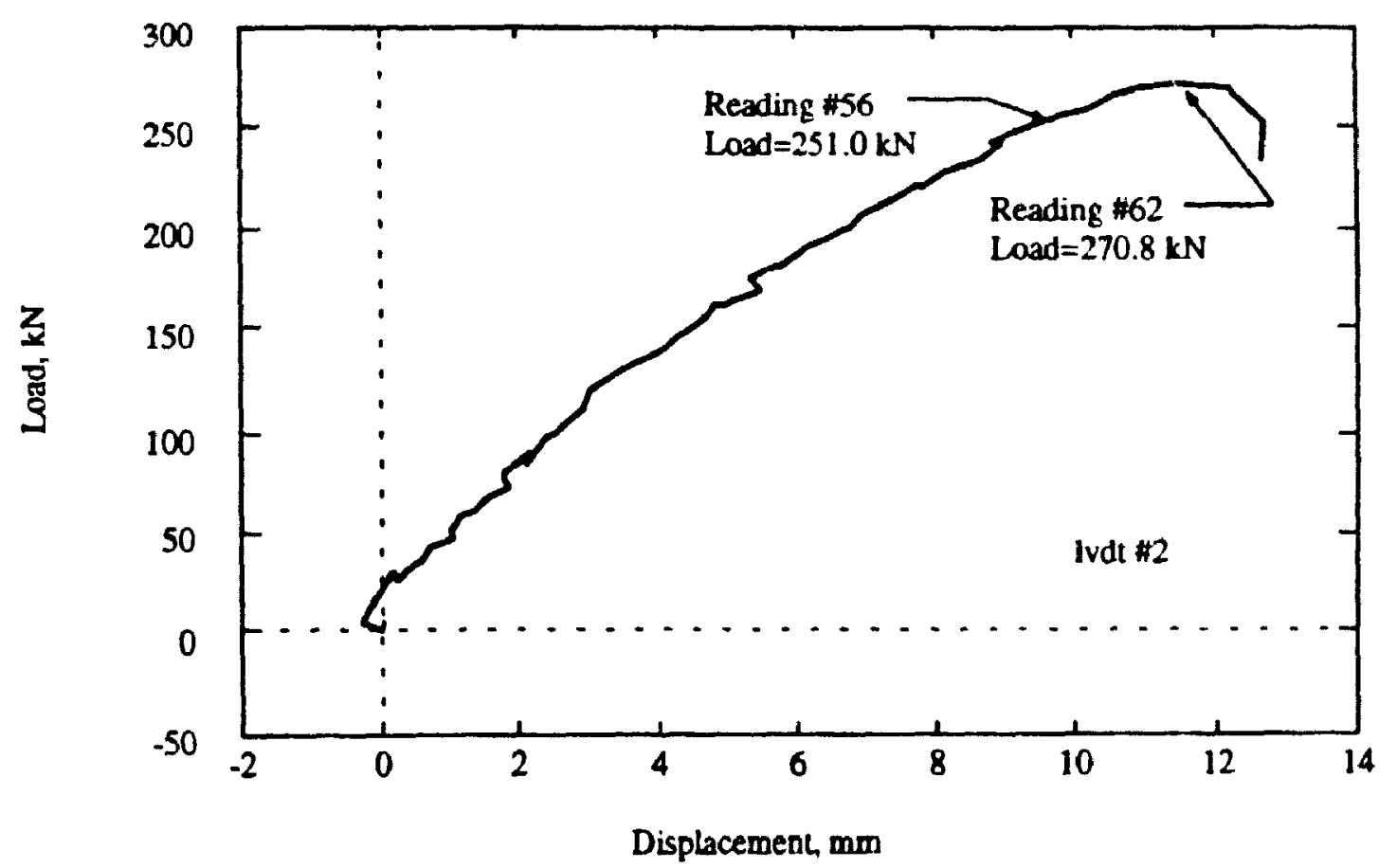

Figure 3.4 Load vs Maximum Displacemeat Curve for WWF $985 \times 71$ (double-welded), Interior Load 


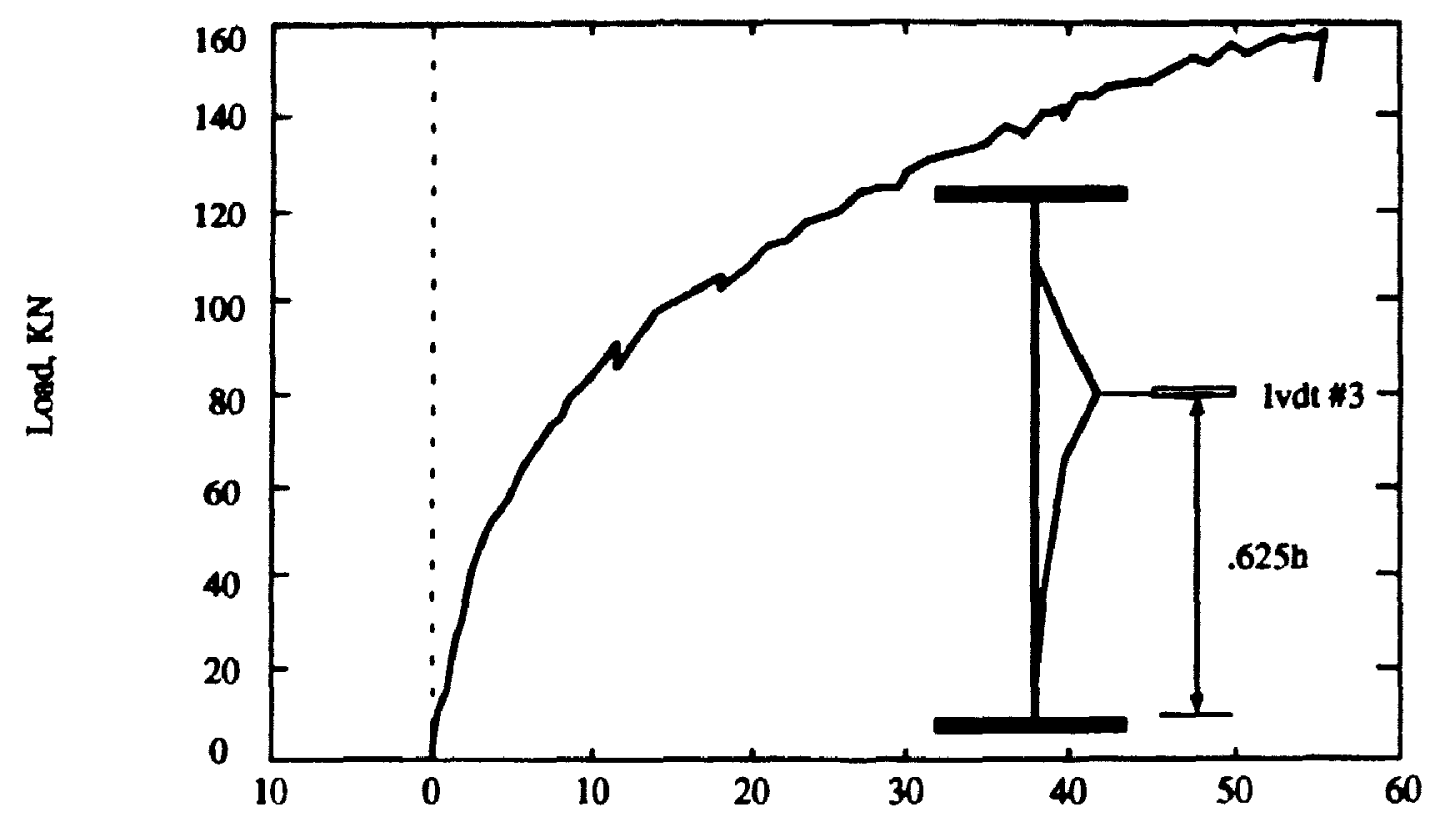

Displacement, mm

Figure 3.5 Load vs. Out of Plane Web Deformation for WWF $98.5 \times 71$ (a) Endtest (welded one-side)

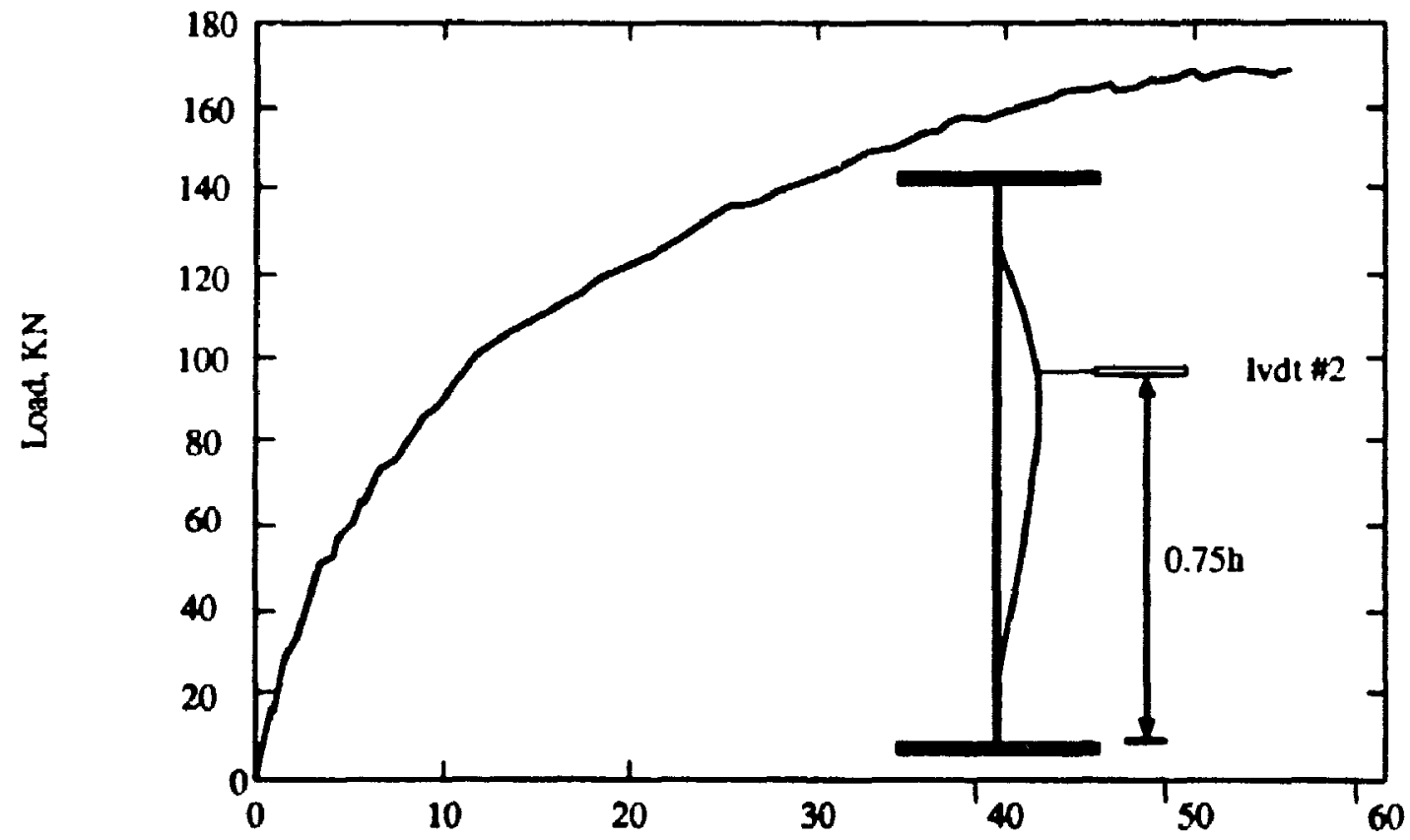

Displacement, mm

Figure 3.6 Load vs Out of Plane Web Deformation for WWF 985×71 (a) Endiest (double welded) 


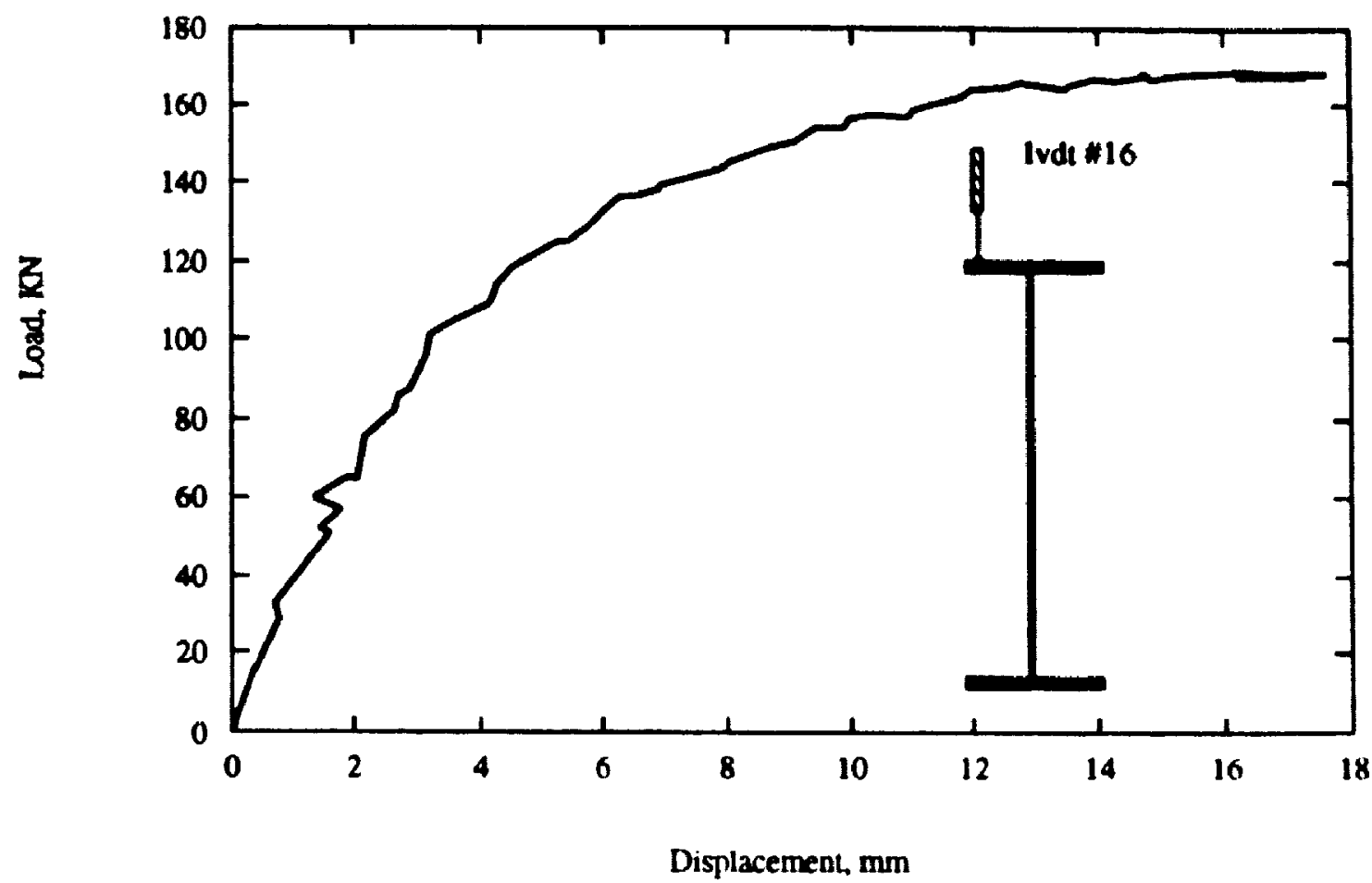

(a) Rotation of One Edge of Flange, LVDT $\# 16$

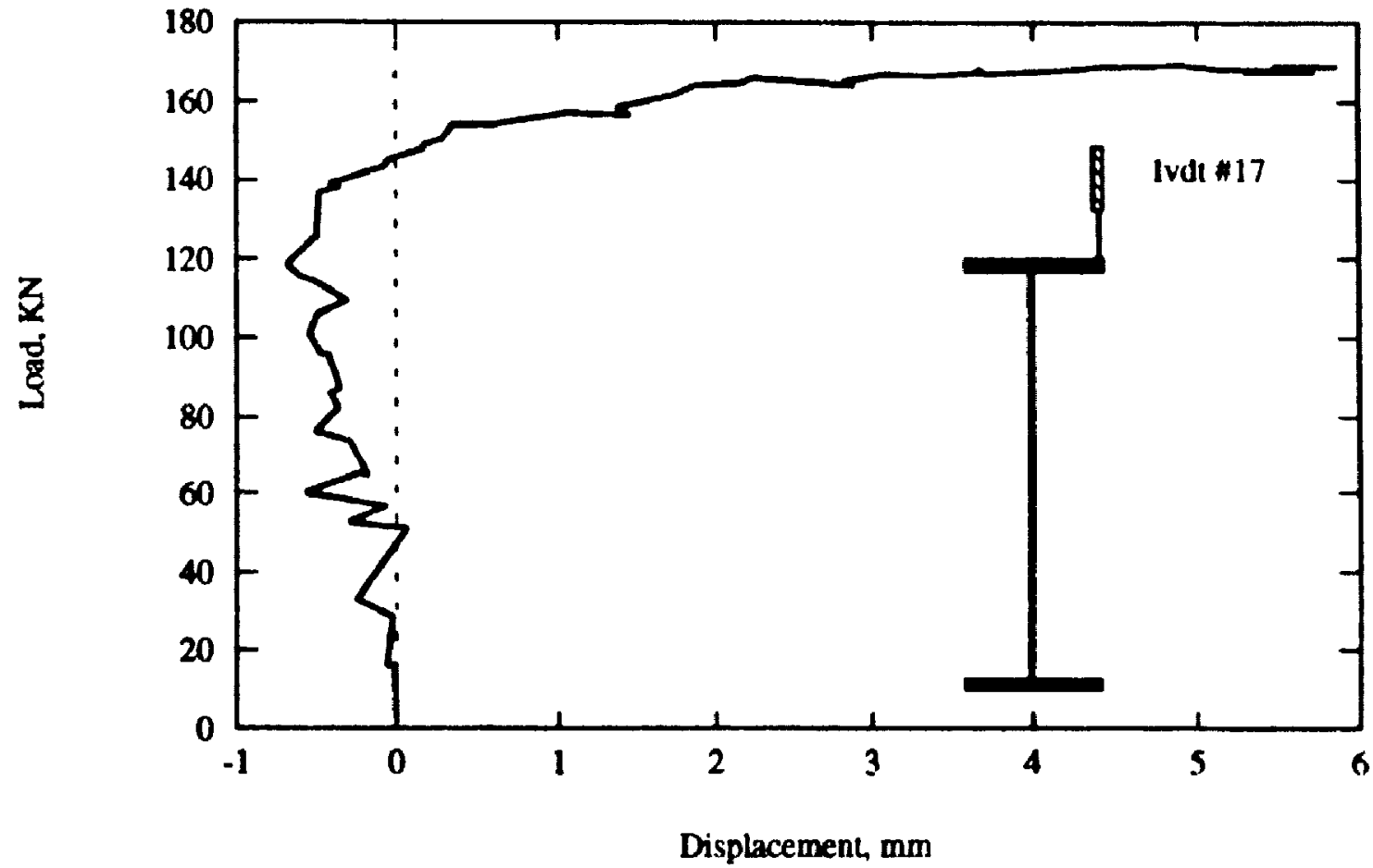

(b) Rotation of One Edge of Flange, LVDT $\# 17$

Figure 3.7 WWF 985x71 (b) Enduest, Rotation of Unloaded Flange 


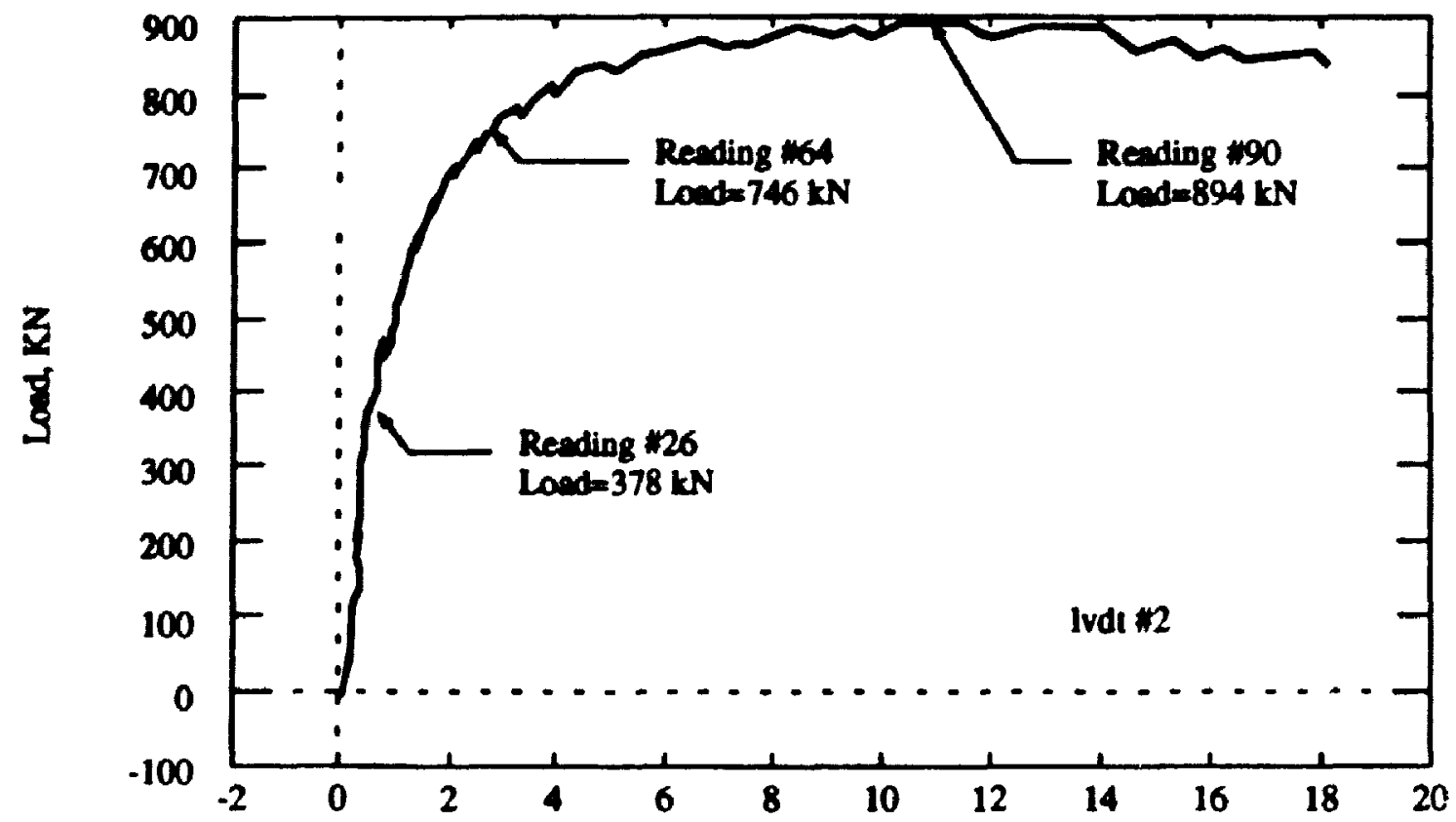

Displacement, mm

(a) Load vs. Maximum Displacement Curve for the Upper Paneh (0.2b)

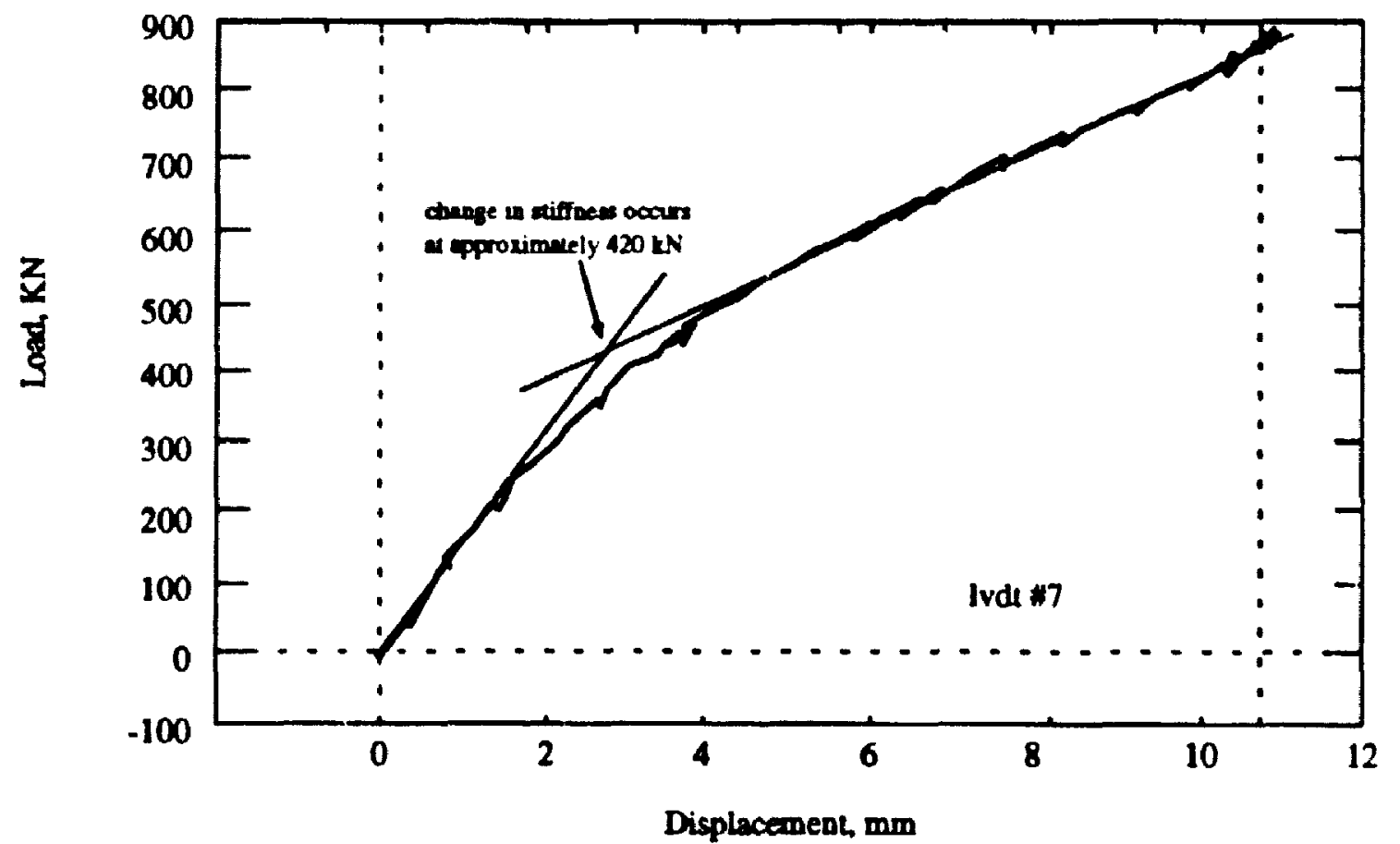

(b) Laad vs. Maximum Displacement Curve in the Lower Panel, $(0.8 \mathrm{~b})$

Figure 3.9 Load vs. Displacement Curves for WWF $1850 \times 273$ (a) 


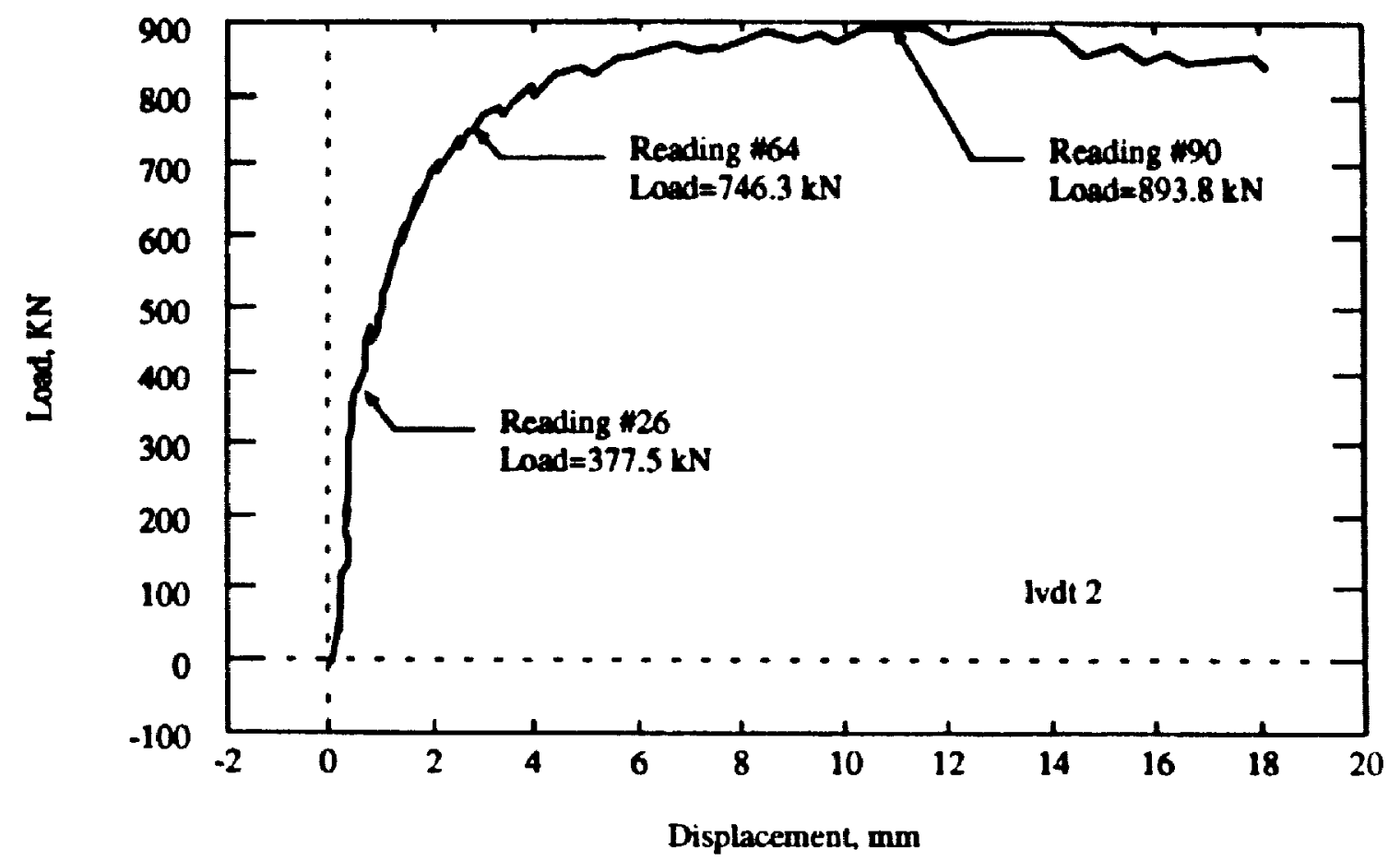

(a) Laad vs. Maximum Displacement Curve for the Upper Panel, (0.2h)

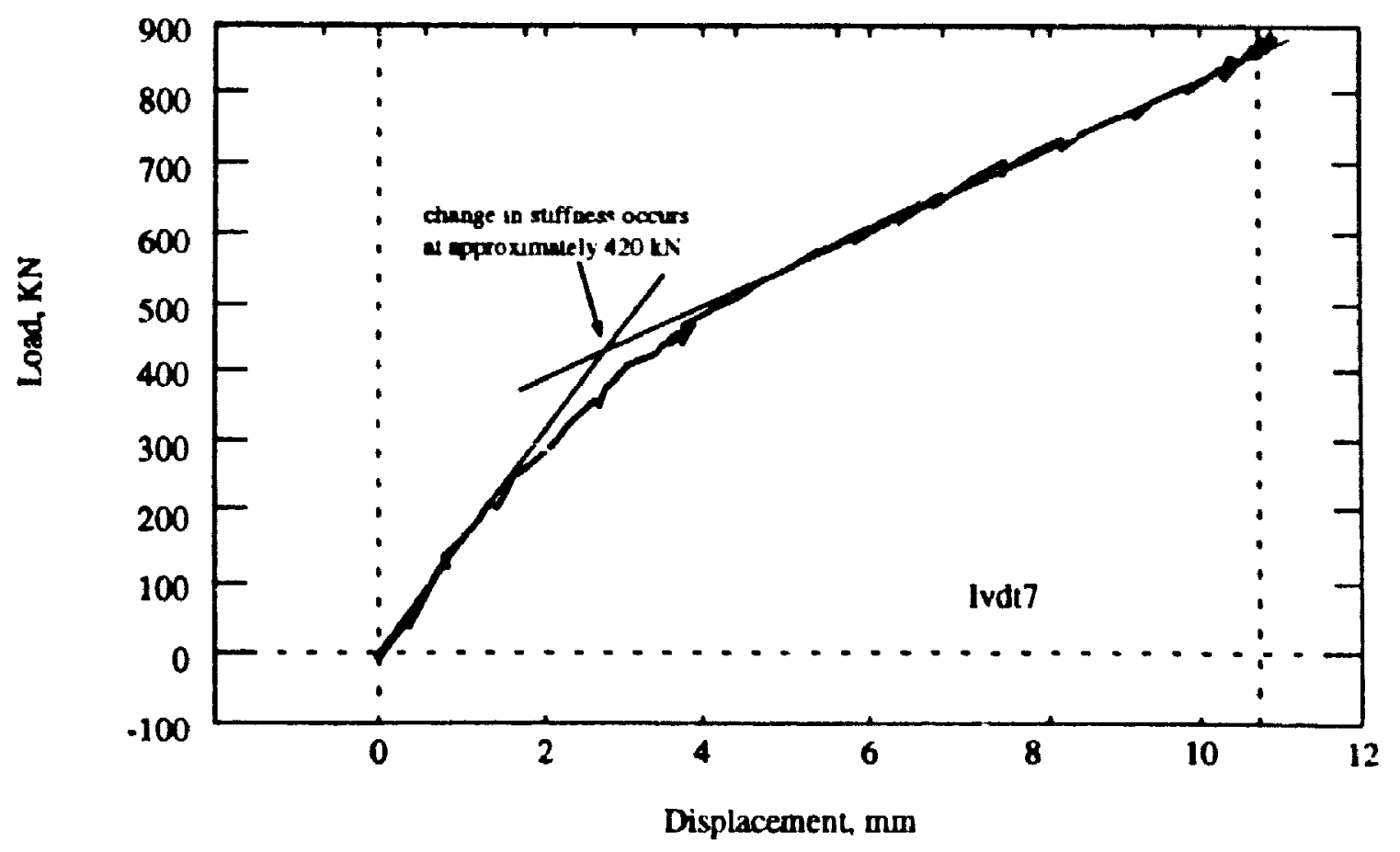

(b) Laad vs. Maximum Displacement Curve in the Lower Panel, $(0.8 \mathrm{~h})$

Figure 3.9 Laad vs. Displacement Curves for WW1: $1850 \times 273$ (a) 


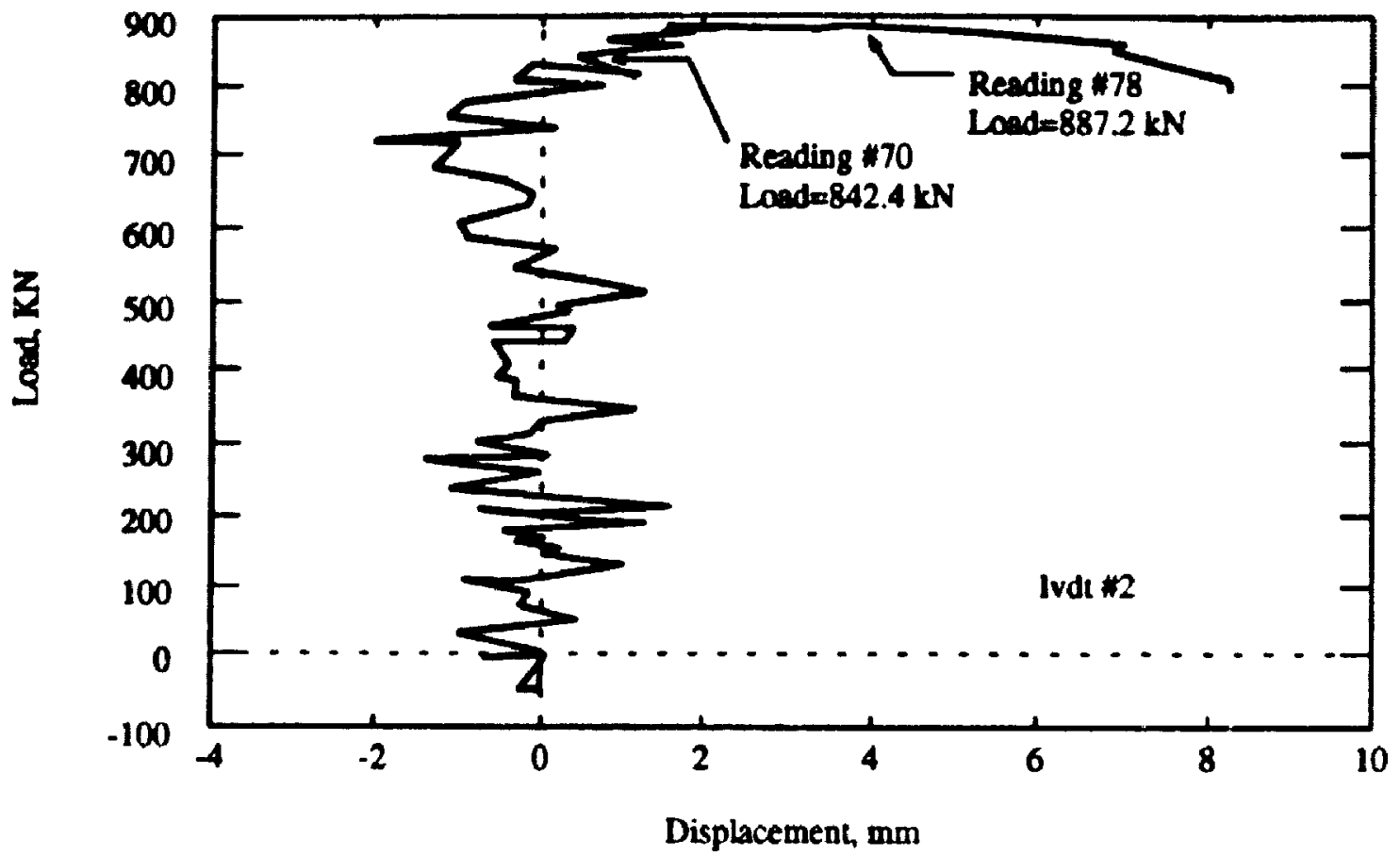

(a) Load vs. Displacement Curve at 0.11h

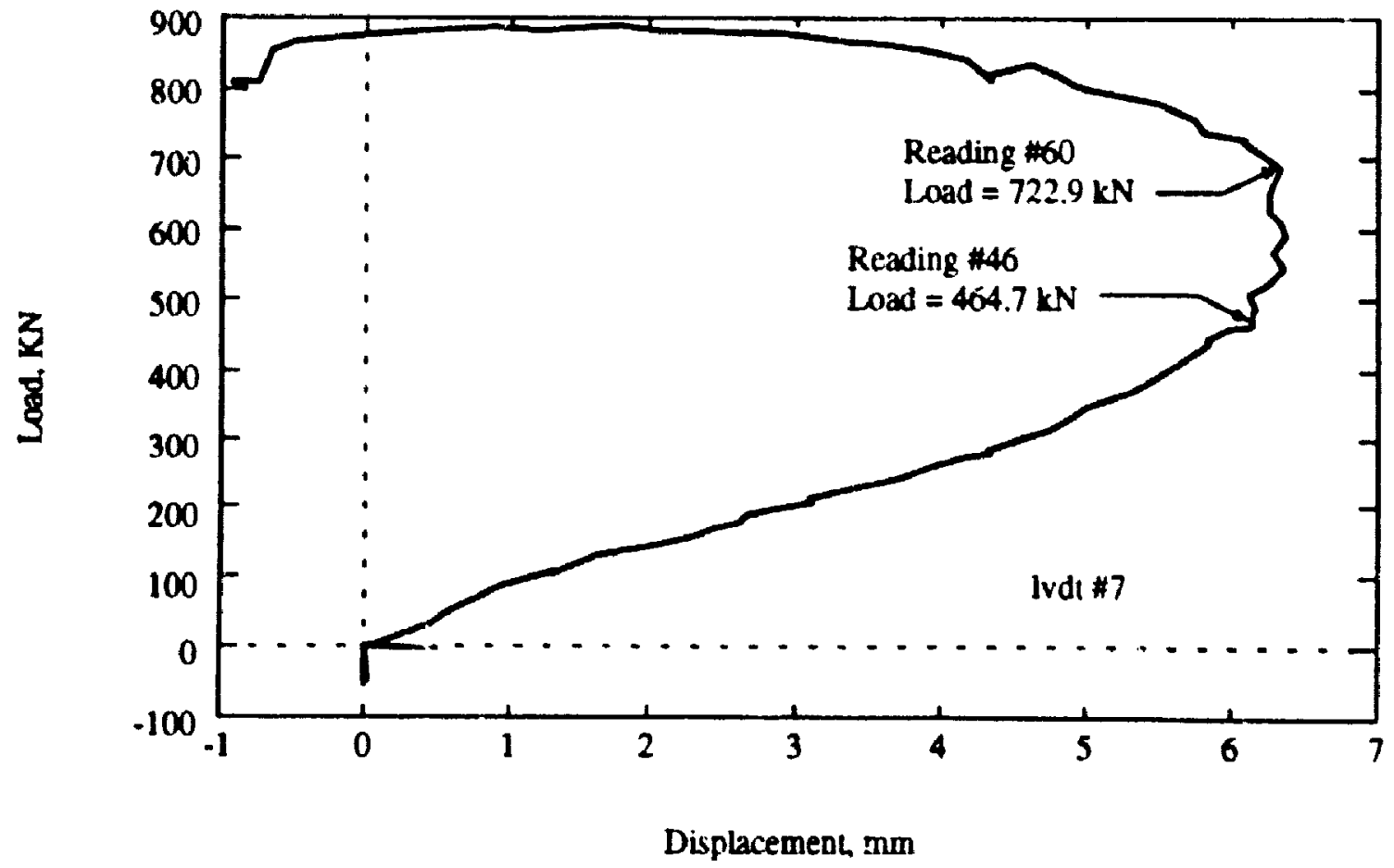

(b) Load vs. Maximum Displacement Curve at $0.5 \mathrm{~h}$

Figure 3.10 Load vs. Displacement Curves for WWF 18.50×273 (b) 


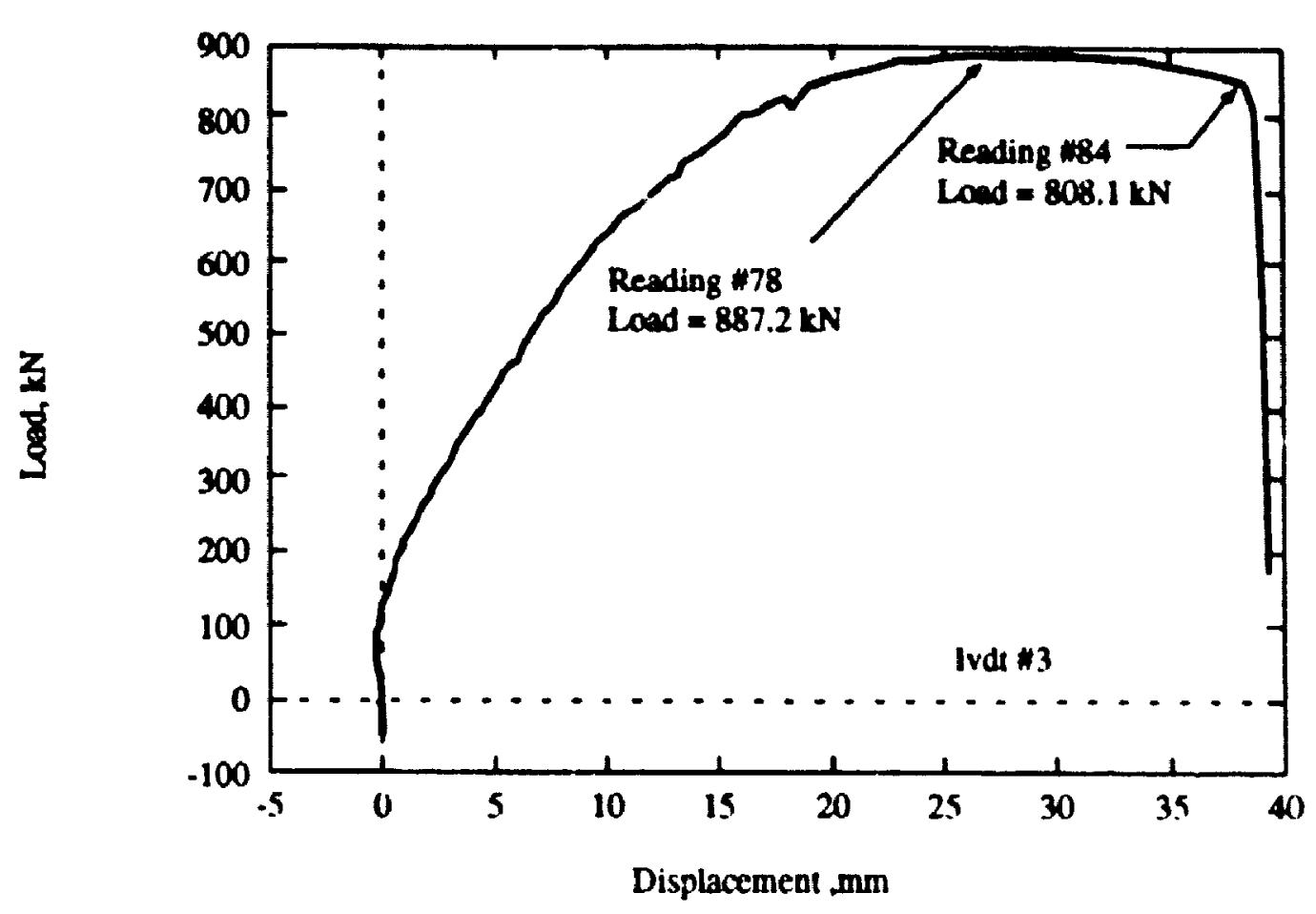

(c) Load vs. Displacement of Curve al $0.16 \mathrm{~h}$

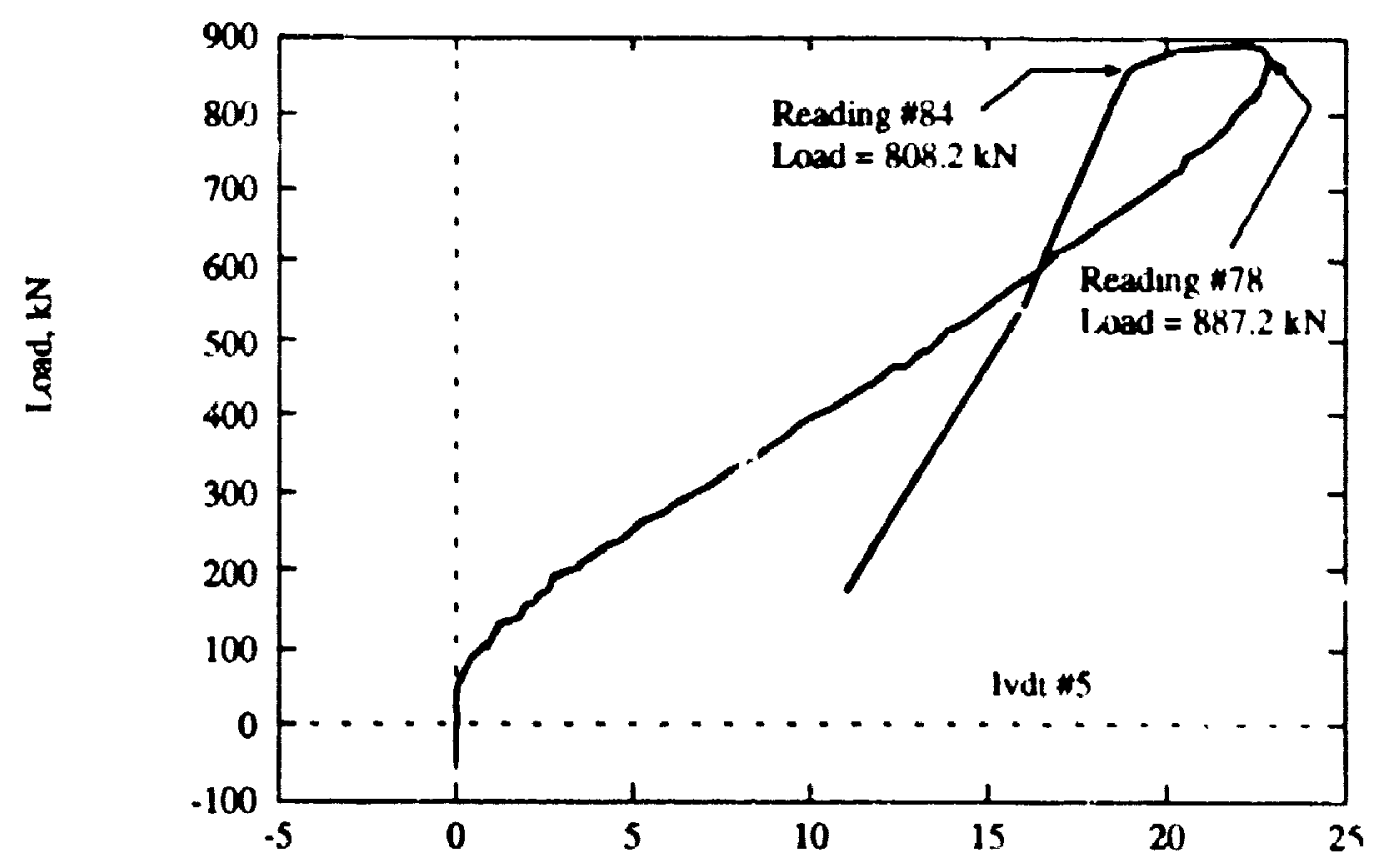

Displacement ,mm

(d) Load vs. Displacement Curve al $0.3 \mathrm{~h}$

Figure 3.10 (cont.) Load vs. Displacement Curves for WW7: i850) 273 (h) 

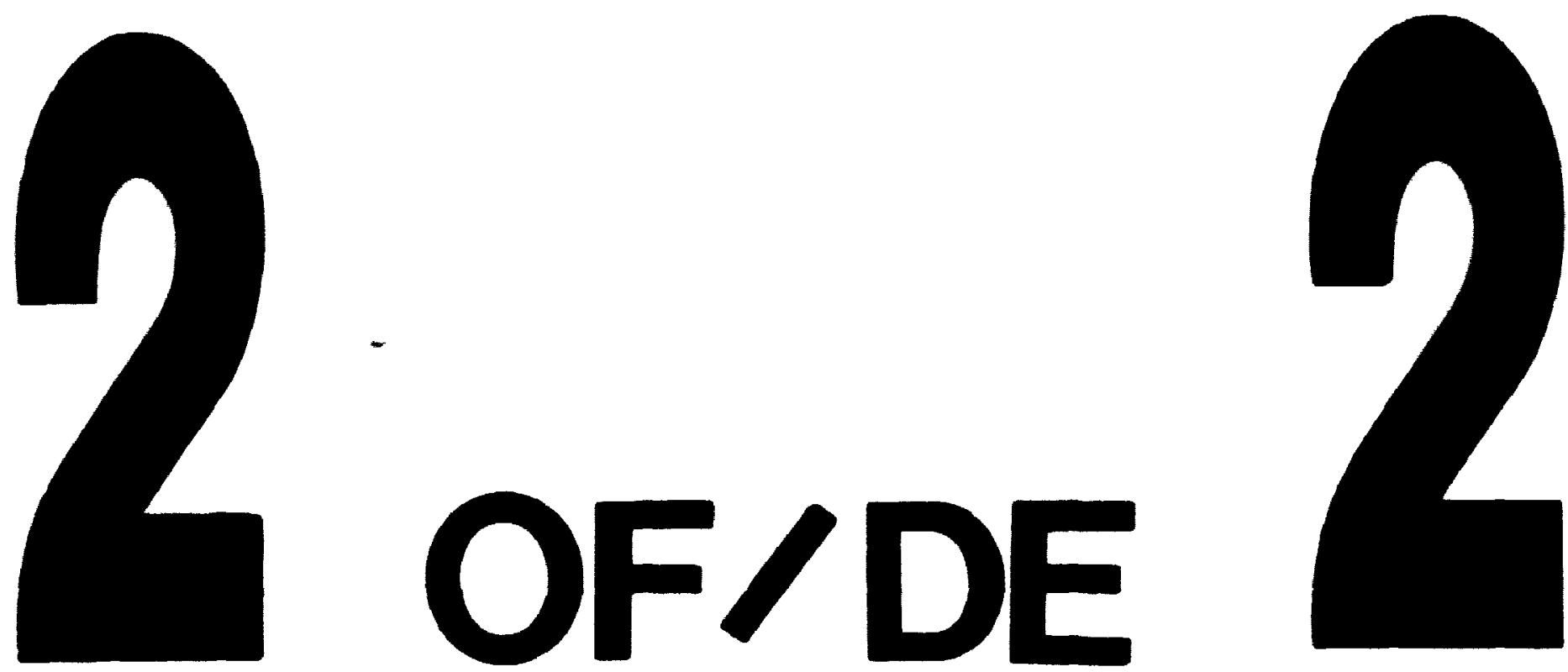

PM. 1 3' 2 × 4" PHOTOGAAPHIC MICROCOPY TARGET NBS 1010a ANSI/ISO \#2 EOUIVALENT

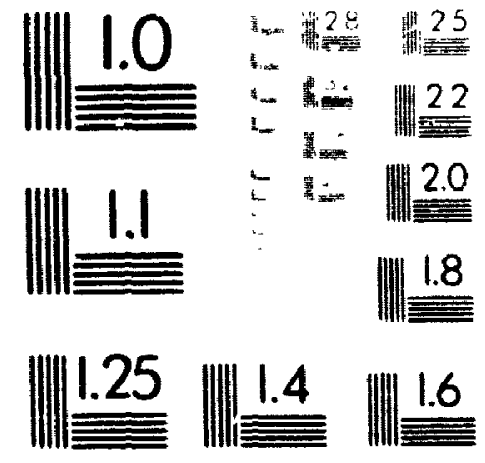

PRECISIONSM RESOLUTION TARGETS 


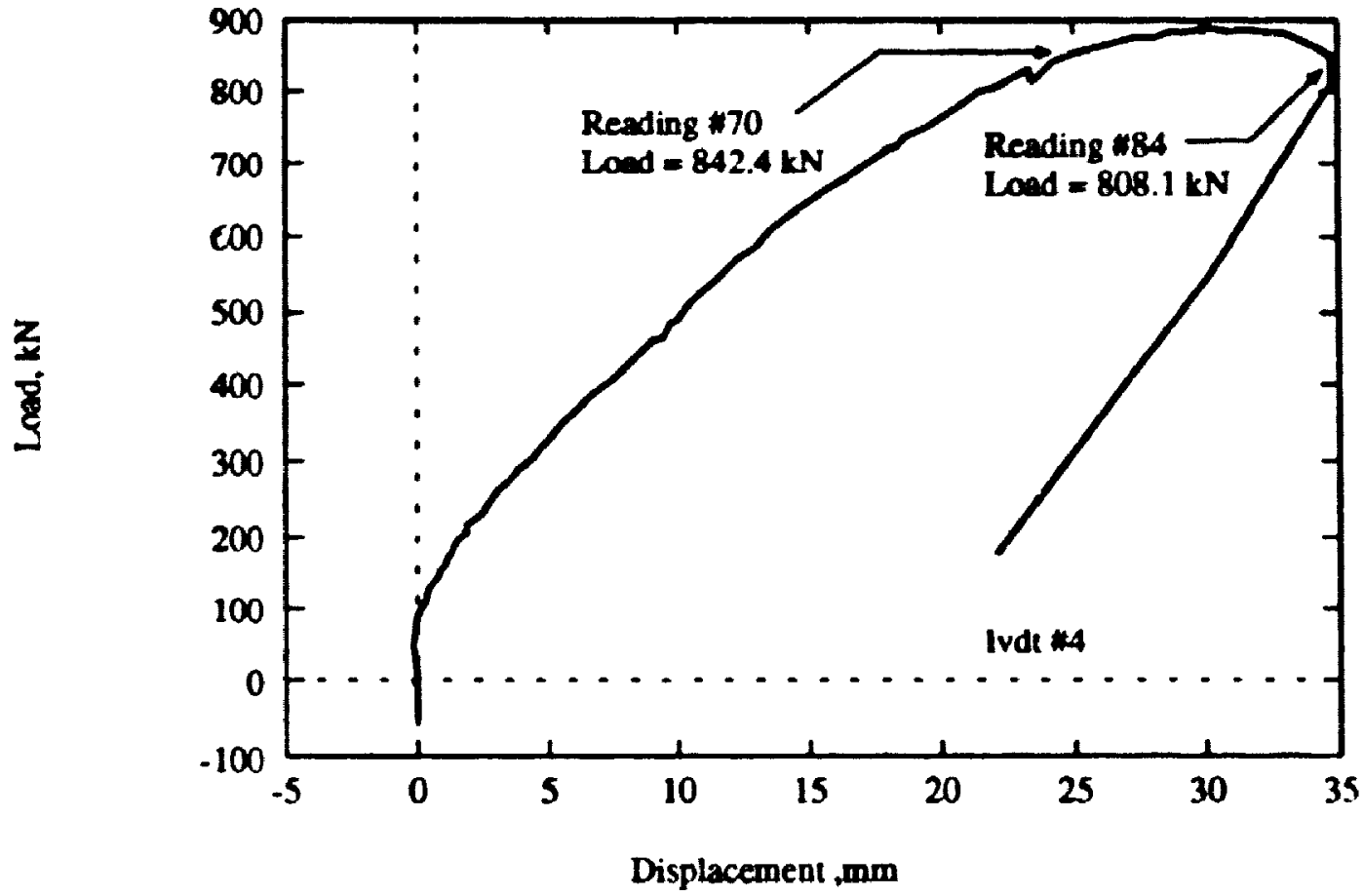

(e) Load vs. Displacement Curve at $0.2 \mathrm{~h}$

Figure 3.10(cont) Laad vs. Displacement Curves for WWF 1850×273 (b) 


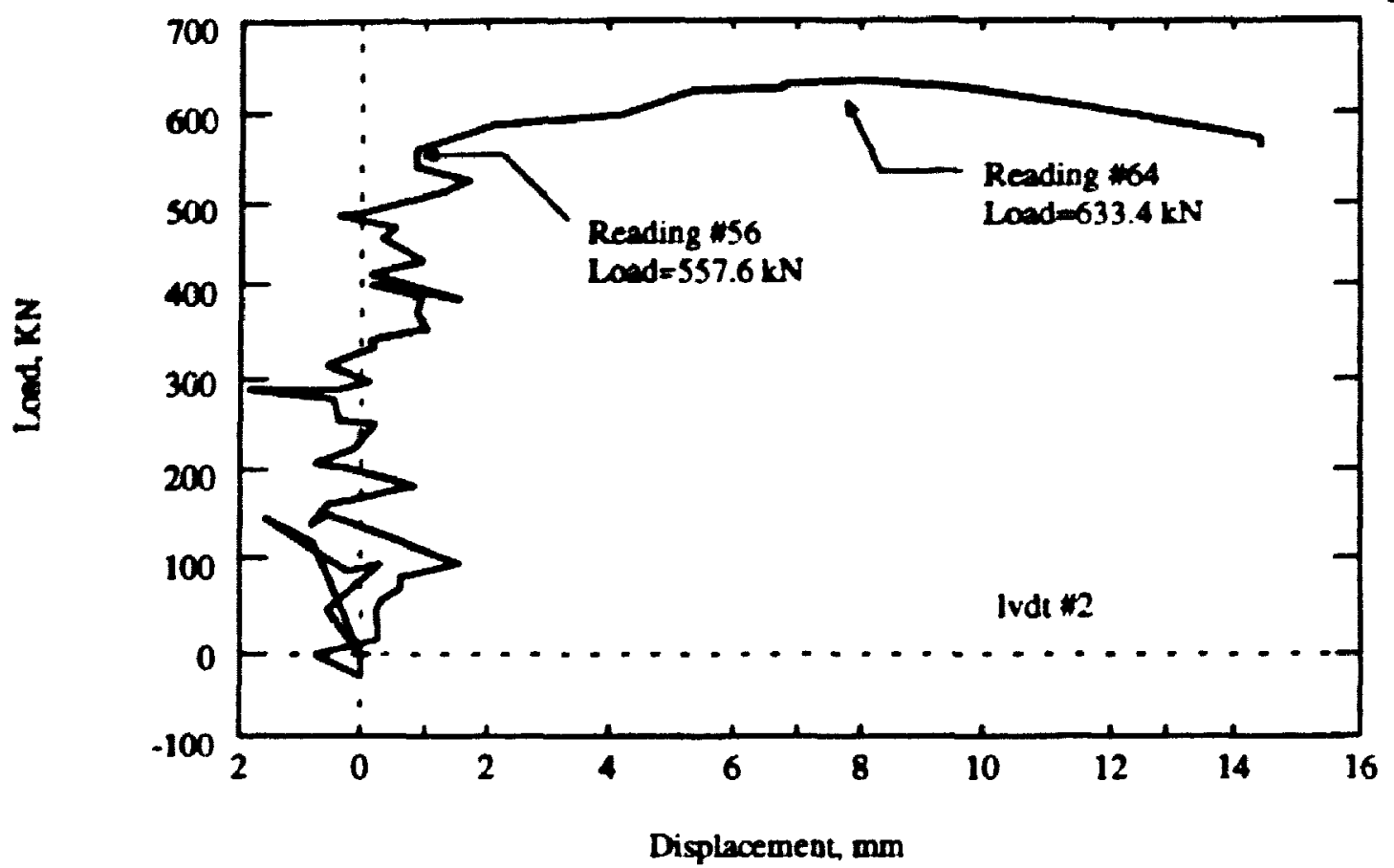

(a) Load vs. Maximum Displacement Curve in the Upper Fanel, (0.2b)

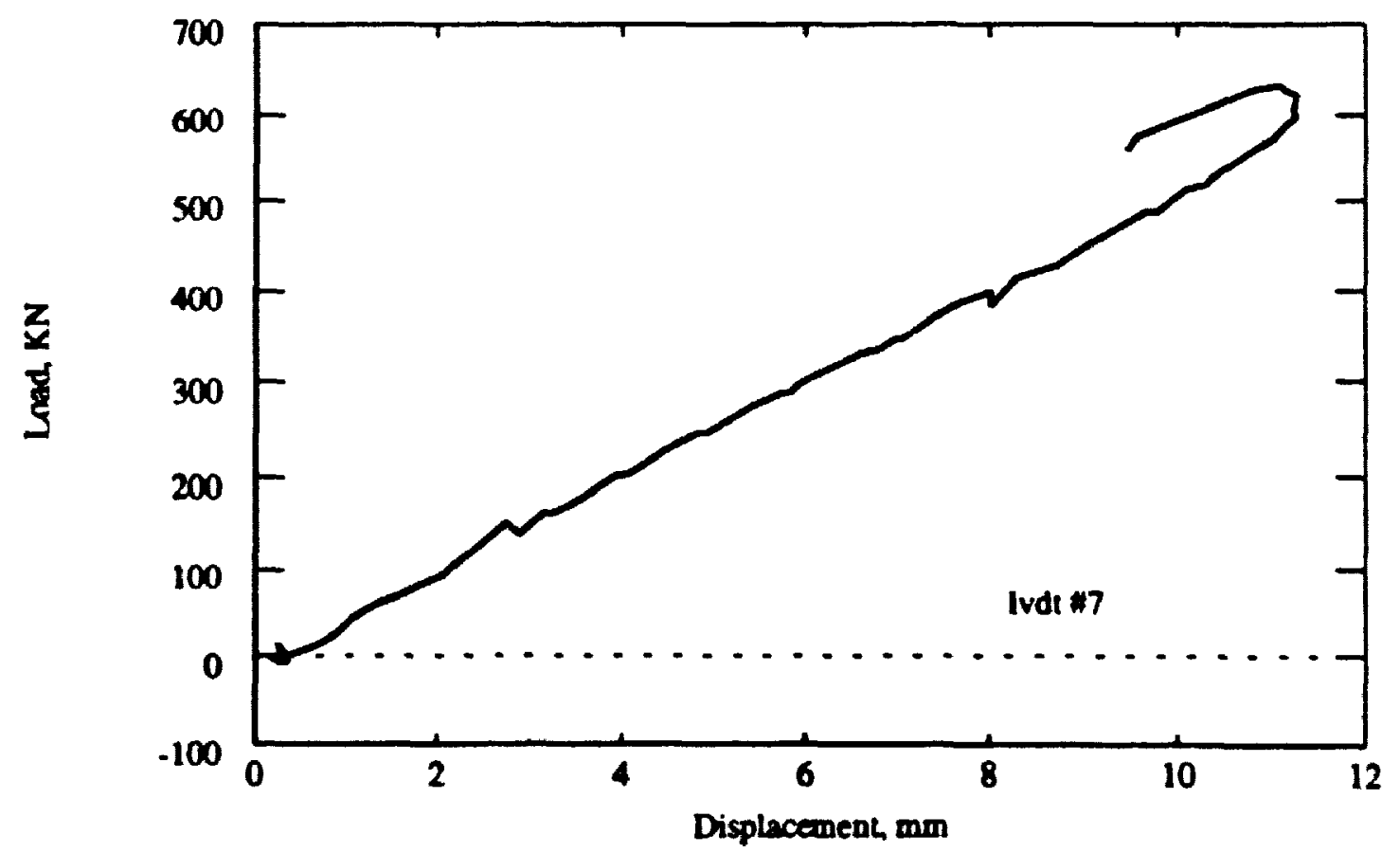

(b) Load vs. Maximum Displacement Curve in the Lower Panel, (0.8b)

Figure 3.11 Load vs. Displacemeat Curves for WWF 1850×257 
$\frac{3}{3}$

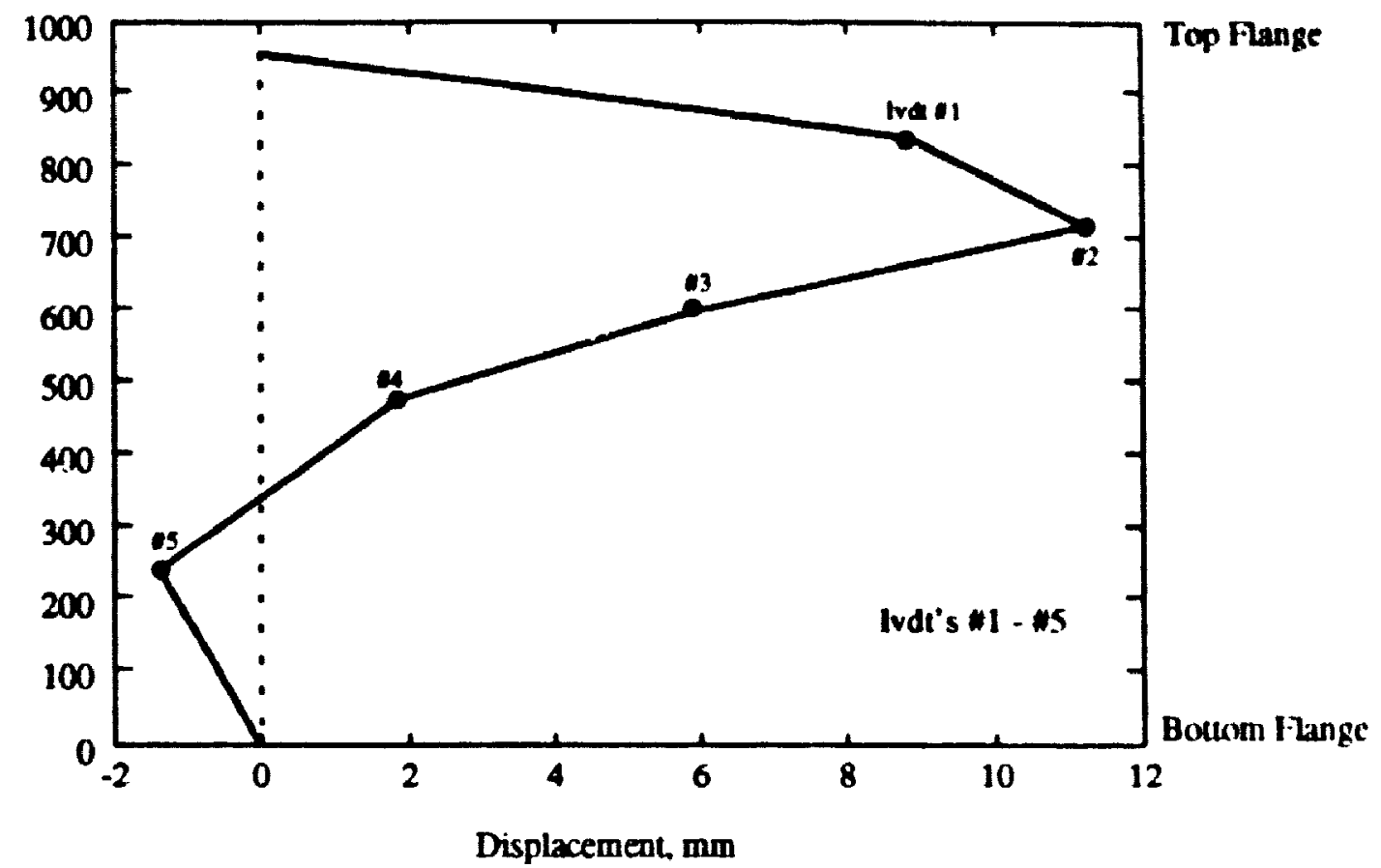

(a) Maximum Out-of-Plane Web Deformation at Centreline

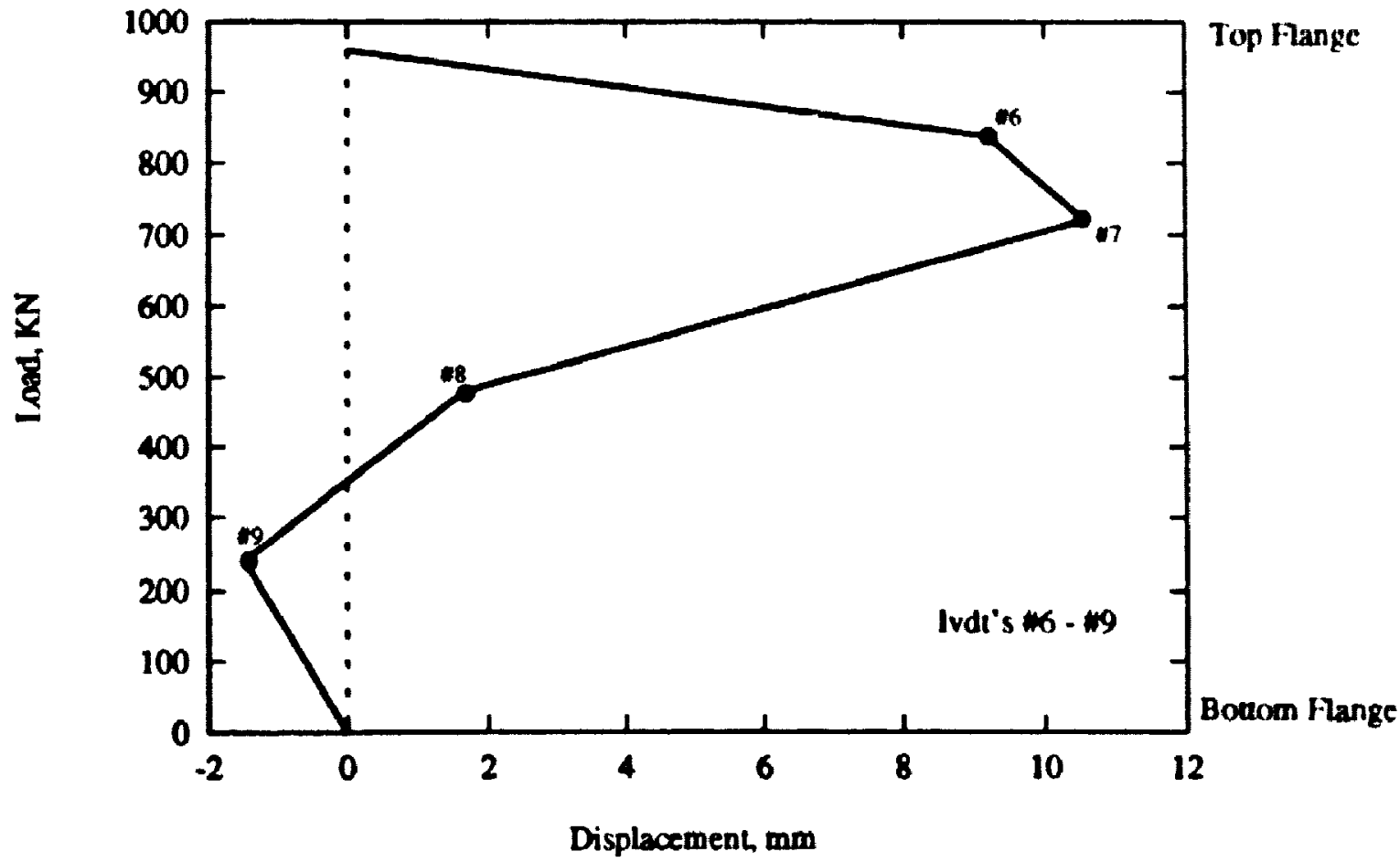

(b) Maximum Out-of-Plane Web Deformation at N/2

Figure 3.12 Out-or-Plane Web Deformation for WWF 985:71 (a) (single-welded), Interior Loed 


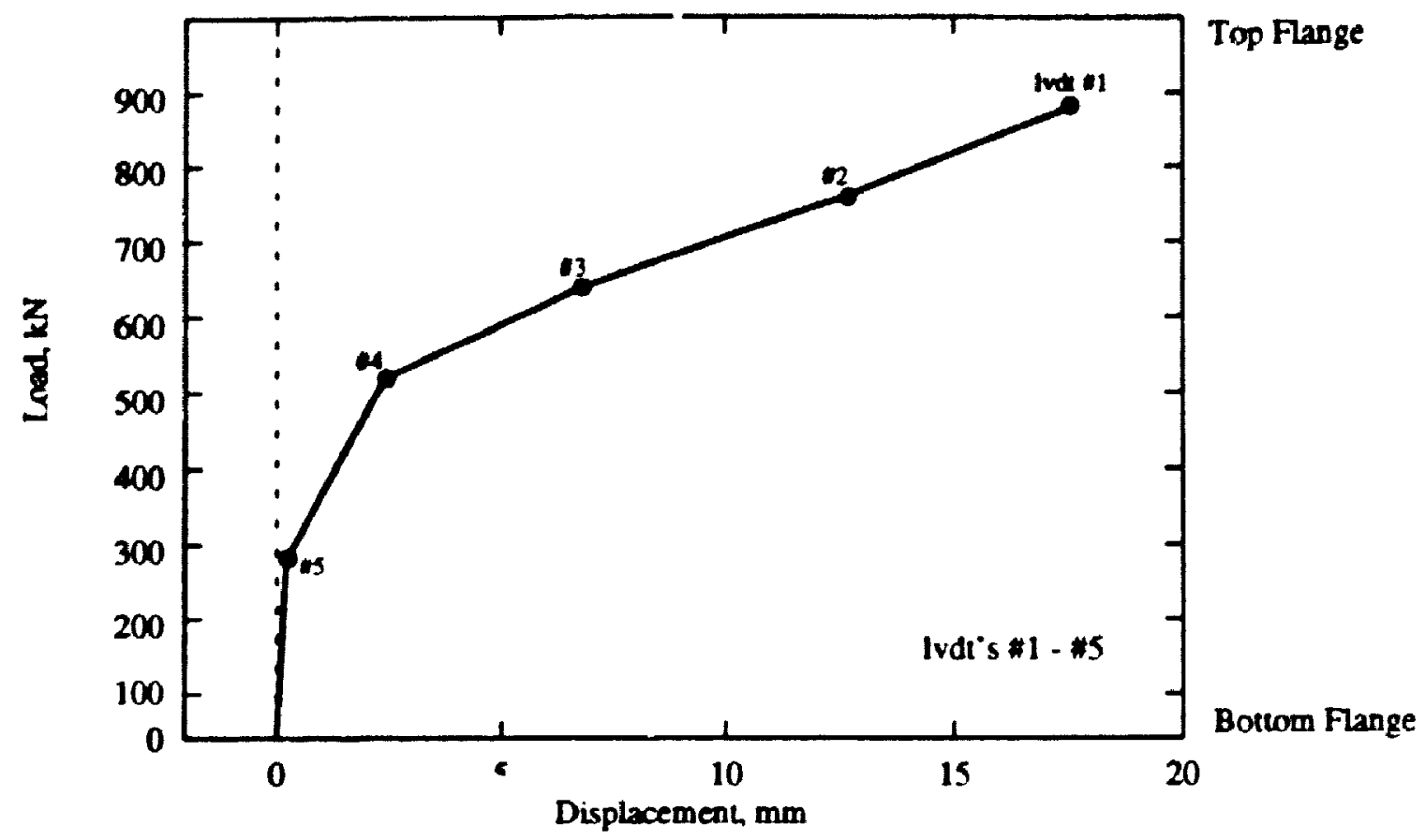

(a) Maximum Out-of-Plane Deformation at Centreline

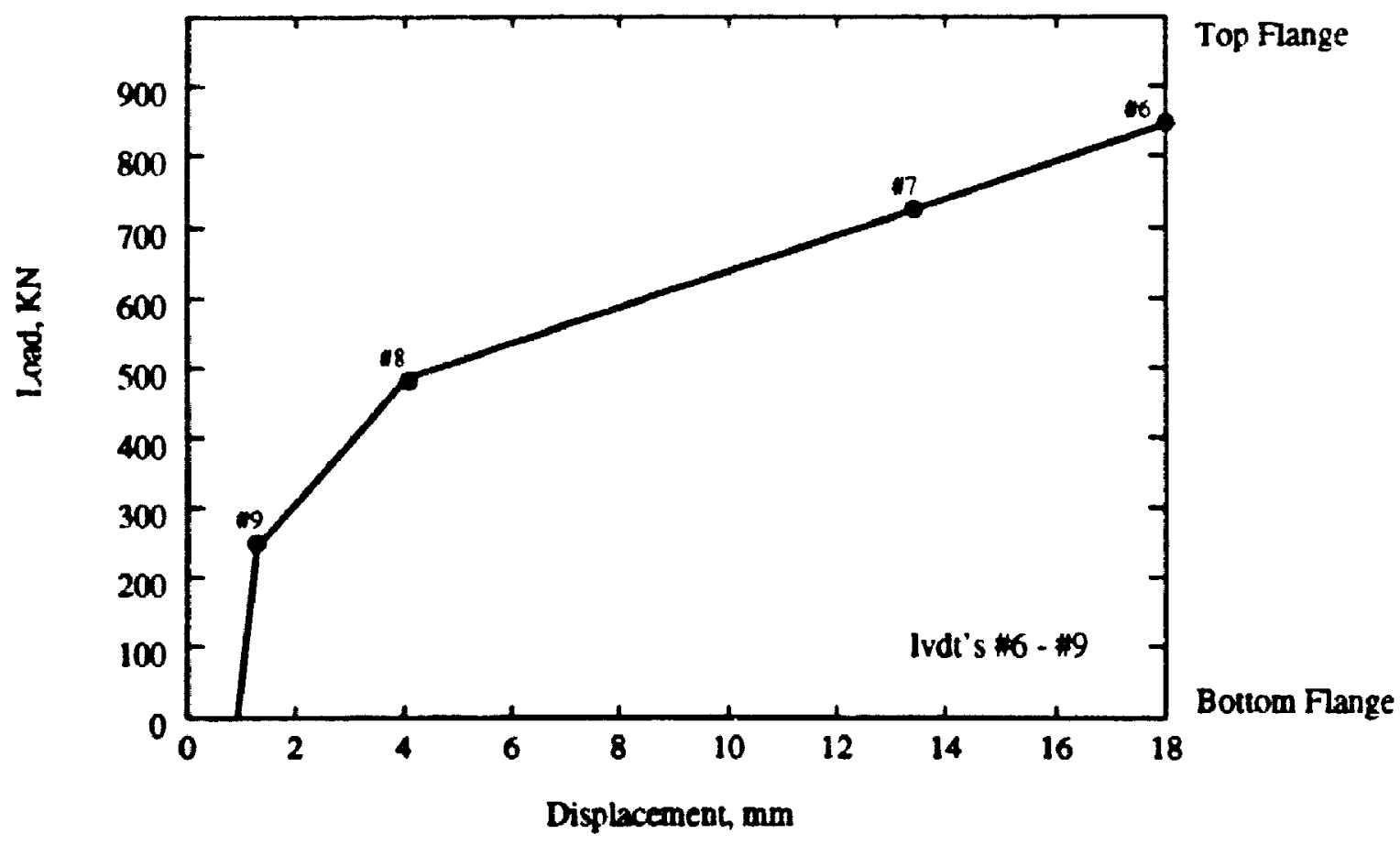

(b) Maximum Out-of-Plane Web Deformation a N/2

Figure 3.13 Out-of-Plane Web Deformation for WWF 985x71 (b) (double-weld), Interior Load 


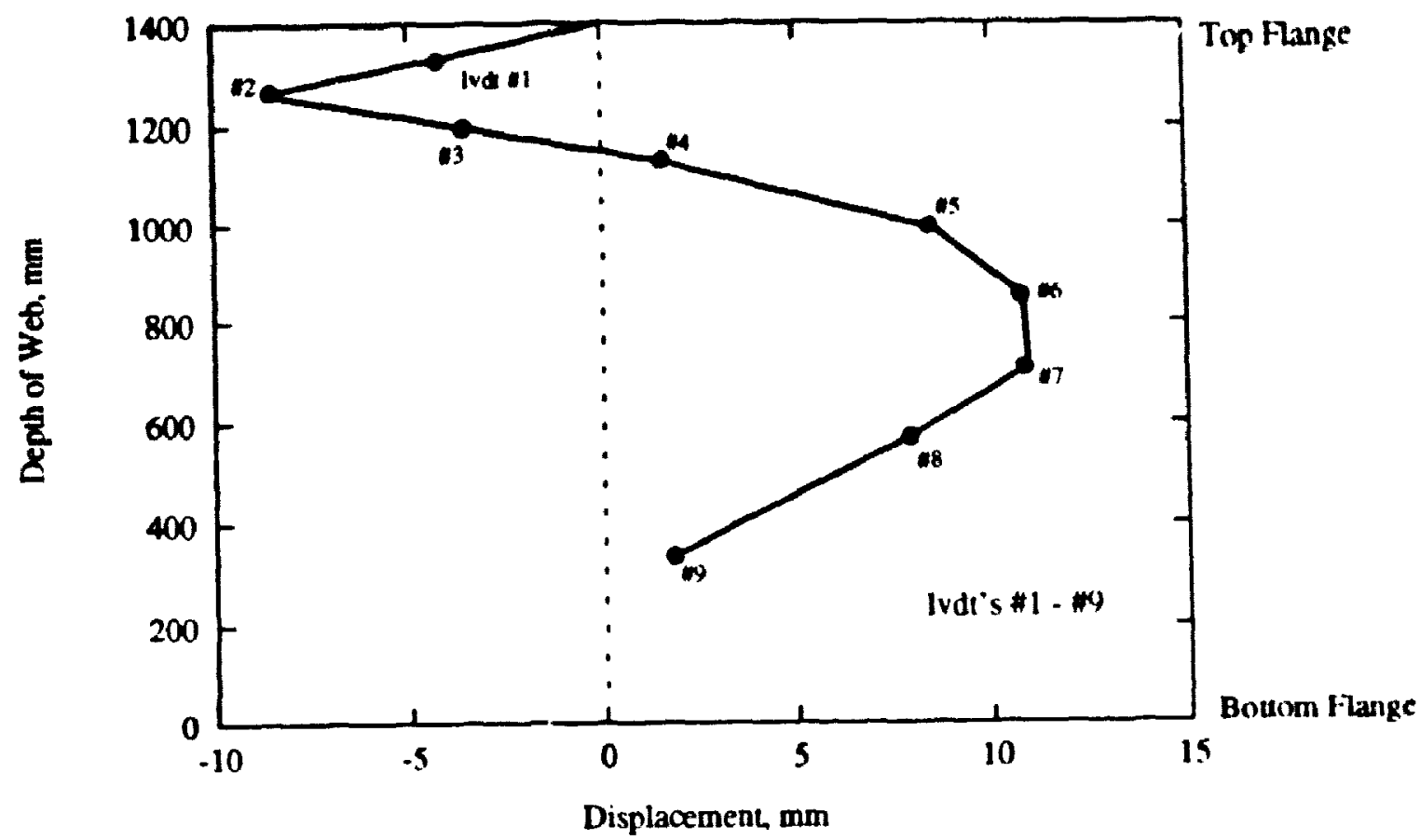

(a) Maximum Out of Plane Wcb Deformation at Centreline

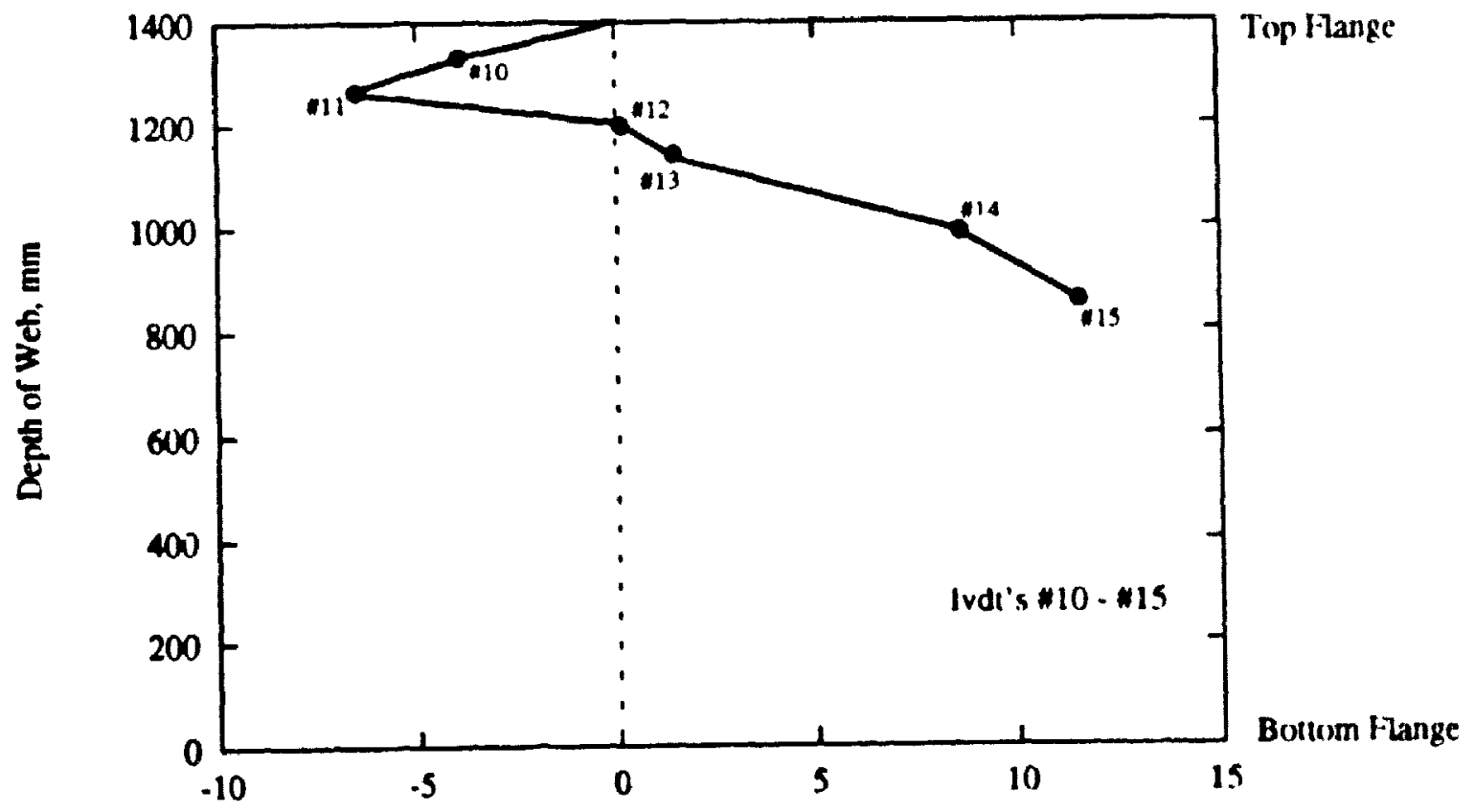

Displacement $\mathrm{mm}$

(b) Maximum Out of Plane Web Deformation at N/2

Figure 3.14 Out-of-Plane Web Deformation for WWT: 1450)247 


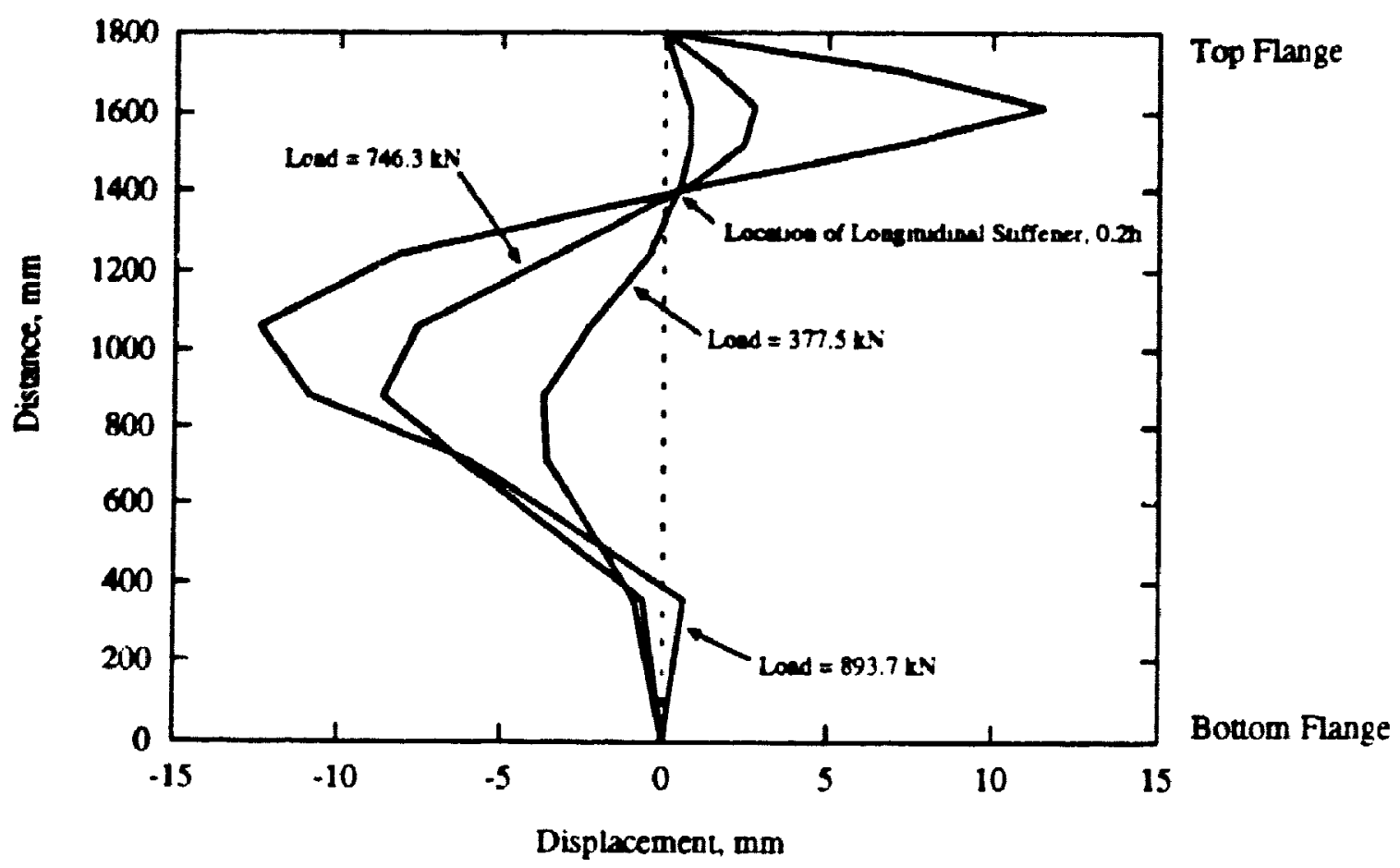

(a) Centreline Web Displacements at Different Load Levels

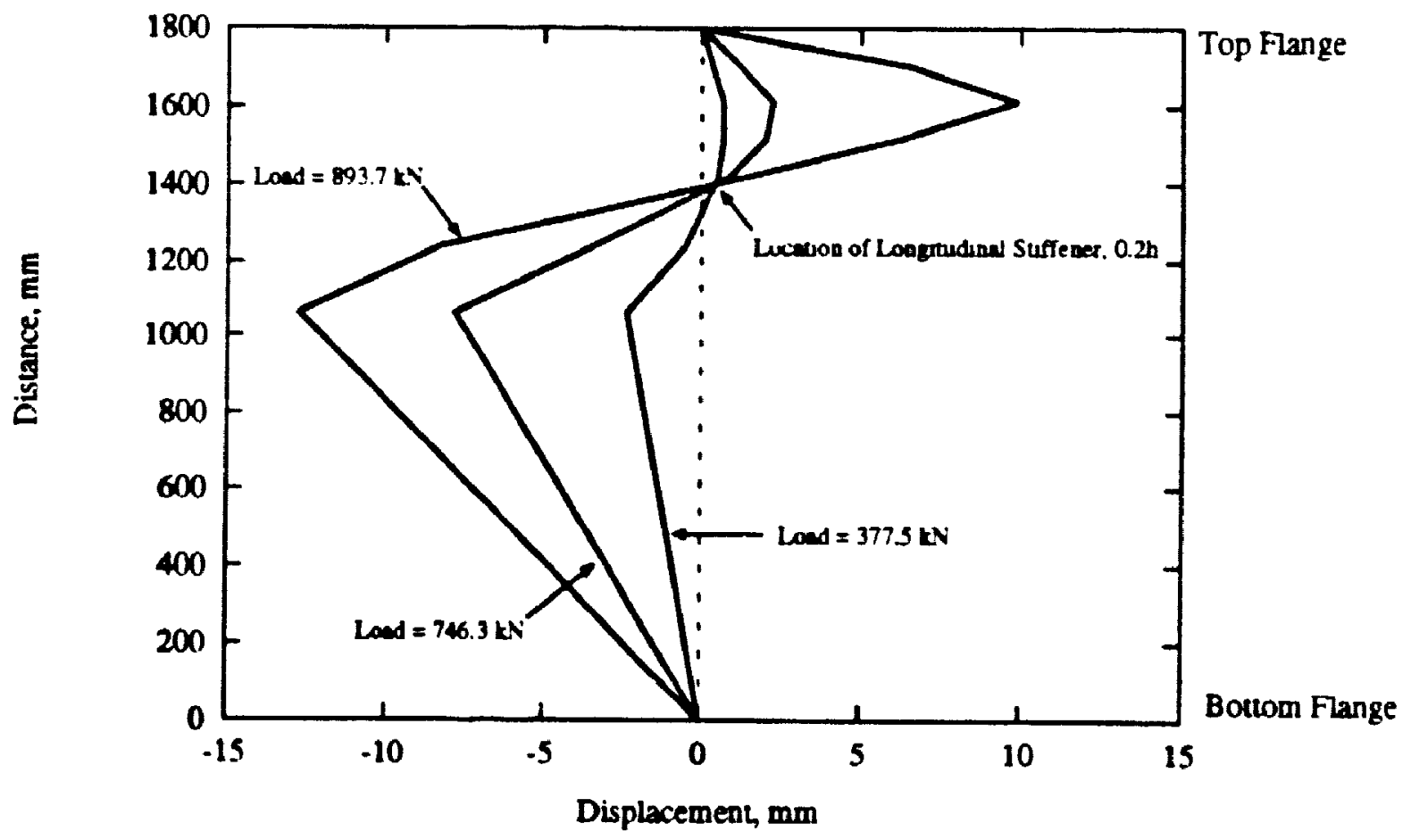

(b) Web Displacements at N/2 at Different Loed Levels

Figure 3.15 Out-or-Plane Web Deformations for WWF $1850 \times 273$ (a) 


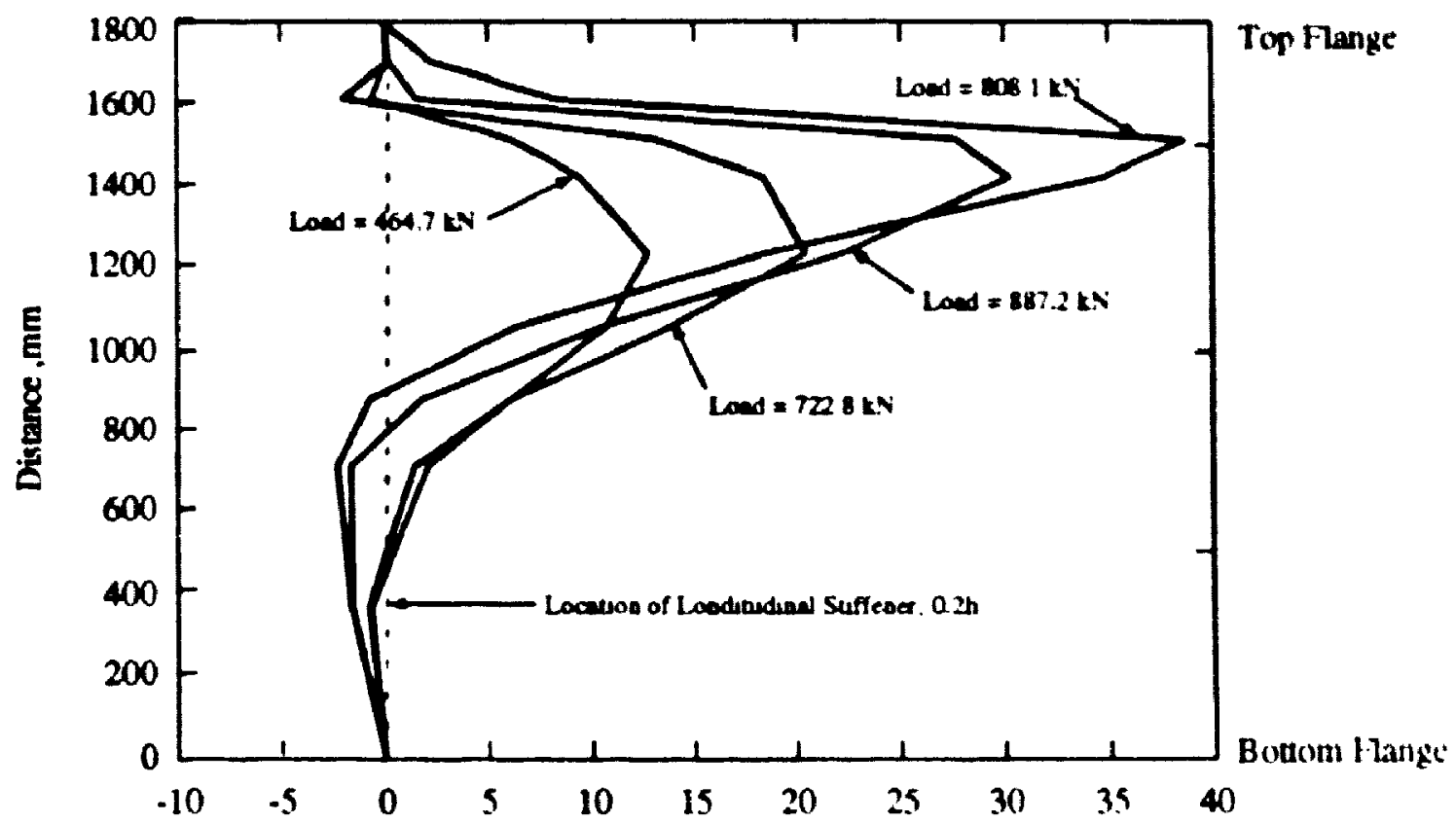

Displacement mm

(a) Centreline Web Displacements at Different Load Levels

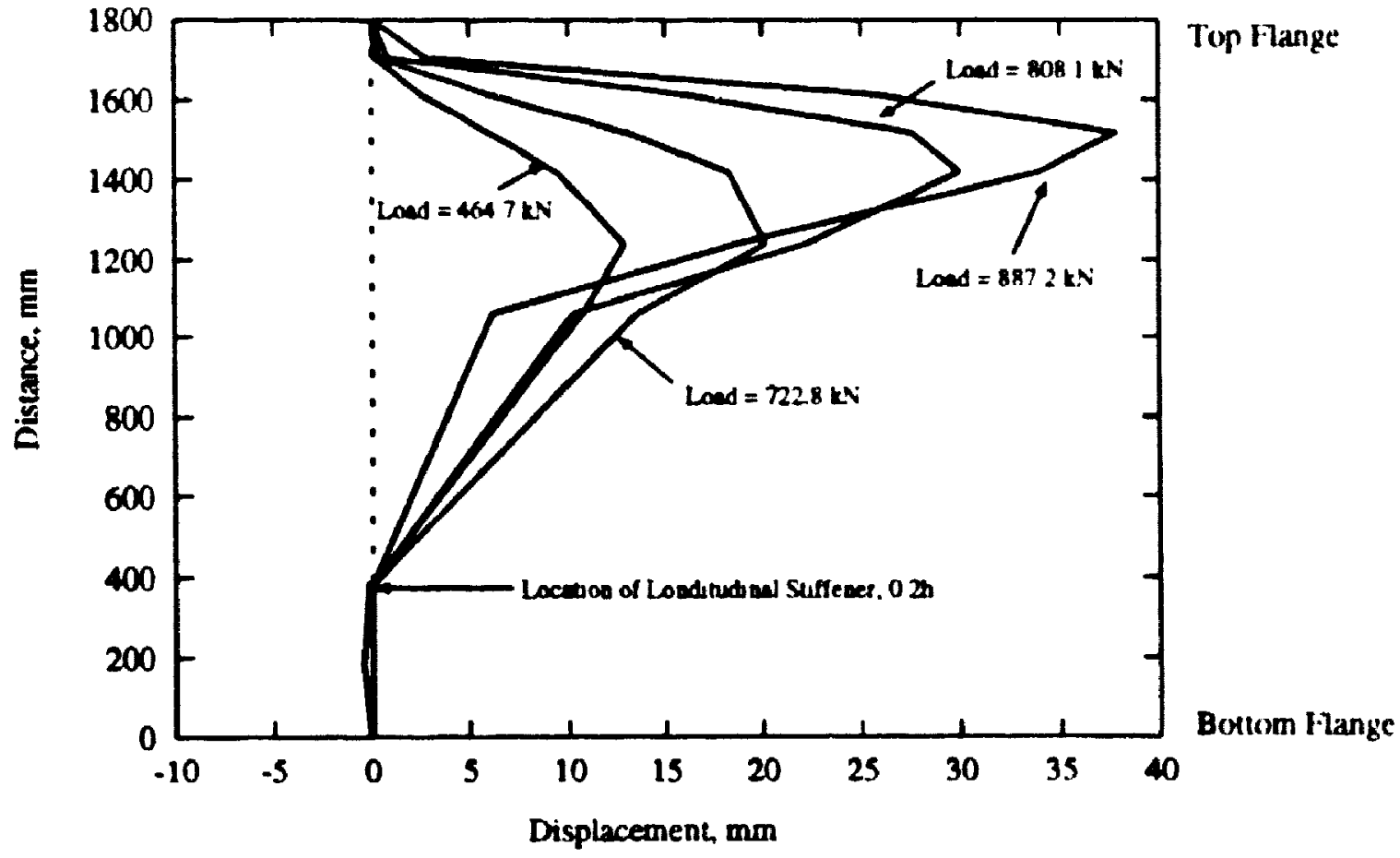

(b) Web Displacement at N/2 a Different Law Levels

Figure 3.16 Out-of.Plane Web Deformation for WWF $1850 \times 273$ (b) 


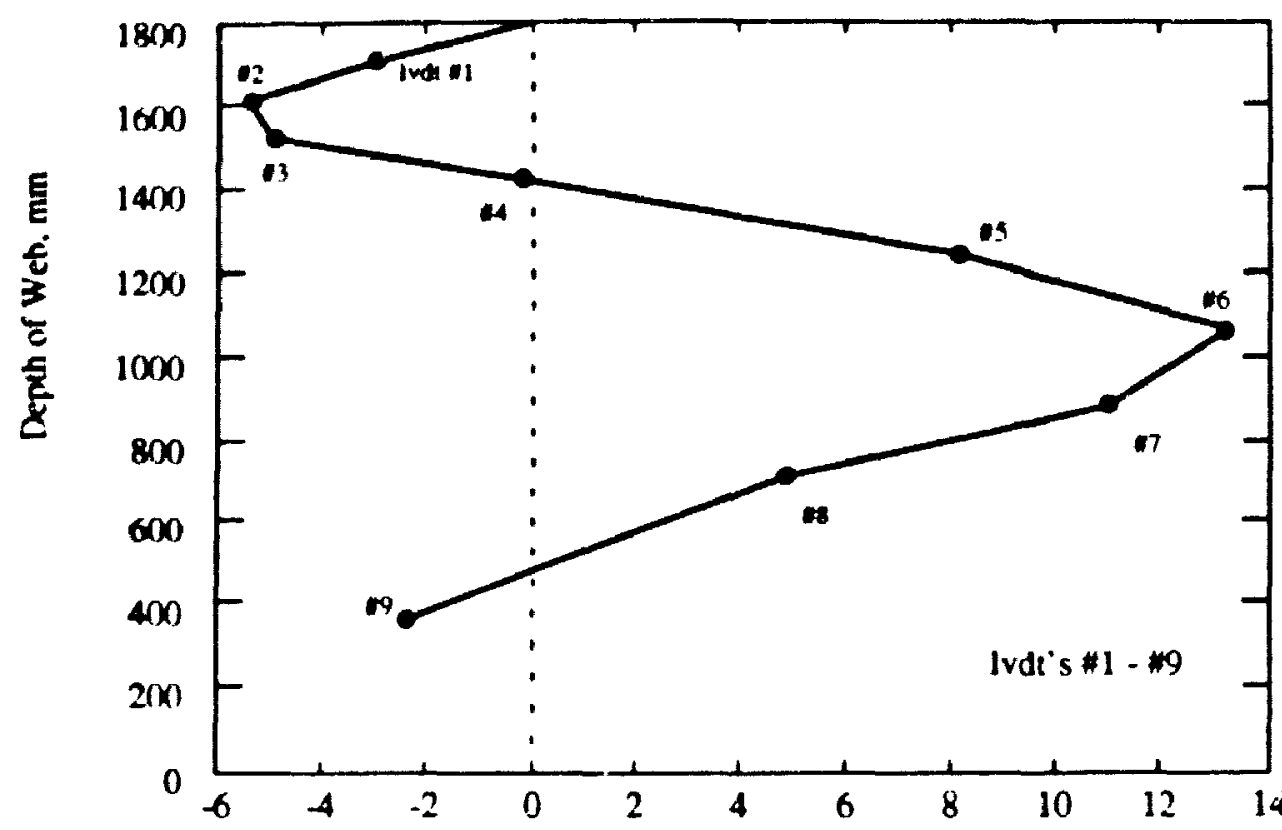

Top Flange

Bottom Flange

Displacement. mm

(a) Maximum Out of Plane Deformaunn at Centreline

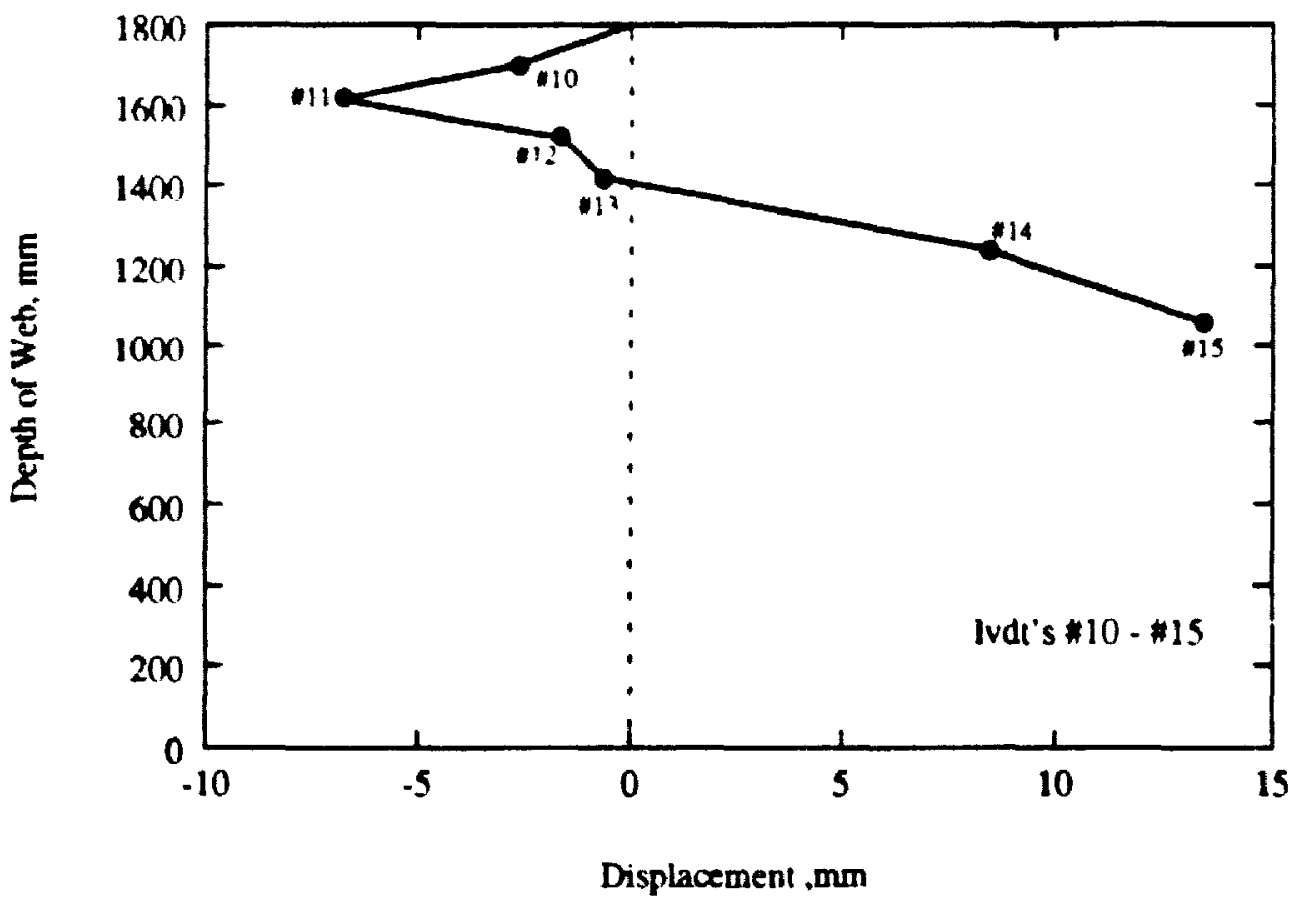

Top Flange

Bottom Flange

(b) Maximum Ovt of Plane Deformation at N/2

Figure 3.17 Oul-of-Plane Keb Deformation for WUF 1850x257 

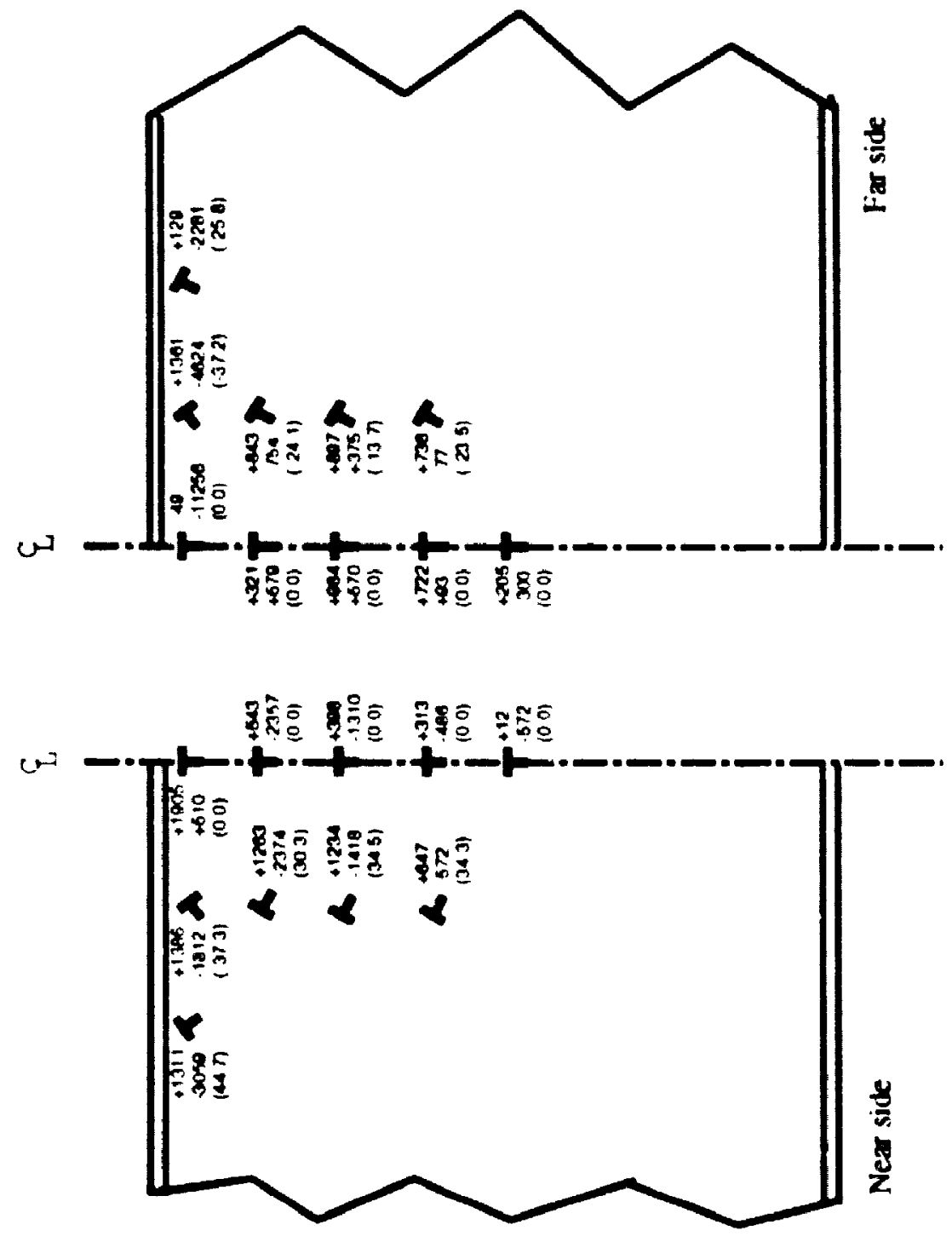

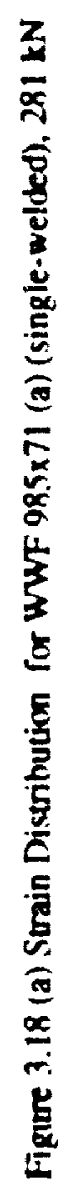




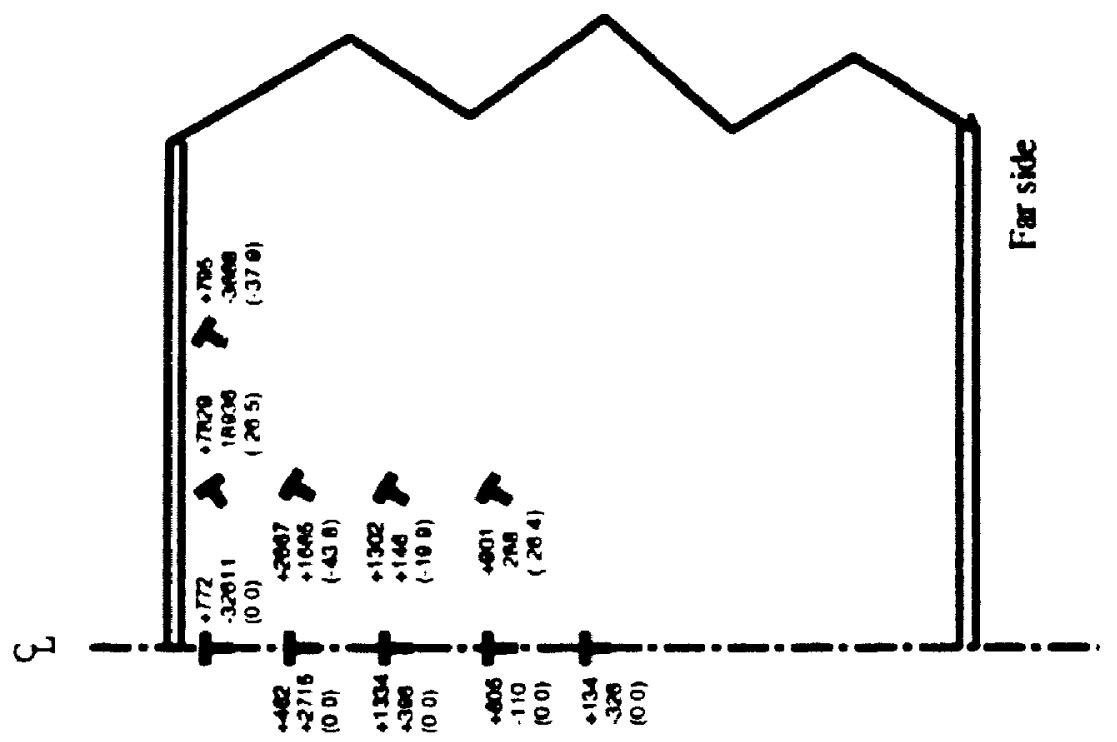

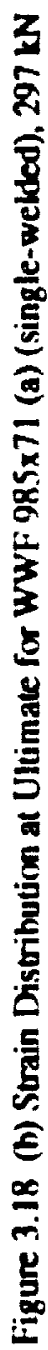




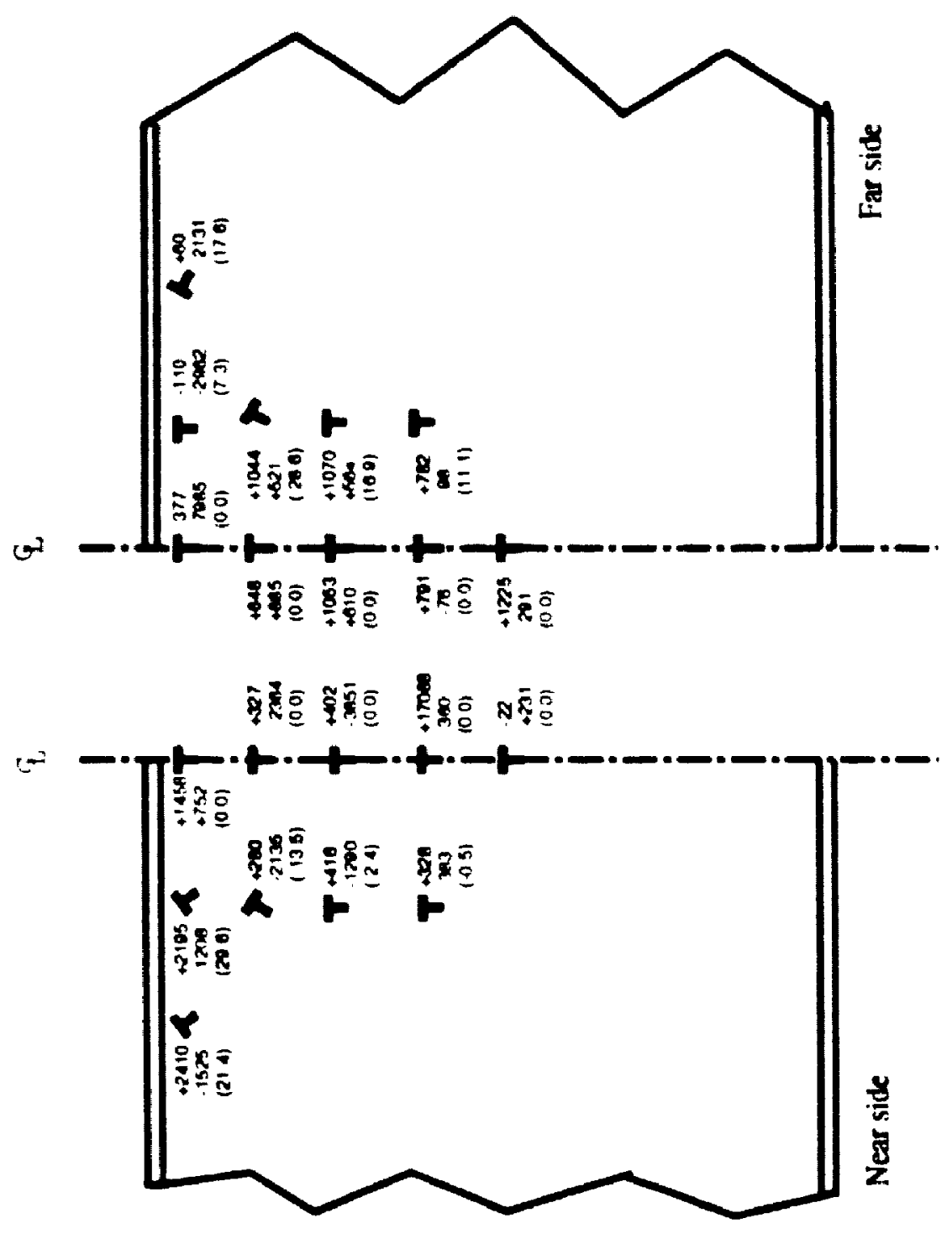

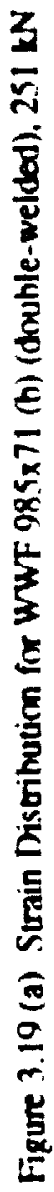




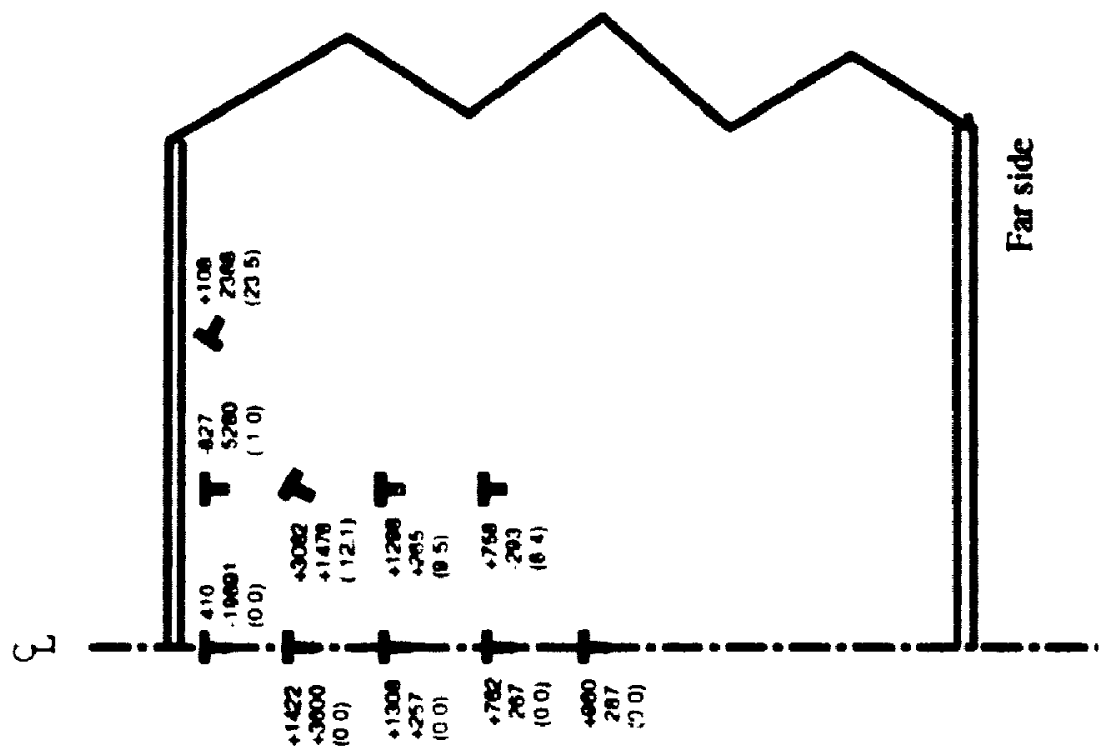

产 


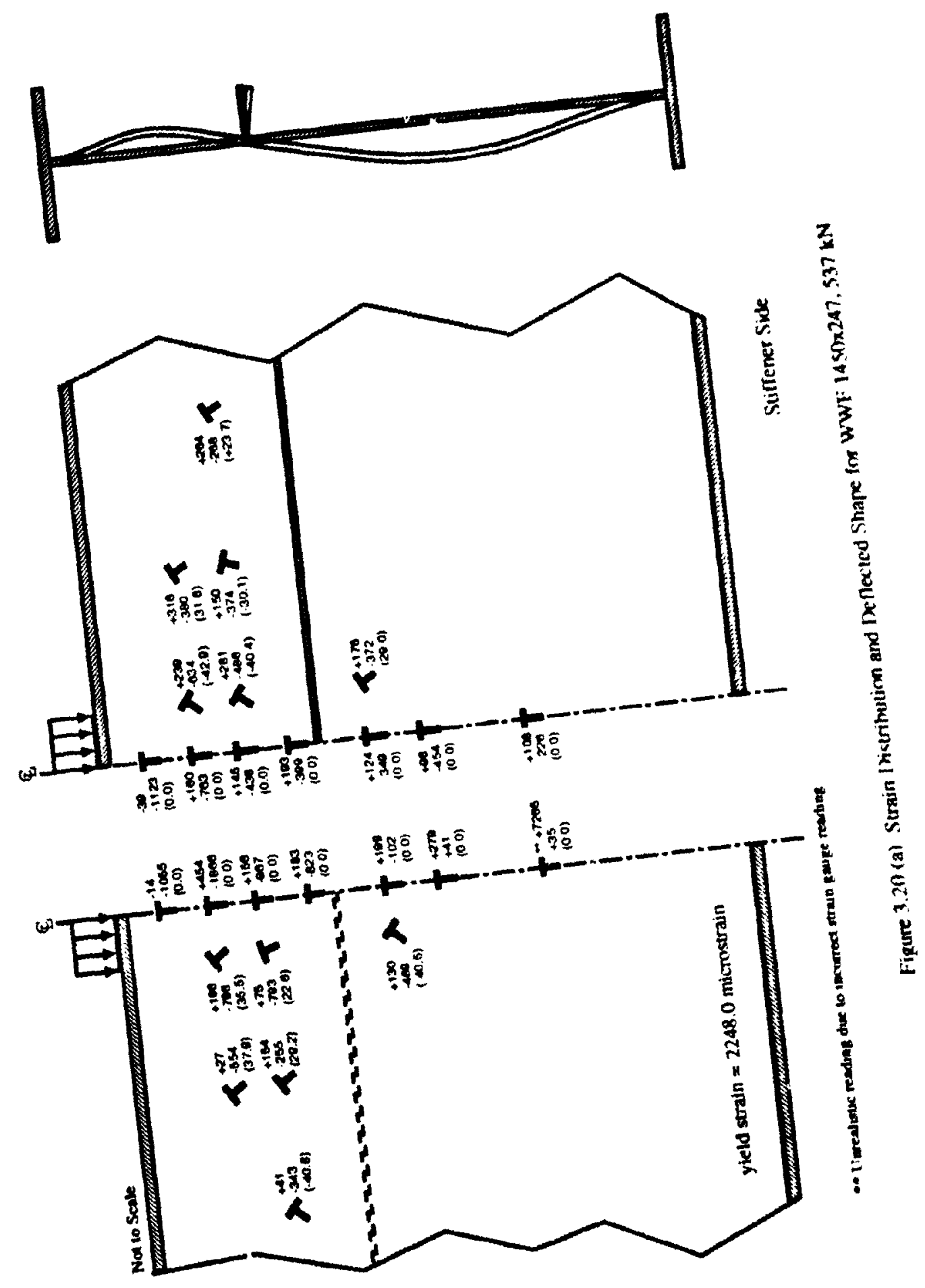



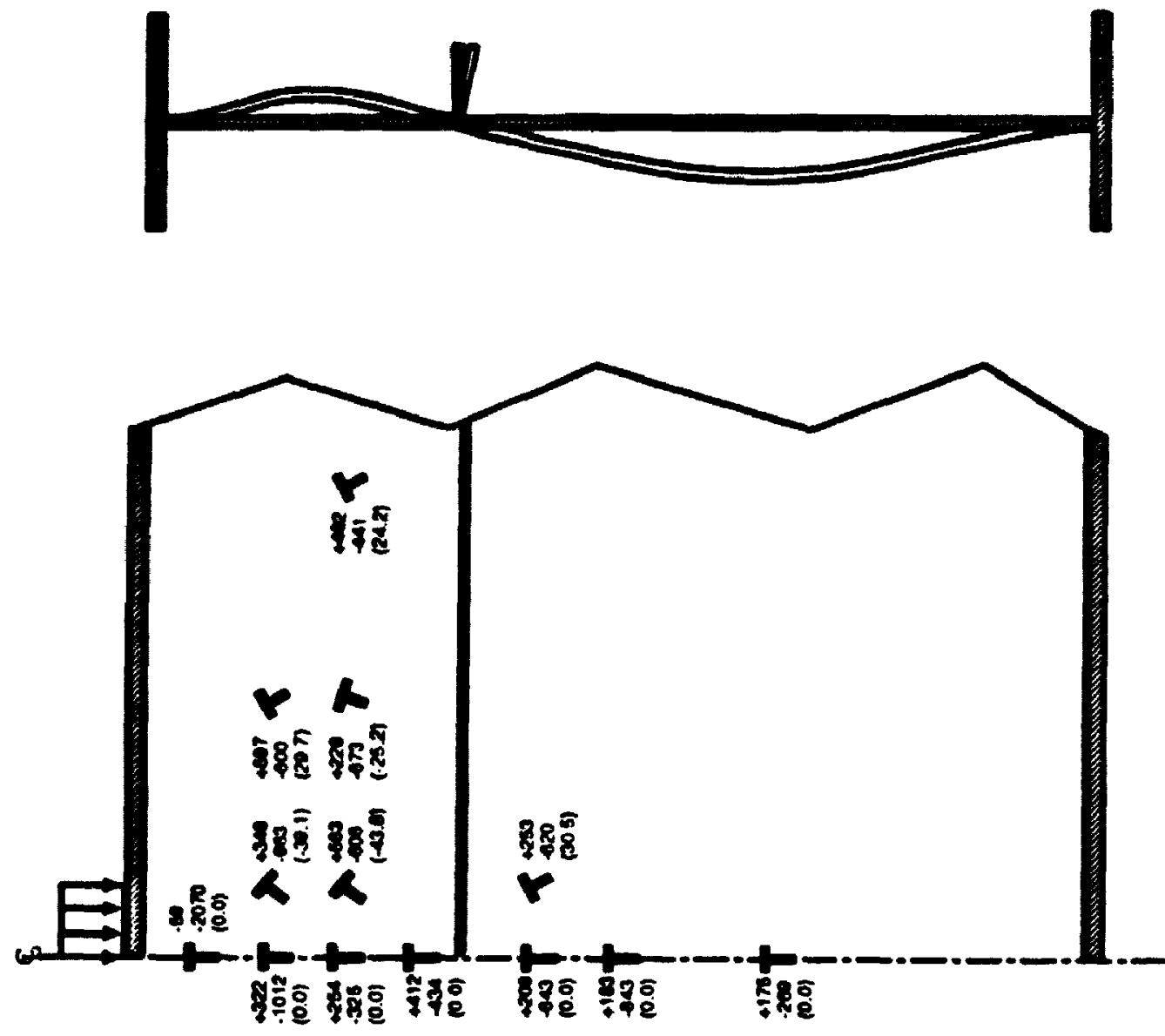

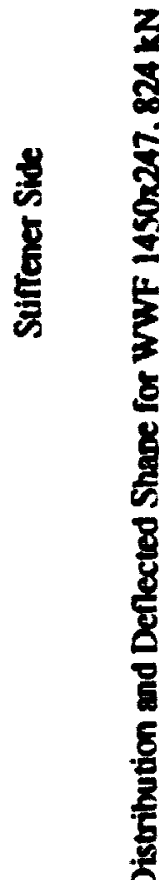

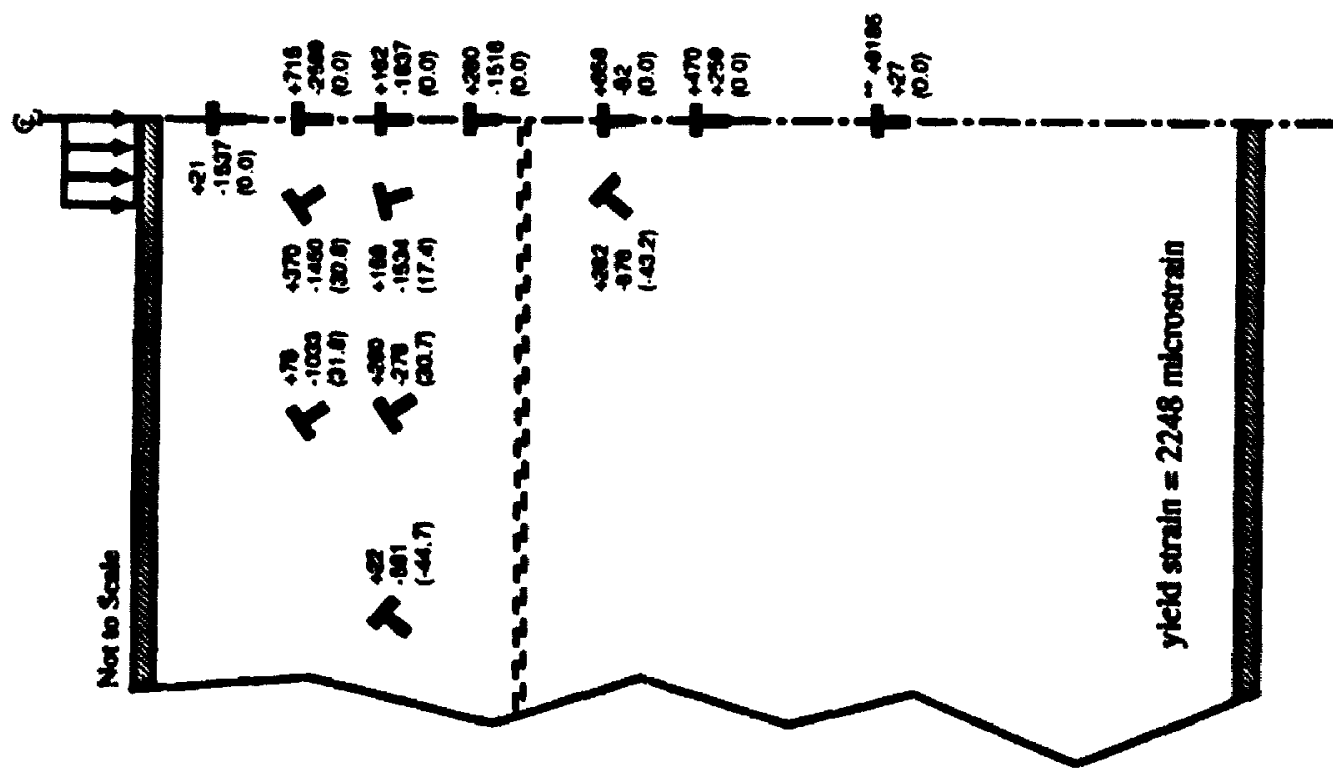

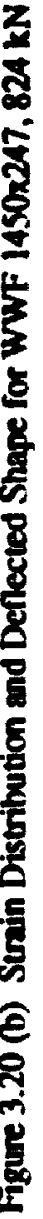




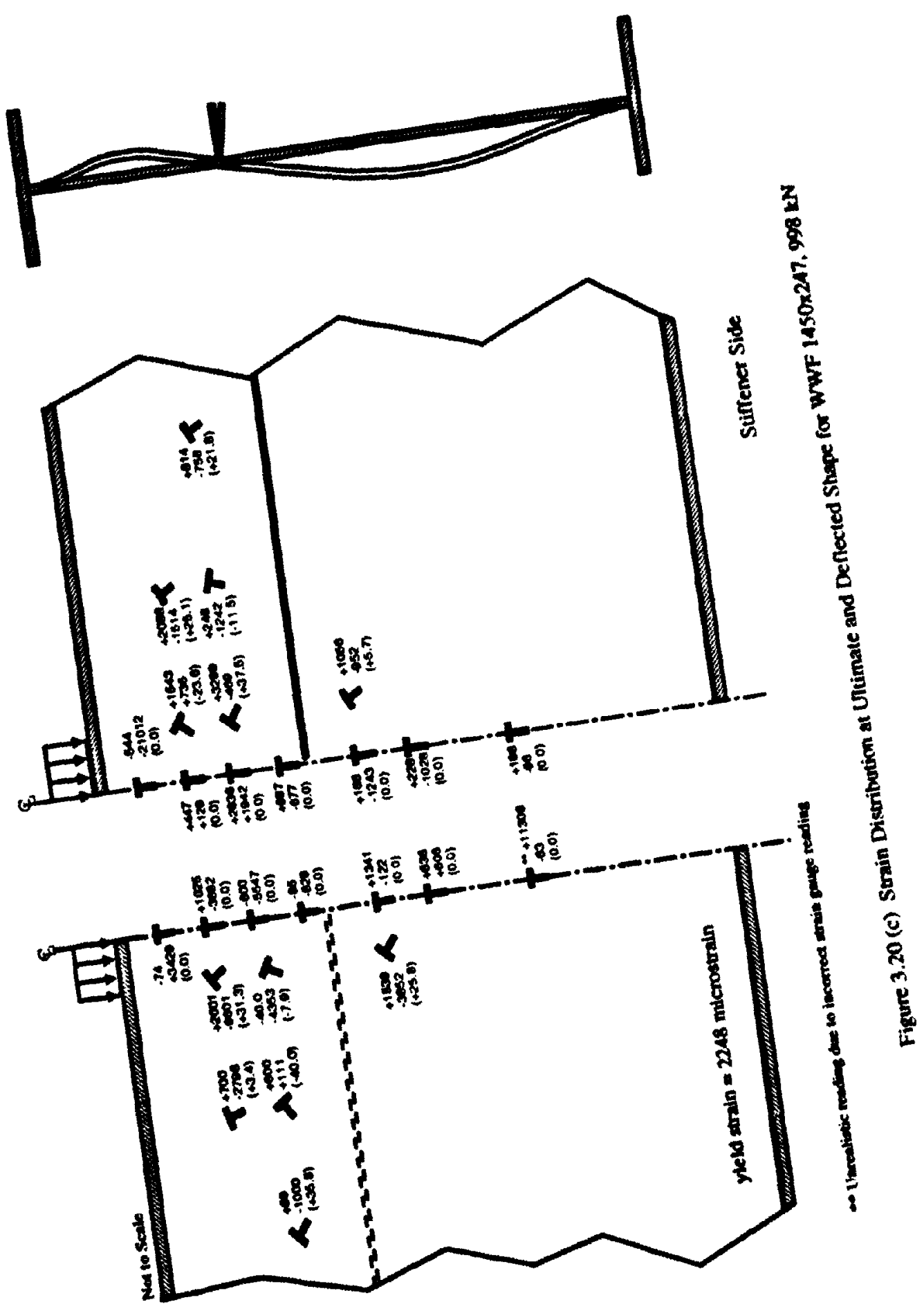



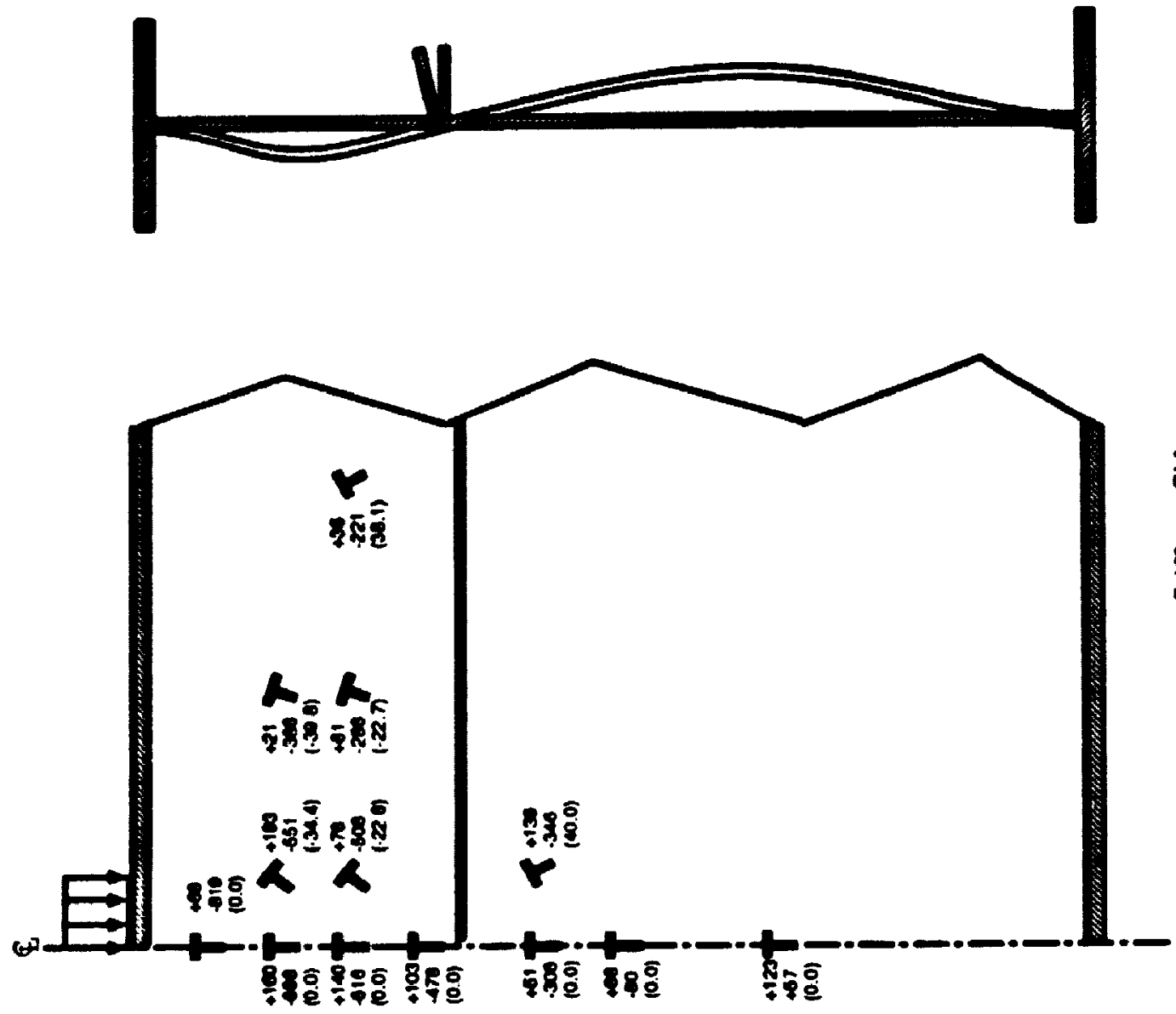

2

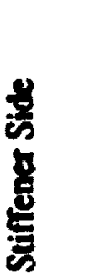

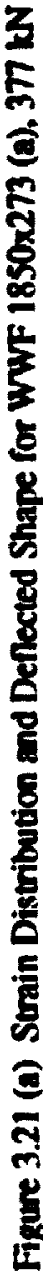

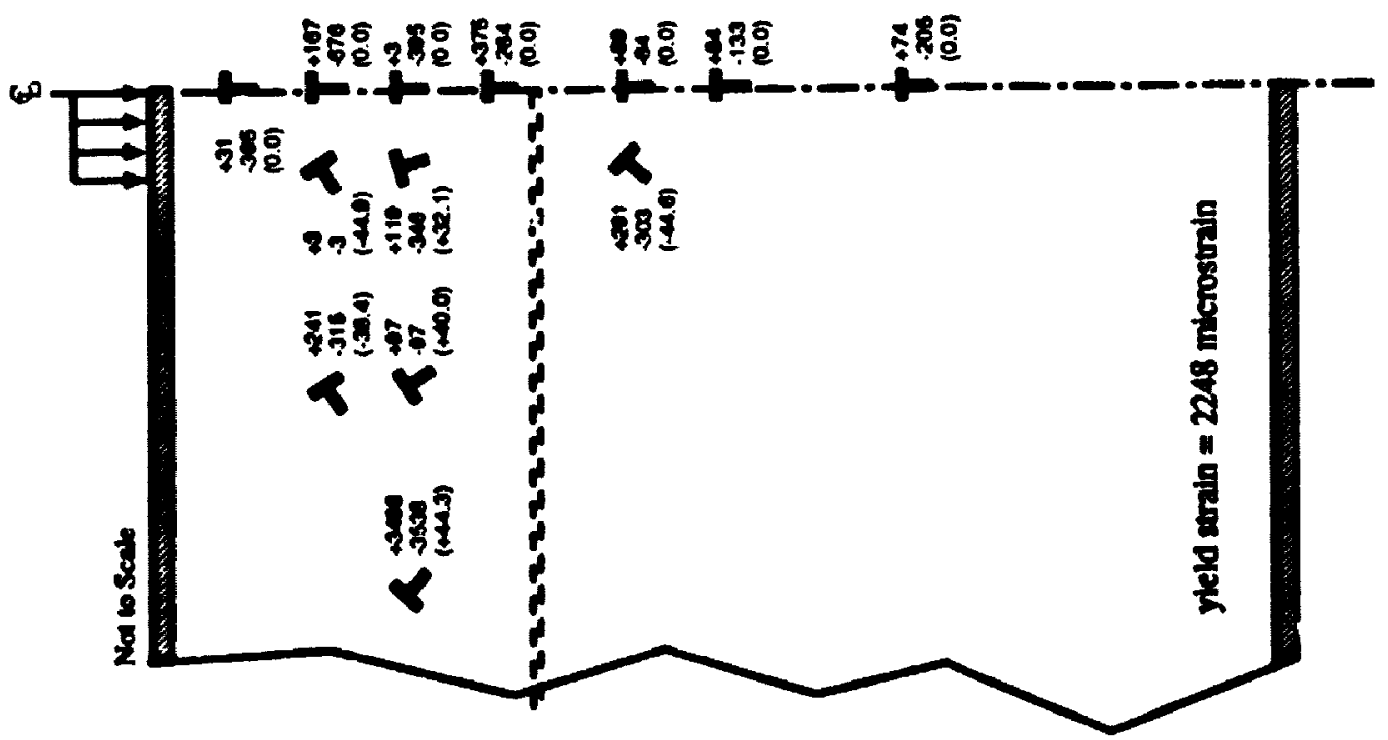



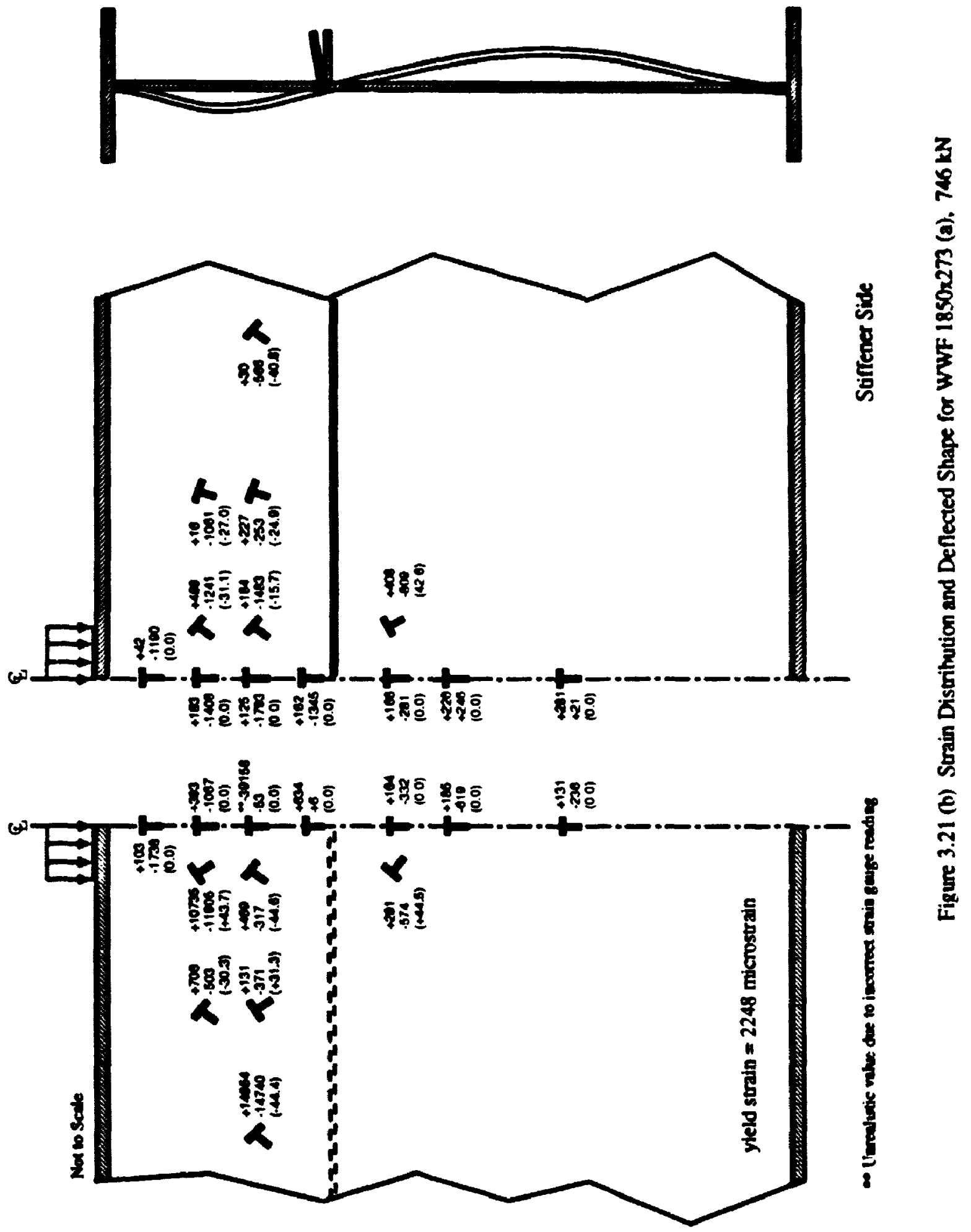

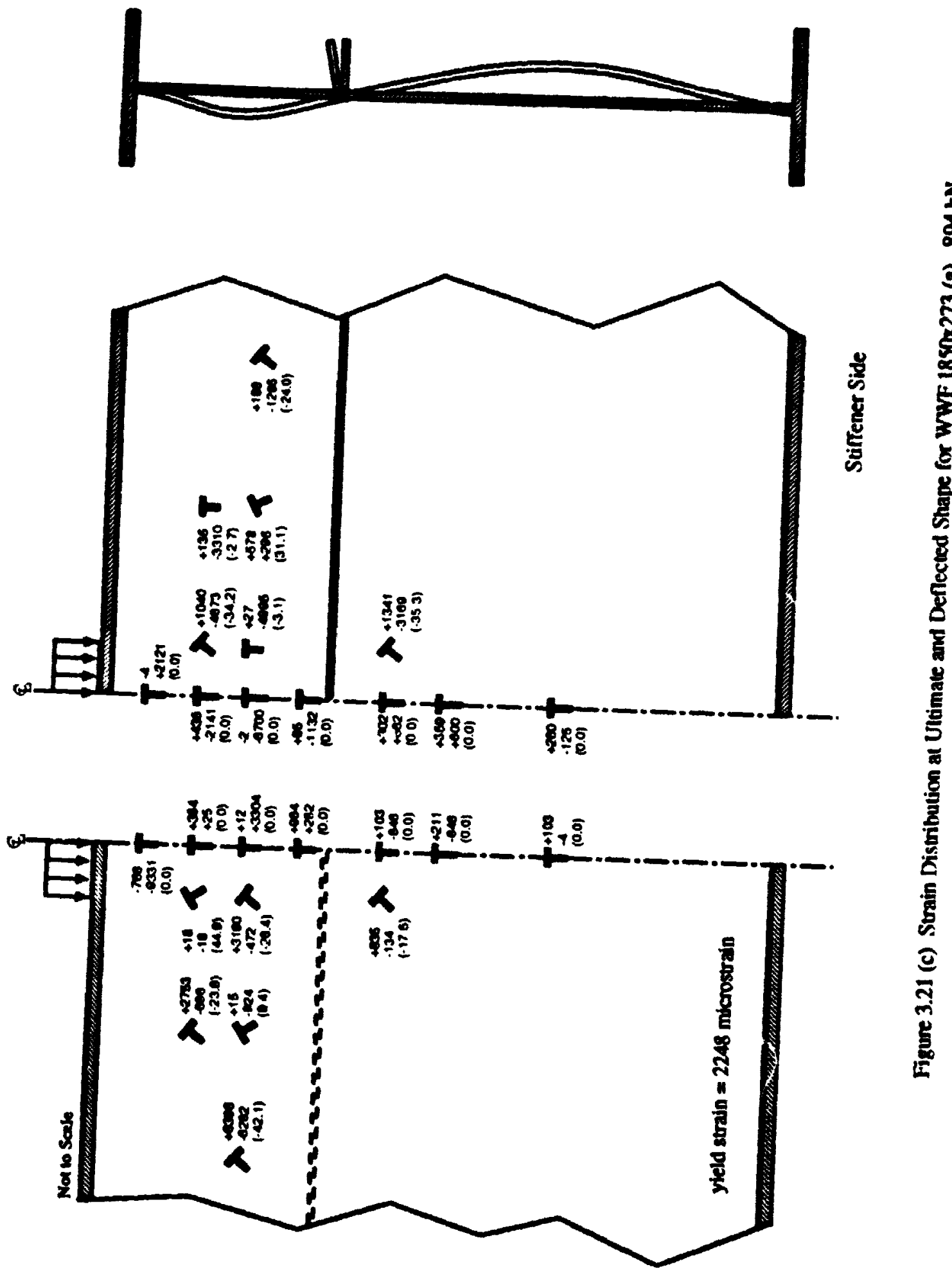

焉 

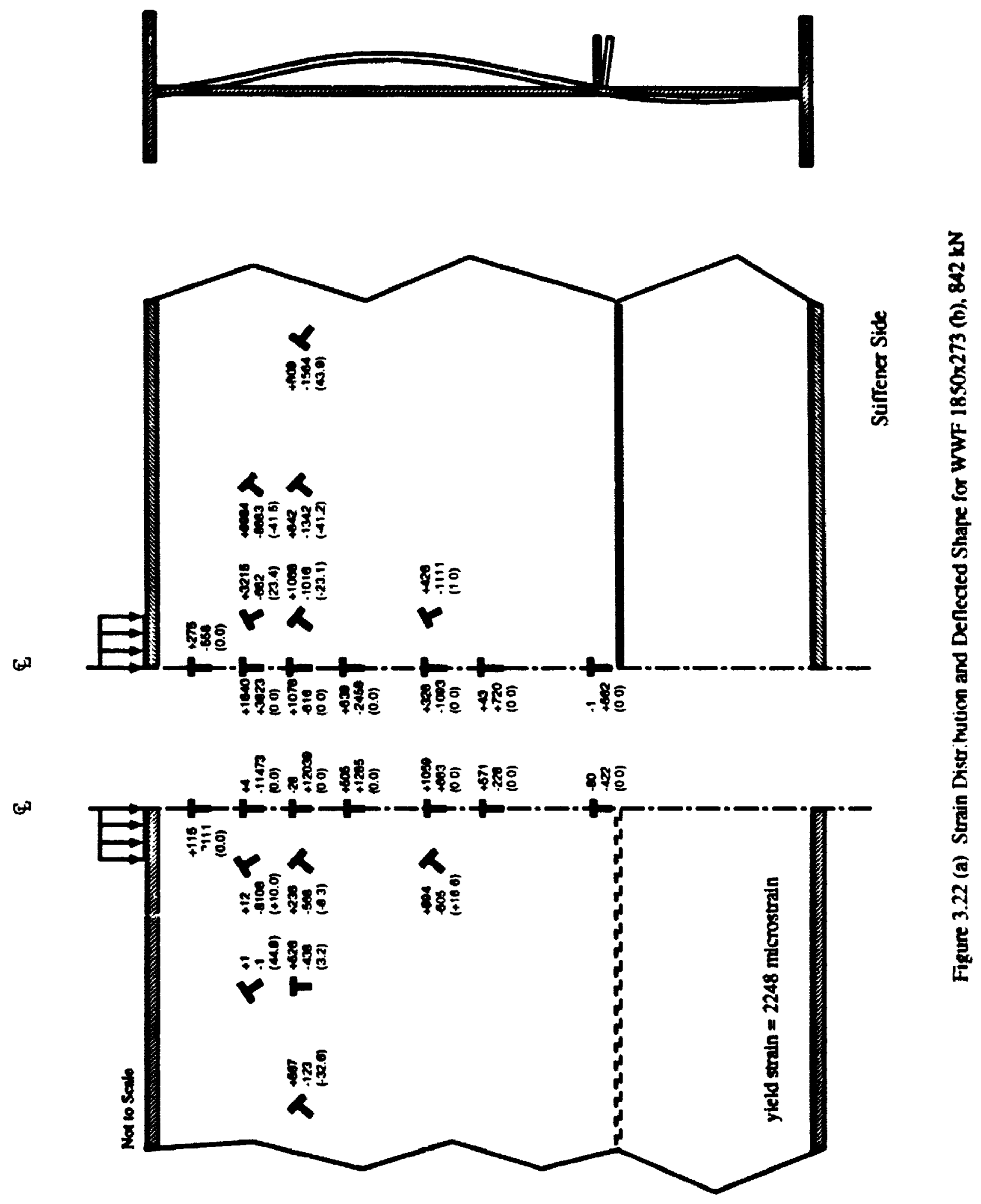


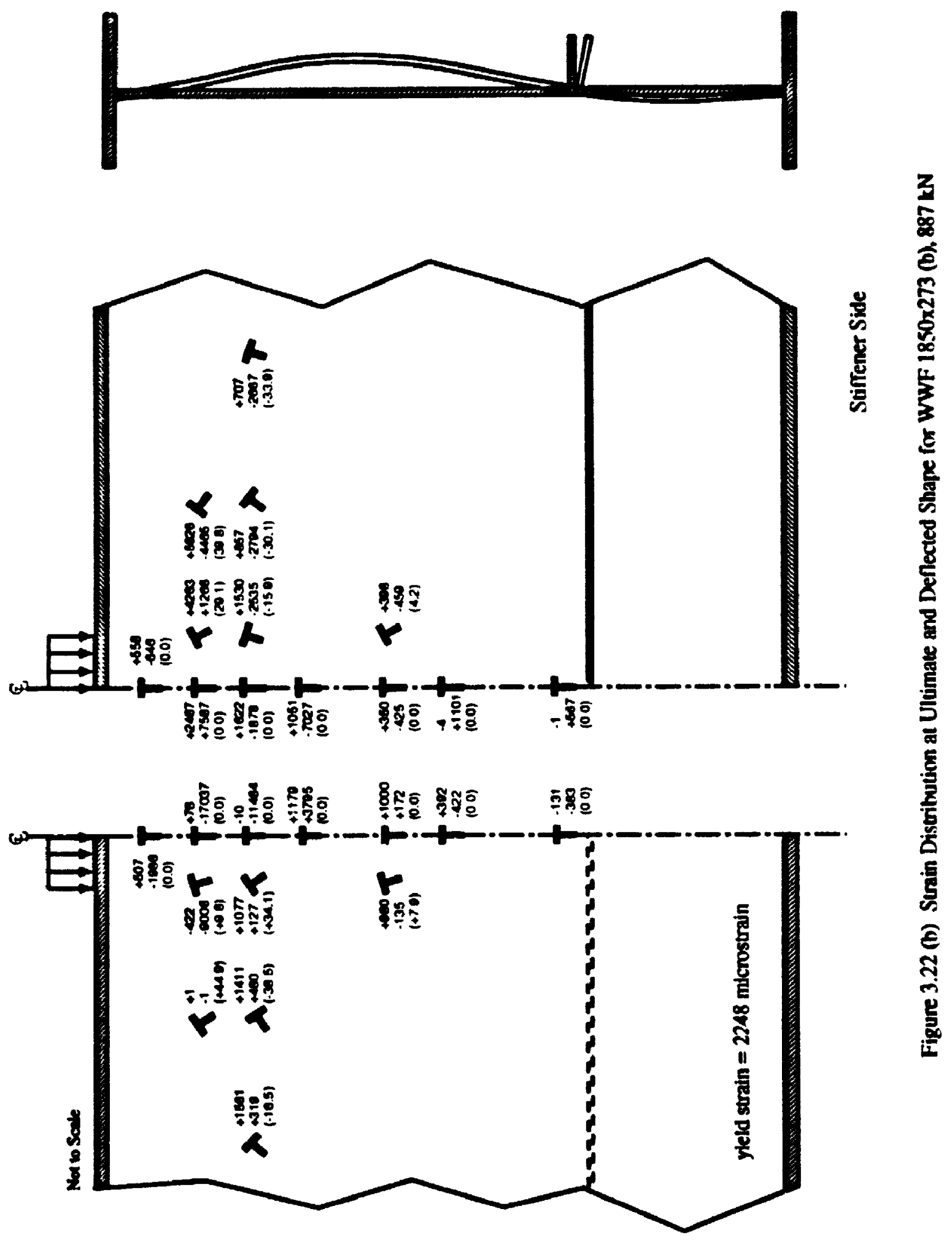




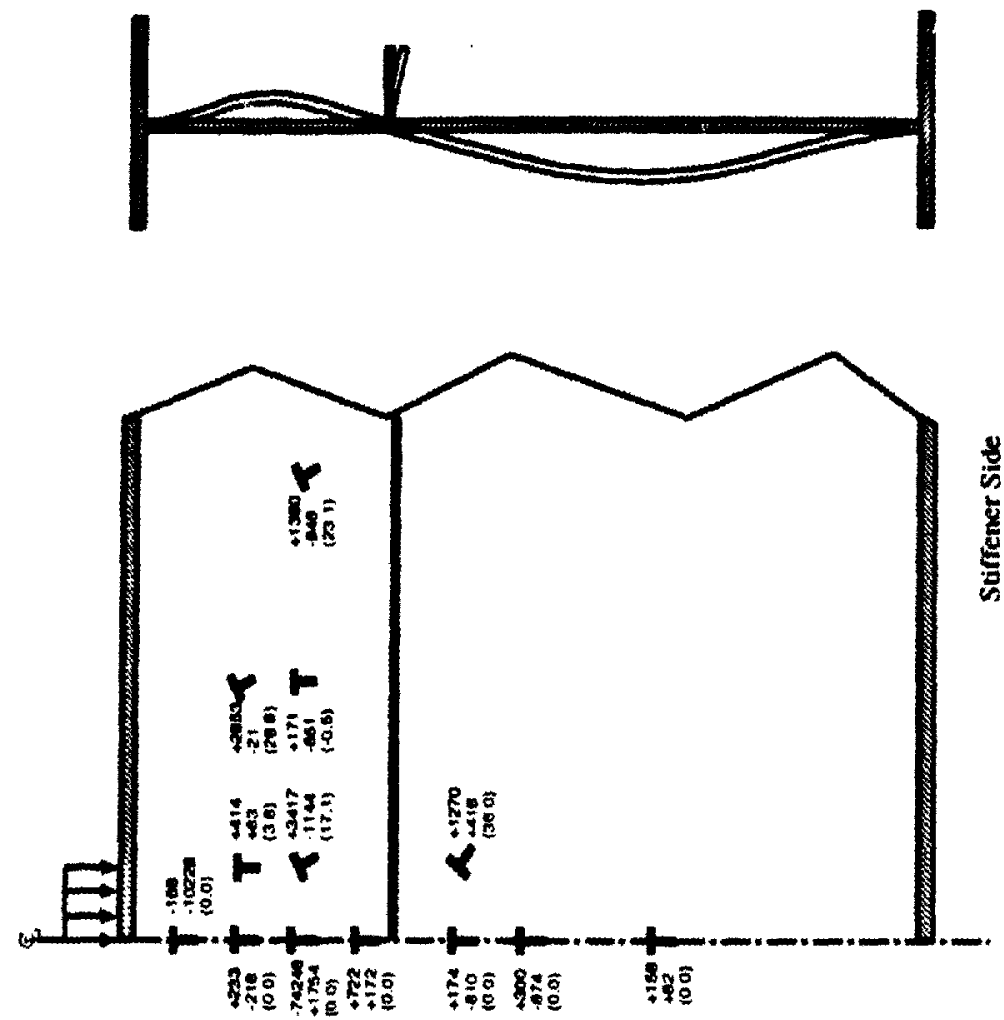

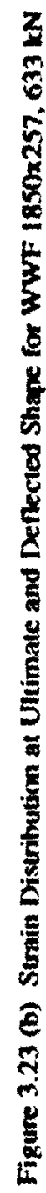

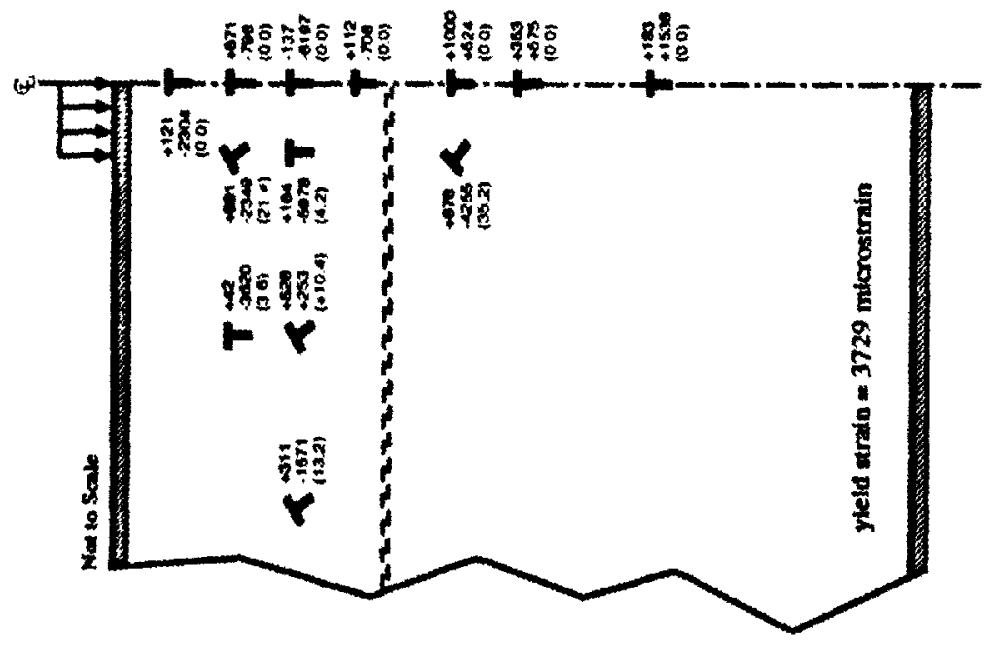




\section{Chapter 4}

\section{Discussion and Application of Equivalent Column Concept}

\subsection{Equivalent Column Concept}

To extend the application of the equivalent column concept and the proposed design equations to slender, customized WWF shapes and bridge girders with longitudinal stiffeners it is necessary:

1. to establish the probable range of shapes that are being built;

2. to test a representative sample to obtain test data related to internal strains and deformed shapes, material data, geometries, initial imperfections, failure modes and mechanisms and make the corresponding observations;

3. to interpret and present the data in a suitable format for comparison to finite element analysis;

4. to conduct and verify the finite element results with the test data;

5. to prepare a description of stresses and displacements for the finite element analyses to develop furthe the proper rational model. These descriptions should include the 
effective width which is a function of the extent of yielding, a description of the distribution of internal forces, the deflected shapes, and the failure modes.

The scope of this thesis is limited to the presentation of data for comparison with the finite element analyses and any related observations that may be useful in the continued development of the equivalent column concept. The principal stress data for the WWF 985 $\times 71$ tests and their general behaviour is presented in the finite element comparison by Prabha (1996) and is not given here.

\subsection{Stress Distribution}

Sixty-four strain gauges arranged in 26 rosettes on both sides of the web girders were used to determine the principal strains and their orientation at thirteen discrete locations. These data were then converted to stresses using a strain data (elastic and inelastic) interpretation program developed by Benichou (1994), and the corresponding material data from the tension coupon tests. First, the principal strains and orientation are determined from the measured strains using Mohr's circle for strains. These strains are then converted to principal stresses by the use of a bi-linear stress strain curve and traditional plasticity algorithms for finite element analysis. The bi-linear curve is defined by the modulus of elasticity, the yield strain calculated by dividing the yield stress by the modulus of elasticity and the strain hardening strain. 
The characteristic material properties used to convert the strain data are given in Table 4.1. These same properties will be used in future finite element analyses.

- Figures 4.1, 4.2, 4.3 and 4.4 show the principal stresses and orientation on each side of the web at load levels associated with the end of the elastic range, in some cases an intermediate load level. and at ultimate for the bridge girders, the WWF $1450 \times 247$. the

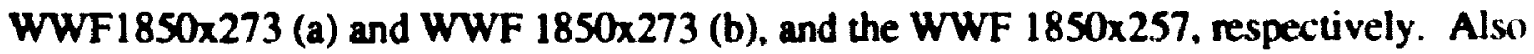
shown are the yield stress, the location of the longitudinal stiffener, the corresponding location of the load and the deflected shape.

The average of the principal stresses on the two sides, most closely aligned with the vertical direction at any load level, diminishes through the depth and with the horizontal distance from the centreline. The following particular observations are drawn from Figure 4.2 (a) to (c) for WWF $1856 \times 273$ (a) and are equally applicable to the other girders with the exception of the WWF $1850 \times 273$ (b) in which the load was applied on the flange located at $0.8 \mathrm{~h}$ from the longitudinal stiffener. These exceptions will be noted where they occur.

The progression of yielding for all bridge girders is also shown in the strain distribution Figures 4.1 to 4.4 , with one of the diagrams indicating the approximate 
locations of yield bands as determined from measured strains. Table 4.2 presents the readings for specific gauges and specific load levels as yielding progressed.

For WWF $1850 \times 273$ (a), initial yielding began at a distance of $0.1 \mathrm{~h}$ from the top flange (mid-heigh: of the upper weh panel) followed by yielding in the region near the fillet on the web. Yielding then propagated outward from the first yield band forming an arc about the load, extending as far as $N+16 \mathrm{~L}$. With increasing out-of-plane deformation of the order of magnitude. $L$ the initial yield band propagated through the thickness of the web forming a progressive collapse mechanism at or just below the ultimate load.

The WWF $1850 \times 273$ (b) exhibits the same characteristic with the excepuon that the initial yield band forms at $0.05 \mathrm{~h}$, the second forms at $0.15 \mathrm{~h}$ and the yielding extends left and right to a value of at least $N+24 t$, but lack of other strain gauge data prevents the exact determination of the distance. Based on the limited data, yield bands need not be fully formed (i.e. a true mechanism) at ultimate. The principal stresses indicate a series of waves forming along the length of the webs alternating from positive to negative to positive.

Prabha (1996) found that the general shape of the average normal stress distribution, at the ultimate load level. is similar to the shape of the normal stress distribution evaluated over any width within the effective column width. From the data available the average normal stress distributions were evaluated along the centerline for 
each bridge girder and plotud in Figure 4.5 for the maximum load. These average normal stress distributions at each load level, determined from the strains measured on the surface, were calculated from the normal stress distribution through the thickness at the ultimate load by assuming a linear strain distribution through the thickness and a bi-linear stress strain curve. Also shown in Figure 4.5, is the best fit power function of the form of $\sigma=\sigma_{\operatorname{man}}(\mathrm{z} / \mathrm{h})^{P}$ for each distribution. The stress distribution for the WWF $1450 \times 247$, the WWF $1850 \times 273$ (a) and the WWF $1850 \times 273$ (b), are best described by a cubic function and the WWF $1850 \times 257$ by a ninth power function. The normal stress distribution does not seem to be influenced by the presence of the longitudinal stiffener. It has yet to be determined whether the longitudinal stiffener extends the effective column width or not As Prabha (1996) showed for the WWF shapes, these stress distritutions could the used in conjunction with the aspect ratio of the equivalent column concept to determine the plate buckling coefficient, $\mathrm{c}$.

\subsection{Deflected Shapes}

The out-of-plane web displacements are illustrated along the length and through

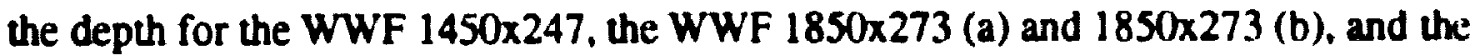
WWF 1850x257, in Figures 4.6, 4.7.4.8, and 4.9 respectively. Level 1 and Level 4 are those displacements measured by LVDTs 1,10 and 16 and LVDTs 6, :5, and 21 . respectively, whereas Levels 2 and 3 are constructed from four LVDT measurements 
numbering 2, 11, 17 and 19 and then 4, 13, 18 and 20 respectively. Also shown in these figures is the assumed effective column half-width of $[\mathrm{N}+10 t] / 2$ as determined by Prabha (1996).

The characteristic deflected shape gives an indication of the boundary conditions of the web plate within the effective column width. As indicated by the displaced shape of each girder at midspan, the top flange was restrained from lateral displacement and rotation about the longitudinal axis by the load and in fact approached fixed support conditions. The bottom flange was restrained against lateral displacement and rotation by the lateral and torsional stiffness of the flange and again approached fixed support conditions. The web was restrained against lateral displacement by the longitudinal stiffener. The rotational stiffness that the longiudinal stiffener provides to the web is very small, and the web plate may be treated as being simply supported by the stiffener.

The out-of-plane web displacements along the length of the web for the upper and lower panels indicate that the boundary conditions along the assumed column width and the displacement functions for the effective column width are difficult to define. Hence, the application of a classical solution to this type of buckled shape may be difficult

In the application of the effective column concept it is necessary to calculate the buckling coefficient, $c$, which is a function of the normal stress distribution, boundary conditions and the deflected shape. The latter two are based on experimental evidence 
and require care in their application. It is possible that the buckling coefticient may only be obtained from a verified finite element analysis as indeed was the case in Prabha's (1996) solution. It is also possible that a buckling coefficient and load may be determined for each panel and then combined to determine the interactive buckling capacity.

The predicted bearing resistance for the girders, as calculated from the proposed Clause 15.9 by Prabha, (1996), are shown in Table 4.3. The mean value of the test-10predicted ratio of 0.817 , which is considerably different from 1.000 , and the large value of the coefficient of variation of about 0.18 , indicate that the direct application of this proposed clause is inappropriate. This was not unexpected as the proposed clause, (Clause 15.9), is tailored for the effective length, normal stress distribution, deflected shape and boundary conditions characteristic of WWF shapes. Modifications to Clause 15.9 need to be made to cover slender built-up sections. 


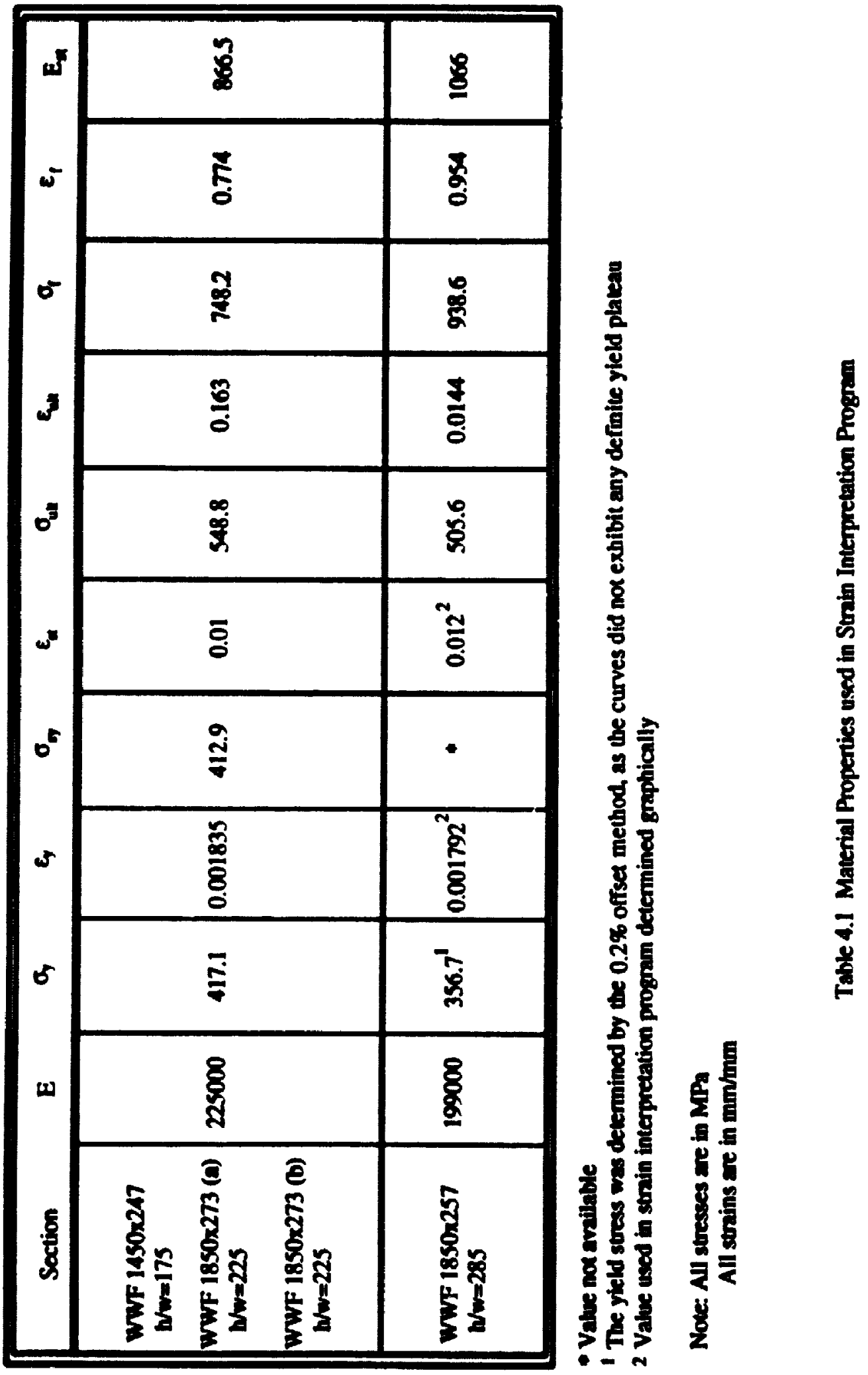




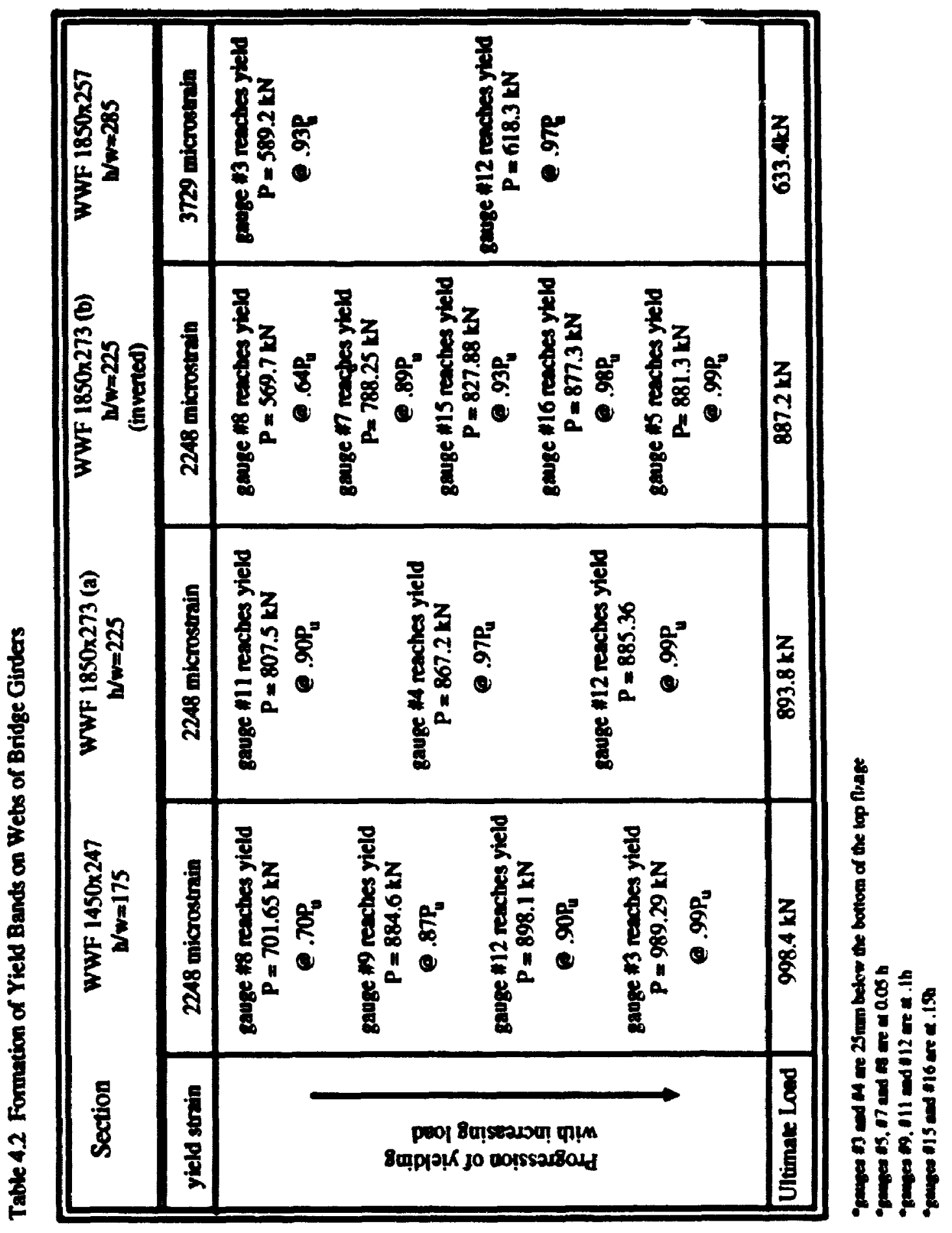




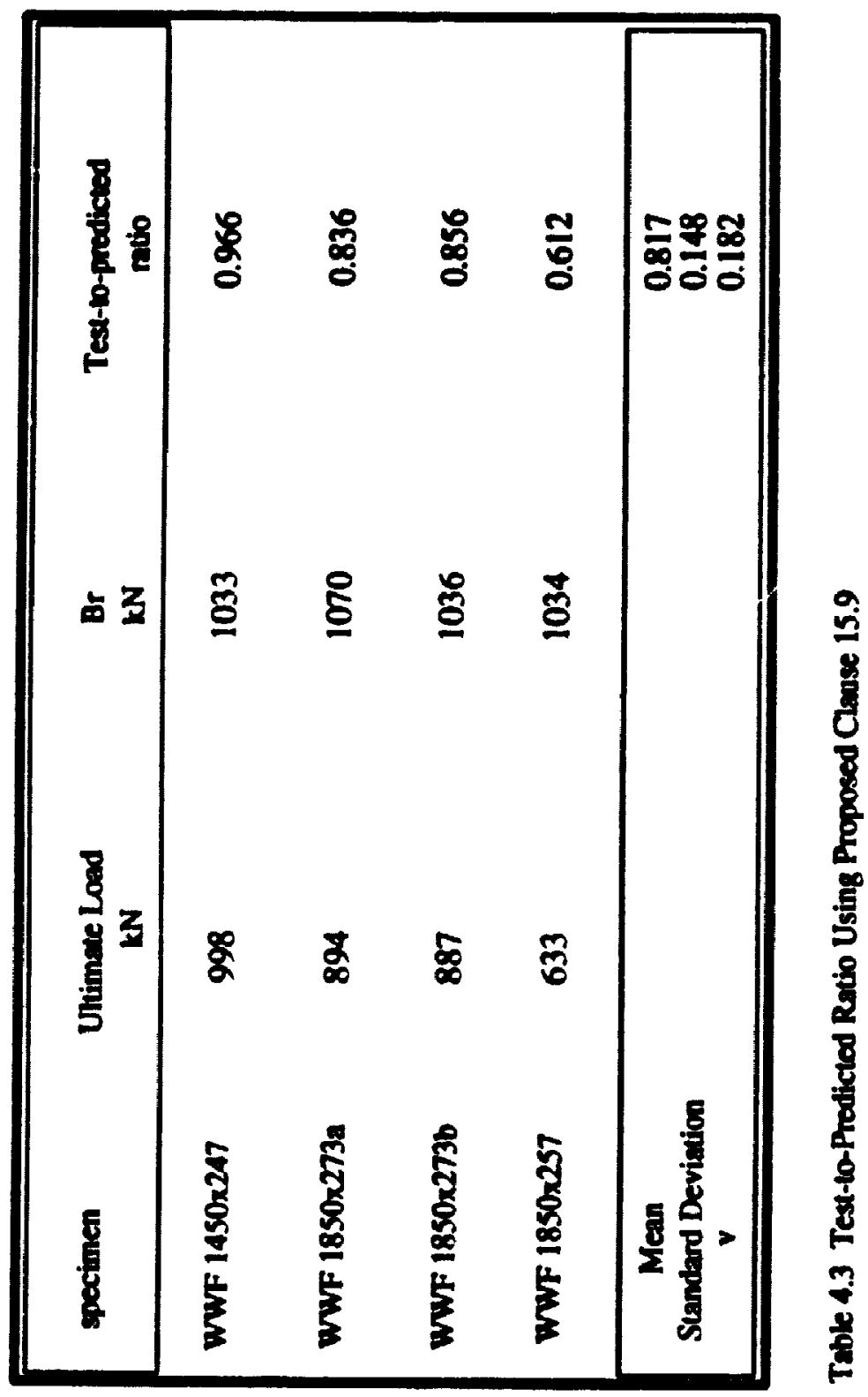



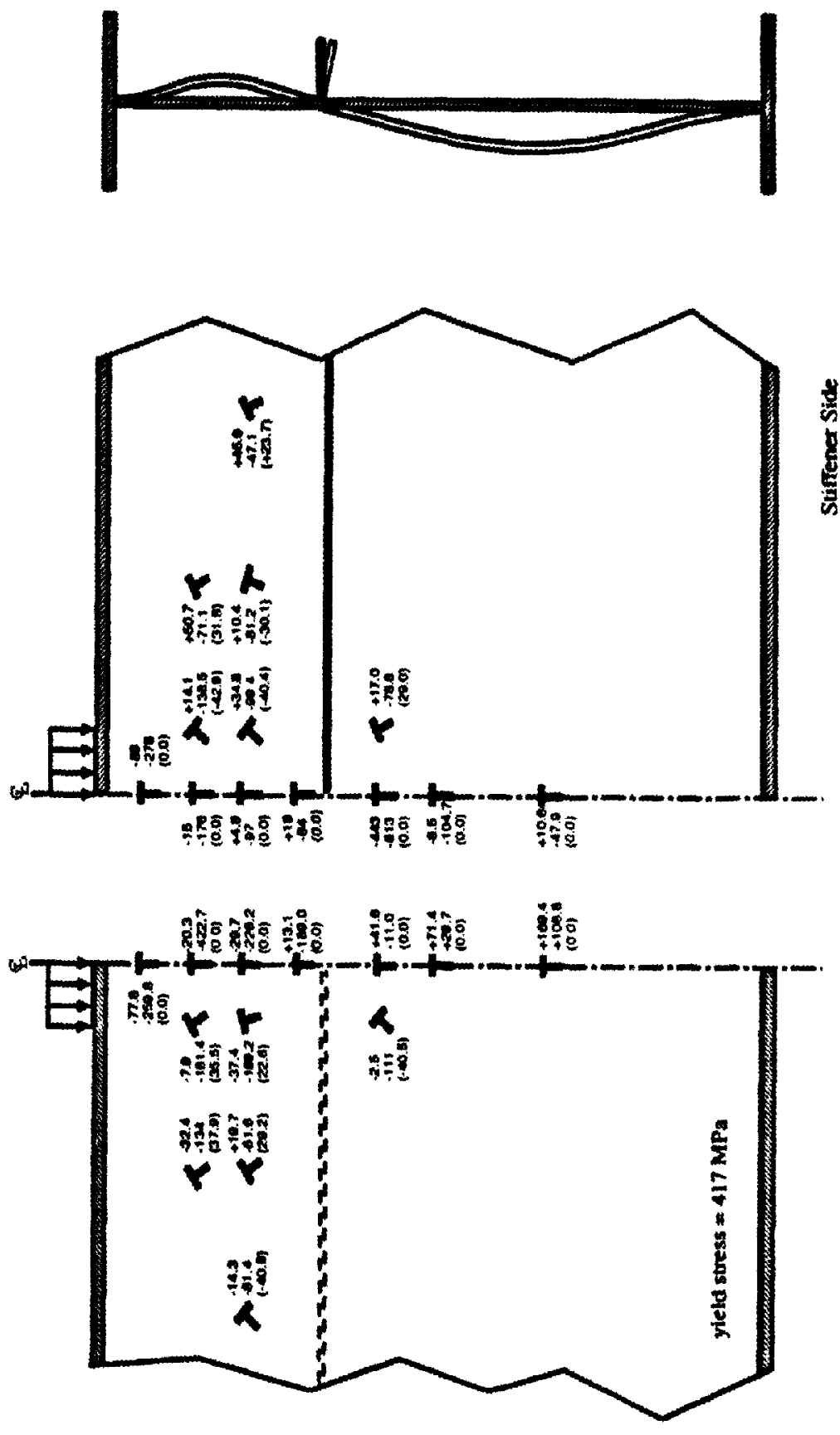

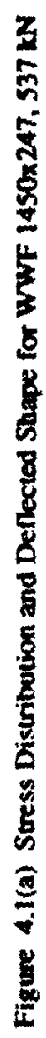



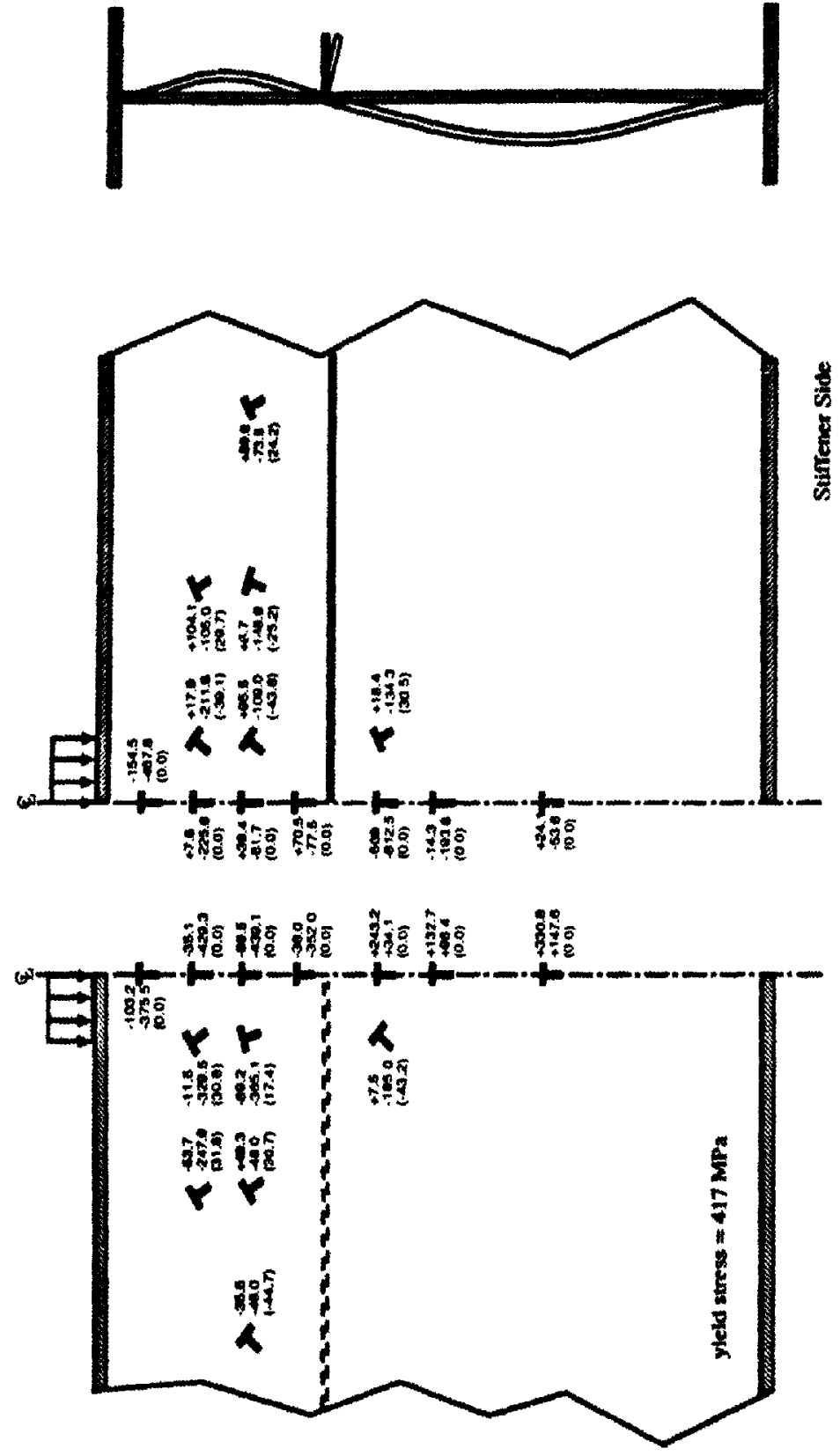

3 

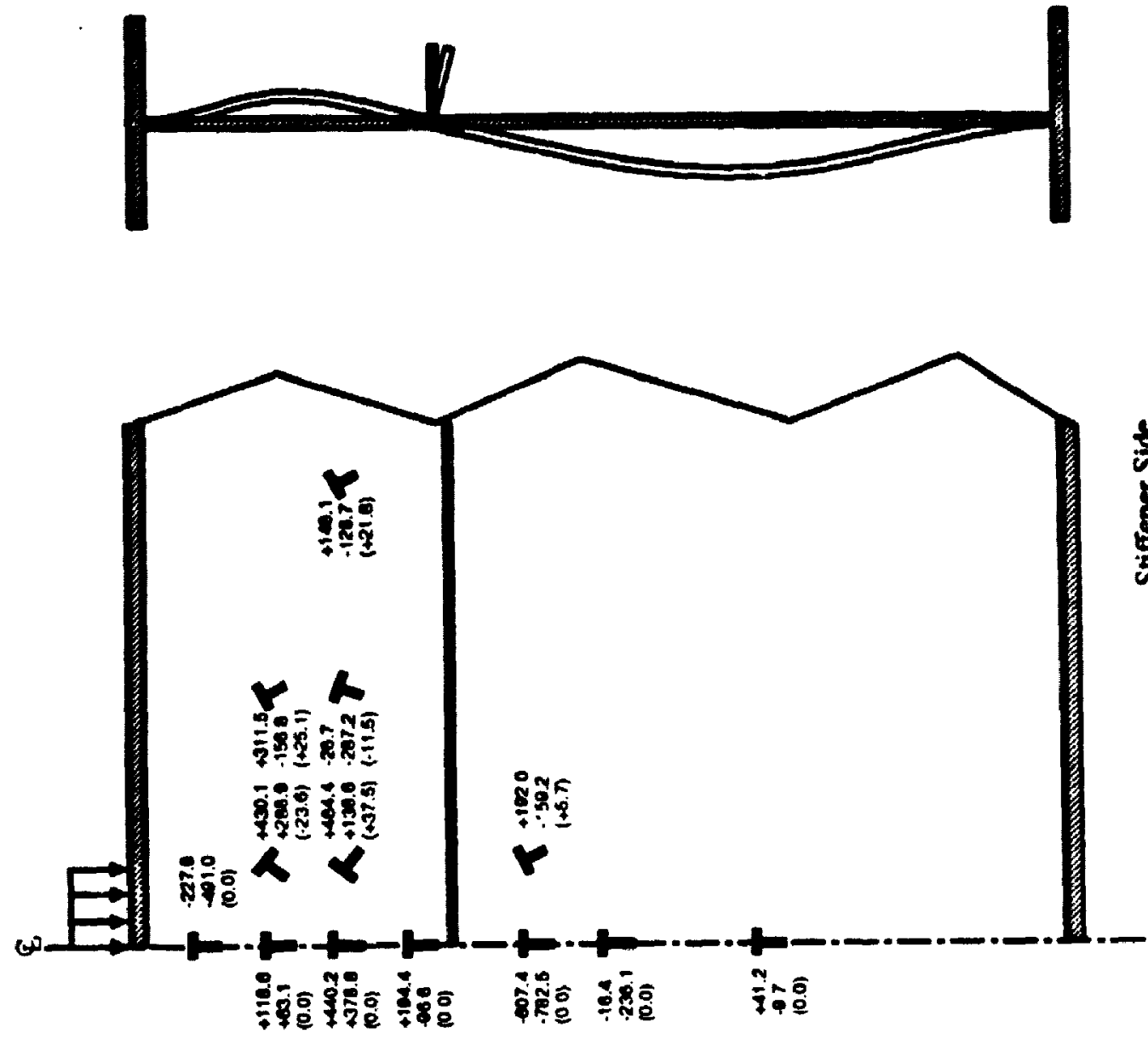

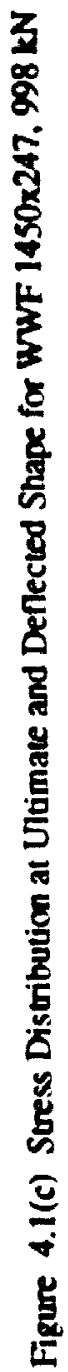

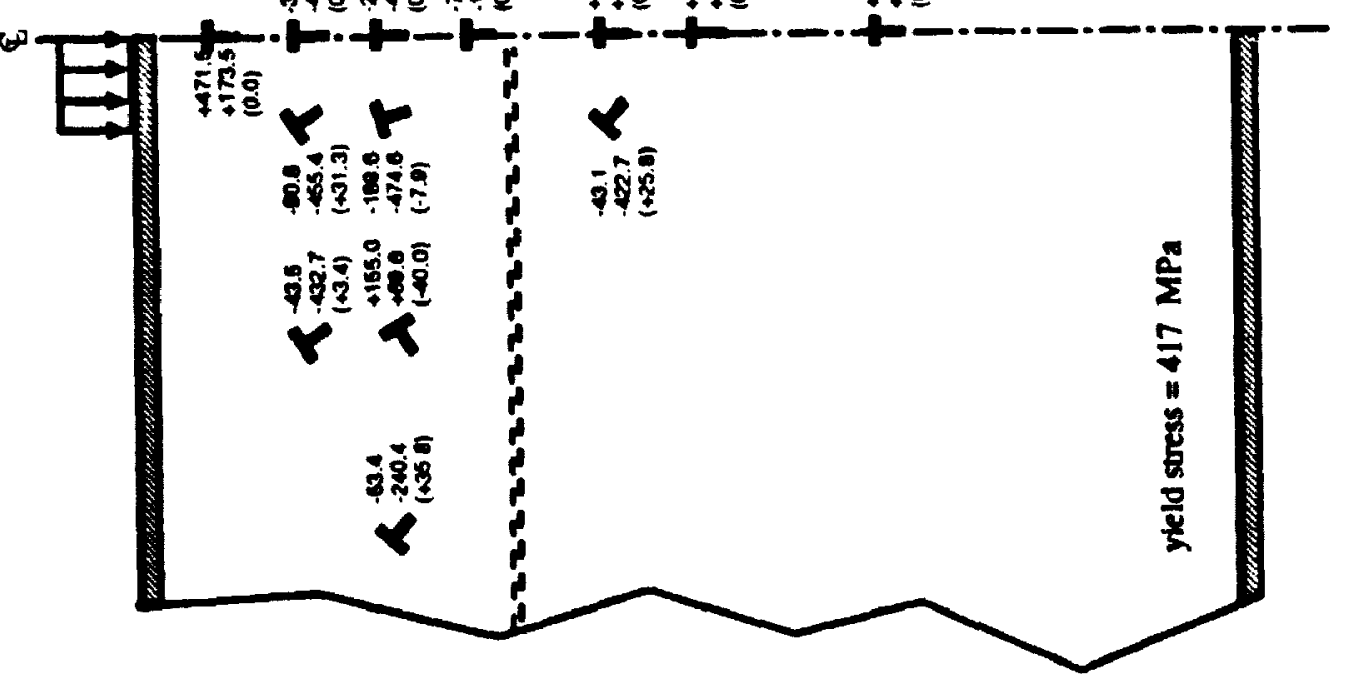



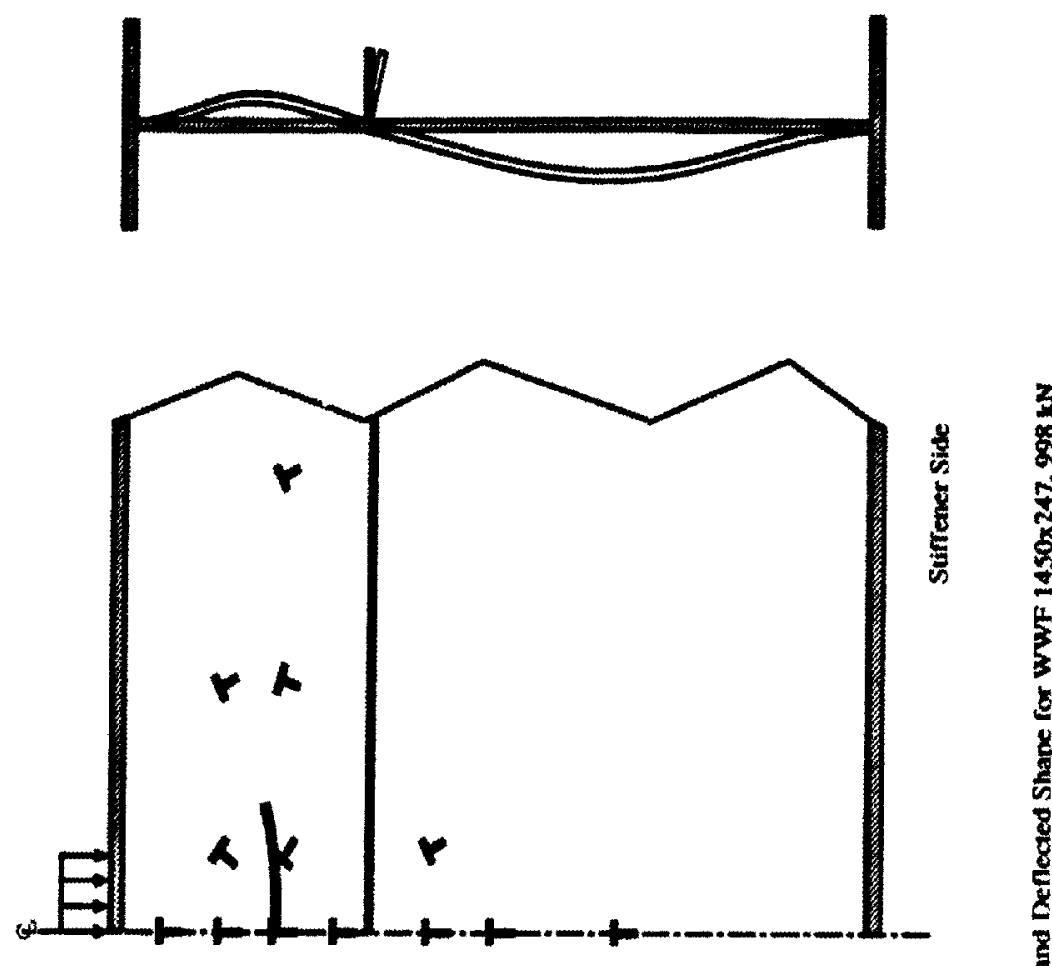

3

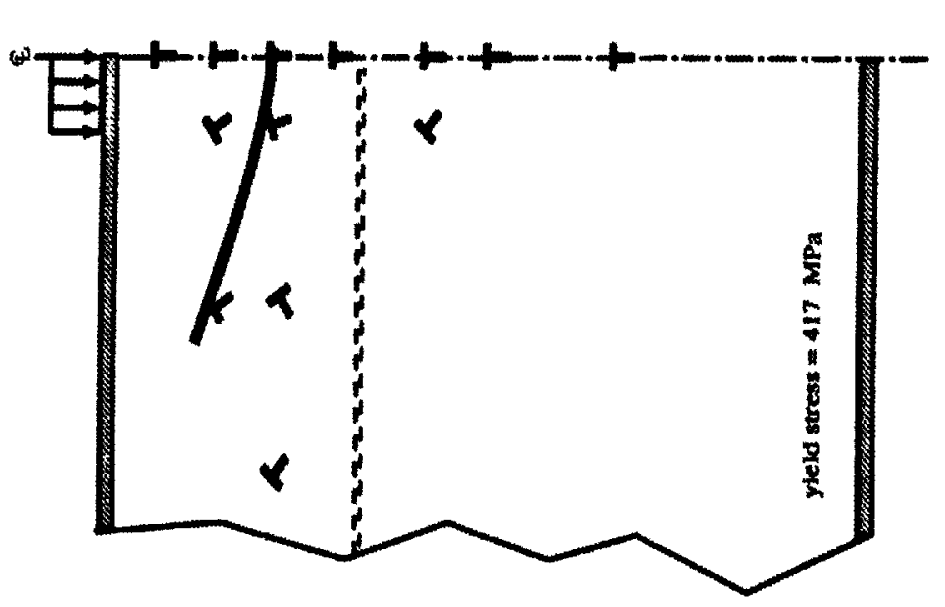



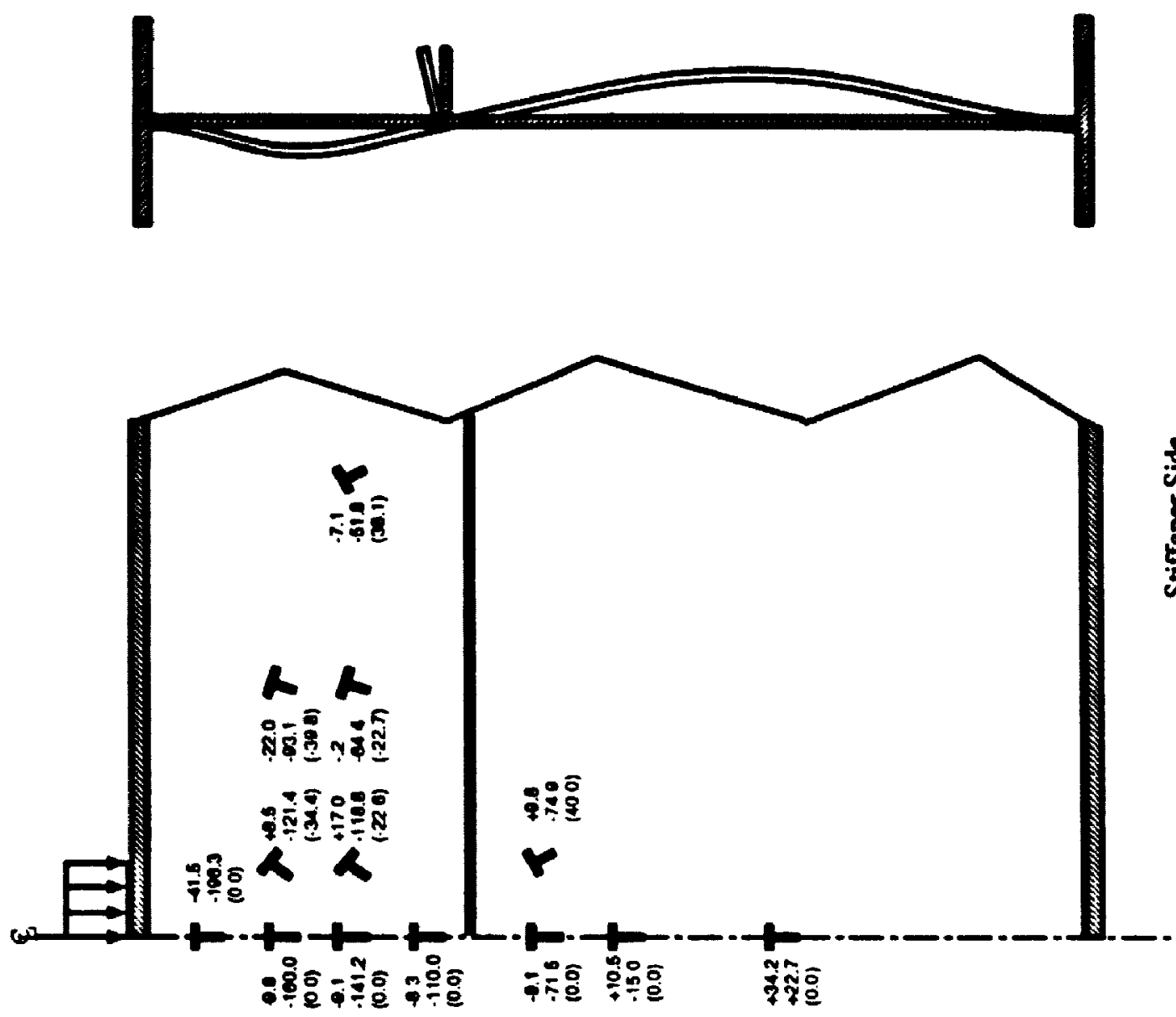

点

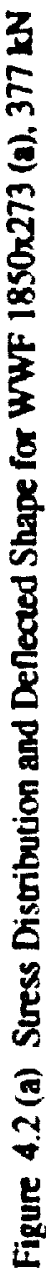

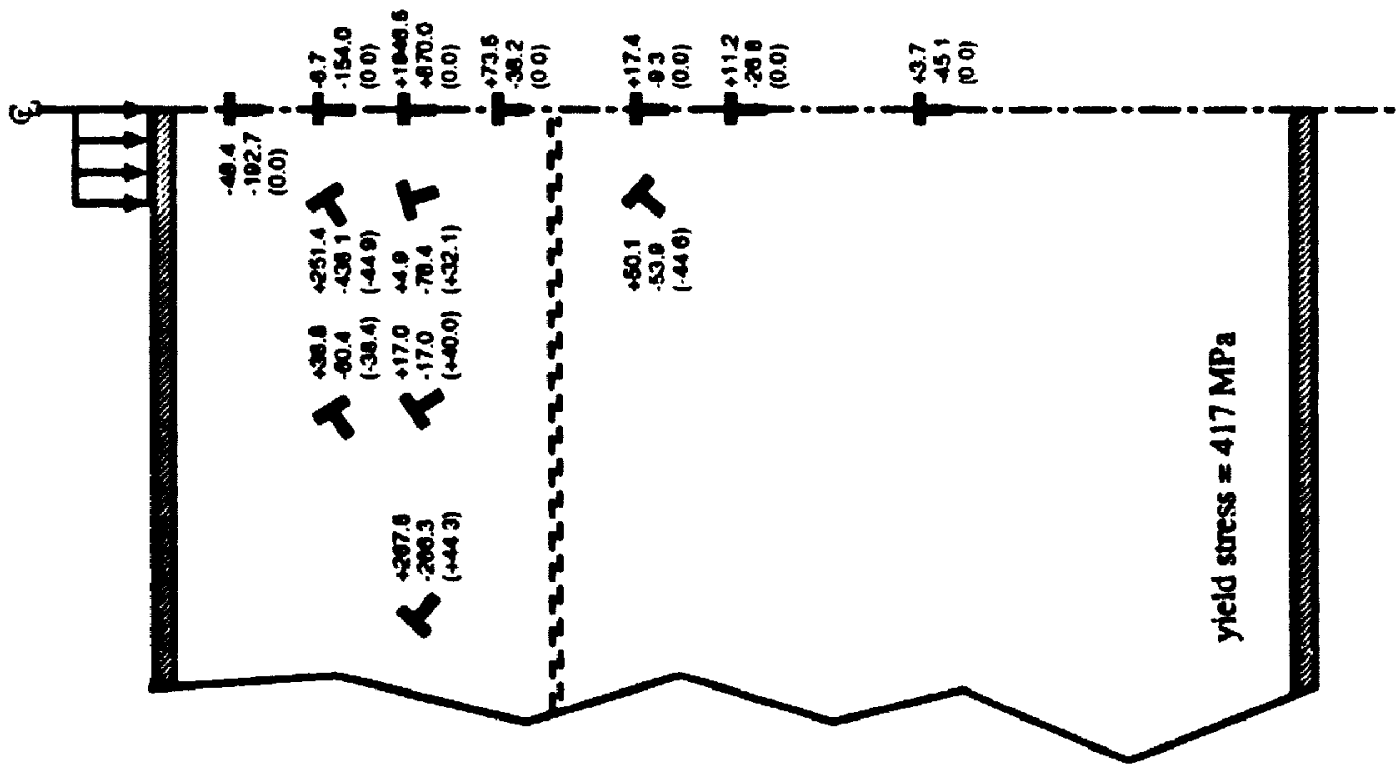



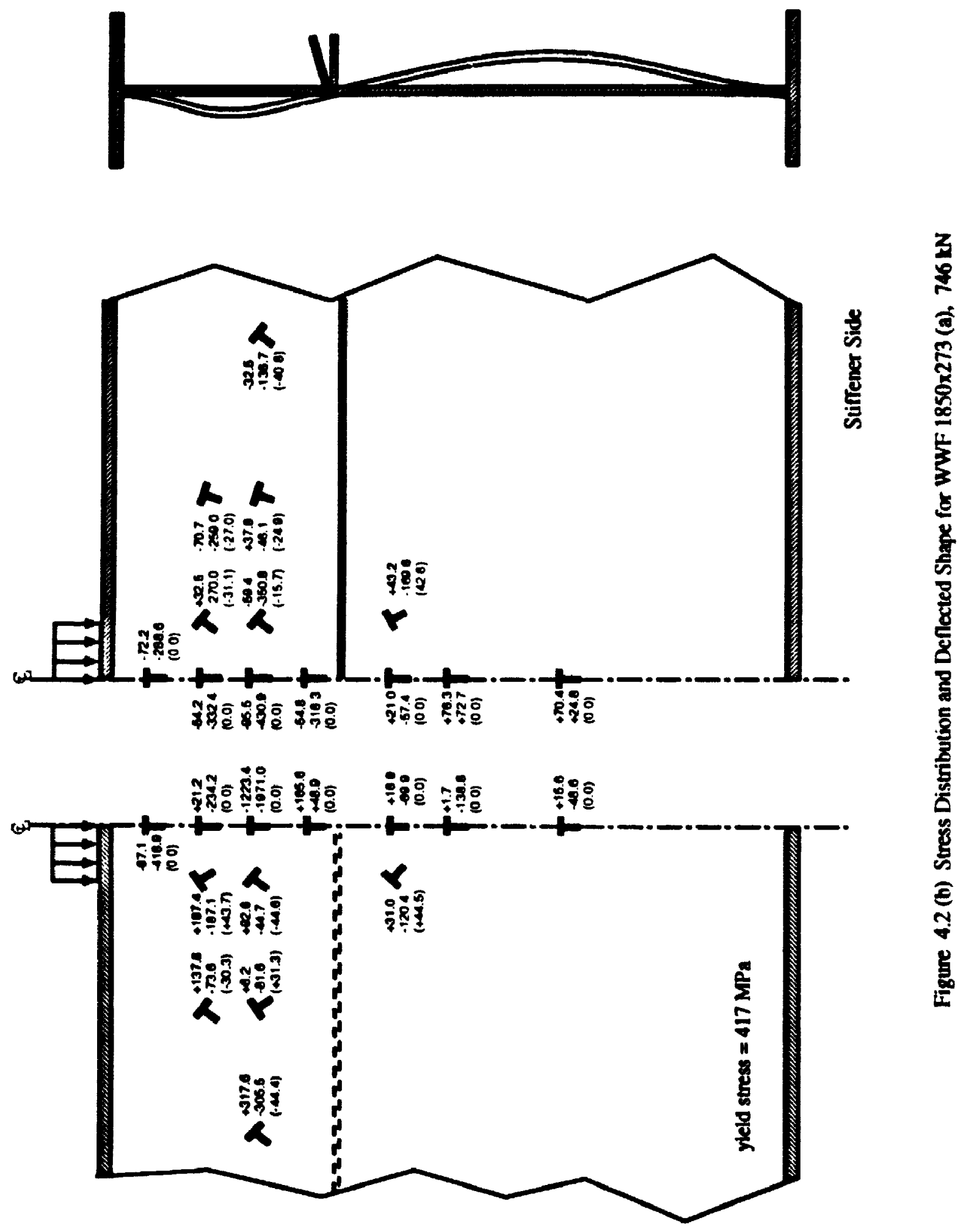

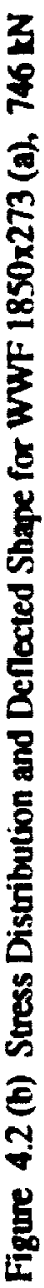



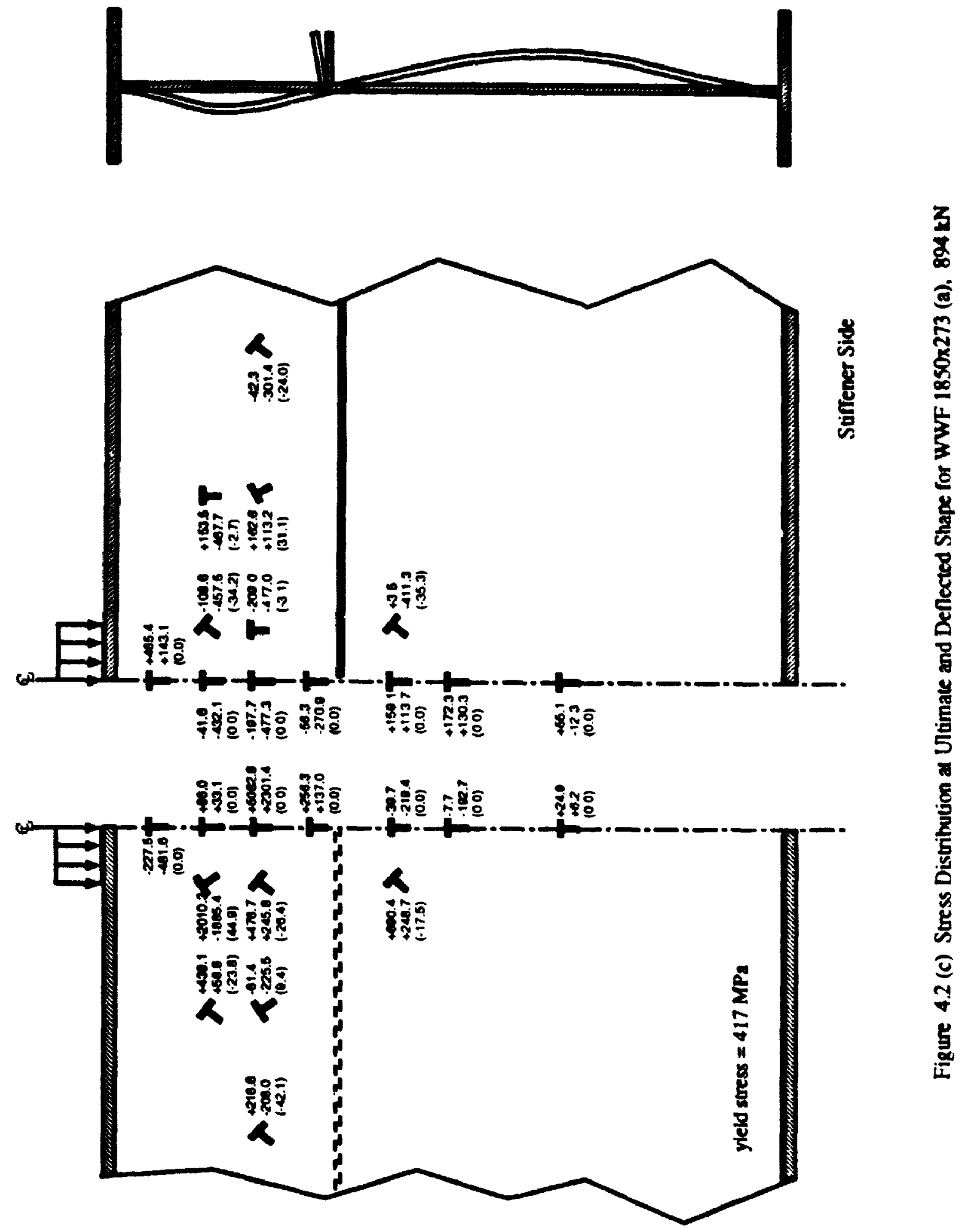

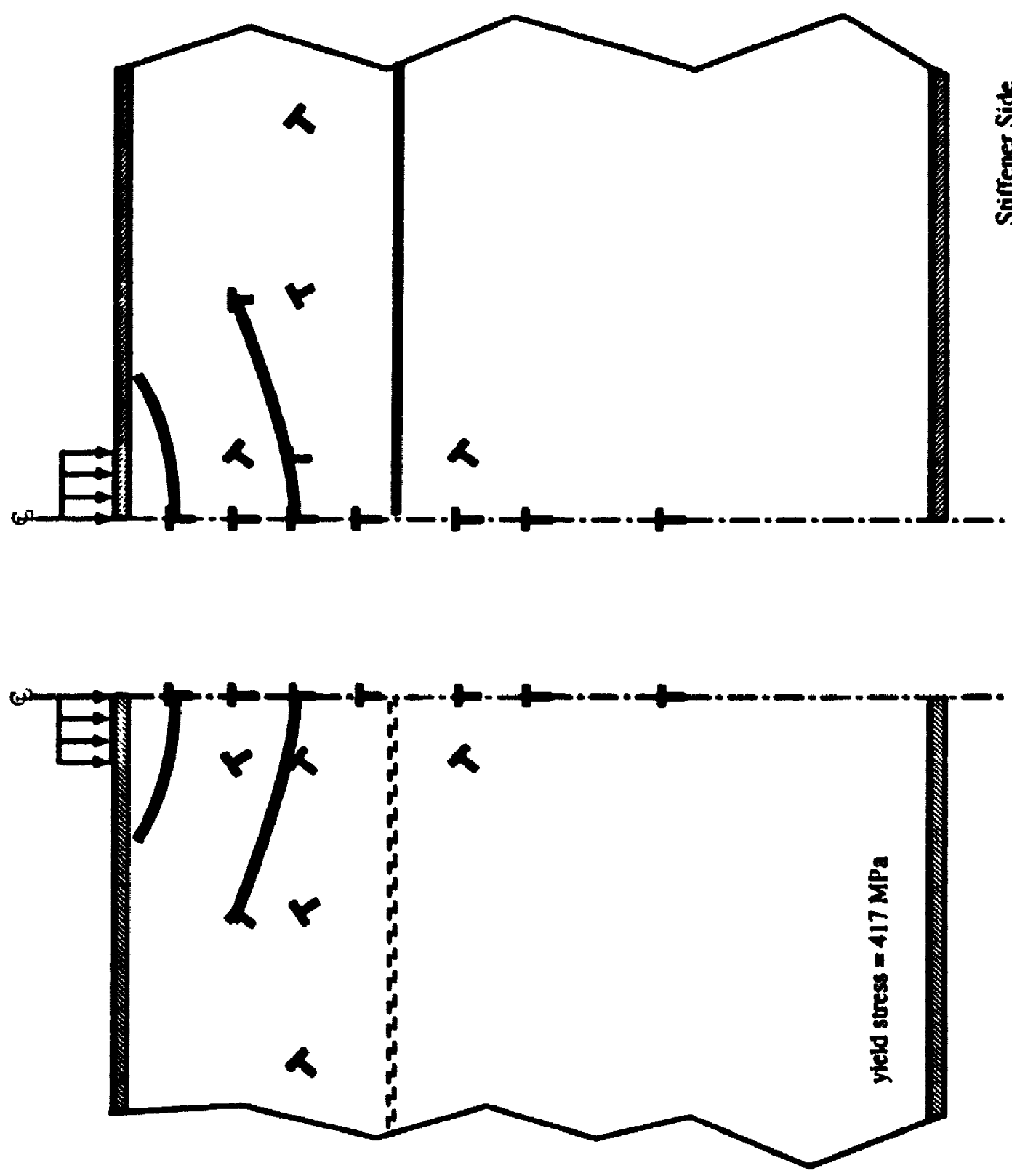

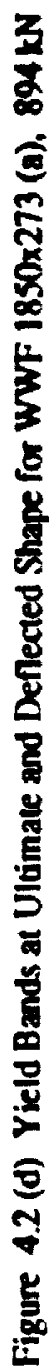



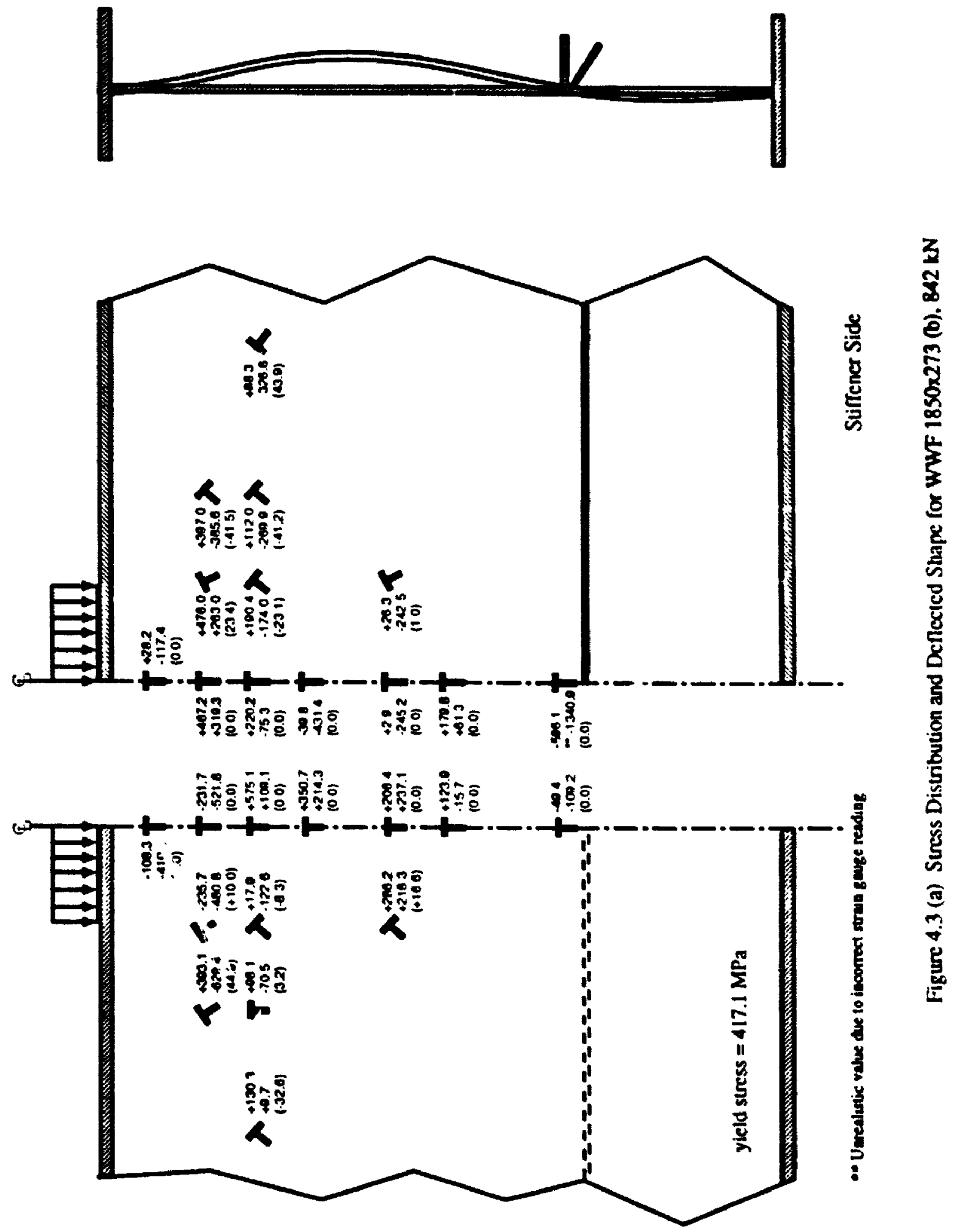


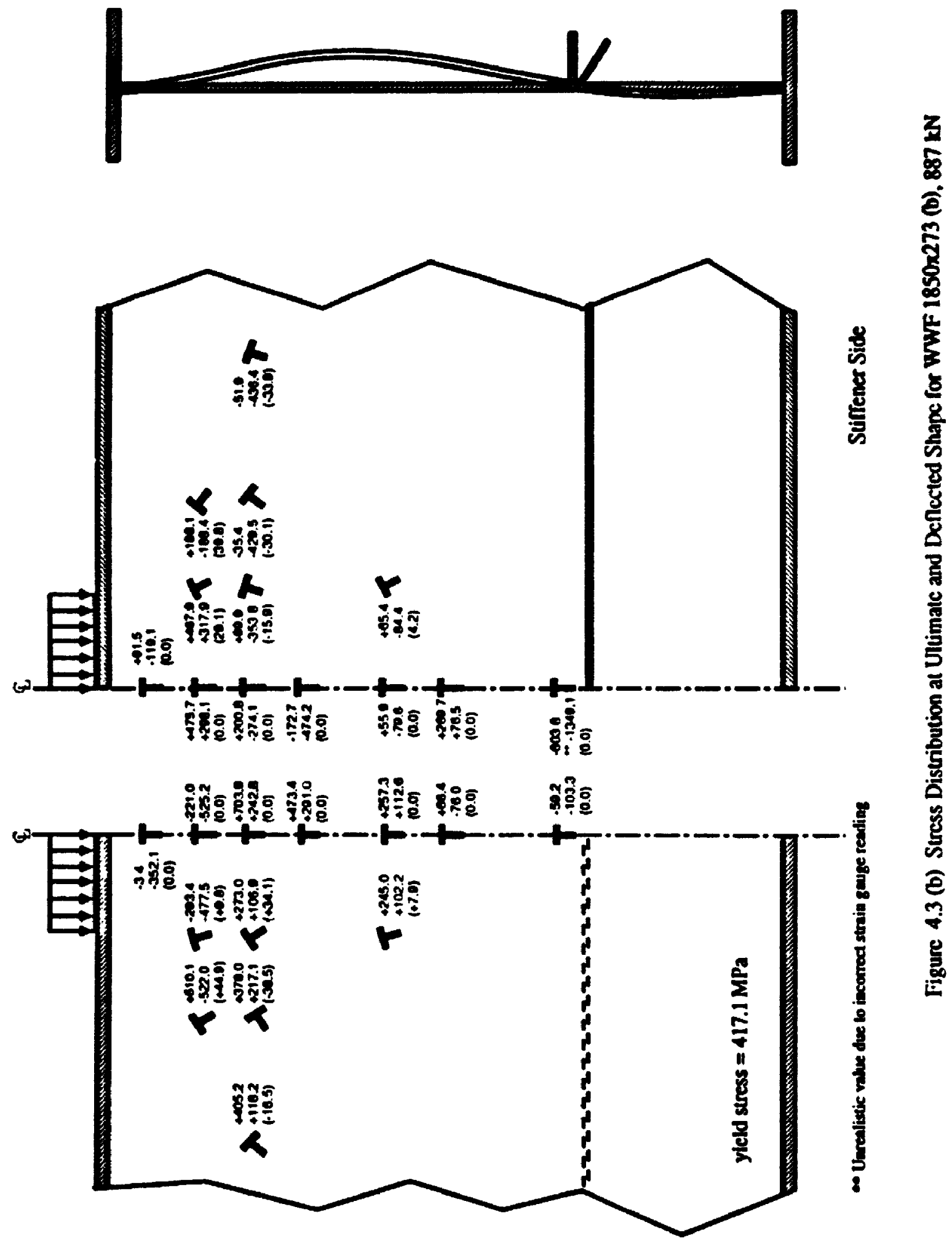



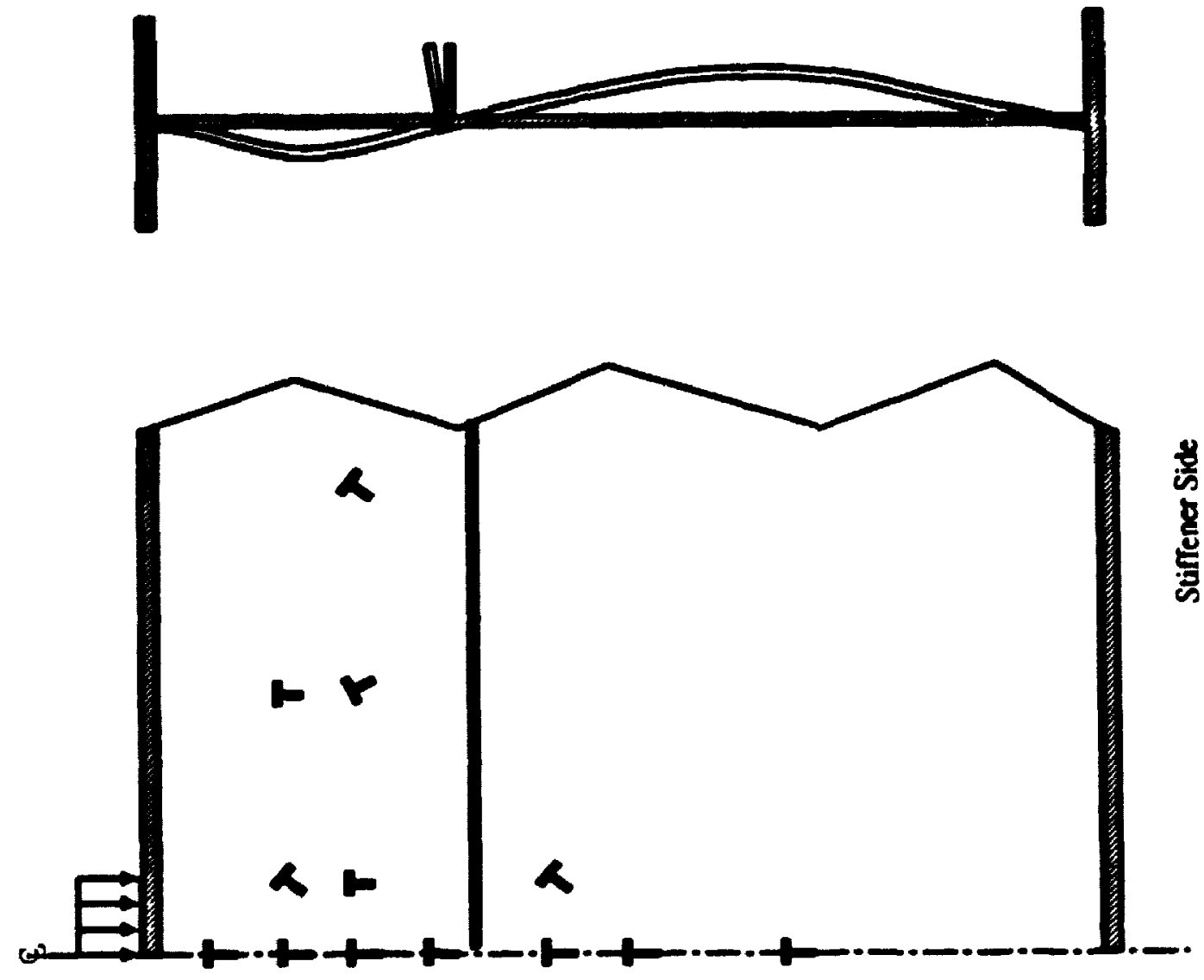

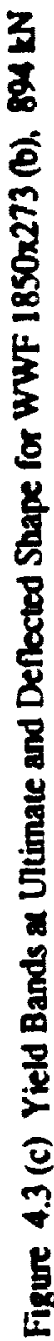

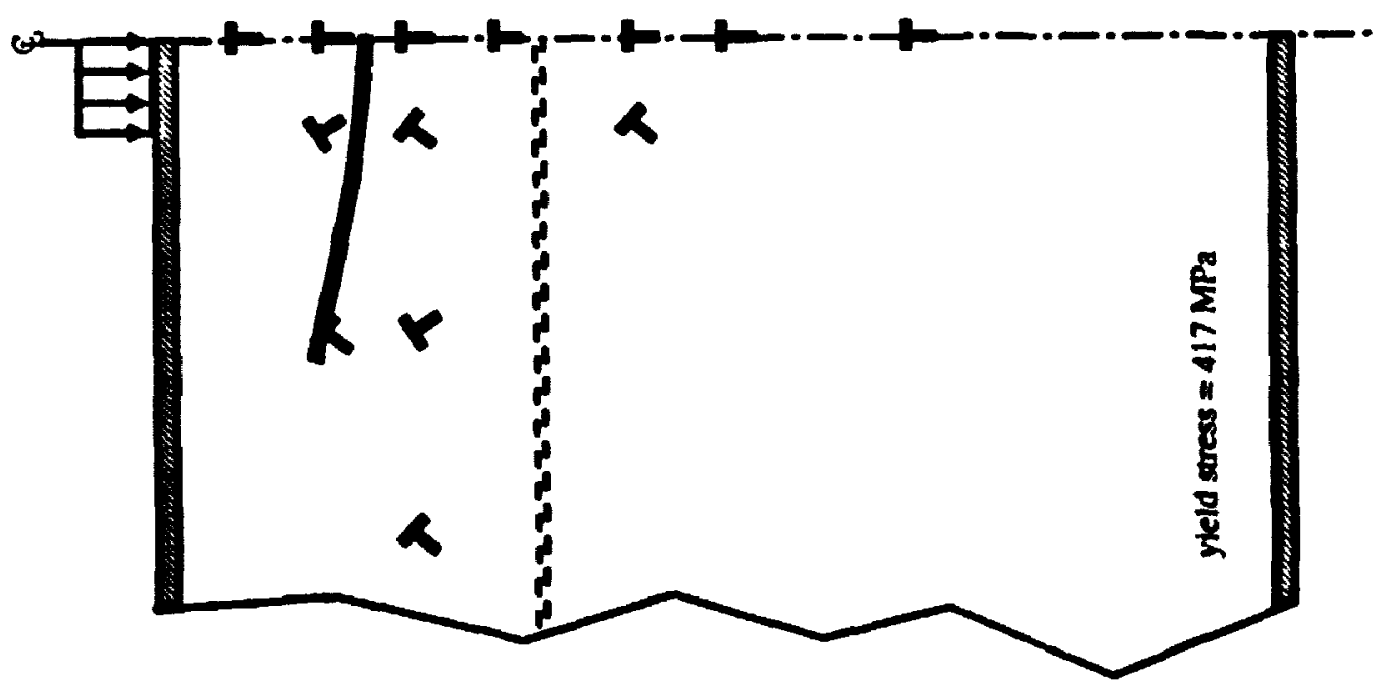



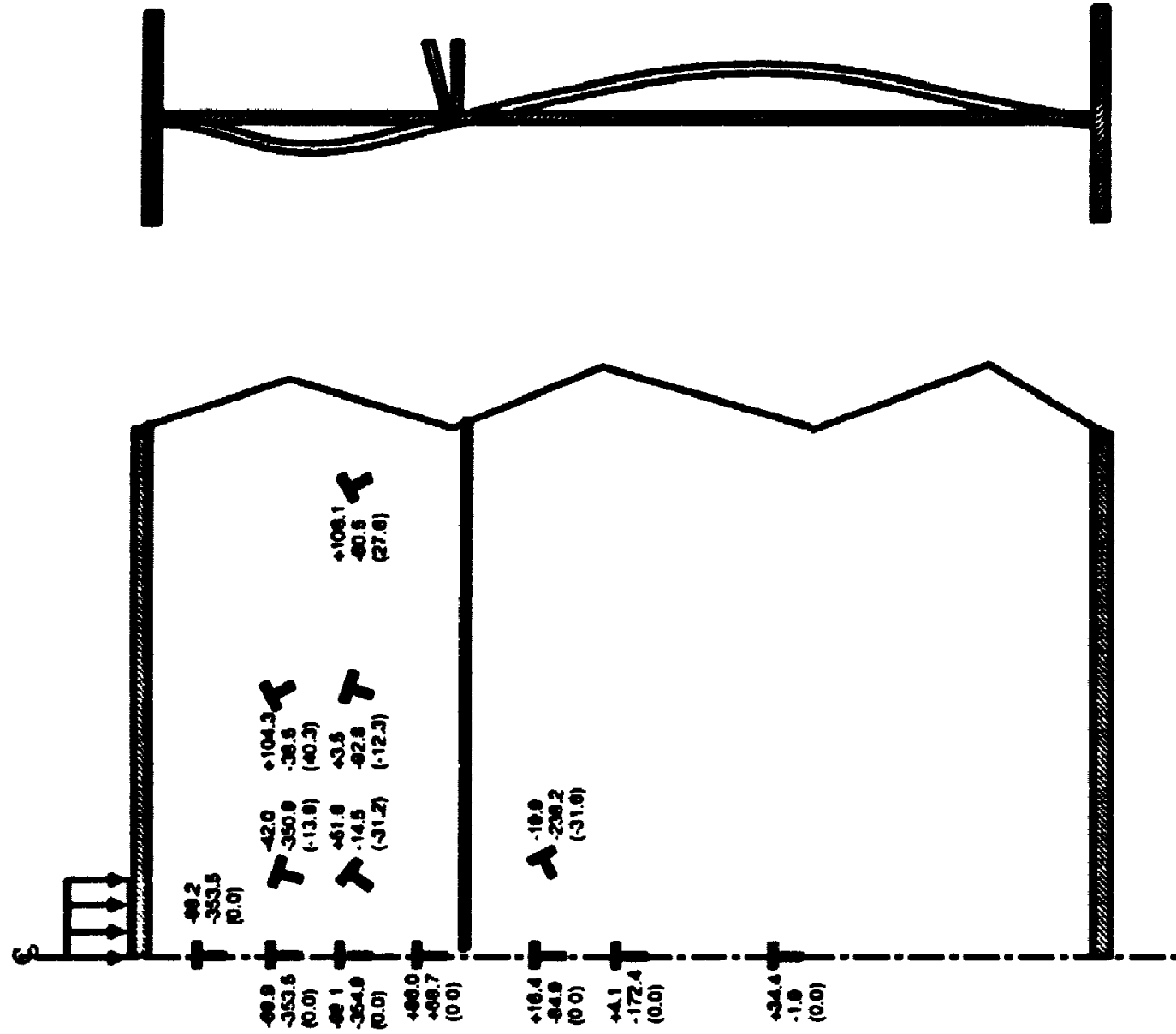

点

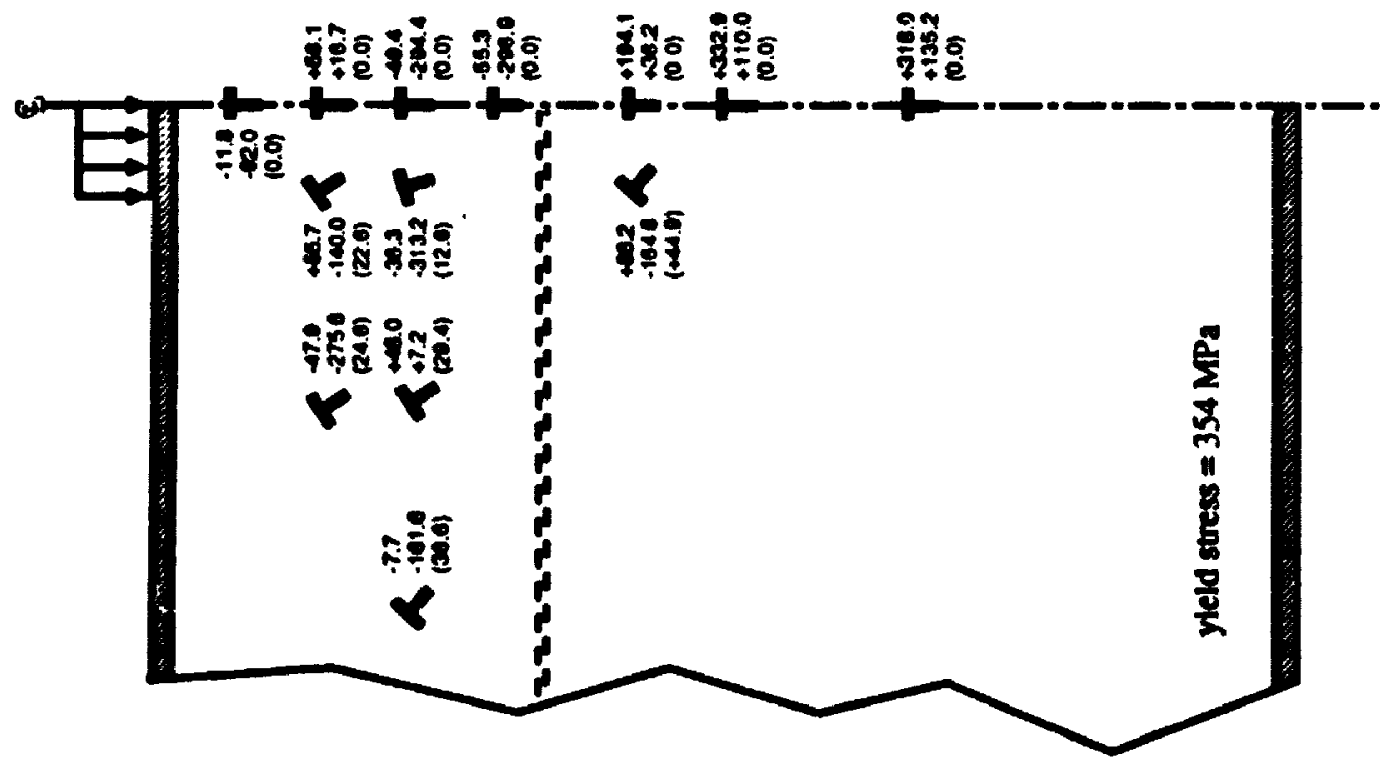

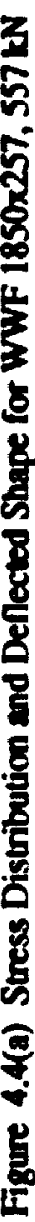



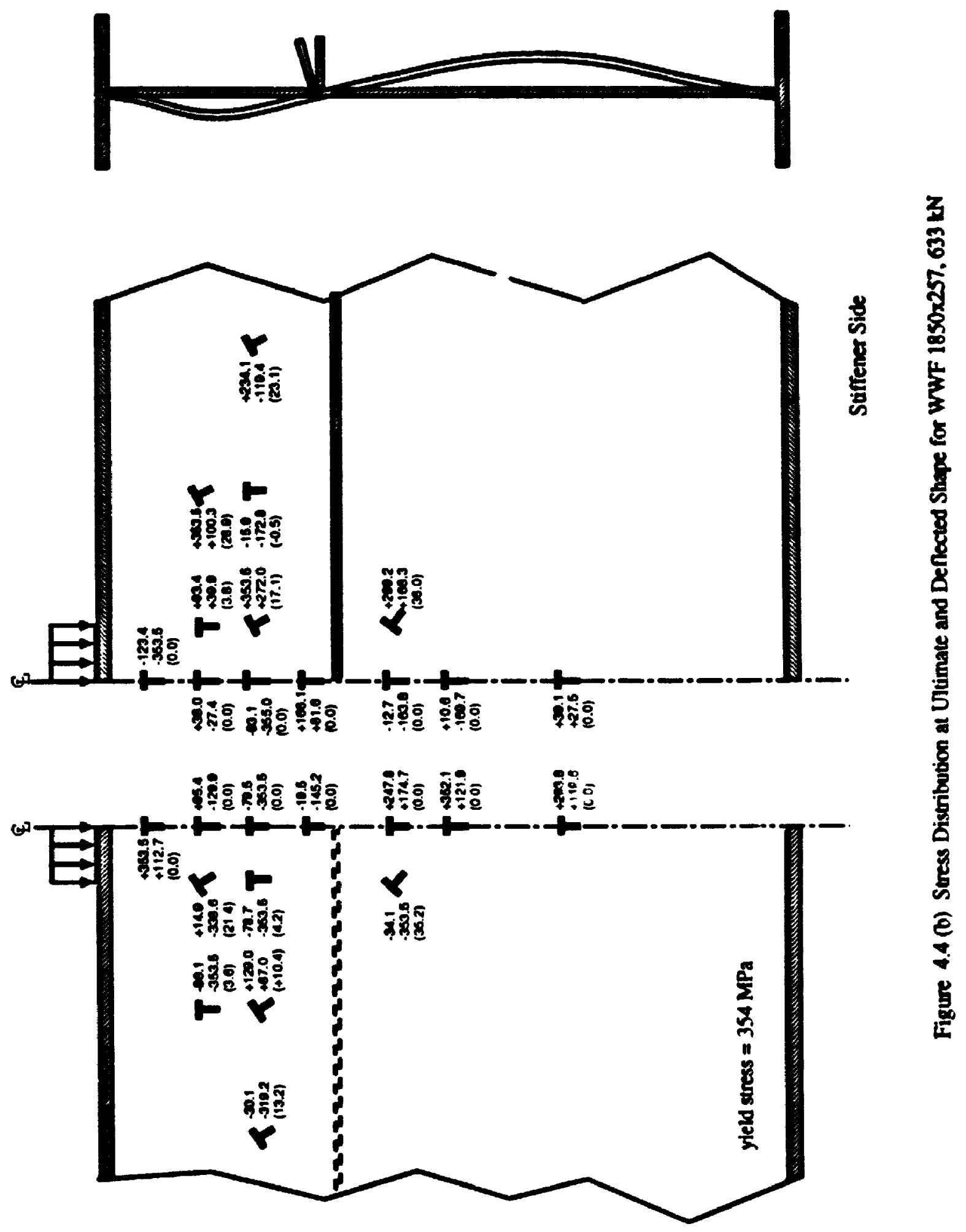

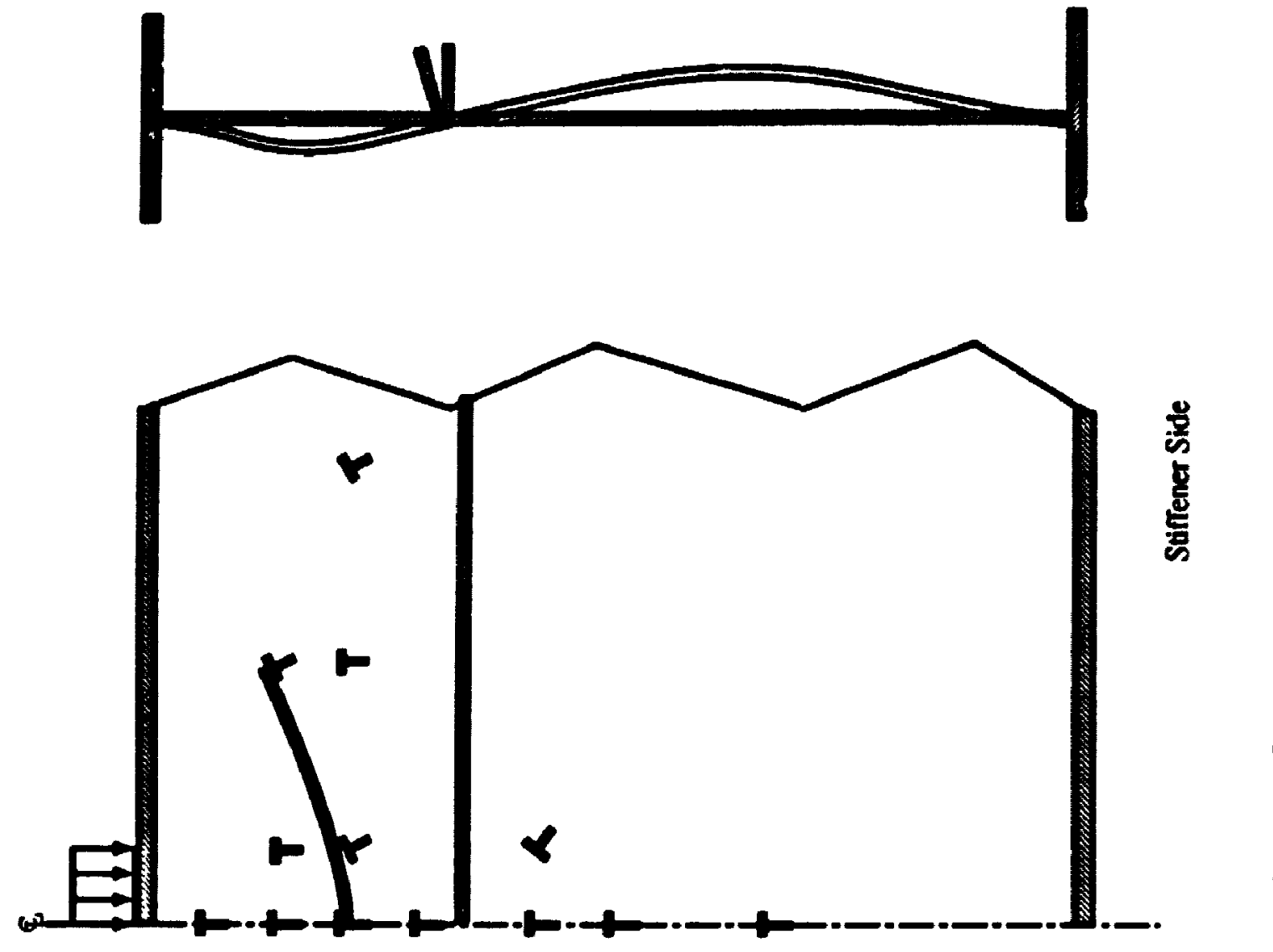

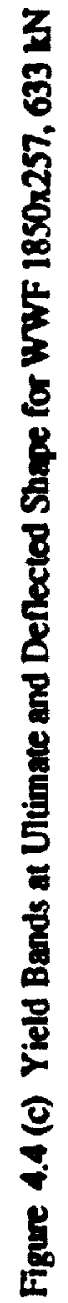

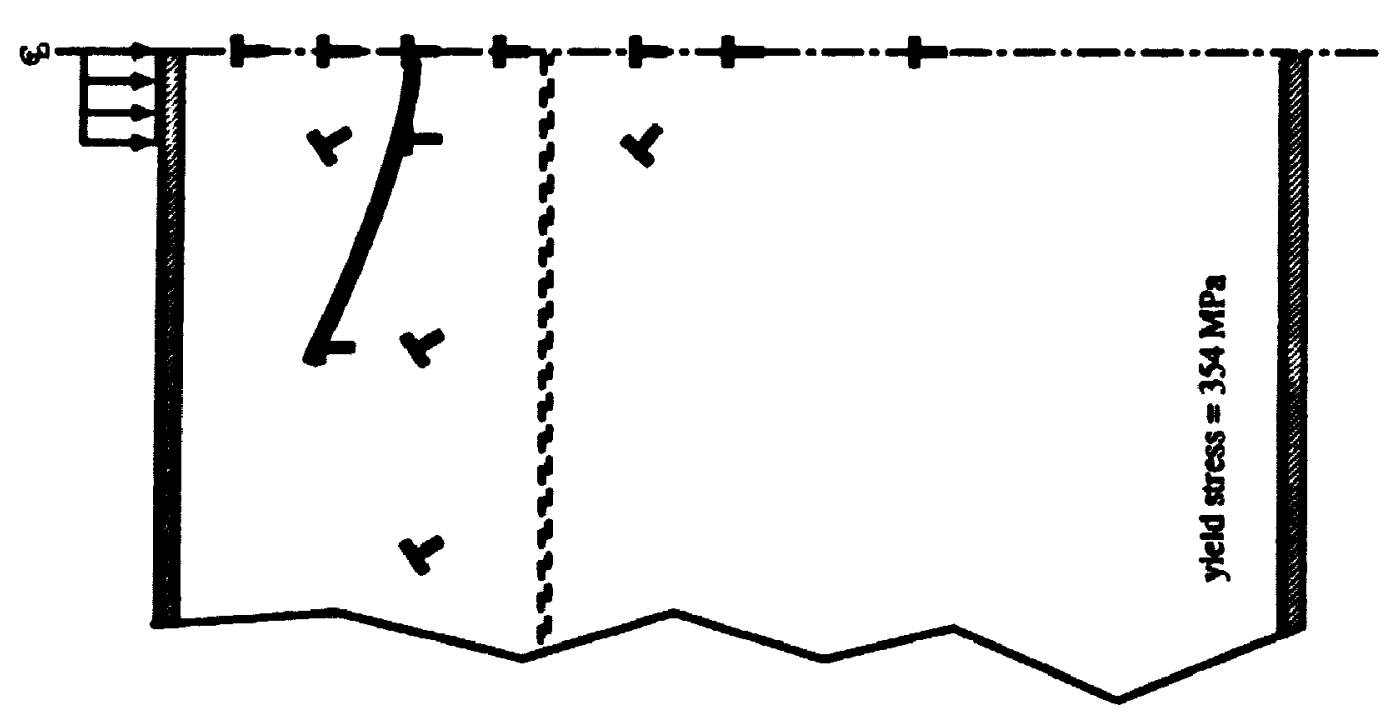



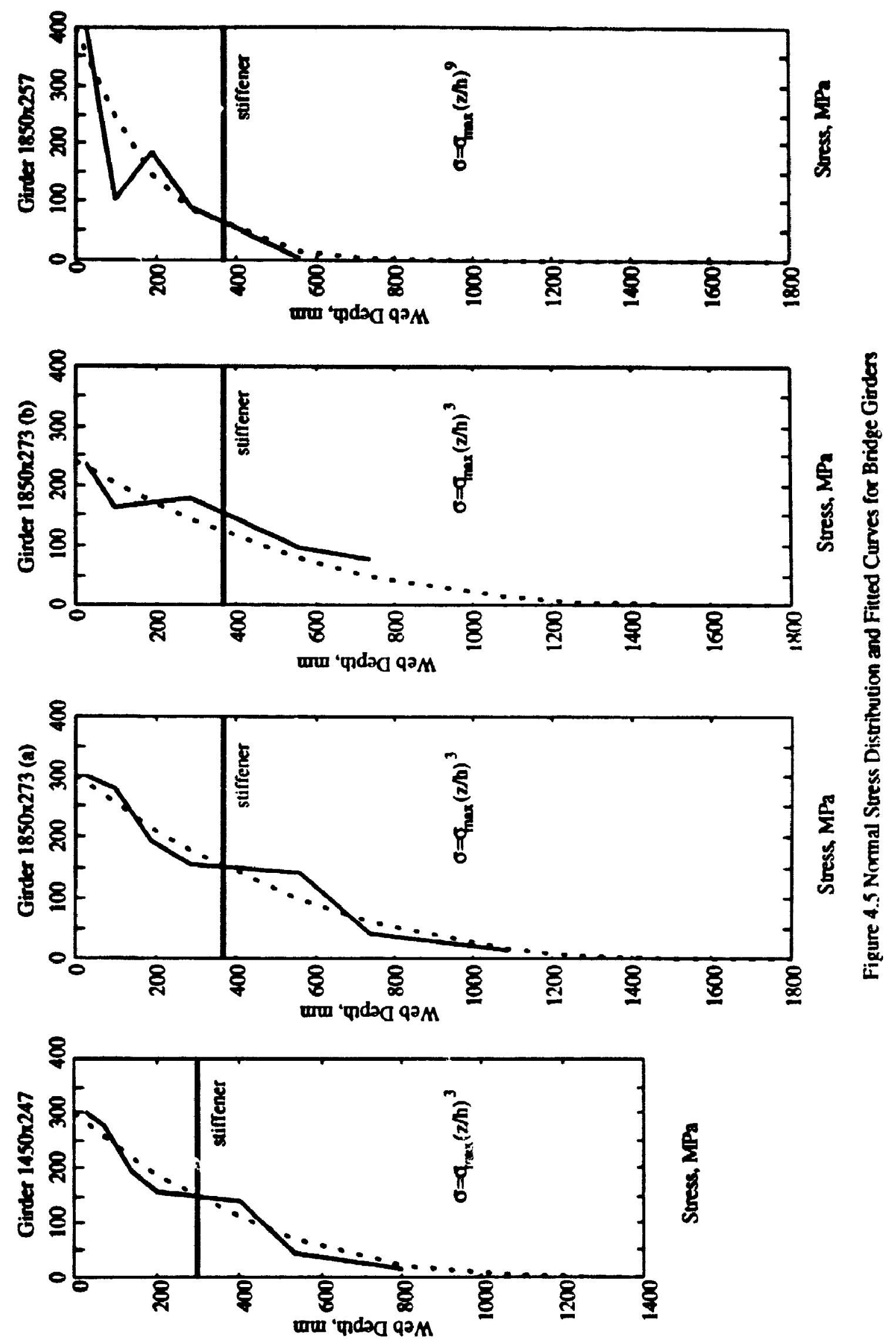


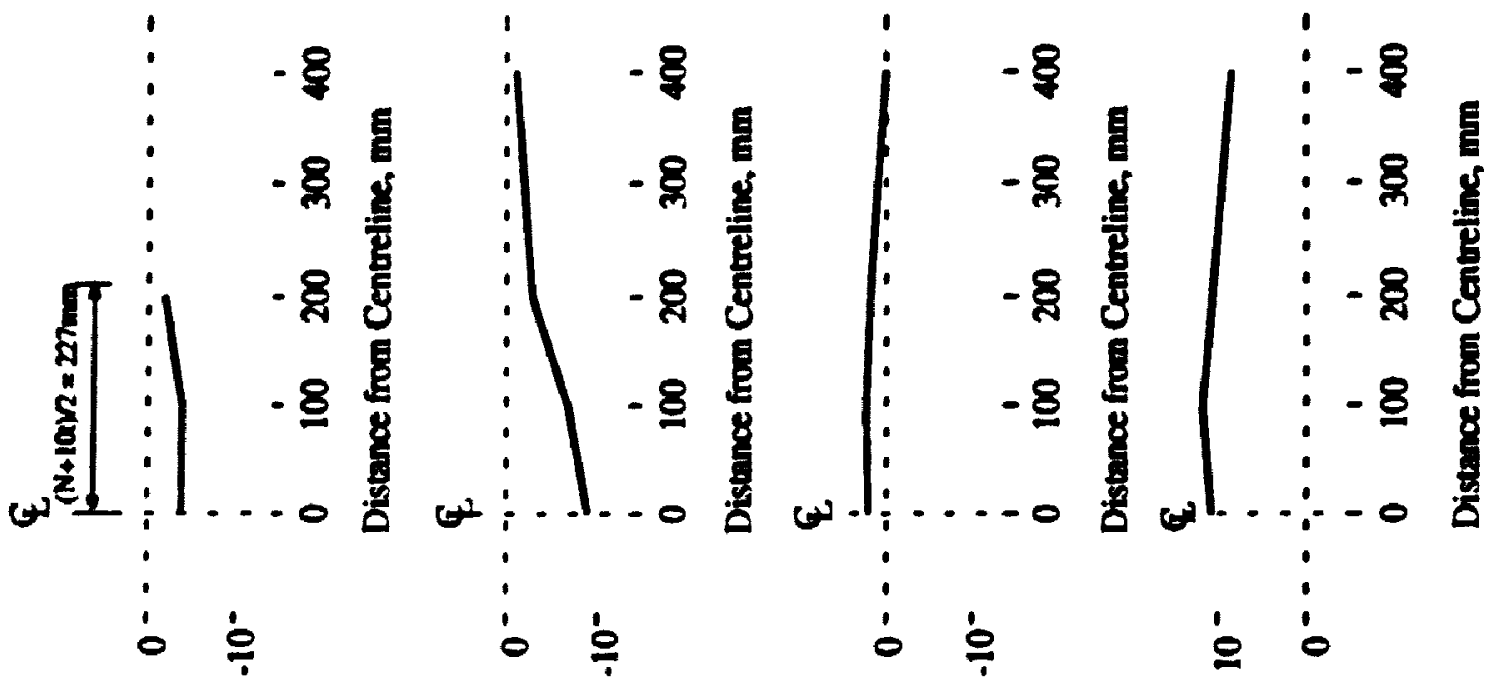

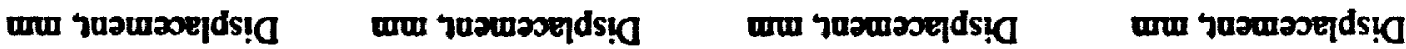
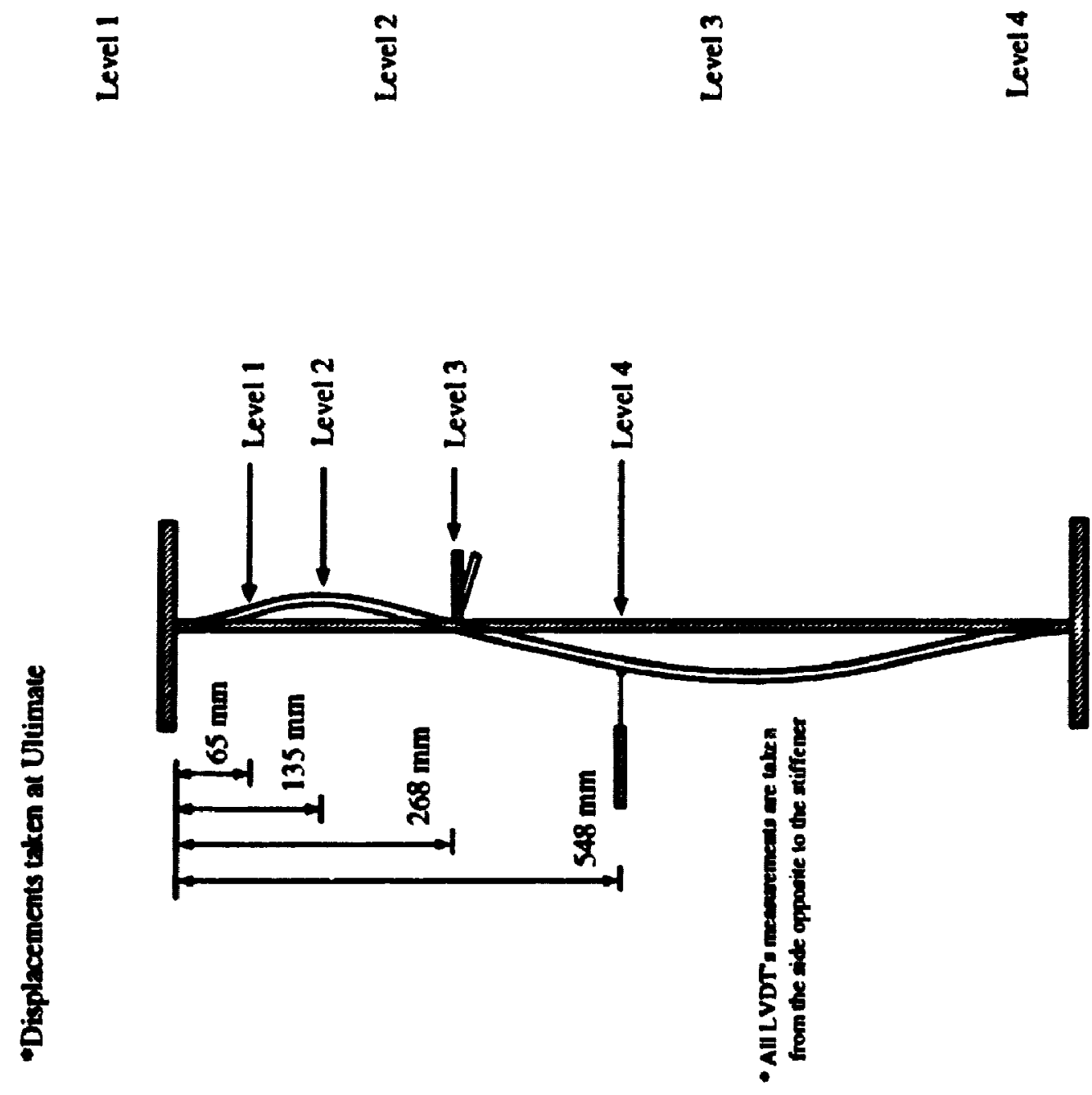

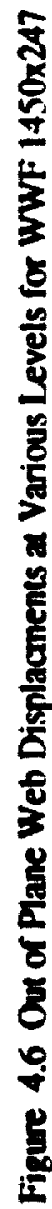




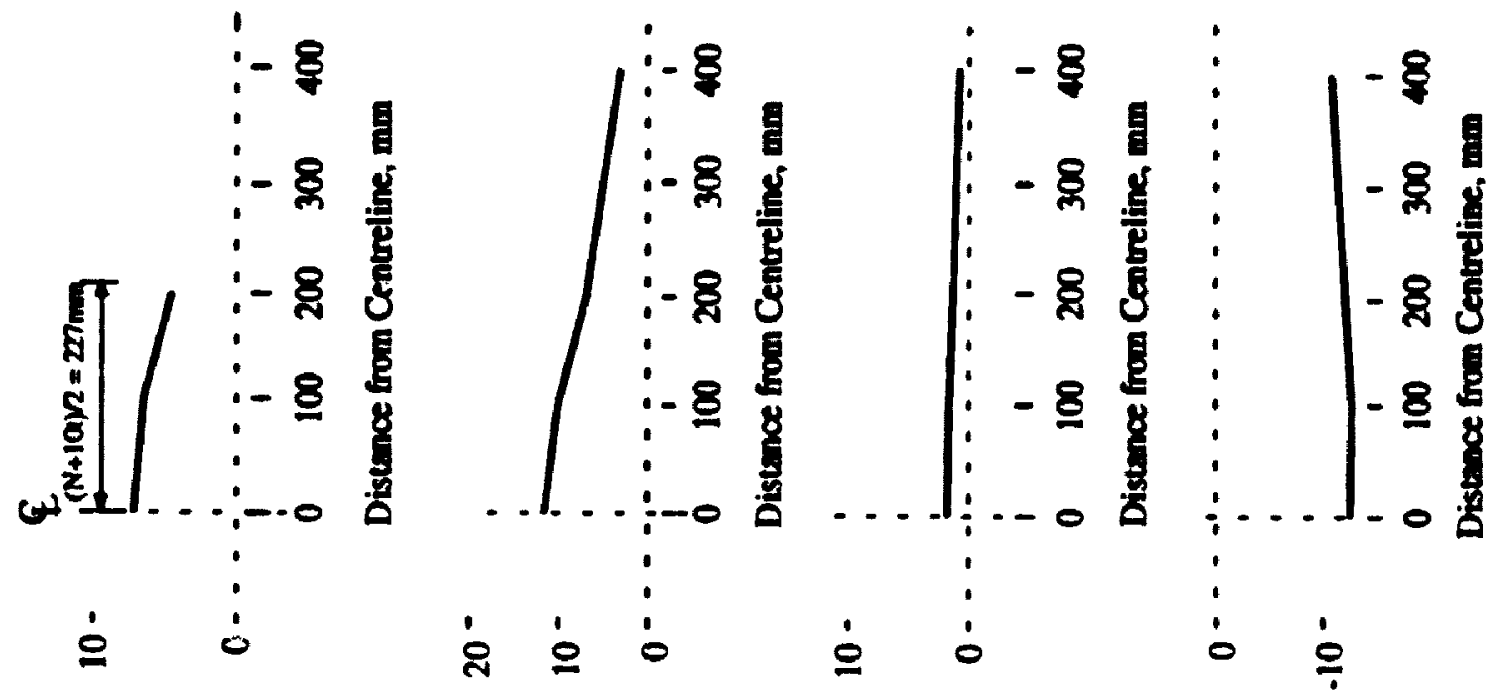

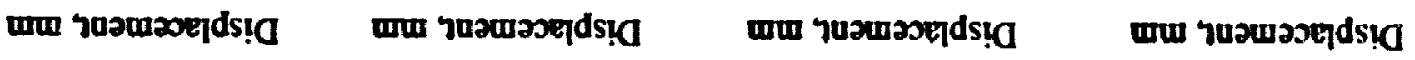

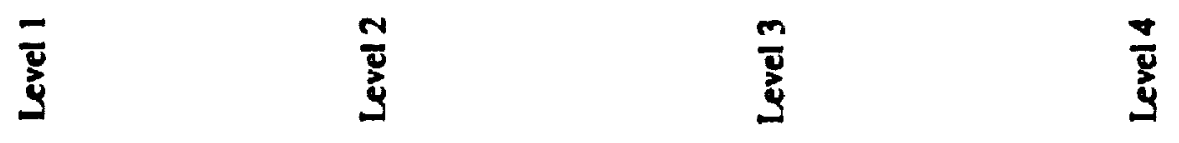

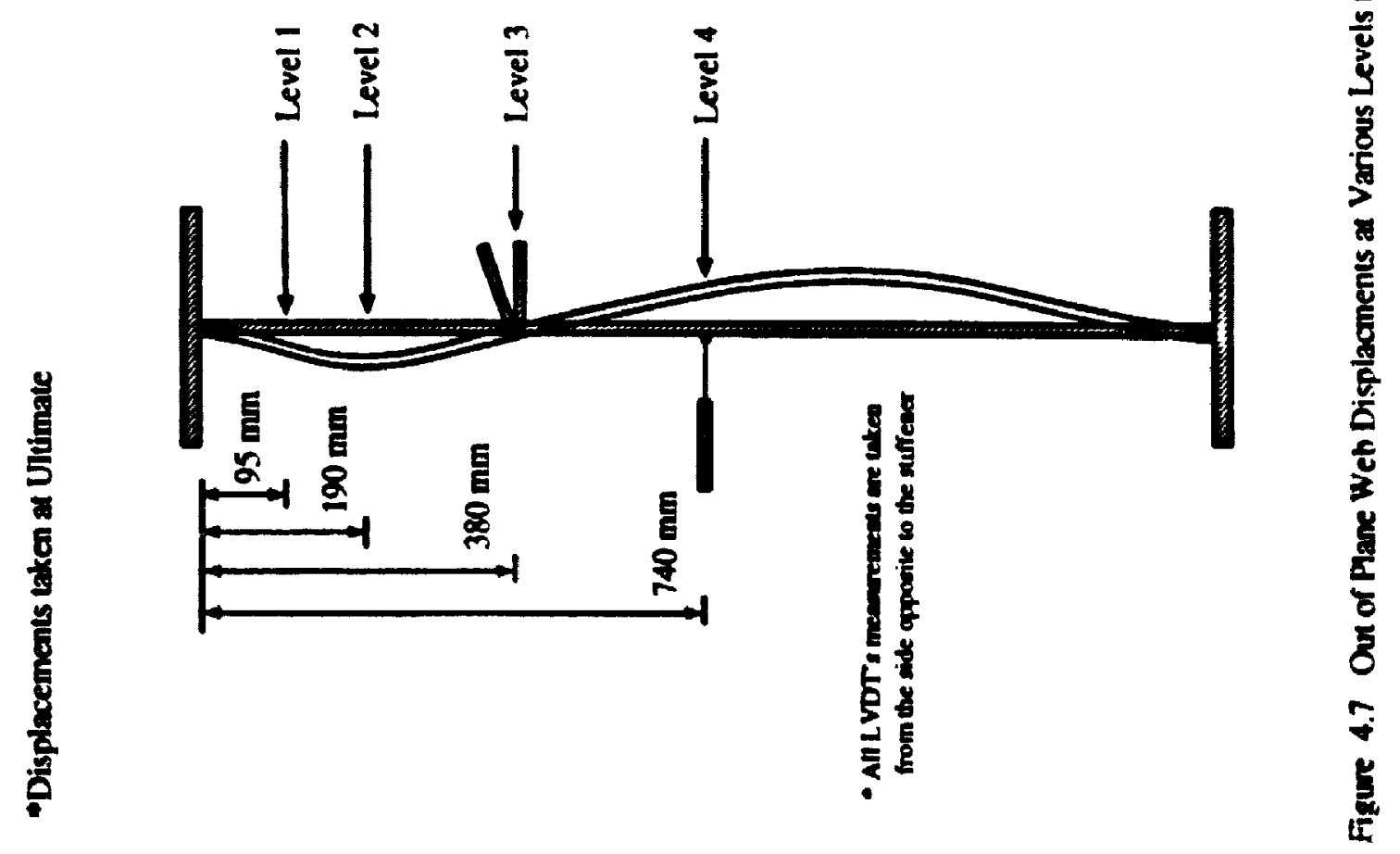




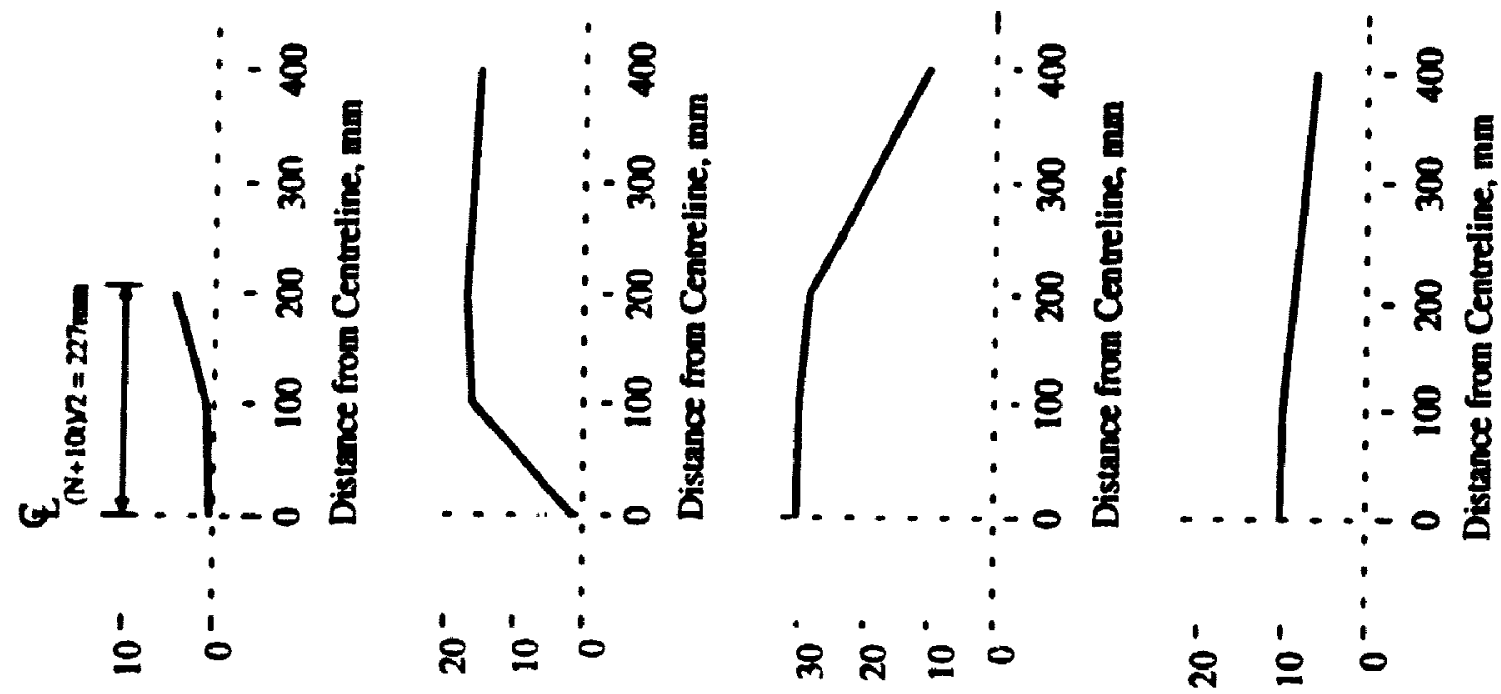

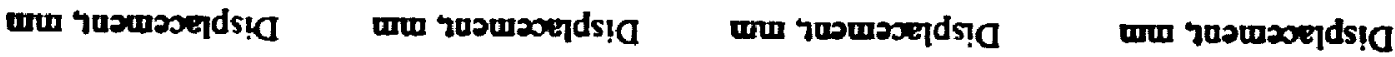
$\overline{\mathbf{y}}$
$\stackrel{\overline{3}}{3}$
$\frac{m}{\square}$
$\frac{\square}{3}$ 


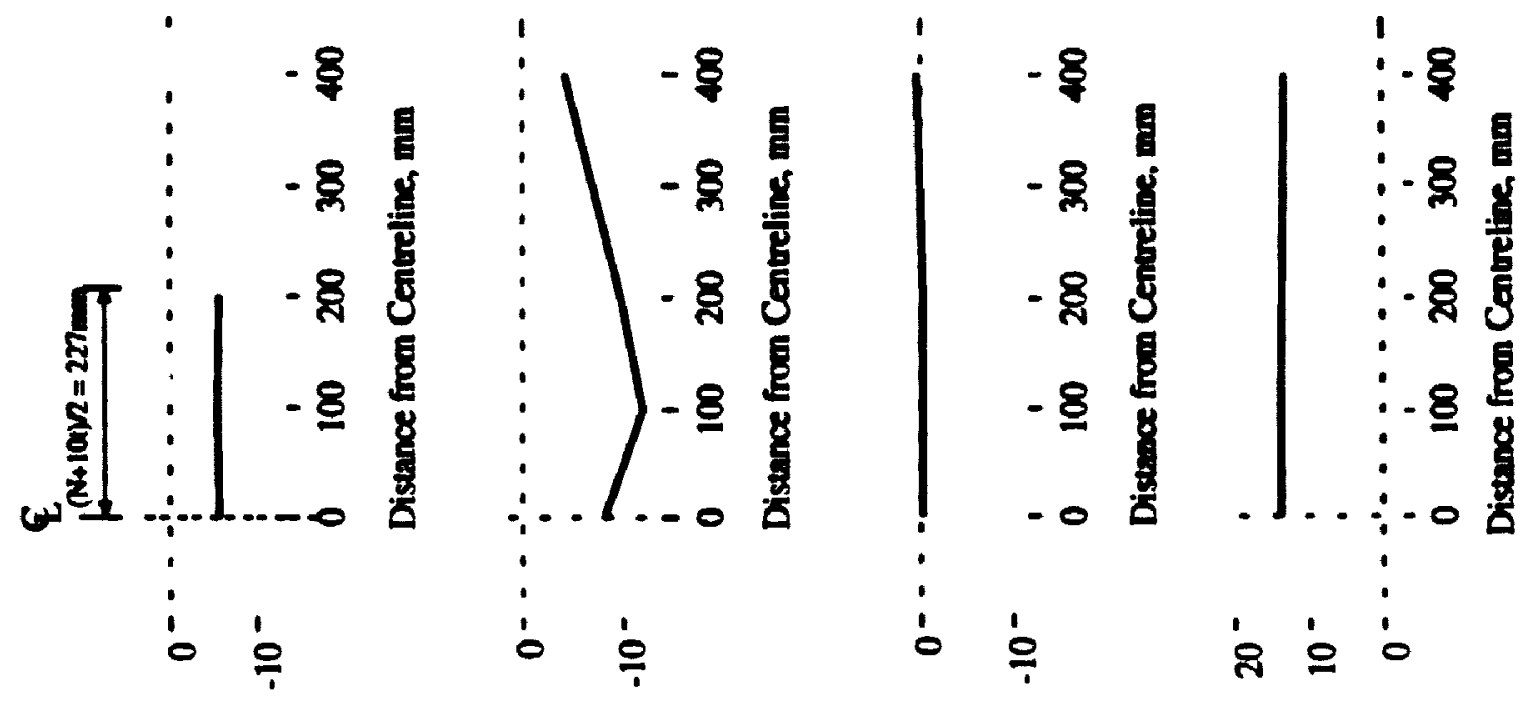

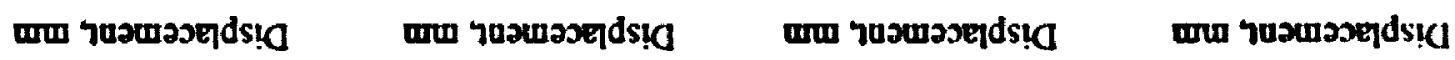
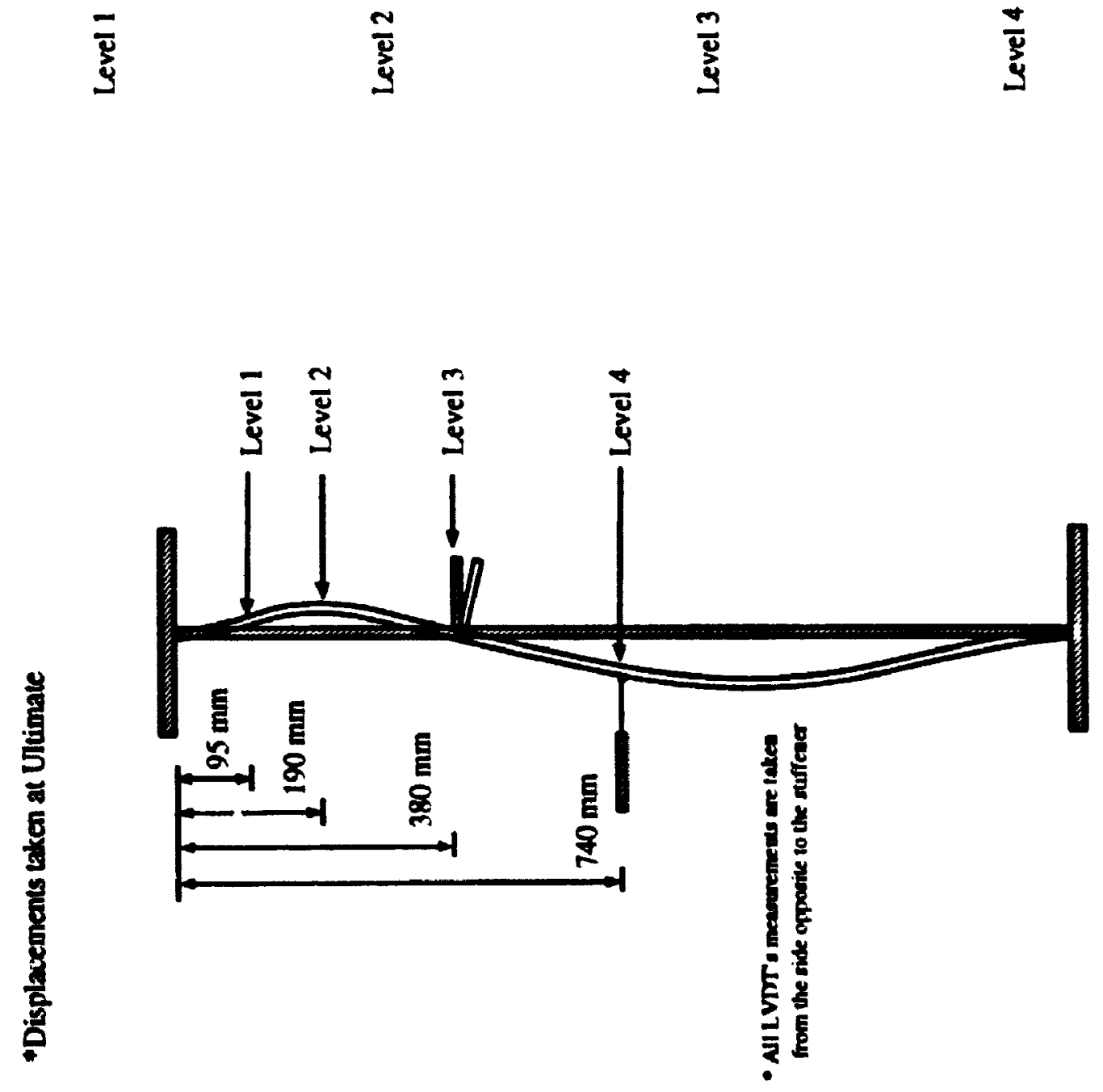

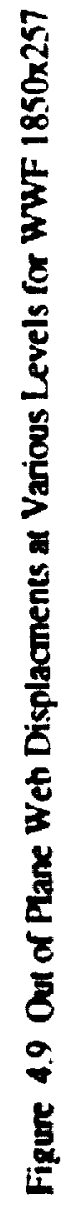




\section{Chapter 5}

\section{Conclusions, Summary and Recommendations}

\subsection{Conclusions and Summary}

Over 660 tests world wide have been carried out to determine the bearing resistance of webs under concentrated loads. Few of these tests are representative of the shapes currintly being manufactured in North America. As well, the loaded lengths used in many cases were too small and led to empirical equations that did not give a clear physical interpretation of the behaviour nor a unified approach to determine the bearing resistance. The three studies at Carleton University (Benichou, 1994, Kirkhope, 1995, and Prabha, 1996) covered the range of W and WWF shape produced by Canadian steel mills and have led to the development of the equivalent concept and appropriate design equations. The mean test-to-predicted ratios and coefficients of variation were 1.064 and 0.073 for WWF shapes with interior loads and 1.012 and 0.053 for end reaction tests; and 1.002 and 0.029 for $W$ shapes with interior loads and 1.171 and 0.205 for end reaction tests. $A$ statistical evaluation of the test data and the test-to-predicted ratios determined a value for the resistance factor to be 0.9 , which resulted in a reliability index of 3.0 or more for each shape. 
This study advances the work by providing an experimental data base of a representative sample of bridge girders and customized built-up shapes, with and without longitudinal stiffeners. The bearing resistance of the webs of such girders is of prime importance for the design and construction of bridge girders. The data will be used to verify finite element models and for the continued development and adaptation of the equivalent column concept.

Four tests were completed on thin-webbed bridge girders with longitudinal stiffeners subjected to concentrated in-plane loads at midspan. Two tests on the WWF $1850 \times 273$ bridge girders, with the longitudinal stiffeners at $0.2 \mathrm{~h}$ and $0.8 \mathrm{~h}$, model the critical load condition on the positive and negative moment regions of a bridge girder that result during launching. Tests were done on two thin-webbed WWF $985 \times 71$ shipes to investigate the behaviour due to concentrated interior loads and end reactions. One of the sections had one-sided web-to-flange welds and the other had two-sided welds. The test data has been processed and presented in such a form as to enable the precise modeling of the specumens by finite element analyses to be carried out; Prabha (1996).

To conduct these tests, six Watt mechanisms were designed and fabricated to provide lateral restraint to the beam while allowing in-plane displacements to occur. Ancillary tests include fifty-one tension coupon tests to determine the material properties for all plates. All relevant geometry and initial imperfections were measured. With 
this information, finite element modeling and statistical evaluation can be carried out as the next phase of this program.

In summary.

1. all tests failed by inelastic web buckling:

2. the longitudinal stiffener provides lateral support and creates a nodal line resulting in two web panels behaving essentially as though having fixed-pinned boundary conditions that buckle interactively:

3. measurements of the deformed shape indicate that the out-of-plane web displacements extend beyond the $\mathrm{N}+10 t$ equivalent column width range. This had been established previously by Kirkhope (1995) and Prabha (1996);

4. preliminary calculations of the normal stresses distribution show the shape of the normal stress distribution with depth are a function of $(2 / h)^{p}$ where $p$ is equal to 3 for most bridge girders but equal to 9 for WWF 1850x257;

5. the presence of the longitudinal stiffener appears to have a localized effect on the normal stress distribution. The maximum normal stress is found to be $\sigma_{y}$ at the loaded 
fange and zero at the bottom nange. This distribution is similar to tests without a longitudinal stiffener.

\subsection{Further Work}

1. Finite element analyses of the bridge girders that take into account all experimental data should be carried out to replicate the tests, in so far as possible. The finite element mesh should be sufficiently refined (representative of local yielding phenomena), to verify the modeling procedure. Subsequently, the finite element analyses can be applied with confidence to other boundary and loading conditions to develop the equivalent column concept for these shapes, along with any adaptations that may be required:

2. Further review and investigation of box girders with and without inclined webs, may be investigated analytically to determine whether or not the design rules developed for this work are satisfactory. These, as they represent a significant extension of this work, should be confirmed by large scale tests. 


\title{
Chapter 6
}

\author{
References
}

American Society for Testing materials (ASTM). 1991, Standard Methods for Tension Testing of Metallic materials (Metric), Designation E8M-91, Annual Book of ASTM Standards, Vol. 3.01, ASTM, Philadelphia, Pennsylvania, pp. 137-151.

Benichou, N., 1994, Behaviour of Webs of Rolled Steel Shapes Subjected to Concentrated Loads, Ph.D. Thesis, Carieton Univerșty, Ouawa, Ontario.

Bagchl, D.K and Rockey, KC.. 1975, Post-Buckling Behaviour of WebPlate Under Partial Edge Loadings, Proc. of the Third Int. Specialty Conference on Cold Formed Steel Structures, Uni. of Missouri-Rolla, Nov., pp. 251-284.

Bergfelt, A., 1971, Studies and Tests on Slender Plate Girders without Intermediate Stiffeners, IABSE Coll. Proc., London, England, pp. 67-83.

Bergfelt, A. 1979, Patch Loeding on a Slender Web-Influence of Horizontal and Vertical Web Stiffeners on the Load Carrying Capacity, Chalmers Uni. of Technology, Goteberg, Report S79.1.

Bossert, T.W. and Ostapenko, A., 1967, Buckling and Ultimate Loads for Plate Girder Web Plates Under Edge Loading, Report No. 319.1, Fritz Engineering Laboratory, Lehigh Uni., Bethlehem. Pa., June.

CISC (Canadian Institute of Steel Construction), 1994, hiandbook of Steel Construction, Sixth Edition, Canadian Institute of Steel Construction, Willowdale, Ontario.

CSA (Canadian Standards Association), 1989, Limit States Design of Steel Structures, National Standard of Canada CAN/CSA S16.1-M89, Canadian Standards Association, Rexdale, Ontario.

Canadian Standards Association (CSA), 1987, General Requirements for Rolled or Welded Structural Quality Steel, National Standard of Canada CAN/CSA. G40.20-M87, Canadian Standards Association, Rexdale, Ontario 
Drdacky, M. and Novotny, R., 1977, Partial Edge Load Caryying Capacity Tests on Thin Plate Girder Webs, Acta Tech, No. 5, Prague.

Durkee, J.L., 1972, Railway Box Girder Bridges Erected by Launching. ASCE. Journal of the Strucural Engineering, Vol. 98, St. 7, p. 1443-1463.

Egaly, M., 1983, Web Design Under Compressive Edge Londs, American Inatitute of Steel Construction Engineering journal, Fourth Quarter, p. 153-170.

Elgaaly, M. and Nunan, WL., 1989. Behavlour of Rolled Section Web Under Eccentric Edge Compressive Loads, ASCE, Journal of Structural Engincering. Vol. 115, No. 7, July. p. 15611578.

Egaaly, M. and Rockey, K.C., 1973, Ultimate Strength of Thin Walled Members Under Patch Londing and Bending. Hoc. of the Second Int. Specialty Conference on Cold Formed Steel Structures, Uni. of Missouri-Rolla, Oct. p. 138-167.

Galambos, T.V., 1988, Guide to Stability Design Criteria for Metal Structures, Fourth Edition. John Wiley and Sons, Toronto, Ontario.

Graham, J.D., Sherbourne, A.N. and Khabbaz, R.N., 1959, Welded Interior Beam-to-Column Connections, American Institute of Steel Construction, Chicago, Illinois.

Khan, M.Z. and Johns, K.C. and Hayman, R., 1977, Buckling of Plates with Partially Loaded Edges, Proceedings of the American Society of Civil Engineers, St. 3. p. 547-558.

Khan, M.Z., and Johns, K.C., 1975, Buckling of Web Plates under Combined Loadings, Proc. ASCE, St. 10, p. 2079-2092.

Ontario Highway Bricge Design Code, 1983, Ministry of Transportation of Ontario.

Prabha, K.K., 1996. (in progress), Behaviour of Webs of WWF Shapes Subjected to Concentraled In-Plane Loads : Analytical Investigation, M.Eng. Thesis, Department of Civil and Environmental Engineering, Carleto:i University, Ottawa, Ontario.

Roberts, T.M., 1981, Slender Plate Girders Subjected to Edge Loading, Proc. Inst. Civil Engrs., Part 2, 71, Sept.

Roberts, T.M. and Chong, K.C., 1981, Collapse of Plate Girders under Edge Loading. Proc. ASCE, Journal of Structural Division, Aug.. p. 1503-1509.

Roberts, T.M. and Markovic, N., 1983, Stocky Plate Girders Subjected to Edge Loading, Proc. Inst. Civil Engrs., Part 2, 67, Sept. p. 539.550. 
Roberts, T.M. and Rockey, K.C., 1979, A Mechanism Solution for Predicting the Collapse Loads of Slender Plate Girders Subjected to In-Plane Patch Loading. Proc. Inst. Civil Engrs., Part 2, 67, March, p. 155-175.

Shimizu, S. Horil, K, and Yoshida, S., 1989, The Collapse Mechanisms of Patch Loaded Web Plates, J. Construct. Steel Research, Vol. 14, Sept., p. 321-337.

Shimizu, S., Yabana, H. and Yoshida, S., 1988, New Collapse Model for Patch-Loaded Web Plates, J. Construct. Steel Research, Vol. 13, p. 61-73.

Skaloud, M. and Novak, M., 1972, Post Buckled Behaviour and Incremental Collapse of Webs Subjected to Concentrated Load, Ninth Congr., IABSE, Prelim. Publ., Amsterdam, pp. 101-110. Vellasco, P. and Hobbs, R., 1996, Local Web Buckling in Tapered Composite Beams, The Structural Engineer. Vol. 74, No. 3

Winter, G. and Pian, R.H.J., 1946, Crushing Strength of Thin Steel Webs, Cornell Univ., Engineering Experiment Station, Bulletin No. 35, Part 1, April. 


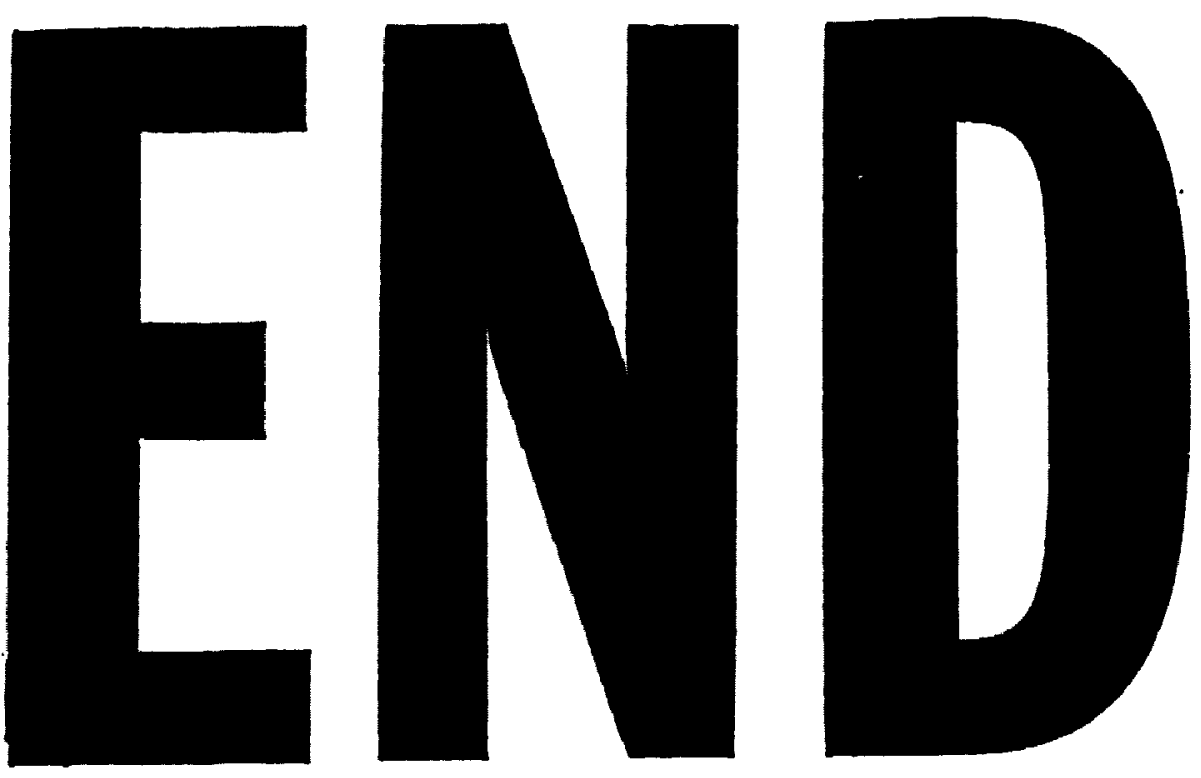

$10 \log 0.07$

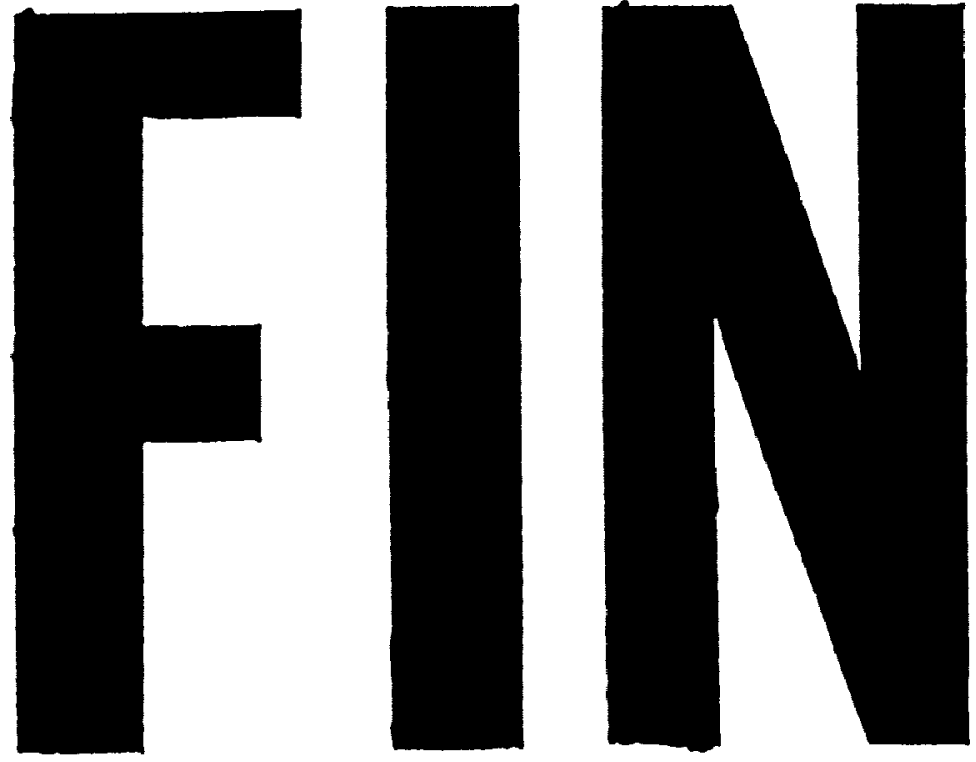

